\title{
UC-NRLF
}

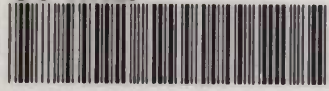

\$B $308 \quad 973$ 


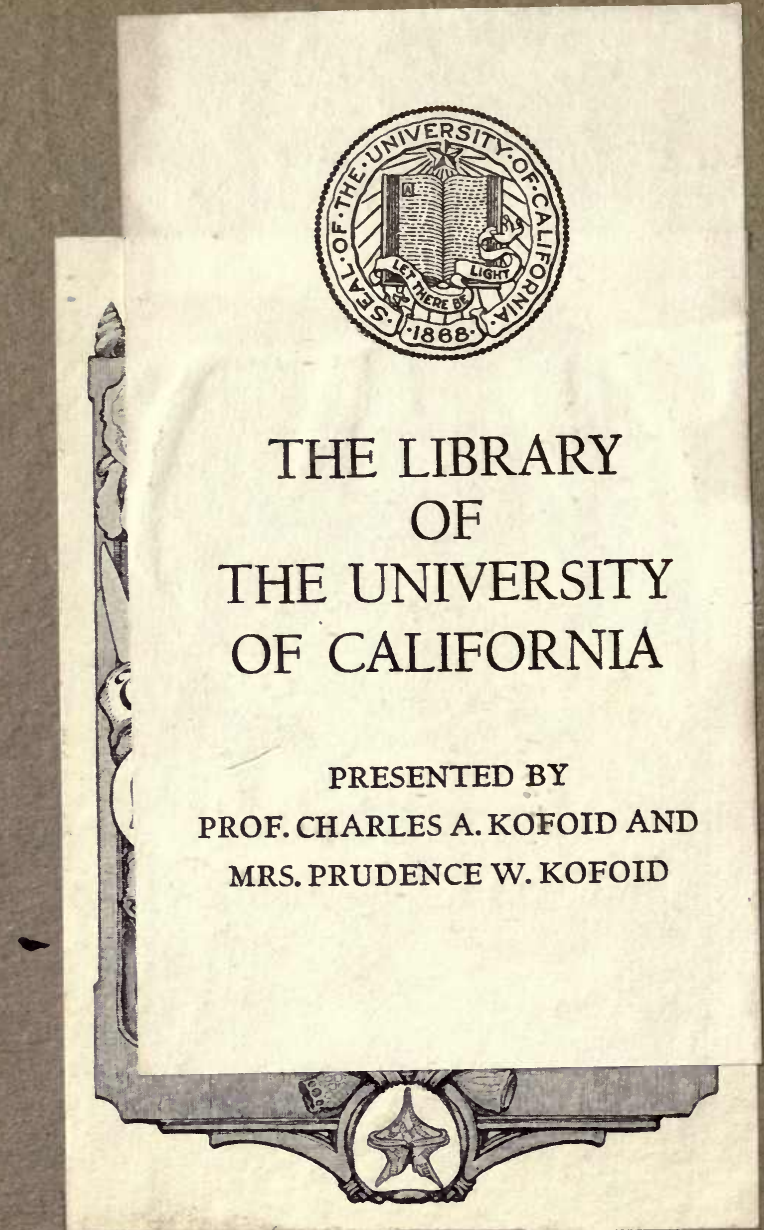




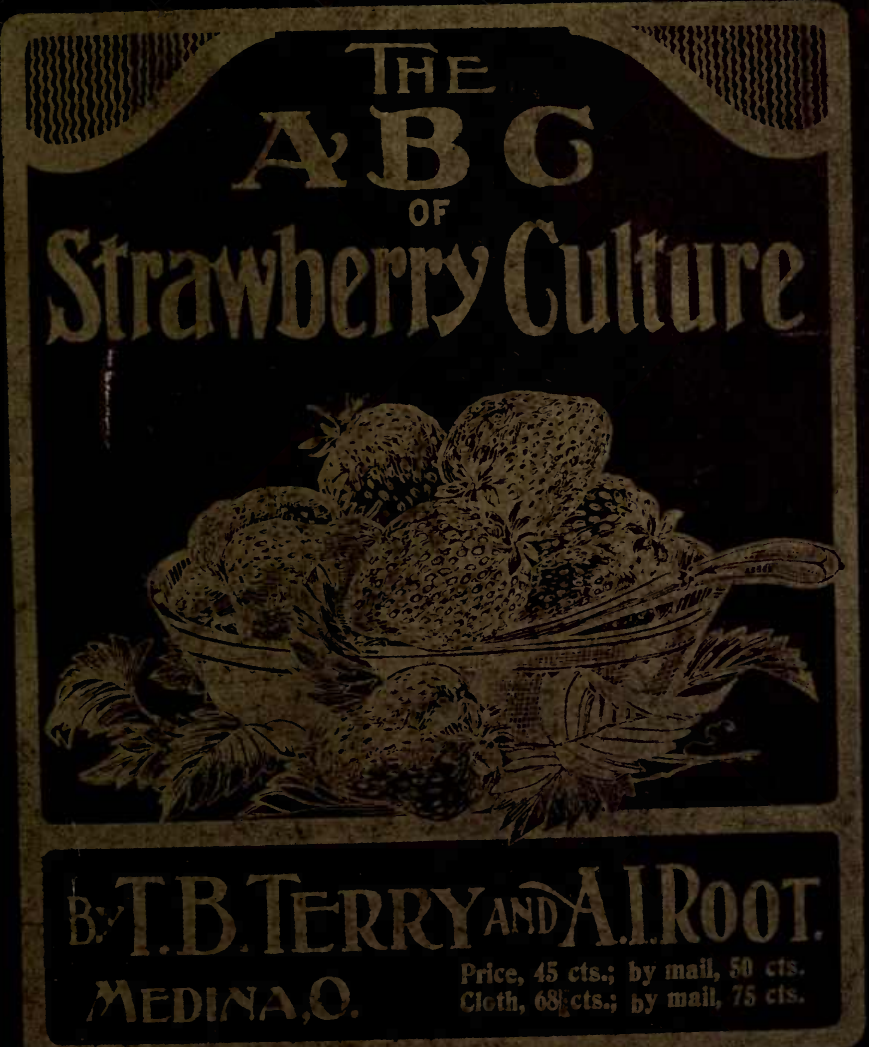





\section{THE A B C OF}

\section{STraWberry Culture,}

FOR-

Farmers, Village People, and Small Growers.

\section{A BOOK FOR BEGINNERS}

By T. B. Terry and A. I. Root.

Second Edition; Revised and Enlarged.

PUBLISHED BY THE A. I. ROOT CO., MEDINA. OHIO.

1902 


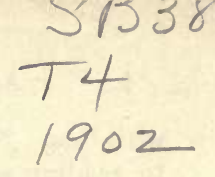

\section{CHAPTER I.-Introduction.}

FRIEND ROOT wants me to write a little pamphlet on strawberry culture. He says: "Now, do not say you would rather wait until you have had more experience." I should prefer to wait two or three years longer, certainly; but still it would be true then the same as now, that I "know only in part." Even of as simple a matter as growing strawberries, the wisest man can continue learning as long as he lives. Friend Crawford, who has spent his life among the strawberries, and is one of the highest authorities in the world, remarked to me the other day: "I am beginning to think that such and such treatment (different from what has heretofore been considered best) is what we want." Friend J. M. Smith, another noted berrygrower of long experience, wrote me last fall that he made no pretensions to being perfect in his line-only to being one who constantly tries to improve from year to year.

The writer will doubtless say some things that he would like to take back five years from now. But if he should wait five years before writing this little book it would be the same. The world is constantly moving on. I shall not attempt to instruct old growers, nor those who raise berries on a large scale. From them I have learned all I could, both on their places and at our institutes, and from their writings. I have picked out, to the best of my ability, what would be of the most use to me, growing berries in a small way. This, I hope, may be told so plainly as to help thousands of farmers and village people, and particularly the young people, who have not had a chance to learn much about the business.

Mr. Charles A. Green says: "No instruction can be given in fruit-growing or any other pursuit that will enable the inexperienced reader to begin largely, without being liable to meet 
with loss. Nothing can supply the need of actual experience. In reading an article on fruit culture, the veteran will gather more valuable information than the novice, for he will know what thoughts and methods are the most practical, while the novice will be more apt to follow impracticable theories, and be led astray, or may not clearly understand the lesson taught." With the first of this I most heartily agree. The novice had better begin in a small way, and work up as he gets experience. As to the latter part, I believe that friend Green could write an article or a book, and tell a novice exactly what to do, leaving out all "impracticable theories" that might lead him astray, and write it so plainly that even a child could understand the lesson taught. Now, this is exactly what the writer will try to do in this little work. When I read "Gregory on Squashes," years ago, all of his directions were so plain that I, although entirely new at the business, made a success from the very beginning in growing from a quarter to half an acre. Why can not the growing of strawberries be made as plain and simple?

Having been through the mill lately myself, perhaps I shall think to make every little matter more plain than some older and more expert hand would. Such are apt to forget how green they were once. For example: When visiting my friend W. W. Farnsworth, a well-known berry-grower, he was laughing over the ignorance displayed by the writer of a letter he had just received. The man wished to know whether, in cutting all blossoms from newly set strawberry-plants, he should just cut the blossoms or buds off the stalk, or cut off the whole stalk, or stem, that had the buds on, along with some little leaves that were on it. Now, I was not going to let brother Farnsworth laugh at me, so I kept still; but I enjoyed the matter greatly all to myself, for only the year before we had just that trouble on our minds. The girls came to me and said there were some little leaves on the stalk with the blossoms and buds; and the books all said, "Cut off all blossoms as they appear." Being entirely green at the business, we did not 
know just what to do. If we do not do any more, we shall try to make every little matter so plain that any girl or boy can understand how to grow strawberries. The writer felt provoked, not long since, when reading an article in an agricultural paper, written by a well-known horticulturist. He seemed to be trying to mystify the matter of fertilization among strawberry plants. He seemed to wish to discourage farmers from growing strawberries, on the ground that, from their lack of knowledge, they would soon have barren beds. And still that wri er had the ability to make the entire matter of fertilization so plain and simple that any child could understand all that is necessary.

Considerable of what is in the following pages was written, in substance, either for the Ohio Farmer, the Country Gentleinan, or the Rural New-Yorker; but it has all been written over and revised and put into more convenient form for reference. The first part of this book, you will nutice, is particularly for farmers and others who want to grow only enough berries for th:ir own use, with the least possible trouble, and where the greatest yield is not an important point. Later on will be found something for those who, like the writer, grow some berries to sell, and enjoy making the most possible out of what they do.

\section{CHAPTER II.-For Farmers.}

Some readers may know that the writer for years argued in the papers against farmers, as a class, fussing to raise their own strawberries, where they can buy nice ones handily. The idea was, that each one, farmer and fruit-grower, had better attend to his own business; that the farmer, so far as money-making is concerned, had better raise a little more of what is in his own line, and take the money and buy strawberries, rather than fuss 
with a little patch. This was my practice for some seventeen years. I could raise $\$ 20.00$ worth extra of potatoes, which were right in my line, and make a fine profit on them, and with the money buy what strawberries we wanted, of a small-fruit grower near by, who made a business of berry-growing, while, had I grown the $\$ 20.00$ worth of strawberries myself, it would probably have been at a loss, and would have been an extra matter to worry over and bother with. Now, I thought at the time that this was sound business policy, and, for that matter, I still think so; but I am just as well satisfied that it will not work. I preached it because I had tried it, and thought it the best way, where one is already overrun with business. But many of our farmers seem to have been born with the feeling that they must not pay out any money for any thing they can possibly get along without. The writer was not born on the farm, and it was just as easy for him to buy five bushels of strawberries as a barrel of salt or a set of chairs, or any thing else that we did not produce. He really had no idea that it made so much difference what one's bringing up had been. But he has been around among farmers a good deal of late, and has learned his mistake. I remember once going home with a well-to-do farmer who had many acres of land to manage, and considerable money invested in outside business. He showed me, among other things, a large bed of strawberries. Now, I knew that this friend was close to a market where he could buy fine home-grown berries at fair prices, and I was rather surprised that a man with so much business on his hands should be bothering to grow his own strawberries. So I said to him: "You grow these, of course for the pleasure of it, and not because it pays you to fuss with such little matters when you have so large a farm and so much other business to attend to?"

"No; I raise them," he replied, "because I should not have them if I did not. I tried your plan, and we did not have, I presume, more than a peck of berries during the season, 
although they were plentiful in market. I could not buy more than a quart or two at a time, and even that went against the grain. My bringing-up on the farm had been of another kind. I could not buy them freely. It was either raise them or go without."

Again, a well-known agriculturist sat with me at a hotel table. He had been a farmer all his life, and is well off. For a wonder, there was some really good cheese on the table. Our farmer friend helped himself several times. He seemed to like it very much. I said to him : "You do not get good cheese down your way, I guess, judging from the way you take hold of that."

His reply was: "They have it at the groceries; but, to tell the truth, as we do not make cheese we do not have it on our table one week out of the fifty-two."

Now, this farmer lives in a house that cost at least $\$ 5000$, and has no lack of funds; but, although evidently fond of cheese, he goes without it because they do not produce it. His bringing-up clings to him, and he can not use freely what must be bought for money-don't you see? If this is the case among such well-to-do farmers, who can draw their checks for thousands of dollars at any time, and have them honored, how would it be likely to be where there are two or three ways for every dollar to go? Well, I visited such a farmer last winter. They are not really poor, but are not yet out of debt, and said they had hard work to pay their interest and, make both ends meet. The wife told me she had tried every spring to get her husband to set out some strawberry-plants. He had always said: "Oh! we can buy strawberries cheaper than we can raise them." "And now," she says, "how many do you think he bought last year? Not one single quart!"

Now, this looks a little against that friend ; but I know how it was. He thought in the spring it was cheaper to buy than to grow them; but when it came time to buy he hadn't the money to spare. He felt as though he must pay his debts for all of 
buying luxuries, and that was honest and square. Just for this reason, thousands will never have berries unless they raise them. Even if they are not in debt they may be short of money to buy with, and berry time will slip by and they will not have any to am:unt to any thing. There are many ways for money to go, on many farms. I know that many farmers went without apples last year because their own crop was a failure. I have also known many to go without potatoes when they failed to grow enough for their own use. In view of all these facts I feel certain that the great mass of our farmers have got to raise their own strawberries or practically go without.

Possibly what I have written in the past may have caused some farmers' families to go without berries. They gare up trying to grow them, because Terry said it did not pay, and they could not buy them. In fact, some ladies have told me that this was the case at their homes. After this I an going to take human nature as we find it, and urge every farmer to grow all the strawberries his family can possibly use - not merely to put out the plants, for that, as it is usually done, is not much better for the family than depending on buying would be. A well-known grower of plants, in answer to a direct question at one of our institutes, acknowledged that he did not think that one farmer in ten who bought plants of him ever made any thing out of them worth speaking of.

Another well-known berry-grower, Mr. L. B. Pierce, says in the Ohio Farmer, in regard to this point: "Almost every farmer of my acquaintance has tried the experiment (of growing his own strawberries), and I have furnished in my time not less than one hundred personal acquaintances with plants for the experiment, and these were not novelties, but well-tried standard varieties, such as the Wilson, Charles Downing, Green Prolific, Cumberland, and Glendale. Less than half a dozen of them kept their plantations up after two years, and the rest either buy berries or go without. The berries had to go, because there was already on the farm an abundance of work that 
must be performed daily, and there was no time to care for a new industry."

This is a rather discouraging state of things; but I suppose Mr. Pierce knows what he says to be true. Others have told me about the same thing, and said it was useless to advise farmers as a class to grow strawberries; that they already have too many things to attend to ; that $I$, with my specialty farming, could get time to attend to them, but the masses can not and will not. "Where there is a will there is a way." I am trying now to get the will into you, and then I will show you the "way."

When I ride by a little neglected patch of small fruits and weeds and grass, and see fine fields of well-cared-for corn, oats, and clover on the same farm, I can not help feeling pity for the man who does not try as hard to grow fine-eating crops for himself and family as he does for his stock. That little neglected patch serves as an excuse for not buying any berries (of course not, for we raise them), and essentially for going without. Now let us be honest, friends ; isn't this just exactly so? You set out a few plants, and let the weeds and grass choke them almost out of existence, and from them comes (or, rather, does not come) your family' supply. Am I getting almost too hard on you? Well, it is only to make you see yourselves as others see you, so there may be some chance to encourage you to do better.

To be sure, the farm crops bring the money that pays debts and buys the necessities of life But surely a life supplied with nnly the barest necessities is not what we want. We ought to have some luxuries; and what greater one can we ask for than delicious ripe strawberries on our tables, in great abundance, every meal, for some three weeks? But let us look into this matter and see whether we can not find out why the farmer's fruit-garden is so frequently neglected. It is not that they do not want good things. It is not that they care more for their cattle than for their families, as my words above would seem to 
indicate. No, no. They usually have many irons in the fire, and the large jobs naturally get the first attention. The result is, when they get around to the fruit-garden it is too late to do the work to the best advantage. I can not blame a man for dreading the job if it has been neglected until the weeds have obtained full possession. Again, they haven't, perhaps, laid out the patch so it can be worked to the best advantage with a horse. I am also convinced, by talking with many farmers, that they do not know how to take care of strawberries and other small fruits properly. All these things I will try to help you out on in the following pages. But let me say right here : Please do not let any thing I have said, or may say, influence you to set out any strawberries unless you have made up your mind that that crop is just as important, so far as it goes, as any other, and shall be taken care of properly and promptly, and not pushed off by all the big jobs. Unless you will do just this, whether or no, I pray you do not begin. Better save the money you pay for plants.

What I said in the first part of this chapter, about its being better business policy, oftentimes, to buy berries than to raise them, would not, of course, apply to very many farmers who could not handily buy good fresh herries. Such must grow them any way, or go without. Around us there are several growers, in a small way, from whom we can get them fresh, but still not quite as choice, usually, as those we grow ourselves. Regular growers must pick them before they are ripe, so they will stand sending to market. To have the strawberry in its perfection you must leave it on the vines until dead ripe, and then eat it very soon after picking.

Right here I may as well confess that, even if I was not brought up on a farm, and thought I could buy what we wanted as freely as though we raised it, we have used more berries since we grew them than we ever did when we bought them. I do not remember that we ever bought more than five or six bushels of strawberries in a season. Last year I suppose we 
ate, canned, and gave away, nearly twenty bushels. The year before, we canned and ate thirteen bushels. Did we use so many more because they were so much better than those we bought? Not entirely. Our minister was here to supper during berry time last year. When he noticed the great heaping saucers full at each plate he remarked: "Berries are a luxury with us in town; but I see they are a common article of food with you." That is it exactly." Why should they not be? It takes but a few rods of land and a little labor, if systematized, to grow them. It is one of the compensations for our isolation out here in the country. God does not give all good things to any one class of people. Our minister can step right into church, or a lecture, or to the depot, dryshod, and get his mail while it is fresh. During the past winter of 1889 we literally had to wallow in the mud to get to town. But when it is hot and dusty in town next summer, we can live on strawberries and cream in a way our minister can not afford. And we shall have better health all summer for it too. God arranged to have strawberries come just at the time when we need them. They are Nature's spring medicine. I get better-natured every day after they come, and they are the best medicine to take I ever got hold of.

Then they give the women-folks a rest, too, from baking and cooking - at least they do so at our house. We almost live on strawberries and nice bread and butter, and milk and cream, for three weeks. Meat and potatoes, and particularly pies and cake and puddings, get a good deal of a rest. Of course, we want some more solid food than strawberries, but it is usually the most simple kind. One season that we kept count, we had strawberries on the table for 66 meals in succession, just as free as water. We call that living. Some farmers say they do not care much for strawberries. Never mind what they say. There isn't one man in fifty who wouldn't enjoy a big dish of large, fully ripe Downing strawberries and cream, and be sorry when the last berry was swallowed. 
Now, a table bountifully supplied with this health-giving luxury for at least three weeks every season, and a few bushels canned for winter, is what every one of us farmers ought to have. We work hard, and we deserve it. Our families work hard, and we owe them this enjoyment. Now, we can do this thing if we will. Turn over, and read just how to do it.

\section{-}

\section{CHAPTER III.}

LOCATION - CHICKEN QUESTION - THE HOME ACRE-HOW MANY SHALI, WE SET OUT?-LONG ROWS AND CHEAP CULTIVATION - ROTATION - MANURING - PREPARING THE GROUND-WHEN TO SET OUT-A PICTURE FROM LIFE.

When selecting a place for the strawberries, one of the first things to be considered is the chicken question. Most farmers keep chickens. Chickens like strawberries. Now, shall the berries be put inside the picket fence along with the garden? Well, you can do that way or you can inclose a yard to keep the poultry in when they would be doing damage at large. The latter way would suit me best. However, we do not keep any hens. They would have to be shut up about all the season, or they would do altogether too much damage on our little farm. We have tried it.* I know that a fenced garden is not a place that an ordinary farmer likes to get in to work; and, besides, garden crops and strawberries do best (the

* There is a way of getting along with chickens, without having either the garden or the chickens fenced; and this is the way we manage: We have about ten acres of ground devoted to market-gardening; and as soou as our men start out with the plow or cultivator, a great drove of ch ckens is sure to follow; and that is just what I want. Why, my old heus will begin to sing just as soon as they see the cultivator or plow start from the tool-house. Now about the berries or tomatoes, etc.: Just as soon as the hens commence meddling with the strawberries we give them all the shelled corn they will eat. In fact. I empty a two-bushel bag into a 
same as all farm crops) where rotation can be practiced. However, one can rotate somewhat in a fenced-in garden which I will speak of soon.

You want some good land-just the richest and best you have near the house. It will be a little better if it slopes to the east or north, rather than the south or west. It will be cooler, and that would just suit the berries. It should be land that is pretty clean. If chickweed and purslain abound, you will have more trouble in keeping your berries clean. You must not set out strawberries on sod ground, for fear of the white grub, unless you know there are none there. I set berries on clover sod, in regular rotation, the same as we do potatoes; but we have no trouble to speak of with grubs. If there are any in the ground they will eat the roots of your plants, and ruin your patch. They are as fond of strawberry-roots as chickens and robins are of the berries themselves. Thus we have to look out for enemies on all sides. You should choose land with no tree-roots in it. These would take up the moisture that strawberries particularly need. Remember that treerocts extend a long way from the body, sometimes.

Strawberries can be grown successfully on almost any kind of soil, from sand to heavy clay. I have scen big crops on sand so light that much of it would blow away, if not protected; but it took much manure to grow them. Very heavy.clay will grow large fine berries; but one must choose varieties fitted to

large tin can placed in the poultry-house. Then I make sure that drinking-water is close by. If you let the hens get out of drinking-water, eve $\mathbf{n}$ for two or three hours, they will at once commence on the juicy strawberries and tomatoes. Or if they get hungry they will eat strawberries, both green and ripe. Be sure they do not get hungry nor thirsty, and they will ordinarily do very little damage. I think the corn and drink are cheaper than a fence. Besides, if we fenced the chickens up and kept them from the garden, they could not follow the cultivator in picking up angleworms, grubs, etc. Our forty or fifty hens that almost board themselves and work for nothing a great part of the year furnish us an amount of eggs for the lunch-room that could not well be spared. It is true, they make trouble in the garden and in the tool-house, more or less. Where mellow laud is so plentiful, however, the year round, their scratching does not a mount to much unless they get into our hot-beds or something of that sort.A. I. R. 
the soil. Some will do best on a particilar kind of soil, and some on another. I should rather prefer what would be called a good potato soil, a happy medium, about half way between sand and clay. Moist soil is good, but not wet soil. If it is wet it should be tile-drained. Just what is best is a well-drained (naturally or with tiles) but still moist piece of land. Again, it should be upland, not lowland, because late spring frosts will be heavier on the latter. A frost, when the berries are in bloom, does much damage; hence, select land where there will be as little chance as possible of loss in this direction. It is pretty hard to work a whole year over a bed and keep them in perfect order, and then have the frost take a large part of the fruit in a single night.

Of course, I am telling you what is best all around; but if much is wrong for your location, set out some berries. You can manage to grow enough for your own use some way; so, do not despair, but just come as near to the right as you can. I would not set strawberries between rows of raspberries or other small fruit in the fruit-garden. We tried it. The raspberries, blackberries, etc., sent their roots under the strawberries and robbed them of fertility and moisture; and when we were picking in the strawberries we packed the ground, walking back and forth so much, greatly to the injury of the other small fruits. If you set strawberries in the garden, put them all in a block by themselves. The accompanying figure shows a plan for a farmer's garden, that would suit me. I have called it "the home acre;" and how much more homelike and en. joyable would thousands of farms be if they had such an acre, more or less, well started and well cared for !

Suppose, to start with, that 1 is set out with strawberries, and 2 and 3 are used for garden-stuff. The next spring you set out a new bed of strawberries in 2, and use 3 and 4 for garden. A year later you set out strawberries in 3 , and have your garden on 1 and 4 , and so on, rotating on these 4 strips. This is supposing you keep a bed in bearing but one year, which I 
think is the best way, and which we will talk more about before we get through. Now you want to know what the space marked 5 is for, I suppose. Well, this is a strawberry-book; but when we are picking out the location we must sort o' fit it in with all the other good things which the farmer should have in his garden. On $5 \mathrm{I}$ would set out raspberries, blackberries, currants, grapes, and gooseberries, if you like them. I would put the grapes on the right hand side of 5 , perhaps two rows through. This is because they will be permanent; but the

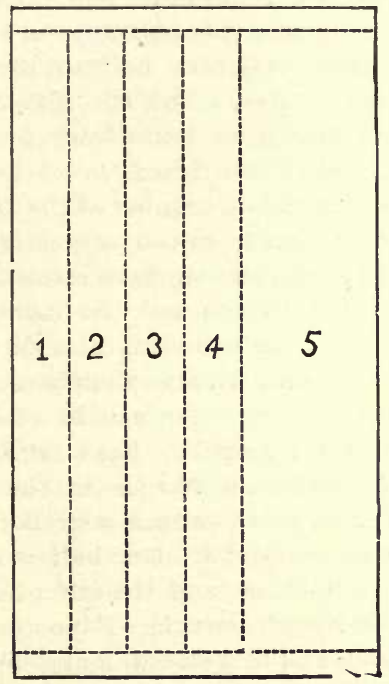

FIG. 1. -THE HOME ACRE.

raspberries, etc., will need resetting in time, and had better be set on new land (rotation). You can set them over on 1 , or 1 and 2 , using part of 5 for garden-truck and strawberries. By this plan you can keep the kitchen garden and fruit-garden on 
a given area for all time, and do it successfully. But we will talk more about this plan soon.

First let us consider the question, How much land shall we plant with strawberries? Well, in order that you may have a great abundance, let me advise that you set out two or three square rods for each person in your family. To the farmer a few rods of land, more or less, amounts to nothing; and when you have the horse hitched to the cultivator you will hardly notice the difference between cultivating a big patch and a little one. I would have one, while I was about it, that amounted to something. The farmer must not expect to grow berries so as to get a full crop. The frost may take half, or the drouth cut the yield short. If the farmer, with such tillage and care as he can probably give, gets from half a bushel to a bushel to the square rod, he may well be satisfied.

Chas. A. Green, in a late number of the Rural New-Yorker, says: "My own family, not a very large one, consumed strawberries for a month, and we have estimated the amount to be over 20 bushels." If you get too many, remember your neighbors, particularly the poor and the sick (remember them any way; a taste of your choice abundance may encourage them to go and do likewise. One can be a missionary without being a preacher of the gospel). For a family of six persons on this plan, you would want 96 rods in the garden (Fig. 1), besides the head lands that you turn your horse on when cultivating, and the strip marked 5. One half will be occupied by the strawberries all the time, and the other half by your potatoes, corn, and other garden-truck. If you prefer raising your potatoes in the field, and this would make too much garden, seed down one strip each year and let it lie in grass, or, better, clover, and plow under the entire growth.

To save time in cultivating I would have this garden long and narrow. One can do the work quicker than where it is square. In the plan given I have figured on having each of the strips, $1,2,3$, and 4,24 feet wide, which will give six rows 
of strawberries on a piece. I would have strip 5, say 64 feet wide, which would give room for eight rows of grapes, raspberries, currants, etc., which I would put 8 feet apart. For a medium-sized family this would require a strip of land about 10 rods long, containing sumething over an acre. You will notice the head lands in this plan. In a fenced garden these are necessary for convenience and fast work. This is the small fruit and vegetable garden. I would not have a tree in or near it. Both are good things, but they do not go well together.

Now about the rotation in this plan. You can raise vegetables and strawberries for many years in the same ground, without seeding down. It will take lots of manure, but it can be done. It is not, however, the wisest plan. Nature teaches us the wisdom of rotation, and the farmer always has use for every load of manure he can get, and he should manage his rotations so as to bring in a renovating crop often, to save manure. Now, I would plow under the vines in plot 1 , for example, just as soon as the last berries were picked, and sow clover and timothy seed on the strip, rolling it in. By the time it needs plowing for garden-stuff the next spring there should be a heavy sod, which would lighten up a heavy soil, and increase the fertility considerably, or, in other words, diminish the quantity of manure required. Then, as soon as the garden-truck is off from 2, the first year I would also seed that and let the grass grow until ready to set out the strawberries. The vegetables that could be gotten off the earliest should be planted on this strip, then it could be seeded in time to make a heavy growth on rich land. With a very little trouble, in this way I would keep my land mellow, and in good heart, without using nearly as much manure.

I would put on the vegetable-ground what manure was used, except, perhaps, some for mulching the strawberries. There will be enough left in the soil for the strawberries, and you can take care of grass and weeds, coming from seeds in the manure, among the vegetables better than among strawber- 
ries. Plow the ground for strawberries as soon in the spring as it is dry enough to crumble nicely from the plow. Spread on the surface the ashes from the house, if you burn wood; then harrow thoroughly, making the land as fine as you can. Last of all, go over it with a roller. Then you are ready for the plants. The sooner these are set out after the ground is dry enough to work in the spring, the better, in the latitude of Northern Ohio. This is the best time, as our large growers all say, to a man; but with care they can be set out almost any time during the summer, even as late as after early potatoes have been dug. If you must set them out as late as that or go without, why, do it, by all means; but give them richer land and extra care. Friend Root has had experience in this line, and he can tell you all about it. You will want some of his transplanting-tubes and the plants growing on your own land, or near by ; then if it is as black with manure as is that of $\mathrm{Mr}$. Root, and your tillage is as perfect, you may expect some berries "as big as peaches" the next year. But under ordinary conditions, set your plants for a new bed about the first of May, in this latitude. I would not freeze my fingers to do it at the earliest possible moment that the ground would do (the writer just about did that once, before he had had any experience, having read that they should be set as early as possible). A few days one way or the other is not important, if all other conditions are right. Supposing you are intending to set out your bed in the spring, we will go on.

Before going to the next chapter, however, one experience in this connection (selecting a place for the strawberries) has occurred to me. A certain farmer's wife induced her husband to get some strawberry-plants and set them out. Where do you think he put them? Well, he selected a place in one corner of the calf-lot, drove some sticks down, and tacked on a few boards to keep the calves out. The farmer never got into that pen once, after setting the plants; but the calves did; and between them and the weeds, not a berry was picked. The 
next spring the good wife said: "Now, Joe, I am going to get some plants and set them out in a bed in my flower-garden."

So she sent to Mr. Crawford for some, and put them in and took good care of them. Joe determined to show her a thing or two ("what does a woman know about plants?" this because she bought them), and went to a neighbor's and got sonie plants from an old run out bed, and set out a bed in the garden. Now, Joe did do considerable work on his patch, just to carry his point. However, his wife said that, before fall, it was hard to tell whether he was trying hardest to raise weeds, grass, $\mathrm{cr}$ berries. They were set out in such a way that all the work had to be done with a hoe. Well, what was the result ? Why, Joe never got one single berry (when "Mrs. Joe" told me this at their fireside last winter he never contradicted the story in any point-for a wonder), while his wife had a fine little bed of berries. Please contrast Joe's location and general plan for taking care of the berries, with the plan given above, of six rows some ten rods long, that can be rapidly cultivated with a horse, and you have one of the morals. In other chapters you may find out why Joe's plants failed to bear.

\section{ח n \\ CHAPTER IV.}

VARIETIES TO PLANT ; WHERE TO GET THEM, AND HOW-GOOD AND BAD PLANTS ILLUSTRATED ; ALSO PERFECT AND IMPERFECT FLOWERS-HERLING IN PLANTS-RUST AND FROST.

Please take notice that I have no plants to sell. This little book is written to tell you all I can about strawberry-growing, from a farmer's standpoint, not to advertise any thing. Buy your plants of the nearest reliable grower. Tell him just what your soil is, and leave it to him to select for you, if you 
are not posted. Tell him whether you are subject to late frosts. I did this when I first started, buying of Matthew Crawford, of Cuyahoga Falls, Ohio, and he sent me just the varieties for $m y$ soil and frosty locality. We made a success of growing strawberries the very first season, thanks largely to his selection.

Some varieties are very easily injured by frost-the Sharpless for example. It would be worthless here on my farm. Some will bring a part of a crop in spite of repeated heavy frosts, the Sterling particularly. Some are best adapted to heavy soils, the Sharpless and Jessie, perhaps, while others do best on lighter soil. Tell your grower to send you only reliable standard varieties. What you want is berries, not the latest novelty, which costs high and may prove dear even if taken as a gift. Have the plants sent you by express, if you get any quantity, as they can be sent in better shape than by mail, and you will naturally get larger plants. If you get only a dozen or so of a kind, to start with, and grow your own plants for a bed - why, they may as well come by mail if it will be much cheaper.

I would have none but the very best plants, and new young plants that have never borne any fruit, and that were grown from plants that produced no fruit. New young plants have white fibrous roots: old ones have black roots that look old and dead. I would not take such as a gift. Better buy the best at high prices. I once sent several hundred miles, to a grower who had a national reputation for having a certain variety in perfection, for some plants, expecting, of course, to get some extra-choice ones. They were sent by express, as I wished to spare no expense in getting the best and in the best shape. Well, he sent me all old plants - at least I received such. I did not know any better then, but learned by sad experience. Should such plants be sent me again I would return them.*

* May I suggest to friend Terry, that, instead of returning them, you "heel them in" and await further orders? Where you return things.by express, an additional expense is imposed upon somebody, and it must be 
If you will look at the accompanying figures, 2 and 3 , you will see a small, feeble plant, and a good strong one.

I set out only the latter kind, and throw the former away. To be sure, the little ones with few roots will live; but I have set them out side by side with large thrifty ones, and watched them; and all through the season they kept just so far behind. Use the best only; this not so much for the first season, when you buy the plants and have to take what comes (although then I would try hard to buy only the best), as for after seasons, when you take them up out of your own bed to set out in a new one. Throw away any that are not strong and thrifty,
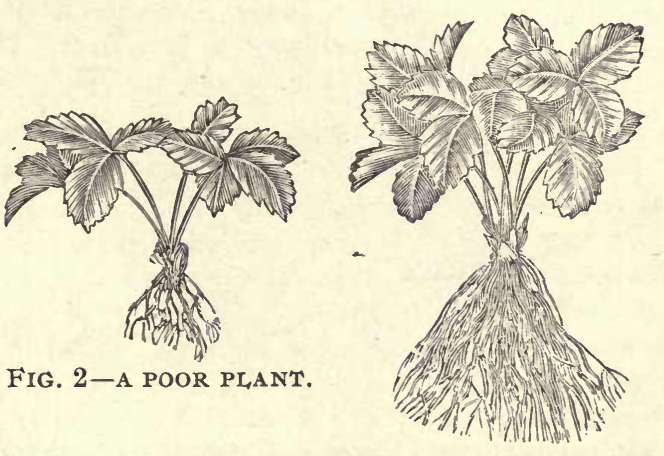

FIG. 2-A POOR PLANT.

Fig. 3-A GOOD PLANT.

like Fig. 3, with a large crown (the body from which the leaves come out), and plenty of roots. In anather chapter you will find the names of the varieties I grow, and all about them, if you wish to read up on the subject.

paid. By the time they get back they are doubtless of but little if any value. Therefore do as above, and ask the shipper for further instructions. Some people leave them at the express office, and refuse to pay the charges. Now, I would not do even this. I would pay charges and take care of them as best I could, and write to the shipper. If he is reasonable he will make things satisfactory. Even if the plants are in bad order. and poor, if the variety is high-priced and valuable you can usually get enough of them to live, so as to grow nice strong plants for the next sea son. By all means use only the best plants, when you can get them.-A.I.R- 
There is one matter connected with varieties that each grower, no matter how few he has, should know about. Each strawberry seed has a pistil through which it must be fertilized to come to perfection. The clump of pistils makes the oval central part of the flower, as seen in Fig. 4. The pollen which does the fertilizing is given off by the stamens, which number some 30 , more or less, in a flower. These can be seen in Fig. 5 , growing out from among the pistils.

The stamens are the male part of the flower, and the pistils the female. Some varieties produce flowers having both stamens and pistils. These are called "staminate," or perfect varieties. Fig. 5 shows such a flower. Varieties having flowers like Fig. 4 are called " pistillate," or imperfect. The correct names for these are staminate and pistillate; but the

FIG. 4.

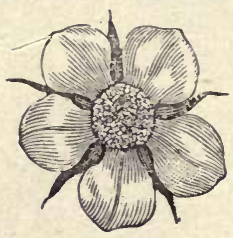

FIG. 5.

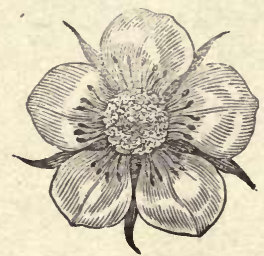

AN IMPERFECT BLOSSOM. - A PERFECT BLOSSOM.

farmer, or young beginner, will remember better if they are called perfect and imperfect, and hence we will make use of these terms only, in this book, to save all confusion. Perfectflowering varieties, such as the Charles Downing or Jessie or Cumberland, can be grown alone. They have both stamens and pistils, and fertilize themselves. Imperfect ones, such as the Bubach No. 5, and Haverland, must have some perfect plants near them to fertilize them. This matter of sex in strawberries was not understood until quite recently. It is claimed that Nicholas Longworth, of Ohio, was the first to dis- 
cover the matter. Even as young a man as Charles A. Green, the well-known horticultural authority, says that, when he was a boy, he cultivated imperfectly blossoming strawberries year after year, receiving no fruit, without knowing the cause of failure. A great many have had the same experience.

Growers usually have about every fourth or fifth row of a perfect-flowering variety in a field of imperfect ones. You may ask, "Why grow the imperfect kinds at all?" They are usually more productive, hence in field culture they are largely used with just enough perfect ones to do the fertilizing. There is some difference of opinion about what proportion should be perfect plants. Probably the season and locality have something to do with it too. Mr. Theodore F. Longenecker, of Dayton, Ohio, a very careful grower, would set out nearly as many rows of perfect plants as of imperfect - never less than three-fifths as many. I noticed when Mr. Crawford sent my plants the first year (some.1500) he sent half and half.

It is claimed that the variety used for fertilizing has an influence on the imperfect one. For example: Putney and Woodward say, if you want firmness you should fertilize with Wilson; if sweetness, use Sharpless ; if dark color is wanted, fertilize with Longfellow, and so on. But t':e farmer will hardly care to delve into.the subject as deep as this. Leave it with the grower of plants to send you the proper varieties for fertilizing, or buy all perfect ones. The pollen is carried from one variety to another by wind, bees, wasps, etc., probably; but we hardly know all about this just yet. A case in point about this fertilizing business has just occurred on my own place. A farmer called, and said that, from what he had learned, the Haverland and Bubach were about as promising berries for his soil as there were, and wanted to know if I could advise him of any better ones to send for. I told him I could not, and he started off, saying he would send for a thousand plants of each. Just in time it occurred to be that he might not know they are both imperfect varieties. He did not know, and would have 
sent for them, and set them out alone, and the dealer would have said nothing, supposing, of course, that he knew what he was ordering.*

Some varieties of strawberries are subject to blight, or rust, on the leaves. This usually injures the growth and yield more or less. But a variety that fails from rust in one locality, or under certain treatment, may be all right in another place, or when grown under different conditions. The Sterling berry is one of the very finest I have, to yield, in thin matted rows; but it utterly fails in hills, from rust. The rust first appears in the form of little dark spots on the leaves, which may increase until the leaves all die. I hardly think there is any practical remedy yet, although some have told me of applications that would stop the disease. The best practical remedy is to grow those kinds that do not rust on such soil as yours. Two or three varieties that I have tried were rendered almost worthless by rust, while the Bubach, Jessie, and Haverland are almost entirely free from it.

By this time you may think you had better buy your plants, when first beginning, of a perfectly reliable man who will study to send you what is best for you. Now, that is just right. Do not buy any cheap plants, or of a man whom you have any fear might send you whatever he had on hand any way. Do not take plants as a gift, out of some old bed of a

* I confess that I have, until this season, been a little skeptical in regard to the importance of planting as above; but a year ago, wishing some Bubachs near the office, that we might take up plants without going to the fields, I planted two rows right in sight of where I am writing now. The ground was heavily manured, and they made a great profusion of runners, which have been used for filling orders. At the time I did it, I had only plants in mind, not thinking of fruit; and when it occurred to me that no other berries were near, I concluded I would wait and see if they would bear fruit. The fruit is now ripening, but the berries are small, gnarly, and knotted, and there is scarcely a perfect one in the patch, although the growth of foliage is equal to any I ever saw. Our Bubachs out in the fields are giving monstrous berries in great quantities, with no knotted or gnarly ones among them. In the fertilized plot, a great many of the berries are simply little knots, or knobs. I give this for the benefit of those who, like myself, think there is some humbug or superstition in regard to the fertilization of strawberries.-A. I. R. 
neighbor's. I have had farmers ask me if they could get some plants from my bed after we were through picking, and just when we were going to plow them under. They were for saving a few cents ; but it was "penny wise and pound foolish." Get good plants to start with, and then I will tell you, further along, how to have good ones ever after. I could not advise you better than to write to the secretary of your nearest horticultural society, putting in some stamps, or attend their meetings and ask your questions. Most of our agricultural papers now have horticultural columns, and one can get advice from reliable sources by writing to the editor.

When your plants come, the sooner they go into the ground the better. If they come at night, or your ground is not quite ready, you may set the box or basket they come in down cellar until you are ready to put them out. If it is likely to be more than a few hours, I would open the bunches (they come tied 25 or 50 in a bunch, usually), slightly spreading out the roots in a little trench of moist mellow soil, and cover them with the same, and then shade the plants. Where you send for a few plants by mail to test, or get a start from, if they come when it is not a favorable time to set them out you can dig a little trench and "heel them in," putting the plants about three inches apart, and covering the roots with moist dirt; then shade from the sun until they start to grow, when they can be taken up carefully, with the dirt adhering to the roots, and set out where they are to grow, some cloudy day, or just before a rain. If I get plants by mail at night $I$ heel them in before I go to bed.

I have spoken in this chapter of late frosts injuring strawberries. Perhaps I may as well describe now just how it hurts them. The leaves are not injured in the least; but the blossoms that are touched by it will usually be killed-that is, they will produce no berries. If you want to know whether they are injured after a frost, go out after the sun has shone on the vines for a few hours; and if the clump of pistils in the center 
of the flower, whether it is a perfect or an imperfect variety, has turned black or quite dark, no berry will come from that blossom. The frost has got the start of you. Quite a good many blossoms may be killed, however, if your plants are thick on the ground, and you still get a full crop, as the rest of the berries will grow larger. It is like picking part of the apples off in June : one may get as many bushels in October, of larger fruit. Judge Miller, in Popular Gardening, says a frost is a good thing to thin out the fruit, and that, under some circumstances, it would pay to hire children to go through and pick off part of the blossoms. But I think I will thin out the plants, as you will learn in the back part of the book, and let all blossoms remain on what are left, and then hope that frost may stay away, or mulch heavy and keep my berries back. If frost touches a berry after it is set it may destroy it, or it may cause only a portion of the berry to wither and not grow any more. A frost will injure some varieties while in the bud; they will blossom out all right; but when the bud unfolds you will see that the center is black.

\section{$\sim \sim \sim$ \\ CHAPTER V.}

MARKING THE GROUND-SETTING THE PLANTS-THE DIS TANCE APART.

We left the land where the plants were to be set, very thoroughly barrowed and then rolled. If you haven't a roller (but every farmer who has a plow and a harrow should have), a clod-crusher will answer. Remember it must be very fine and firm, if you want the plants to do their best from the start. If you have any doubts about its being in the best shape, harrow and roll it alternately two or three times more, when the land is dry enough not to pack hard. Of course, you under- 
stand that you must be careful not to work land that is at all heavy, for any crop when it is even a little too wet. It will make it hard. What we want is a fine, mellow seed-bed, firmly packed There is a difference between firm and hard.

Now take a line and stretch through where you want the first row. I have used common binding twine. You want the line attached to a stake at each end, of course. I would put the first row three feet from the edge of the plowed land. If you put it too near the edge it will bother you to get through with the cultivator. After the line is stretched in place, take a sharp stick ( $I$ have used the end rod out of my lumber wagon, which was just the thing) and draw a little mark right by the side of the line, from end to end. Then take the line up, one person at each end, and put it down four feet further in on your piece of land. Next, in a few minutes' time you can make a little marker, something like the one shown in Fig. 6 , with which you can go along the rows you have marked lengthwise, and make, almost as fast as you can walk, little crossmarks, to show where to set the plants.

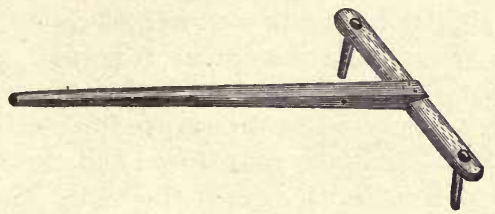

FIG. 6.-A MARKER FOR SPACING OFF ROWS.

The first plants we set out we measured with a stick which we carried along, to get them the right distance apart. This was slow and bothersome. So my son went to the tool-house and made a marker like the above, in about ten minutes, which is still in use.* I set the plants two feet apart. The rows are

* In regard to the use of the line-marker, etc., let me suggest that market-gardeners have a plan which I think is much simpler. I,et your line be of pretty good size-say something like a small clothes-line. After you have stretched it, walk the whole length by stepping the whole length upon the entire line. This gives you a mark absolutely straight. In our 
four feet apart, and the plants two feet in the row. This is about the usual distance apart for matted-row culture. Now go to the cellar, or to where you may have heeled in your plants, with a pail half full of water. If it is a cold day, warm the water slightly by putting in a little that is hot, until it feels comfortable to the hand. This is for the comfort of the one setting out the plants. Next open your plants and put forty or fifty in the water, being sure that all roots are under; and if the tops are too, it will not matter. Cover the rest of the plants from the air again. You are now ready for setting.

You can make the holes to put the plants in with either a garden-trowel or a brick-layer's trowel. But I found it easier to take my narrow four-inch spade (English ditching-spade), stand on one side of the row, push the spade down about five inches, with the back to the long mark, and the front toward me ; work it back and forth once, and then pull it out with an upward and sidewise pull. This makes a nole about four inches deep, with a nearly perpendicular bank in line with the row. A man can throw out the holes very rapidly in this way. You can make a similar hole with a trowel, of course, but not near1y as easily. Next take one plant from the pail of water; spread the roots out fan-shaped, as in Fig. 3, and with the left hand hold this plant against the perpendicular side of the hole. With your right hand take your trowel and throw two or three inches deep of moist earth against the roots. Then press the earth firmly against the roots, using both hands on the trowel. Fill the rest of the hole with mellow earth, leaving it loose. Never let the strawberry-roots get dry, nor put dry earth direct-

tool house we have a machine something like a wheelbarrow with a wheel nearly a yard across. Movable pins are set in the rim of this wheel. It is wheeled over the line like a wheelbarrow. Now, if you walk on your clothes-line as you go over, you will make a plain mark, and the pins will space it accurately. I think a common wheelbarrow will answer very well by winding some wire or tying a cord around the felloe and tire, say on each opposite side of the wheel; that is, supposing you can get a wheelbarrow with a wheel of such size that half the circumference will be the distance you need the plants apart. We mark out our ground by means of a two-horse marker which will be described at the close of this book. -A. I R. 
1y against them. If the surface is dry, scrape it off with your trowel and get moist soil to throw next to the roots. Wet roots put in moist soil, well firmed about the roots, and mellow or loose on the surface, are the best conditions possible.

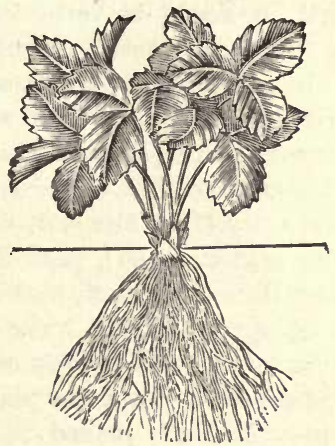

FIG. 7.-SET JUST RIGHT.

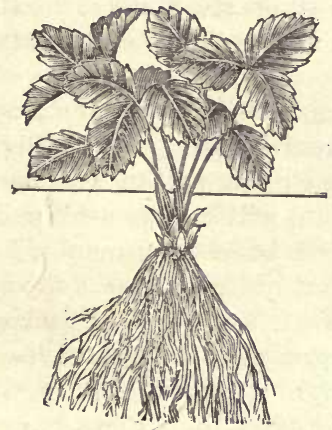

FIG. 8. - SET TOO DEEP.

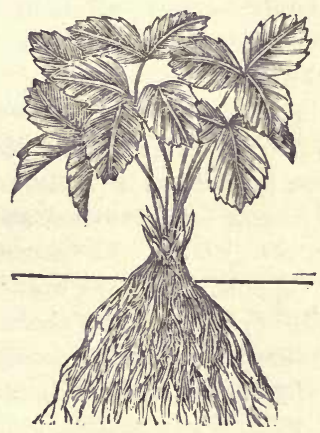

FIG. 9.-SET TOO SHALLOW.

Some people laugh at such carefulness, and say that "strawberry-plants will grow if stuck in almost any way; even a plant left lying on the surface, by the person setting out, will 
often take root." So it will; but let me tell you that, when you find a man farming in any such careless, slipshod, trust-toluck way, you will find a man who is not very successful in his business. "No paius no gains ;" or, "Man's fortunes are according to his pains." It would be better if the plants could be set out on a cloudy day, or toward night, or just before a rain; but where one buys plants from a distance they must be set when they come or soon after. If you set them just as I direct, and they are good plants, they will not wilt a particle, be the day ever so bright and hot. Do no watering or covering. If the soil is very dry (but fine soil, well firmed in the early spring, will very seldom be so), pack it by stepping on it next to the plant, after it is all set out, and scrape a little loose soil over where you stepped. If you have no trowel you can get a garden-trowel for a few cents, or you can make a paddle of wood that will answer to set out a few plants.

Fig. 7 shows a plant properly placed in the ground. The top of the crown, where the leaves come out, should be just above the surface, after the plant is all set and the soil leveled down around it. The lines in these figures indicate the surface of the ground.

Fig. 8 shows a plant set too deep. Earth over the crown will usually kill it, or at least prevent its doing well. Fig. 9 shows a plant set too shallow. The air can get to the roots, and so can the sunshine, and the plant will not do well under such conditions. The roots should ail be in the ground. I do not suppose any one would set a plant quite as deep as the one in Fig. 8, nor quite as shallow as shown by Fig. 9. I have exaggerated these cuts to make the lesson plain. Also the leaves on the plants are a little more upright than you will usua!ly find them when setting out. They often crinkle down so as to be in the way. Of course, we had to put them up out of the way in these pictures so as to show you plainly just how to do the setting. Do not dig holes, except as fast as you want to put in the plants, so as to have the soil that the roots will touch 
moist. Take the plants out of the pail of water, only as fast as you are ready to set them.

To find how many plants you want, you have only to measure one of the rows and divide the number of feet by two, and then multiply by the number of rows. Or if you know the amount of land, it will be easy to figure, as it will take about 35 plants to the square rod. If you set out 500 or 1000 plants, and do it well, you will be likely to have a first-class backache before you get through, not being used to such work; but just think of those 66 meals with all the great, large, delicious, ripe berries you can eat, and push ahead, and do not slight your work.

Since writing the above $I$ have been reading an article in the Rural New-Yorker, written by J. M. Smith, telling all about how he sets out strawberry-plants. I was not surprised to find that Mr. S. is extremely careful about how his plants are set. He would not call what I have written over-particular. He says: "There are but few things in either the market or home garden that are of more importance than setting out the plants." He also says : "A few years ago, I lost heavily upon some of my strawberry-beds, owing to some careless setters who, when neither I nor my sons were with them, merely opened the earth and laid the long beautiful roots about two or three inches deep and covered them with earth. It came on very dry, and I soon noticed that they were suffering more than there was any apparent reason for, even though it was dry. In fact, some of them were dead, and many more nearly so. Upon examination I soon found the cause of the trouble; but it was too late to repair the damages, and the next season I suffered the loss of hundreds of dollars through the carelessness of the men who set those plants." You see the men were too lazy or careless to make the holes deep enough to put the roots straight down, or nearly so, so that part of them would be in moist earth in a dry time. Mr. S. speaks of another fatal mistakeneglecting to press the earth sufficiently close around the plant 
roots. After all this, my friends, it must certainly be your own fault if you do not set your strawberry-plants so that they all grow finely.*

\section{CHAPTER VI.}

ALI, ABOUT CULTIVATING AND HOEING-CUT'TING BLOSSOMS AND RUNNERS OFF, AND PLACING RUNNERS.

There is just one secret about taking care of a strawberrypatch easily; and that is, never let any weeds see daylight. Do this, and the work will always be pleasant and profitable, and it will not take a great deal of time. I think it was $\mathrm{Mr}$. Putney who said first, "It is cheaper to hoe three times than

* In regard to the careful setting-out of plants, last spring I was visiting a strawberry-grower in Leelanaw Co., Michigan, who grows several acres every year. He was just setting out a piece of four acres. His method of marking the ground will be described in the latter part of this book: and his way of setting the plants in the ground impressed me very favorably. The tool used for making the holes was a long handled round. pointed spade, such as we see in common use among laborers who handle dirt. The point of the spade was pushed down vertically, right along the line on the spot where the plant was to be set. The dirt was then pulled away from the line so as to leave a perpendicular side of fresh earth-a sort of half-circle, say six inches deep, and nearly a foot across. A plant was then taken from a bucket of water, the roots spread out fan-shaped. and held up against this perpendicular wall of fresh earth until some of the dirt that had been scooped out had been pushed back against the root of the plant. The operator then pressed the dirt down with his foot, tight up against the roots. The proprietor (Mr. James Hilbert. Bingham, Mich.), nade the holes with the spade, and kept his eye on the setters to see that every plant had the roots properly spread out so as to be evenly distributed along this vertical wall of earth, and then he watched to see that every man firmed the dirt arornd the plant with his foot. I think there were about half a dozen in the crowd setting plants, and the proprietor's eye was on almost every plant in the whole 28,000 while they were being set out. I have seen the plants several times this summer; and although a severe drouth followed not long after the setting, there is scarcely a plant missing out of the 28,000 . They were set in April ; and at this writing, Sept. 16, almost every plant has a nice family of little plants scattered to the right and left. You will notice this plan of setting the roots along a straight live enables us to cultivate within an inch of the roots-that is, shortly after they are set out-without injuring them. Of course, the ground was kept constantly stirred so that no crust should form after a rain. or no such success could have attended planting so large a tract as four acres, almost without the loss of a plant. But the next chapter considers the matter of cultivating. - A. I. R. 
once." Yes, and it is pleasanter too. The idea is, of course, that, instead of waiting till the weeds get well started, and working hard to hoe them up once, you just rapidly run over the mellow surface two or three times, simply stirring it so no weeds can grow at all. This is the way ne grow potatoes; it is the only correct way to farm, now, and it is just the way to grow strawberries. Read this over and over; learn it by heart.

It will help if the land set out in strawberry-plants was in corn or potatoes or garden-truck the year previous, or corn one year and potatoes the next, and was kept entirely free from weeds. But even if the land is full of foul weed-seeds you can keep them down quite readily if you, never let them get started at all. Cultivate the ground once a week or oftener. I would not go more than one inch deep within 6 inches of the plants, and then in hoeing the little strip that is left, that you can not cultivate, I would not hoe more than half an inch deep right around the flants. I do not want to disturb them at all-just mellow the immediate surface, and make it fine, and prevent any weeds from coming up. I set a somewhat careless man to hoeing my strawberries once, and he did great damage by hoeing some two inches deep, and breaking up the earth around the roots too much. Do not pull any earth up around the plants when hoeing, but leave it level all the season, just as it was when you finished setting them out. With a little hilling up, the rains may wash the earth over the crowns and rot them and kill the plants. My own experience is that a pronged hoe is the best tool for stirring the soil between the plants that the cultivator does not reach. This is just like a hoe, only there are four or five tines in the place of the blade of the hoe. The potato hook that some use to dig potatoes with is practically the same thing. There is no better tool to stir soil about plants with to keep weeds from starting and to break the crust, or keep it from forming. This hoe is nice to use among the flowers, etc., too. Walking backward I can stir the little strip between and around strawberry-plants very rapidly. But this is 
only for clean and timely culture. If weeds get started oncewhy, then we must use a common hoe to destroy them. The pronged hoe acts as a rake or a weeder in the field.

Now, remember that just stirring the soil slightly to keep weeds from growing or showing at all, is nice work; but that if you let them once get a good foothold you have got either defeat or a discouraging job before you. I know how hard it will be, with the press of work that often comes on the farm, to attend to this matter always promptly; but that is the way, and I know you can do it. The first summer we had strawberries (a quarter of an acre) we took good care of them without much trouble until haying and wheat harvest and potato cultivating all came in a lump, without a breathing-spell between. For two or three weeks then we did not have a moment to spare for the berries, as it seemed to us. We were much troubled with purslain. During that hot weather it got well started in these berries; and if we did not have a time cleaning them after that! We picked up and carried out bushel after bushel, as it had got started so well that hoeing would not kill it. Well, we conquered, but at great cost. Since then we have taken time to stir the soil hastily, even during harvest time, so as to prevent the purslain from starting, and our other work has been done all right too, some way. Few men are now doing so much that they can not do more by a little better management or more system.

I might say that the soil we selected for berries, although moist, is a little better drained than some portions of our fields. During a heavy shower water will collect in the low places in the fields; and although the drains take it away promptly, these spots are not dry enough to cultivate as soon as the berry ground where there are no low places. So we can have two or three hours to work in the berries, after a shower, before the land is dry enough to cultivate right through in the field. Thus the berries have had proper attention without interfering at all with field work, and we have all sorts of berries besides 
strawberries, and liberal quanticies of them too. Did I not tell you, in a previous chapter, that, where there is a will there is a way? One of those farmers who never have any time for such jobs stopped to talk with me once, when I was hastily going over my fruit-garden, before the fields were dry enough for cultivating. He looked with longing eyes at the nice rows of berries, and said it would do for $m e$ to fuss with such things; he wished he had the time; but it was no use to think of it, etc. Meanwhile my man and son kept the horse and cultivator briskly moving, and I hoed row after row, long ones too; and before that man's business called him to move on we had cultivated and hoed over far more ground than would be necessary to grow all the berries he and his family could possibly use.

Some eighteen years ago we set out a strawberry-patch, without having them in shape for horse culture, and the result was that the money paid for plants would have bought more berries than we ever picked. Perhaps we had all imperfect varieties too; I am sure I do not know. And I guess we were about like the brother last spoken of-hadn't time to fuss with them. The "will" was lacking. I suspect we have lots of company in that experience. I hope we may have as much in our later practice. Man can do almost any thing if he sets out with the determination to conquer.

Soon after your plants are set out you will see stems coming up with buds on. There will be little leaves on the stems also. Cut off all these stems as fast as they appear. It will weaken the plant to grow any fruit the first year. What you want is to grow as strong plants as you can, to become parents of other strong plants, which will produce abundant and fine fruit the following season. After a time you will see little round shoots starting out from the plants you set. These are called "runners." If allowed to grow, after running from six to ten inches (according to variety; late berries have long runners and early ones shorter, usually), they will throw up leaves and roots downward, and produce new plants. But you should 
cut all these runners off as fast as they appear, in this latitude, until the latter part of July (this for farmers, not small-fruit growers). Cut the runners as soon as they start. Do not let them exhaust the plant by growing out long, before they are cut off. Some one should look over the patch once in four or five days, and cut off all blossom-stems and runners. I use a pair of common shears for doing this.

Now, this gives you a chance to cultivate and hoe rapidly, and get the weed seeds in the surface soil about all sprouted and killed. After the runners start it is more work to cultivate and hoe, and keep the ground clean. After harvest you will have more time; then let the runners grow. Before they take root I would go through the patch occasionally and spread them out around, something like the spokes of a wheel, the old plant being the hub. A clod or a little dirt placed on them will hold them in place, if they are obstinate, until they get rooted. The object of this placing, of course, is to get plants all over the ground, instead of letting them grow five times too thick in some places and none in others, as they often would natural1y. It is strange, but the first year we grew strawberries I knew nothing about this helping of the runners to cover the ground. I had not seen a word about it in the books, nor heard a word about it at the institutes, where many men had told all about strawberry-growing. Our quarter of an acre had made a sp!endid growth; but the runners had gone out in bunches, or ropes (pulled around together by the cultivator sometimes), many times too thick and much of the ground was bare. Just at that time my friend J. M. Smith paid me a visit. He told me how to fix those runners, and the young folks worked for days transplanting them, as they had got rooted somewhat, and soon had our bed in shape to do its best. I said to my friend: "Mr. Smith, how is it that I hever heard you speak of this at an institute, when you were telling us how to grow strawberries?"

"Why," he says, "I was talking to farmers, and I did not 


\section{A BC OF STRIWBERRY CULTURE.}

know that they would care to learn all the little niceties of the business."

I have given you the best way, and you can do as you please. 'If the runners are entirely neglected they will produce considerable fruit; but not as much or of as fine quality. A plant every six or eight inches, all over the ground, and no Inore, is best. I am a little more particular in this part written for farmers than I should be, because I hope that thousands of farmers' boys and girls will get interested in strawberry-growing, from reading these pages, and I certainly want to advise them to do their very best in whatever they undertake. It will help greatly to make them successful men and women; aud al. though I am only a farmer, I suspect that my berry-patch would have to be just as good as I could make it, even if I grew only enough for my own use.

For a garden-patch I would not cultivate any more after the runners half covered the ground; and if the tillage was perfect in the early part of the season you will not usually need to do much more hoeing. Let what you do do, be very shallow. Simply hoe over the ground that is bare, half an inch deep, leaving the plants all the soil possible to send their roots out in. They are thought to be laying up food in the crowns then, to make berries of next season. By winter the ground should be well covered with strong plants, if the soil was rich. I would keep a path about 16 inches wide, hoed up between the rows. If you have different kinds you must be sure to do this, to prevent the plants running together and getting mixed. This would do no harm for fruiting; but you want to get pure plants from your bed to set out the next spring. But of this in another chapter.

Of course, when hoeing, all through the season, you must pull with your fingers any little weeds that may get started in the hills, too close to cut off with the hoe. There need be very little fingerwork, however, with the hoeing always done on ime. 


\section{CHAPTER VII.}

ALI, ABOUT MULCHING-SPRING WORK ON OLD BED-SETTING NEW BED-HOW TO TAKE UP PLANTS-HOW TO EAT STRAWBERRIES-HOW TO CAN THEM.

The first time the ground freezes hard enough to bear up a team, in the late fall or early winter (usually between the 15 th of November and the 1st of December here), the strawberryplants should be mulched-that is, covered with some material to prevent sudden freezing and thawing during the winter, or, more particularly, the early spring. It is said by some good authorities that the plants are perfectly hardy, and do not need any covering, so far as protecting them is concerned. But from my short experience I should say that the plants stand the winter better, and are stronger in the spring, for being covered; and I like to get the covering on before the frost has killed all the leaves. But the main object of covering is to prevent the frost from lifting the plants.

On your garden patch, probably the best mulching material you can use is your strawy horse manure, if there are not too many seeds in it.* Shake it up very finely and spread all over the ground, just thick enough so you can not see the plants through it. Spread over the paths between the rows as well as over the rows. If your land is rich enough, or manure is scarce,

* In conversing with friend Terry in regard to straw for mulch, I asked him what he did to prevent getting grains of wheat left by poor thrashing. He replied, first, that he did not have poor thrashers; second, that the straw was first thrown on to a platform of rails in order to shake out all the grain as far as possible, that might be left. In purchasing straw of the farmers I have been greatly annoyed by the amount of grain left in it ; and on one occasion, when my strawberries were mulched with rye straw, enough rye came up among the berries, after fruiting, so that it was cut and thrashed, and it gave me a good yield. Of course, I was so much ahead on my crop of rye, but I am sure I was a good deal more behind on the berries in consequence of the rank growth of grain in my berry-crop. Whatever you do, don't use any kind of mulch for your strawberries, unless you know it is free from seeds of weeds and grass, grain, etc.-A. I. R. 
use marsh hay (because there are no seeds in it), or, what will be handiest for most farmers, wheat straw, spreading it evenly over the bed, just so you can not see through. Do not leave any bunches of either straw or manure, or you may smother some plants. I have heard of mice destroying strawberry-plants on a mulched patch; but they have never got into mine. We use wheat straw for mulching. Our fields are kept very clean, so there is no chance for mice to hide, and I think you will hardly find one at any time within fifty rods of our strawberries. Where they are abundant I would try a light coat of cut straw for mulching, not over an inch or so deep. I never have any mice in my stubble (wheat stubble, newly seeded), because we mow them once or twice; and all the growth falls down and partly decays, hugging the ground closely. Mice will not come into such a field. They are too exposed. Cut straw will lie down closely about the strawberry-plants, affording less shelter to the mice from the eyes of hawks. In the spring, after freezing weather is about over, select a wet day and rake about half the straw (if long straw was used) off from the plants, and tread it down in the paths between the rows. You can do this best when it is wet. The plants will grow up through the other half, with a little help. If there are any bare spots, leave all the straw on them. You must watch, and not wait too long before removing part of the straw from the plants. If they grow much under the straw it will be a white, feeble, tender growth; and taking the straw off then would leave the plants liable to injury by a frost, or the hot sun. Remove the straw, then, before they make much new growth. Do it in rainy, cloudy weather, so they can get a little used to outdoor weather before the sun strikes them. If you use manure for mulch, and shake it very finely, you may not need to remove much. The plants may find their way up through it all right. I like to have all the mulch left on them that they can comfortably grow up through. You will, of course, keep watch and help any plants that find trouble in 
pushing their way up through the manure, or the straw either. This help will consist in simply opening or removing the covering a little, where you may see a plant raising it up iustead of coming through. This manure, or straw, on the surface, will serve two important ends. First, it will keep the fruit clean. Soil is a good thing, but I do not like to eat it directly. Sugar is preferable on berries. Mulched as I have directed, your berries should be always perfectly clean; the rain can not spatter any dirt on them. To be sure, the berries can be washed; but the best way is to fix it so they can not get dirty. And then, again, if it is a dry year it will keep the ground more moist, and thus increase the crop. Perhaps you may think that manure would not be just the proper thing for a mulch to keep berries clean. But all filthiness will be washed out by the rains long before the berries are ripe. Any weeds that may start in the bed in the spring may be pulled up or cut off. There should not be many if the tillage the season hefore was thorough.*

*'This matter of getting the seeds of weeds into the strawberry-patch along with mulching has made so much trouble that a great variety of material has been used in place of straw and strawy manure. Friend Terry has alluded to marsh hay. We have had very good success with cornstalks. In this case the mulching was not removed in the spring at all. The berry-plants climbed up through it. Some strawberry-growers use green corn fodder. The corn is sow a broadcast close to the patch, so as to be just right to cut and spread between the rows just as the fruit is beginning to ripen. But by far the most satisfactory material we have ever used is dry potato-tops. When you dig your potatoes, rake up the vines and put them in heaps somewhere out of the way and near the strawberry-patch. As soon as the ground freezes, cover the whole bed with these dried-up potato-vines as thickly as you choose. They will not smother the strawberries, and they contain no weed seeds, and they need not he removed in the spring, for the plants will grow up through them. If put on just right you can see the green foliage down through the potato top mulching all winter long. They hold the snow better than any thing else I know of, and they never settle dow a so compact as to smother the plants and make them rot. In our potato-book you will see mention made of a late strong-growing potato called the Craig. I often find vines long enough late in the fall to pull them up and wind them about my neck while the other end remains in the ground. This potato makes a very large amount of tops. After digging they can be raked up with a horserake, and handled with a pitchfork, so it is very little trouble to put them on strawberries. Potato-tops, when they decay, furnish a large amount of potash, and this just suits the strawberry.-A. I. R. 
When the plants come to bloom, examine them and see the difference between the perfect and imperfect flowers. I would advise that you set out another bed in the spring, prepared as before, with large nice plants from your own bed. Do not take any of the old original plants, with their black roots. I think it better, take it all around, to set out a new bed each year than to try to clean out the old one. You have then the best of plants to set out, of your own growing. If you keep a bed two or more years, the plants then would not be such as I would set out. You should always have plants that have never borne fruit, grown from plants that also produced none.* Again, enemies are becoming abundant in strawberry-beds, and the longer we leave them the greater chance they have. Also, treated as I have advised, you will get the largest crop and fin. est berries the first season you pick a bed.

You may not know how to take up plants. I use a fourtined potato-fork, sticking it down by the side of a few plants as you would to dig a hill of potatoes; then lift up the plants, dirt and all, and shake them on the fork until most of the dirt is off. If it is very dry weather, on heavy soil it pays to water heavily, the night before, the plants you wish to take up. If you have no potato-fork you might take up a few with a spade. Many growers use the old-fashioned potato-hooks that used to be used for digging potatoes. After shaking the plants clean, cut the roots off at the bottom, leaving four inches on the

* I fear the above sentence will not be understood and acted on unless I put a little more emphasis on it. It is very exhaustive work for strawberry-plants to bear a big crop of fruit. After the fruit season is over the plant withers up, gets rusty, and for quite a time looks almost dead. Now, if you pick all the blossoms off so the plant can not bear any fruit it is spared from this exhaustive process. It keeps its leaves bright and green, and it sends out strong and thrifty runners much earlier than it would have done had it borne a crop of fruit. Therefore, to get the best plants you must secure them from parent plants that have never been allowed to bear. Set a part a portion of your bed, or, better still, have a nursery for growing plants where the parent plants have plenty of room, say none of them nearer than a foot, and where they are not allowed to bear a single berry. This should be extra-strong ground: then yol will have strong bright young thrifty plants, ready to put out either in the spring or in the fall, and plants that will "get right down to business."-A. I. R. 
plant-this for early spring. In the summer, leave them all on so they can go down deeper. The old roots do not grow after you set out the plants; but they keep the plants alive until new ones can start. Trim off all dead leaves and runners, as they will be in the way when setting the plants out. After shaking all dirt off, place the choice plants in a pail of water, to take over to set in your new bed. Mr. Crawford says he would shake all dirt off any way, to get rid of any worms that might be in the roots, to save transplanting them to the new bed. He pulled up some plants on his grounds, and showed me the little enemy that was not wanted, quietly suggesting that shaking thoroughly, and keeping in water, was bad for him. Skill is better than luck to trust to. Of course, you will understand that the roots of your plants should not be exposed to sun and wind when you are taking them up. Some growers throw them into a wet bag as fast as taken up, and remuve them to a cellar to trim. But we trim them right on the ground, one person taking them up while two trim and put in water, having a plant exposed but a few seconds. For transplanting in your own grounds, use such care as I have spoken of, and your plants will grow right along, every single one of them, as though they had not been moved.

There are many ways of growing strawberries. The farmer will not care to be perplexed with the details and advantages of the different systems. I have given you a good, simple, and safe way to grow berries for your own use. All is now told, I believe, except how to eat the berries and how to can them. Go out some morning while they are cool and moist with the early dew, and bring in for breakfast a quart for each member of the family, of great, large, dead-ripe Downings or Bubachs or Jessies. Put on sugar and cream if you will, but it can hardly improve them. After trying this princely way of living for 66 straight meals, or longer, own up that you never knew what luxury was when you bought your berries, now and then a few quarts (picked before they were fully ripe, and common 
fruit like the Crescents), or depended on a little neglected patch a few feet square only. Do not forget to send a big mess to each of your neighbors who do not grow them yet. I have allowed plenty of land, so you can have enough. Offer them some plants to set out the next spring; lend them this book; help them up to where you have got.

Some have called the writer extravagant for using berries so freely. Well, friends, I use no liquor, not even preserved (?). cider, and no tobacco; drink no tea and coffee, even; and if you can not let me eat what strawberries I can grow on two or three square rods of ground, why, then I shall have to do it without your letting. This is a free country, and I live on my own little bit of it, and I am going to enjoy all the nice things. that God has given us that I can raise; and I am not going to eat ten parts bread to one of berries, as I had to when a boy, but just make the proportion to suit myself.

Canned strawberries, of course, do not have the flavor and deliciousness of fresh ones. But in the winter and early spring, when we can not get fresh ones, a few canned ones would be relished by most people. There is a peculiar acid flavor to them that is very pleasing for variety, and to the writer, at least, certainly healthful. I get very much used up attending farmers' institutes winters. Often when I get home Saturday night I feel as though I could not eat a mouthful of any thing. Not long since I return ed home late one evening in this shape, and wife said: "What can I get you to eat?"

I replied, "I do not want to see a particle of any thing;" but nevertheless she got me a can of strawberries and some nice bread and butter and a glass of milk, not whitened water such as I get at the hotels, and as soon as I saw the berries I felt better. Quite a hole was made in that can. No fruit agrees with me so thoroughly well as the strawberry, fresh when it can be had, and canned occasionally, after the fresh ones are gone. But we are not all built alike. My wife cares little for canned strawberries. Some who read this will not care for them; but 
I think most people will, if the berries are properly canned, and that they will find them a healthful sauce. They are rather expensive when one has to buy them, sometimes; but the farmer who grows them need not mind this. He can have plenty if he likes them. Let him make money from his farm crops, but take care of his little fruit-garden for his own pleasure, first of all, and that of his family. As friend Root puts it: "Thank God that there is one place where he isn't working for the almighty doilar." The last two seasons we (I mean "we," literally, for I always come in and help if possible) put up about 80 quarts each year. Not one quart has ever spoiled. We think them about right, so I will tell you just how we did it.

After picking over good ripe berries, we take a common coffee-cup, full of granulated sugar, to each two quarts of hulled berries, and fill a porcelain-lined kettle about two-thirds full. No water is put in. The kettle is stood on back of the stove until sugar dissolves. Then we put it on in front and bring it to the boiling-point, and boil slowly for about twenty minutes, stirring very carefully so as not to break the berries. The most of the stirring necessary is to help the berries on top down into the syrup, so as to be sure all are well cooked. While this kettleful is boiling we set another mess on the back of the stove in a tin pan, for the sugar to dissolve and to warm up a little, so it will be ready to put into the kettle and boil as soon as the first kettleful is canned. This, of course, is to hurry up the business. From the kettle, the berries are dipped into glass cans, and the tops screwed on in the usual way. My wife is very careful in dipping them and putting in the can to not mash up the berries. She thinks they look so much better when they keep their shape. You will find some varieties of berries better for canning than others. We find some cans look better than others, and the flavor is better. Our Sterlings are good. The Warfield is, I think, about the same. The old Wilson is good. When cool, and all covers have been tight- 


\section{A B C OF STRAWBERRY CULTURE.}

ened over, the cans are put away in a dark cupboard in the cellar.

And now perhaps the farmer will not care for the rest of this book ; but read the first part of the next chapter, any way, for it may do you good.

\section{nnmm \\ CHAPTER ViII.}

CAN FARMERS GROW BERRIES TO SELI? NO AND YES-PROFESSIONAL MEN AND VILLAGE PEOPLE (LADIFS AS WELL, AS MEN) ADVISED TO GROW STRAWBERRIES FOR RECREATION, AND TO IMPROVE THEIR HEALTH-HILI, CUI,TURE, USUALLY BEST FOR SUCH-FRUIT-BEARING FLOWERS.

I heard a good German friend say once, at an institute, that mixed farming and berry-growing didn't splice. He was correct. On most farms there would be the clover to cut, and the corn and potatoes needing constant cultivation, and wheat harvest coming right on, all this at just the time when the new1y set strawberry-beds must have frequent tillage, and the berries from the old ones must be picked and marketed daily, or the fruit lost. Truly, under these circumstances, ordinarily, the berries had better be left alone. A few things well done pay better than more half done. But if the farmer has children whom he does rot need at other work, large ewough to set out the plants, cut the runners and blossoms off, pull the weeds, pick the fruit, and perhaps do some of the hoeing, and has a home market for his surplus, he might sometimes, when preparing the ground for his own patch, fix up, say, a quarter of an acre and giv 2 the children a little business to attend to. It would be little more trouble for the farmer if the piece were the right shape (long and narrow), to cultivate 40 rods, or even 80 , than 20 , after he had got hitched up ready. Of course, every one could not do this or tinere would be no market for 
the surplus; but there are thousands of farms where it could be done. The consumers could get nicer, riper, fresher berries, and the young people make quite a little spending money. Our people are fast becoming more of a fruit-eating people. In many small towns several farmers could make a good market for a small surplus of berries, particularly if they were extra nice. In a great many towns the berries come from the large cities, where they have been sent by those who grow in a large way. The home grower could cut out such trade without any trouble, and then, in a great many towns where but few berries are now sold, a market could be gradually made for more.

Now, this isn't preaching not founded on practice. Let me tell you just what we have done ourselves. In the spring of 1887 we put out a quarter of an acre of strawberries. My two daughters and son did the most of the work of setting out and caring for them, and about all the picking; at any rate, the writer did not do any. He helped some about the marketing. The cultivating was done for them, as, when we were cultivating the rest of the field, which was in potatoes, we went right through the strawberries too. It was hardly any extra trouble. My man and myself helped some about the hoeing also. The strip set out was about 3 rods by 14 . They were set out and cared for just as I have advised in the first chapters of this book. Do not think it was all play, though. Four of us worked hard all day setting out the plants (oh the backache!), and then did not get through. An expert would have put them out in three or four hours; but we did it well, any way. They all grew nicely. Our young folks had the promise of the money from berries sold. They had charge of the business; and their books, neatly kept, show that they sold, for cash, berries to the amount of $\$ 83.57$. We ate and canned about 13 bushels. These could have been sold, choice berries as they were, for $\$ 50$; so the actual cash returns from that little patch of land were $\$ 133$. The berries were sold at wholesale to dealers in 
town, not at retail. In another chapter you will find that quality had much to do with finding us a ready sale in a market oversupplied with a common shipping grade of berries. Our crop was not a large one. We were entirely green at the business, practically. Too many plants were allowed to grow in our matted rows, for one thing. Again, there were three nights in June when the leaves of the vines froze stiff, and the blossoms on one variety were seriously injured. Then the rust hurt another kind. An old grower who called here and looked them over said the frost killed at least a half (we live in an unusually frosty locality), and the rust would considerably reduce our yield. But with all these discouragements the above success was attained, the first time trying. What we had for our own use would have paid well for the rent of land, plants, labor, etc.; so the $\$ 83$ was clear profit. The young folks had every cent of it. It was not "their calf and father's cow." There was nothing fancy or beyond the reach of any bright boy or girl in the way this crop was grown.

Matthew Crawford, who can be depended on, told the writer that he knew a woman over 60 years old who grew, that same season, a quarter of an acre of strawberries that brought her $\$ 145$, besides furnishing enough for family use, and a good many for friends. I can easily believe this, as, if we had had no late frosts, our own yield would almost certainly have been as great. Now, I hope these experiences may encourage hundreds of young people who are situated so they can do something of this kind to start out; but they had better not expect as large returns as these, for it is better to be disappointed the right way. And still, to be truthful, I know of cases where, beyond all doubt, very much larger yields have been grown on acres, when managed by an expert. This is told to encourage you, my young friends, if at first you do not succeed, do not stop short of a pretty high round in the ladder. The remaining chapters in this book are for any young friends or others who may grow some strawberries to sell, and are interested in 
studying over the different points that come up to one who is trying to do his best. But before going en, just a word to tcwn people who may happen to see these pages.

There is a story told of St. John which is not in the Bible, but which we have good reason to think is genuine. It is said, that while he was-residing at Ephesus there came one day a sportsman who had heard so much of this wise old man that he went out of his way to see him ; and his surprise was great when !e found St. John engaged in gently stroking a partridge which he held in his hand. The sportsman could not help telling how surprised he was to see so great a man employed on any thing so small. Then St. John said : "What have you in your hand?"

"A bow," replied the sportsman.

St. John asked, "Why is it not bent?"

The sportsman replied: "Because if always bent it would lose its strength."

"'That is just the reason," said St. John, "why I play with the partridge. It is that my mind may be kept strong by not being always at work."

Now, we have thousands of ministers, doctors, lawyers, business men, clerks, etc., in our town, who need to rest their minds with something that is an entire change. Many of them have garden-plots, or at least a little land where they could grow strawberries. Would that they could be interested in this most delightful pursuit. Allowing me to judge, it would be far ahead of St. John's plan for recreation. There would be profit in it as well as pleasure. There would be exercise in the pure sunlight, and contact with mother earth-the best medicine in the world. There is something that can be done on a strawberry-bed almost every day, from the time spring opens until winter closes in. The strawberry is so lovely and refined that no lady need be ashamed to be in its company. We have amateur growers who have come to love this method of recreation, and who from constant daily attention have grown berries 
seven inches or more in circumference, and a yield per square rod, or hill, that I would hardly dare mention.

Again, there are a great many village people who have their gardens, but no horse to cultivate with (where they have a horse, of course they can cultivate berries on the same plan that is given in the first chapters of this book, for farmers). All of these can grow strawberries successfully; but they should be set out a little differently from where horse culture is to be used, and treated in a different way. For this class of growers, as well as for ministers, doctors, etc., I should advise hill culture. Set the plants, say, in rows 2 feet apart, and 15 to 18 inches in rows, and keep the ground properly stirred between them by hand. If the land is rich enough (and I would make it very rich for this method of growing) they will almost cover it, and give very large fine berries. One should get varieties suitable for hill culture and the soil where they are to be grown. Near-by reliable growers could advise best on these points. Of course, all runners are to be kept off during the entire season, when strawberries are grown in this way. A good wheel-hoe could be used to advantage, such as the Planet $\mathrm{Jr}$. When kept in hills on nice rich ground, the plants will stool out and form immense hills. I have had them grow in a single season from 18 inches to 2 feet across. These hills can be kept for two or three years, if desired, although they will probably yie:d the best the first season they bear. I would set out the plants in the spring, the same as recommended to farmers, in former chapters, although, with rich soil and constant care, half a crop could be obtained from early fall setting.

When a person in a village has to hire all the work done by one who is not an expert, and where he does not understand all about it himself, it would probably be better economy, financially, to buy his berries. But if he could interest himself in the study of the strawberry, and its habits and wants, and do all the work himself, or nearly all, then it might be made to. pay in cash as well as better health, oftentimes, and real enjoy- 
ment. The.writer was visiting at a home in one of our large cities once, where there was a blooming, rosy-cheeked young lady. She showed me just a square rod of land, no more, which she had attended to all alone, and from which she had picked 108 quarts of delicious strawberries that were measured, besides some that were eaten right from the vines, and this in a single season. These berries were worth to them $\$ 15$; but that was a very small part of the enjoyment this lady got out of them. Of course, to yield like this they received the best treatment known to the art. She treated them somewhat as the man did who, some years ago, received the prize offered for growing the largest quantity of berries from a dozen plants of a new variety. As nearly as I can now remember, he said he watered and fed them as regularly as he did his horse. I have had two letters from another city lady whose health has been very poor for years. She has two or three rods of strawberries now, in which she is deeply interested. It begins to look as though strawberry culture might cheat the doctors out of any further job. Many people who raise flowers might get as much enjoyment out of strawberries on a part of the ground. A neatly kept strawberry-bed would not be out of place anywhere. If there is any prettier flower-bed in Ohio to-day than our strawberrypatch, now in full bloom, I should like to see it. We like other flowers. We used to have five beds on the lawn for them. This spring we sodded over all but two of them. We are getting more interested in the flowers on strawberries, currants, raspberries, blackberries, grapes, etc.-fruit-bearing flowers, useful flowers. Still, I would not have you love the other kind less, but rather these useful ones more. Can you think of any plant that would afford any more enjoyment than a strawberryplant cared for so that, when it comes to bear, it shall be loaded down with berries from four to seven inches in circumference, and as handsome as any flower too; and not only that, but delicious to eat, also, after you are through looking at it? 


\section{CHAPTER IX.}

\section{A TALK ON VARIETIES.}

Every year there are a number of new varieties of strawberries brought before the public. Each one is usually better than any thing that was ever introduced before, if we may believe all that is said about it. Well, now, it is a nice thing to have so many horticulturists trying to bring out strawberries that are better than any thing we have. Without such men we should not have the improvement of the last fifty years. The first improved strawberry of importance, Mr. C. A. Green says, was the Hovey, which originated with Mr. Hovey, of Boston, in 1834. After that came the Wilson, then the Downing, Crescent, Sharpless, etc., until now we have a great many varieties. It is a fact, however, that of these new varieties brought out, not one in ten turns out in the end to be any real improvement.

When at Mr. W. W. Farnsworth's, a year ago (who grows berries largely, at Waterville, Ohio, for the Toledo market), I found that he was trying all the new and high-priced varieties of strawberries, having an acre and a half set out with them. I was quite surprised to find that, for his field culture, Mr. F. had only Crescent and Sucker State berries, four rows of the former and then one of the latter, and so on through the field. The rows of Sucker States were, of course, set out to fertilize the Crescents, which have an imperfect blossom. I said to Mr. Farnsworth: "Would not some of these newer varieties, such as the Jessie, do better?"

He answered: "Possibly there may be some kind among the many new ones that will prove to be better than the old ones ; I hope so."

Determined to get at the whole truth, I then asked him how that acre and a half of new, choice (so-called) varieties would yield, compared with his Crescents. His answer quite 
took my breath away. He said: "If I get as many berries from that acre and a half as I do from half an acre of those Crescent and Sucker States over there (pointing to one of his large fields), I shall be well satisfied."

"Why, I thought from the reports of reliable men that the Jessie was the best berry yet brought out," I said.

"Well," he answered, "these are not all Jessies, and I can not say what the Jessie may amount to; it may prove better than what we have; but I do say that my statement about the average of new varieties will not come far from the truth."

My next question was: "Why, then, do you fuss with these new kinds at all?"

"Oh!" he said, "I want to test them, so as to know whether any thing better than we have does come along; and then, being in the business, I must have the plants to sell, of all the newer varieties. People will have them."

Mr. F. also remarked: "I can always tell when an order received for plants is from a beginner, because such will order many different kinds, while an old grower will send for but two or three, and these of well-established merit."

Mr. J. M. Smith stands by the old Wilson berry yet, for his main crop, although many other much-lauded kinds have been tried by him. There must be a great deal of money paid out for these new varieties that are brought out every year, with, as Prof. Henry says, only a "catalog reputation" behind them, and much of it comes from green hands at the business. I could give you the experiences of other well-known growers on a large scale (who get their living from selling berries), right in this same line. They stick to the old standard kinds like the Wilson, Crescent, Sharpless, Downing, etc. I asked Mr. Farnsworth if some of the larger varieties like the Sharpless, Bubach, etc., would not pay him better. He said they would often hring more money per bushel; but after years of watching and trial he was sure that the Crescents yet brought him the most dollars per acre, for his market, as they outyield 
the large-growing varieties so decidedly, in ordinary field culture. You see, Mr. F. grows many acres, and must sell them at wholesale to a large jobber; and a good common berry that will yield largely is what he wants, for his particular market. There is an unlimited demand, almost, for such, for a rather cheap berry within the reach of the laboring classes. He said to me, however, that for one growing herries in a small way, for home market or a fancy city trade, some of the choicer,

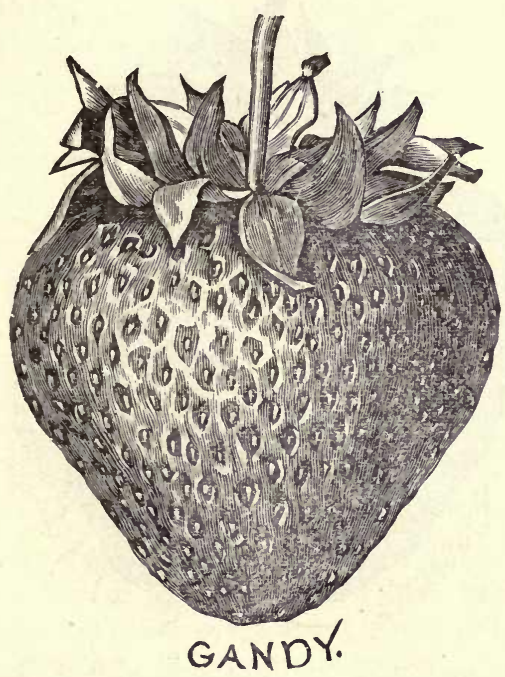

larger varieties might be better; but his trade in a large way would not pay enough extra for them so he could afford to touch them.

This let me out, as I do not want any Crescent berries to eat myself, nor to sell for my trade. I want something larger and of finer quality. Theo. Longenecker says the Crescent will stand more neglect than any other berry, and still yield a 
fair crop. But I do not propose to neglect them, and prefer to do more work, and have something much nicer. And I have found that the people in our little town would take the finest every time, at a much higher price. I have watched closely, and noticed that those with little money to spend will go right by common Crescents, to pay more for large choice Downings and Sterlings. Mr. F. hit me also when he spoke of beginners

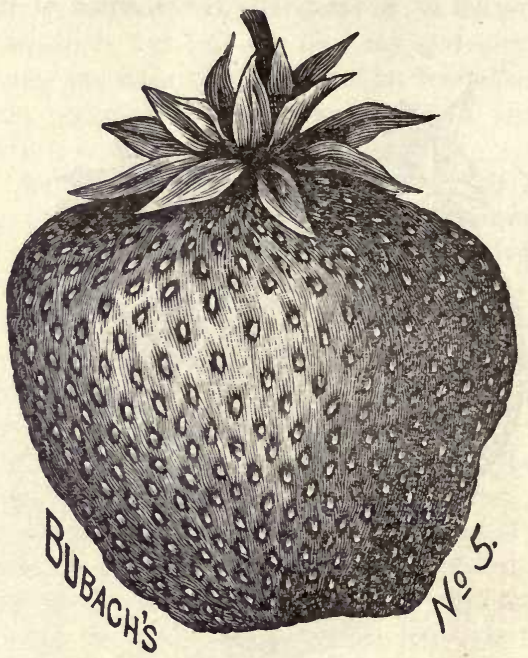

ordering many varieties, etc. But, how else is one to learn what they will do on his grounds? Certain ones do best on certain soils, and no one can tell surely which is the best berry for him to grow, except by experience. And it may seem an easy matter to pick out the best one or two kinds, after you have grown a number of varieties side by side for two or three years : but I have not found it so. One may have the healthiest foliage, another may produce the largest berries, another the 
finest-flavored ones; still another, which is a little behind in these respects, may yield tremendously; then another may be just perfect, only the fruit-stems are too short or too weak, letting the berries lie on the ground and making them hard to pick, or perhaps it is liable to rust, and so it goes. Take it all in all, the perfect strawberry is easiest found on paper yet; but, do not let me discourage you from looking for it, and trying the most promising new varieties in a small way.

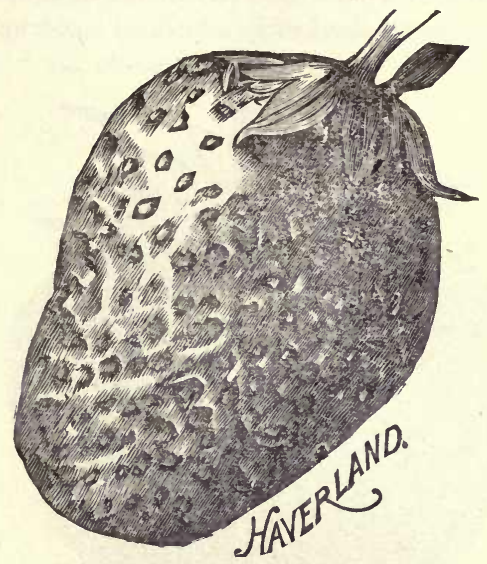

A friend who wanted to set out half an acre of strawberries wrote me to know what varieties he had better get. He wanted to grow what they could use at home, and then sell the rest in town, close by. He wrote that he wanted early and medium and late varieties, so as to prolong the season. This reminds me of a remark of Mr. Crawford when I was getting the plants of him to set out our first bed, some three years ago. I wanted early and medium and late berries also. Mr. Crawford did not seem to think that an important point for me; but in my simplicity I did. So I questioned him to know whether there wasn't considerable difference in the time of ripening of 
different kinds. He laughingly replied: "Oh! there may be fifteen minutes or so."

Well, he sent me two varieties, one perfect and the other imperfect. But nevertheless I sent and got some of the earliest and latest berries, as advertised, afterward ; and now, after eating the fruit and watching results, I am in a better state of mind for appreciating Mr. C.'s remark. What fools we all are, often, that we can not take the advice of one who knows, but must each learn in the costly school of experience!

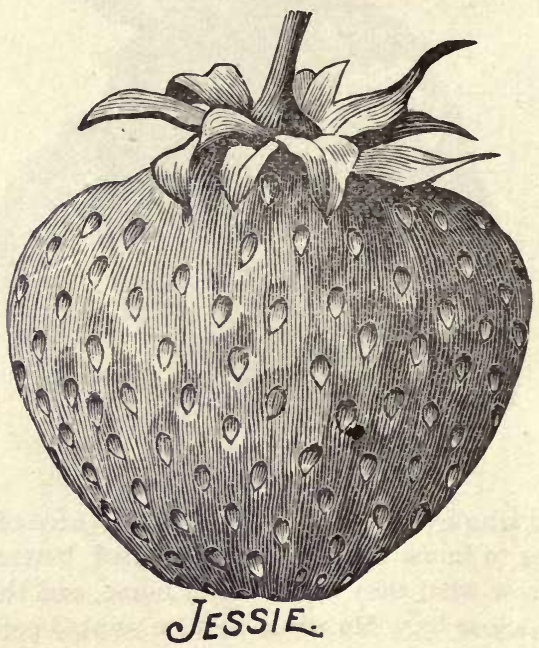

The Monmouth was advertised as the earliest berry out; and the Carmichael, through its originator, promised me berries in abundance long after all others were gone. These were just what I wanted, of course. As to the latter, we did not get five decent berries from 24 feet of matted row. The Monmouth proved no earlier than other standard kinds that were vastly 
better-no earlier to speak of than one kind Mr. C. sent me. I found the Gandy also advertised as the latest of all strawberries. Well, now, you know that caught me again. I did want to prolong the season a week or so. Well, it did ripen its first berries ten days later than ordinary varieties. It is a good grower, and the fruit very large and fine; but for some reason we picked the last good berries, to amount to any thing, only about "fifteen minutes" after the other standard kinds were all done bearing. It is a late berry to begin to ripen, but did not, last year, hold out at the latter end of the season.*

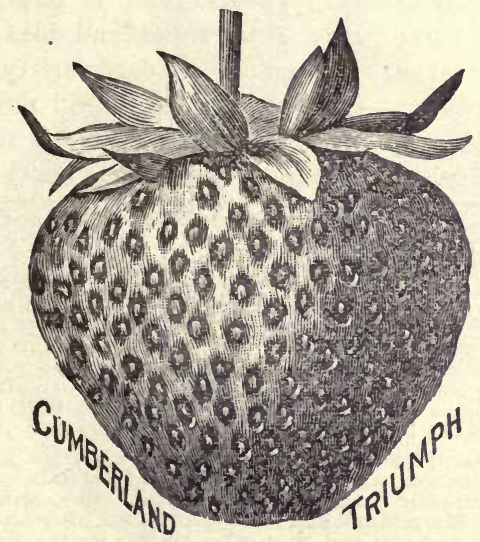

* We, too, had great expectations of the Gandy. The first ripe berry we got last year from it was on the 4th of July, and the plant was such a beautiful grower-the berries so very large-that we made quite a little planting of the Gandy. This season they made a magnificent growth; but only about one plant out of four bore any berries at all. The old plantation of last year has done very little better. We also noticed what friend Terry mentions-that, although it was so very late before it ripened a single berry, the season was so short that they were gone almost as soon as the Jessie, that gave us our first berries.

Laler, June 20,1890 .- Since writing the above I have been down to the patch where the old original Gandies stand. I picked a quart of berries from perhaps two dozen plants. Out of this quart I selected 2 heaping 
All this was a little discouraging to a beginner; but still he learned by experience, without any great harm being done. $\mathrm{He}$ did have sense enough to let $\mathrm{Mr}$. C. pick out the main varieties for him, and to experiment with the novelties in a small way. We bought only a dozen plants of each kind tested. Among them we shall find some, probably, that will stay. The Gandy is worthy of trial as a late berry, in a small way. The Haverlands, with us, just lie in piles.* They are of good size and fair quality, and hold out well. The Bubach gives us extra large, choice fruit, and both it and the Haverland and Gandy have very healthy foliage. The Summit is large and choice, but not as free from rust. The Cumberland does well for us. The berries are large. It is an old standard variety. May King proved very ordinary-good enough if we did not have much better kinds. The quality was more satisfactory than the yield and size of berry. We bought it as an early berry; but it is no

pint of the largest, finest, and most beautiful berries I ever saw in my life. Each one was a model of beautiful shape, color brighter and more bewitching, it seems to me, than any thing I ever saw in the shape of a strawberry, and the whole set off to wonderful advantage by a remarkably large, bright-green petiole surrounding the stem. The stalk is very strong, and the biggest part of these berries stood up clear from the ground. For beauty of foliage, and for rank, luxuriant growth, I have never seen any thing to equal the Gandy. Now, my friend, if you will be satisfied with a quart of berries from one picking of two dozen plants, it will pay you to plant the Gandy. My impression is, that they should be at least two years old before you can expect a fair crop.

* We want to emphasize the remark, that the berries just lay in piles. It was a refreshing contrast to look at the Haverlands, after we became disgusted with the poor fruiting of the Gandy. Why, some of our large old plants of the Haverlands had fruit in piles not only on the south side, but on the north and east and west sides. Some writer, in speaking of a new strawberry, said that no mulching to keep the berries out of the dirt was required, for the plant bore so bountifully that the berries lay three or four tiers deep all around the plant; consequently only the lower tier got in the dirt. All this has been literally true with these Haverlands. Unless I had seen them down on our rich creek-bottom land, with my own eyes, I should never have believed that any single strawberry-plant could ripen such a quantity of fruit. I felt like saying to one of them, "Why, you poor, silly, dear little plant ! you can never ripen all this great mass of fruit, any way in the world." But I tell you, friends, they are ripening up nobly. The first that turned red were so long and large that they compared quite fairly with the neighboring Jessies and Bubachs. We are just now making preparations to plant tremendously of the Haverlands. Perhaps I should say that this ground that gives berries in piles has been very heavily manured for several years. $-A$. I. $R$. 
earlier than the Haverland, which will outyield it two to one. The Mammoth (bought for the largest berry) was a failure. We got a dozen or two tremendous berries from our trial row of 24 feet, but no larger than the Summit or Bubach gave at the same time. After that the berries were few and inferior. After all my trouble I am not sure to-day that I have any better berries, all around, for my purpose, than Mr. C. sent me the first year, the Sterling, with the Downing as a fertilizer. The

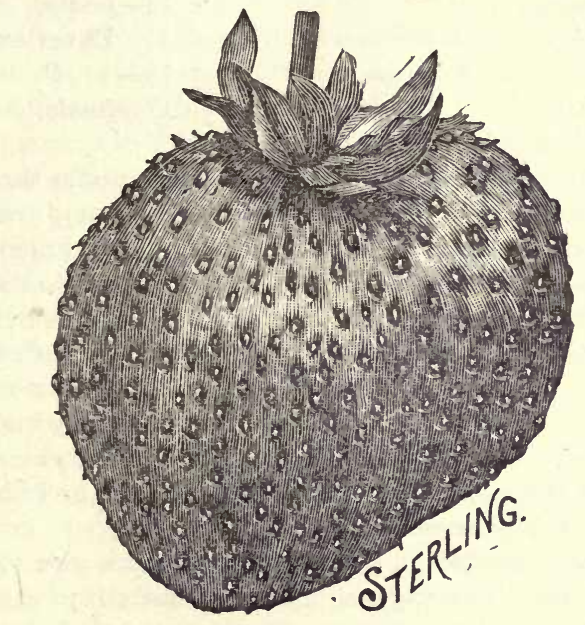

former' is a failure in hills; but in thin matted rows it has done grandly. Mr. C. said its only fault was short fruit-stems; but that is one of its advantages with me, probably, as the leaves, I think, protect the fruit better from our late frosts.

We have half an acre of berries now in full bloom (May 26 ), and another half-acre which we set out the first of the month. It may be of interest to some to know just what we set out this spring, after all our experiments, and just the pro- 
portion of perfect to imperfect kinds, etc.; so I will tell you, and $I$ assure you we did considerable studying over the matter before a plan was settled on. There are 17 rows of plants. The following list gives the varieties in order for the 17 rows :

\begin{tabular}{|c|c|c|}
\hline 1-Sterling, & $I(m$ perfect $)$ & 10-Bubach, \\
\hline 2-Downing, & $P($ erfect $)$ & 11-Cumberland, \\
\hline 3-Sterling, & I. & 12-Bubach, \\
\hline $4-\because$ & I. & 13-Haverland, \\
\hline 5-Downing, & P. & 14-Jessie, \\
\hline 6-Sterling, & I. & 15-Haverland, \\
\hline 7-Gandy, & P. & $16-\quad " 6$ \\
\hline $\begin{array}{l}\text { 8-Bubach, } \\
\text { 9-Cumberla }\end{array}$ & I. & 17-Jessie, \\
\hline
\end{tabular}

Mr. Kellogg, of Wisconsin, and others, prefer the Jessie to fertilize the Bubach; they say it makes a strong team. Perhaps so; but the Cumberland and Bubach blossom more nearly together, and, on our soil, I think now they will do the best together. The Jessie is considerably too early for the Bubach, but just exactly right for the Haverland. I shouldn't wonder if they made us a strong team. The Downing fertilizes the Sterling well. We have three strong teams. I hardly know which is the strongest. That row of Gandy is put in where it may help to fertilize some of the late blossoms on the Bubachs and Sterlings, which are medium late in blooming.

Of these varieties, a careful watching this year shows that the Jessie and Downing are the most easily injured by frost. The thrie imperfect varieties were very slightly injured. The Jessie was the first berry to bloom; but the Haverland came close after. All other varieties which we have tested have been dropped out.

Now, this experience is not given for others to go by blind$1 y$, in a large way, unless it agrees with that of your nearest horticultural authority, who knows your soil and locality. But you may safely set a few plants of the above varieties for experiment, and more, perhaps, if your soil is like mine-a good, 
deep, rich loam, neither too light nor too heavy. For experiment, buy a dozen plants of a kind. Set them two feet apart in your rows, but leaving four feet (skipping one place) between varieties in the rows. See to it that no runners get across from one row to another, or from one variety to another in the row, otherwise you will have your plants mixed to set out another year. After giowing them two or three years you may find out what two or three kinds best suit your soil and treatment and taste.

I would not be understood as condemning all the varieties mentioned above that failed to do well for me. They might succeed better under different conditions.

The pictures in this chapter will give you a fair idea of the looks of six of the seven varieties we have set out this spring. Of course, these pictures are of the largest, finest specimens. The Sterling is from a photograph of one grown by Mr. Crawford, and is life size, exactly. We picked some berries last year of each variety as large as these pictures, and many that came near it. You may notice the Bubach quite closely resembles the Sharpless. The Cumberland is as perfect in shape as though turned in a lathe-almost to 0 perfect. The Haverland is thimble-shaped. The Downing, with us, so closely resembles the Gandy that we thought one picture would do for both. I have seen larger berries than these on exhibition at a berryshow; but they were grown specially for the occasion by forcing. Some as large as these can be grown with good ordinary culture. 


\section{CHAPTER X.}

HOW MARKET-GROWERS MARK OUT-MAKING PLANTS GROW RIGHT ALONG IN DRY WEATHER-TILLAGE, TOOLS AND HOW TO USE THEM-A STRAWBERRY-HARROW-WORK BRINGS THE BERRIES.

Most growers who set out only a quarter or half an acre of strawberries will hardly be able to do better in the way of marking out and setting than to use a line, spade, and trowel, as spoken of in a previous chapter. I know some who set a good many more than that, who set by a line, as they consider it so important to have their rows straight. Where berries are grown on a large scale they are sometimes put in in a faster manner; but I would do my best, and let speed be a secondary matter. If you happen to have an Aspinwall potato-planter you can dispense with the line and spade, however, and still do as straight and perfect work. I used this tool for marking out my half-acre, last year and this year. The coverers were taken off, and the plow set to run nearly five inches deep. This implement can be driven so as to make furrows almost perfectly straight, and just the right depth. They are narrow, and just the thing. Some of the dirt falls back into the furrow; but it is loose, and quickly thrown out with the trowel, where the plant is to be set. We mark but two rows at a time, leaving the team standing on the planter, so as to have the ground fresh and moist to set the plants in-that is, if it is a drying day. The plants, of course, are all set out on one side of the mark, or furrow, so as to keep them in line. After marking with the planter we walked through with the hand marker, shown in Fig. 1, and scratched on one side of the furrow where the plants were to be set. So well pleased have I been with this way of opening a furrow, that, if I grew berries by the acre, and had no use for a potato-planter, I would either make a marker something after the same plan, or buy the necessary 
parts of a planter to do the marking; viz., the wheels, shaft, seat, marker, pole, and plow.

Mr. W. G. Farnsworth was visiting me last summer. He also is a large grower of berries, like his brother W. W. F. His way of opening a furrow to set plants in (and I think his brother does the same) is with a light plow. Then he places the plants against the land side of the furrow, and, with a garden-trowel, throws some soil against them and packs it, afterward doing the rest of the filling with the Planet Jr. cultivator, with the side-shovels on. Mr. F. was much interested in my straight rows, and I think he went home determined to study up some way of opening a straighter, nicer furrow, than he can with a one-horse plow. One needs some implements on wheels, or runners, that he can drive two horses to, in order to open a straight furrow. And, aside from looks, every grower knows that, the nearer the plants are in line, the closer the cultivator or harrow can be run, and hence the less hand labor. If I used a plow to mark out, I would attach it to a sulky and use two horses, and fix a marker to swing over from side to side, to make a mark to drive the pole over. Then one could do perfect work. Friend Pierce's plan of setting out is good for a small grower. If you want to set plants two feet apart in the rows, make knots in your line, or tie in tags, that distance apart, from end to end. Then after your line is stretched, leave it there and set a plant at each knot. I haven't tried it, but it might suit some better than my way of making a scratch by the side of the line, and then taking it away. It would seem to me that the line would be somewhat in the way, when setting out the plants; but it would save the time I spend marking the places to set plants, and a trifle more.

Let me emphasize the following points by repeating them :

Set out only large, choice plants ; and when transplanting on your own grounds, let them go from the soil directly into a pail of water, and from there into moist soil, and do not forget to pack the soil next to the roots, even with your feet, if it is 
very dry (p'ants should not be set out when the soil is wet), and to also have the ground very fine and firm before you begin. I notice some fancy growers, in a small way, talk about having the soil so mellow they can run the hand down in to the shoulder. I should not care to set out plants in soil as loose as that. One spring it was very dry for some weeks after strawberry-setting time. But by using care in the above lines, our plants grew right along, splendidly, all of them. It was dry when we set them out ; but we put moist earth in contact with the plants, and tramped them in with the feet. We could not have had a better season to show the benefits of firming the soil. It happened that a large grower called here about a mouth after setting time. He walked back and forth on my half-acre for some time without saying a word. At last I said to him: "I suppose your berries look better than mine. I am quite a new hand at the buisiness, you know."

He replied: "No, they do not. I wish they looked as. well. It has been so dry that they have scarcely started since they were put out, and many are dead entirely. Yours are gr =wing right along."

This was pleasing to me, although I felt sorry for my friend. Of course, however, as he was a large experienced grower I did not presume to tell him what I thought was the cause of the difference. But let me ask you, reader, if you do not think it was simply better care all the way through? We never tried to see how fast we could do any of the work, but how thoroughly well we could manage in every particular. It being dry, we set the plants so they could stand it and grow right along, and they did.

In a former chapter I think I spoke of a grower saying that a strawberry-plant would often live and take root when thrown away and left on the surface of the ground. This is true, for I found some once when cultivating a newly set patch. One plant was actually in blossom, and about as large as those set out. But that was a very wet season. A little less care in 
setting might have answered then; but that year I know some large growers lost half their plants. It won't do to take the chance of balf doing any part of our work. Well, the friend last spoken of used this fact, that berries would grow when thus carelessly treated, as an argument to prove that it was useless to spend so much time in keeping the roots wet and setting out so carefully. He said it was a pretty hard matter to kill a strawberry-plant. We have too many men of that sort, both among horticulturists and agriculturists. If such can make a living in their line, reader, rest assured that there is a good profit for you in thorough work.

Mr. C. A. Green says : "But let me tell you that it is work that brings the berries; work, I say, and hard work too, tugging and sweating. Don't take stock in those poetry fellows. Don't get the notion that a big crop of berries, growing as rank as horseradish, without gaps along the rows, came there by whistling for them. Just bet your life that the man who owns that patch nearly broke his back planting and weeding and hoeing; and if he hadn't he would not get any profit out of them." These are the words of one of our most successful horticulturists.

In the way of tillage implements, we use the Planet Jr. one-horse cultivator, with narrow $1 \frac{1}{4}$-inch teeth on it, and a wheel to keep it from going too deep. This is a good tool; but we found one trouble which doubtless many growers bave experienced. The teeth, although narrow, would throw some dirt over the leaves of the plants, if we ran very near, and even on the crowns. So we had to be satisfied with cultivating about two-thirds of the land, and hand-hoeing the rest. By going very slowly with the cultivator (which we do not like), and stopping to uncover plants occasionally, we might cultivate three-fourths of the land. Well, this sort of work was not satisfactory. It occurred to me that small harrow-teeth would throw no dirt, and would run close to the plant, pushing the leaves aside instead of covering them, thus leaving considera- 
bly less for the hoe to do. So I went to the tool-house and got a piece of plank, about two inches by six, and two feet long. Then I took some round half-inch harrow-teeth, that were sharpened,* and, boring holes, I drove them through the plank, as shown in Fig. 10, a tooth at each dot. The holes were bored through square, not slanting. A slanting tooth would cut off the leaves instead of pushing them aside. Next with two little hook bolts, shown in Fig. 10 at B, which were found among the old irons, I fastened this little harrow under a Planet cultivator-frame (leaving the wheel on), after having taken off all the teeth and teeth-standards. I then had a cultivator with nine harrow-teeth instead of five curved teeth. One can

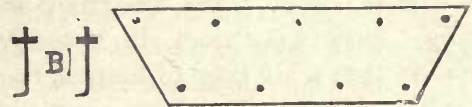

FIG. 10.-HARROW ATTACHMENT FOR CULTIVATOR.

buy something of the kind; but one made in this way, as an attachment to the cultivator, costs but little, and it can not track. The bolts $B$ hook up over the cultivator frame, one each side, and the nuts, of course, go under the plank. To use it, the land must be clean-no rubbish or stones of much size. Under these circumstances you will be pleased with the harrow, to use in connection with a cultivator. You can put in more or less teeth, according to the condition of your land. I tried about fifteen at first, but had to reduce the number to nine. With this harrow one can stir the soil about an inch deep, very close to the crowns of the plants, leaving it level, and do it at quite a rapid pace, as the teeth throw no dirt, no matter how fast you go. The tooth next to the row we did not drive through as far as the rest, by about half an inch, so as to be sure not to disturb the roots of the plants. We go through twice in a row, of course, in our four-foot rows, once on each

* See last chapter in regard to the manner of sharpening the teeth. 


\section{A B C OF STRAWBERRY CULTURE.}

side of each row. After a hard rain, which packs the ground so a harrow would hardly touch it, we use the cultivator first, not running very close to the plants, and then finish up by going over again with the harrow, and then continue the use of the harrow until another hard rain packs the soil. I suppose we used that harrow about twice a week last season, on an average. We put it on an old cultivator-frame and left it on.

The Iron Age cultivator and harrow combined is a good tool in the strawberry-patch, if you raise enough to need a special tool. I can go within an inch of plants with this and throw no earth on leaves.

For the hoeing we use a pronged or common hoe, like most other growers, except after the runners partly cover the ground. Then we use, to work in between them, to stir the surface in little places where a common hoe would not go in handily, a little V-shaped hoe. Needing two one day, my son made a second one by nailing an old mowing-machine section (a large one) on to the end of a broom handle, so the point would be down at right angles to the handle. The hoe we bought was not hung right for this business. We heated the shank and bent the $\mathrm{V}$-shaped blade down until it stood about at right angles with the handle. Then we could use the point or sides to hoe in among the runners, nicely.

This sort of hoeing may not pay always, at least I presume few would take the trouble to do it. The writer is called something of a crank on tillage. Well, he likes to see every thing just do its best; and you know one can grow $\$ 50$ worth of strawberries on half an acre, or $\$ 500$ worth, or anywhere along hetween (there is a little luck about the matter, however), according as he does his part. And in this matter of a surface kept mellow all the time lies part of the secret of a great yield.

A farmer was asking at an institute in Pennsylvania, last winter, why his berries did not do better. My old friend Sisson, who has sold over a thousand dollars' worth of strawberries from an acre, inquired all about how he cared for them; and 
at last, laughingly, told him that he didn't think he "dropped quite enough sweat" on his patch.

For preparing the ground, the best farm tools are all that are needed. If I were now buying new the best of tools for both purposes, I would get a good plow with a jointer on (Oliver chilled 40 is my favorite-have two), a cut-away harrow and a Thomas, and a good roller. After plowing the land as deep as it was ever plowed before, I would run over it with the Thomas the same way it was plowed; then roll it. Next take the cut-away and go lengthwise and crosswise, lapping half each time (four times over the land). Then level and smooth down with the Thomas, and roll ready for marking. If it were not just as fine and nice as a garden bed I would harrow and roll more. All this, of course, when the land was sufficiently dry. Fine, mellow, but firm soil, is what you want. On some soils a subsoil plow following the other would help, beyond a doubt. The subsoil in my patch is not hard enough to be benefited by stirring. If I had a hard clay subsoil (underdrained, of course) I would plow narrow furrows, say 8 inches wide, and follow with a subsoil plow, drawn by one stout horse walking in the furrow. With a narrow furrow the subsoil plow would break up all the subsoil. Careful experiments have shown that subsoiling did not pay on our porous subsoil. 


\section{CHAPTER XI.}

ALI, THE DIFFERENT WAYS OF GROWING STRAWBERRIES TALKED OVER-MATTED BEDS ; MATTED ROWS, THICK AND THIN, WIDE AND NARROW ; ROWS OF STOOLS ; CHECK ROWS, ETC. - WHEN TO LE'T RUNNERS GROW-JUST HOW OUR HALFACRE WAS MANAGED-CIRCUMSTANCES ALTER CASES.

Before the writer began strawberry-growing he talked with many growers in Ohio and Wisconsin, while attending institutes. Almost without exception he was told that the best way to grow for market was in matted rows. But some favored narrow rows; and some, wider ones. Right here it had better be explained to beginners, that growing in matted beds means setting out the plants in lows, say four feet apart, and theu letting the runners entirely cover the ground. When grown in what is called matted rows they are set out in the same way; but by the use of the cultivator and hoe, and what are called runner-cutters by some, they are kept in rows or drills vary ing in width according to the grower's notion. When I was at Mr. Farnsworth's I judged his rows of plants were about 18 inches wide. He said the cultivator had been kept busy in the rest of the space. In the spring, after taking out what plants he wants from the outside edges of the rows, in such a way as to leave them about a foot wide, he hoes up all the other plants necessary to reduce the rows to this width of one foot throughout. In this foot of row he prefers to have the plants stand rather thinly. Mr. F. considers this the best plan for field culture in a large way, or did at the time of my visit. He grows, a good many acres of strawberries. If grown in hills he says he would expect larger berries, but does not consider it possible for him to make as many dollars per acre in that way.

Mr. F.'s plan is about the same as that of most growers I visited or talked with, although on an average the sows of plants are left wider. However, growers were found who kept 
the drills down to eight or nine inches in width, claiming that all the large fine berries, or nearly all, grow on the outside of rows, and therefore they might as well be narrow; also that the plants get more benefit from the tillage in the narrow rows. In wide matted rows the soil could not be stirred around the plants, or near enough to help them any, after the runners got well started. From the bulk of testimony, probably the berries will average somewhat larger in very narrow rows, unless the wide ones are considerably thinned out, at least; but I doubt the yield per acre being as large. What I want is a large yield per acre of large berries; but we will come to that soon. Now, on the other hand, growers were found who left their rows two feet or even three in width, leaving just a narrow path to get through when picking.

Again, there is another method of growing which I have spoken of before as hill culture. The plants are kept in hills, or stools, by cutting all runners as fast as they appear. For growing in this way, the plants are set out from 12 to 20 inches apart in the rows, which may be from 3 to $3 \frac{1}{2}$ feet apart. It is commonly stated that larger berries can be grown in hill culture, but not as many bushels per acre.

Now after getting all this general information, I set out our first quarter-acre in rows four feet apart, and intended to keep them within two feet, leaving two feet for cultivation and a path. But I found it hard to hoe up any plants that. could possibly be left, and have even a very narrow path left between the rows; so from my tender-heartedness the rows were probably three feet wide, and from the same reason, along with some greenness, they were terribly thick. And, to tell the truth, I thought that, where my thickest and heaviest growth of vines was, there I should get the most berries. Well, I did not, by any means; but we had taken such good care of them otherwise that we had a very fair crop any way, and the size averaged unusually large too.

When we were picking, a friend called here who had had 
much experience in growing strawberries, and he shook his head sadly at the great thick growth of vines I had (what a time we had plowing them under, or trying to, after picking the fruit!) and said if I had kept the runners all cut off, and just had my single hills 2 feet by 4 , I would have had larger berries, and more of them, and more satisfaction. This, with the generally expressed opinion that hill culture produces the largest, finest fruit, caused me to decide to keep the most of the new bed set out that season in hills. We did so, and they grew finely (except the Sterlings) and stooled out so as to make very large hills. When friend Root and Dr. Fenn (an authority) were looking at them in the fall, the doctor remarked: "Those hills," pointing to some of the best, "will yield two quarts apiece." This made me happy, for one quart to the hill was all I had hoped for. But when picking time came, I do not think the average was over a pint to the hill. I learned something -at a cost of, say, $\$ 75$. Do you think that perhaps the same varieties in matted rows would not have done any better, that season, under the same conditions? Well, I was smart enough to grow a few that way, some in narrow rows and some in wide, some thick, and some thin. An exact account was not kept of the yield from the different strips, as I had no thought of ever telling of. it, and it was so decidedly in favor of the wide, thin matted rows. An old bachelor brother-in-law of mine, who gets a little impatient sometimes when things do not go right, helped pick these berries. He would run over two or three rows of the hills to get a peck basketful; but when he came to that wide, thin matted row, he would bring in his basket full and say: "Confound that row! I have picked there for an hour, and there is another basketful there yet!" (a little exaggerated).

Another point which I could hardly believe : There was very little if any difference in the size of the berries, on an average. Could we have had our harvest-time experience a year beforehand, we could easily have made one hundred dol- 
lars more from that little patch-experience as to the methods of growing, and the best varieties for us, etc. Now, this was but a single experiment, and you must not give it too much weight. It may not settle the matter for all growers and all conditions, by any means ; but it did for us, taken in connection with former experience. All our berries were set out last year in rows four feet apart, and two feet apart in the rows. The plants were set in the spring, before we knew how the different varieties would yield, of course; so some kinds were set out that were rejected this spring. But we got the matted-row experience in time, and all our half-acre was trained in thin wide matted rows. We didn't even care to leave a few in hills, or keep them in narrow rows, to further test the matter.

Another point: Having large choice plants right from our own grounds to set out, and doing the work so carefuily that practically their growth was not checked at all, and the land being pretty clean, it semed to me unnecessary, and, indeed, not best to keep the runners cut off the newly set plants until the middle of Inly or first of August, as most market-gardeners advise, and as I have advised farmers to do, in a previous chapter. I reasoned that my plants were as large and strong and able to grow runners that were thrifty by the middle of June, or soon after, as plants under ordinary field culture were a month or six weeks later. Again, that the sooner the plants which were to bear the berries the next season could be started, with a sufficiently thrifty parent, the larger and stronger they would have time to become, and the better able to prcduce a big crop of berries.* Therefore we set out the plants as early

* Friend T., on account of the value of our land, and the close crop. ping we give it, we put out our strawberties after early peas or early corn or poiatoes. We have not the ground to spase at any other time. Like yourself, I want the very best plants I can get, and I want to get them going as soon as possible, that I may get at least part of a crop next season. Alter setting them unt, of course we keep the runners off, it being so late in the season. Well, with verv rich ground and good treatment we get enormous plants, usually, by November, and often plow them under after getting just one crop of fruit. So you see our strawberry-patch gets really no more time than a crop of cabbage, corn, and many other vegetables; 
in the spring as the ground was fit to work, and let the runners grow as soon as the plant was able to throw out strong and thrirty ones in abuudance, which was about the 20 th of June. We went over the piece two or three times, training the runners a little, after they got well started, so they would as soon as possible cover all the surface with plants. By the middle of August the vines were a beautiful sight, about covering the ground, and people began to stop and look at them and praise them. We went through from time to time between rows of different varieties, and cut the runners just enough so they would not cross and get mixed. This after they had made such a growth that we had stopped using the cultivator. Where two rows were of the same variety we let them cover the ground entirely betweeu-let them grow and run according to their own sweet will. There was practically no ground on the halfacre, except where the runners were cut off to prevent mixing of varieties, that they failed to cover, with a little help from us in the way of training.

Aside from my experience, it seems as though this was the natural way for strawberry-vines to grow. They are vines, running vines, and not bushes. They were just running in clover, so to speak (literally as to their roots). But in the fall, Nature had to be looked after a little, so that she should not overdo the

for after their fruiting. cabbages and many other things can be put on after. Bit I have been curious to know whether we should get less fruit by letting the runners grow in the spring. On one occasion we had a narrow strip of very nice mellow ground along the outside row of berries. As we wanted some plants, we let the outside row of Jessies (and this row only), send runners over into this mellow ground. Then I asked the boys to see how many less berries this outside row produced because it furnished plants and berries both at the same time. To my astonishment they said it not only gave those great handsome plants, but it gave rather more berries than the other rows where the runners were carefully cut off In this case the runners were all pulled over to one side in this bed of mellow soil, and they were spaced by laying a tandful of dirt on the end of the runner. With this treatment the young plant was very quickly self-supporting. Perhaps the reason why these plants bore just as well as or better than those where the runuers were picked off, was because the ground was so very rich, and possibly this strip of mellow soil, extending clear up the row of plants, may have given this outside row more thrift and vigor. 
matter of plant-making. Man, having given her such an excellent chance, must keep the reins in his hands, although the controlling should be in the most natural way possible. To cut off the runners all summer is not natural. We let them have their own way until the season's growth was about over. About the middle of October, when we had our work done up so we had plenty of time (perhaps a little earlier would be better), we stretched lines through between the rows; and one man with shears cut runners, and another, with a hoe, cleaned out paths 16 inches wide. This left two-thirds of the ground covered with plants. Next we went through these plants and took out the old ones, set in the spring, all the little weak ones, and enough of the strong ones so that what were left stood not less than six inches apart, on an average. We did this work with an old table-knife, having about two inches of the end of the blade bent nearly at right angles with the rest. We could cut them out pretty well with this; but friend Smith afterward wrote me that, if I had taken my garden-trowels and ground the ends sharp, I could have taken out, or, rather, cut off the plants we wished to destroy, much faster. By the way, while I think of it, we did not cut quite low enough down on some of the plants. Some few that were cut near the surface, although all the top was taken off, sprouted and grew some weak shoots from the sides of the decapitated crowns. We will look out and cut a little lower next time. When we got through this thinning process, about two-thirds of the plants had been destroyed. But my expectation is, that I shall get more fruit, and finer-in fact, the largest possible yield per acre. Great care was taken not to disturb any plants except those taken out. The plants. left have grown in a natural way, and, since the others were removed, have had, each one of them, reasonable feeding-ground. It was no small job to take out these plants with an eye to the "survival of the fittest." Our rows were some 25 rods long. It was a pretty good day's work for a man to go over one row a day, with some varieties. Others, however, which naturally. 
made less plants, could be thinned faster. But it seems to me that it may easily make a difference of one or two bushels in the yield of a row, or two or three cents a quart in the size, on half a dozen or more bushels, or perhaps both. In thickly matted rows, all the plants do not bear fruit to amount to any thing, and these non-yielders are using up the fertility of the soil-are, in effect, so many weeds; why not treat them as such, and remove them? It might be wiser not to let so many runners grow; but this would take endless watching at a busy season, and would not be quite as natural.

But, now, there is a difference in the habits of growth of different varieties. I am studying and trying to do my best with those we grow. The Crescent, I am told, will stand the most neglect, and yield better in a thick solid matted row, than any other variety having the same treatment. Possibly this thinning would not pay for them; probably not as well. Of this I do not know, however. I do not want any Crescents, any way On the other hand, it is said that the Sharpless and the Jewell do well in hills, on certain soils and in certain localities, with the runners all kept off. But I can not grow Sharpless; my land is too much subject to late frosts, which they endure poorly, and is hardly heavy enough to suit that berry. For the rank growing kinds that I grow, the above appears to me now to be the very best.

Mr. C. E. Chapman said, in the Country Gentleman, last fall, in regard to my taking out the old plants set in the spring: "This is contrary to my experience. The old plant is in its prime, not having borne fruit during the season. It has a vigorous, healthy growth, and will give more and larger berries than any of its runners. Why take it out?" True, it hasn't borne fruit ; but, has it not exhausted itself sending out runners? But I took it out because some other growers told me they would, and because, with two varieties we grow, we had tried leaving the old plants and found they produced next to nothing. Probably Mr. C. is right, for the varieties he 
grows, and I may be partly wrong. How many things we have to learn yet, and how circumstances alter cases ! I wish I could tell every grower who is just starting out in the business, exactly what to get and what to do, but I can not. This would ue an impossibility for any mortal man. Selling plants is no part of our business, or such a wholesale thinning-out of plants in the fall would be wasteful. We grow berries and sell no plants. Some grow plants and sell no berries. Mr. Chapman thought we might sell the plants we destroyed in the fall, and make considerable. Well, I would not set plants under ordinary circumstances in the fall, for myself, nor would I advise others to. If I sold a man plants, I should want him to have them.when there was the be st chance for him to get some good from them. It wouldn't be right, even to keep still and make money out of my brother's ignorance.* I do not know a market-grower in the State who practices fall planting. Agaiu, these plants taken out are mostly the poorest. In this respect I should not like Mr. Farnsworth's way of getting plants from the outside of rows for setting. They would hardly be the best.

The first runners to take root around the old hills will usually be the strongest, thriftiest plants. To get plants to set myself, I prefer to take the row clean, as far as I go, throwing away all poor plants. This saves tramping the ground, too, as one would in taking up plants all along between the rows. Usually in the early spring I should not want any one tramp-

* Friend $T$., I fear this remark is a little too sweeping, and perhaps unjust to some. I am very well aware that there are plant sellers who recommend the fall of the year, in the fall, and then in the spring they recommend the springtime; but with the excellent success we have had in receiving plants, both by mail and express, during all the summer and fall months, we can not feel that it is a risky business. Besides, there are quite a few people who have ltisure in July and August, or in September, who have not at other seasons of the year. They can attend to it then, and do well. whereas they could not in the springtime. Another thing, untidy gardens may be slicked up and made a thing of beauty and a source of profit by planting strawberries during the months when gardens as a rule look most untidy. Yes, this can be done, and a crop of verries secur. ed in less than one year from the time the plants were put out. Very like1y. where land is plentiful, and where berries are grown largely for market, the springtime is preferable.-A. I. R. 
ing between my strawberry-rows. But Mr. Farnsworth's soil is very light and sandy, and would not pack like mine; perhaps not so as to injure it at all. "Circumstances alter cases," again.

There is still another way of growing strawberries. This is the way Mr. Little, of Canada, tells of it, in a late number of the American Farm and Horticulturist:

"There are different modes of planting and cultivating the strawberry; but very few have adopted the best. The most careless way is to allow the sunness to fill the beds and form a dense mass of plants." (I agree so far.) "Another mode, a compromise between good and bad, is the matted-row system, the plants growing thickly in the row, but admitting cultivation between." (O. K. again.) "A still better way is to keep the plants in stools, with the runners cut off, which gives fine berries and abundance of them." (Sometimes, if one has the right variety, and no worms to trouble the roots when they are kept in bearing two or three years, as Mr. L. suggests.) "But there is a still better mode, costing less to keep in perfect order, than the matted bed or matted rows, or rows in stools with cut runners." (Has friend L. forgotten that there is "no excellence without great labor?") "This is the check-row system. Set the plants in squares, or in rows both ways, say two feet apart." This, it is claimed, gives a chance to cultivate both ways, and reduces the amount of hand labor required. It is a question in my mind whether the amount of hand labor is reduced, and it would take twice as much cultivating. Rows two feet wide would be too narrow for my horses to walk in. It seems to me that I would make the squares three feet, and let several plants $\mathrm{f}: \mathrm{rm}$ in each one. I once heard Mr. Obmer say that, if he were intending to set out 20 acres, he would put them all out this way. But I did not intend to discuss $\mathrm{Mr}$. Little's plan, oaly give it to you. Mr. Little knows a great deal more about berry-growing than the writer of this. Mr. Hale, of Connecticut, I think, grows berries on about the same 
plan. With varieties adapted to it, it is, of course, a good way. But each reader must study out for himself his best way. This talk is intended to set you to thinking and bunting for it.

I have no hobby on this point. I should like this last way of growing berries if it would surely bring best results, and were practical for me. But there are objections to hill culture in some localities, which I have not mentioned. Single plants will sometimes die out during the winter (because they have been unnaturally treated?) even if well mulched. If one happens to have any white grubs in his soil, when they destroy a hill where they are set in squares there will be quite a loss. In a thin matted row there is less risk.

I have now explaiued about the different ways of growing strawberries, and told you just how I did last year (and am doing this year) and why I did so. The best of results are expected, and the show for berries at this writing is all that man could ask for. Much study has been expended on this point; but I shall undoubtedly know more about it a few years in the future.

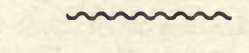

\section{CHAPTER XII.}

THE MULCHING QUESTION-CUT STRAW AS A MULCH-THE EARTH MULCH-MULCHING TO PROLONG THE SEASON-COVERING WITH STRAW TO PROTECT FROM FROST-MULCHING VS IRRIGATION.

The first two years that we grew strawberries we mulched them with long wheat straw, as told in a former chapter. It worked well; but we tried another plan last fall which we have reason to think will be an improvement. We cut the straw into about two-inch lengths, and then covered the entire surface over plants and paths with it. The cost of cutting was not much, as we have the straw all in the barn, and it was cut when 
we could not work outdoors. It is hard to tell just how thick we put it on, but probably something over an inch. Then after that we put a light coat of long straw over all the land. We put this on so that, when finished, we could just see through and catch sight of strawberry leaves here and there; not so as to entirely hide them (they were pretty tall rank vines). The cut straw was taken out in our big wagon, which, with sideboards on, will hold probably 100 bushels. The boys brought it to me from the wagon in bushel baskets, from which I scattered it out by shaking from side to side. We tried to spread both cut and long straw as evenly as possible. In the spring, just as the plants were pushing up through the cut straw, we raked the long straw into the patbs and trod it down. This was done on a wet day. In fact, we went over the piece three times, when the straw was soaking wet, poking it into the path with a fork or rake, and treading it down, before we got it all to stay where it was wanted. The cut straw was left to mulch the ground among the plants in the rows. They came up through it without any trouble at all. Perhaps more could have been put on safely and to advantage. It lies closer around the plants than long straw, and hence must answer the purposes better for which it was put there. Our short-stem varieties are least hurt by frost, and probably are what we shall have to raise largely. This fine mulch so entirely covers the surface of the ground that it will keep the berries clean, even where they lie right on it. The grower of choice berries, hoping to get fancy prices, doesn't want any earth on his fruit. Many large growers of market berries do not mulch at all. Our market berries from Cleveland are usually very sandy after a rain.

But when there is no rain this mulch will probably do the most good by checking the evaporation of moisture from the soil, and thus giving us a crop instead of a partial failure. There is plenty of water in the subsoil and earth beneath, as a rule, that will be brought up by capillary attraction, if a man will only manage to prevent unnecessary evaporation. The 
long straw makes a better mulch in the paths than cut straw. This is one reason why we put on both kinds. It is not so easi1y moved out of place by tramping, after it is once trodden down in the paths, and then much more of it can be kept there than could be of cut straw. We think we have enough so it will not dry out under it, in any weather It will be nice to get down on to pick the berries. This heavy mulching will retard the ripening a little; but this is no matter to us. By saving us from frost it may be an advantage. Shipped-in berries break down the market before we can get any ripe any way, the same as it is with early potatoes now. With us, choice berries sell as well late as early-that is, as early as it would be possible to get any ripe here.

Now, this way of mulching is an experiment, from which we hope to get the best results, for reasons given above. Up to this time (June 2) I can see no reason why it is not just perfect. Several fruit-growers from other States were here last week, and, after a careful examination of the mulching, and the thinned wide matted rows, with the ground almost covered with loaded fruit-stems, they one and all said it was the finest half-acre of strawberries they ever saw. Now, I don't want to brag; but I do believe I am on the right track. Here is a photograph of the piece to show you; but, of course, you can not see the fruit, and you wouldn't know that many of the leaves are from four to five inches long; but it will give you a general idea of how the patch looks.

The quantity of mulching I used may be thought by some to be excessive; but some very successful growers have put on more. Mr. Sisson, of Pennsylvania, told me that he had put on an acre as high as 1200 bushels of forest-leaves (12 loads drawn on a wagon that would hold 100 bushels), and then two or three tons of straw besides. He has great faith in heavy mulching for small fruits. His strawberries were grown in hills, or narrow rows, when they were mulched so heavily, and were helped through the mulch, of course. I think we shall 


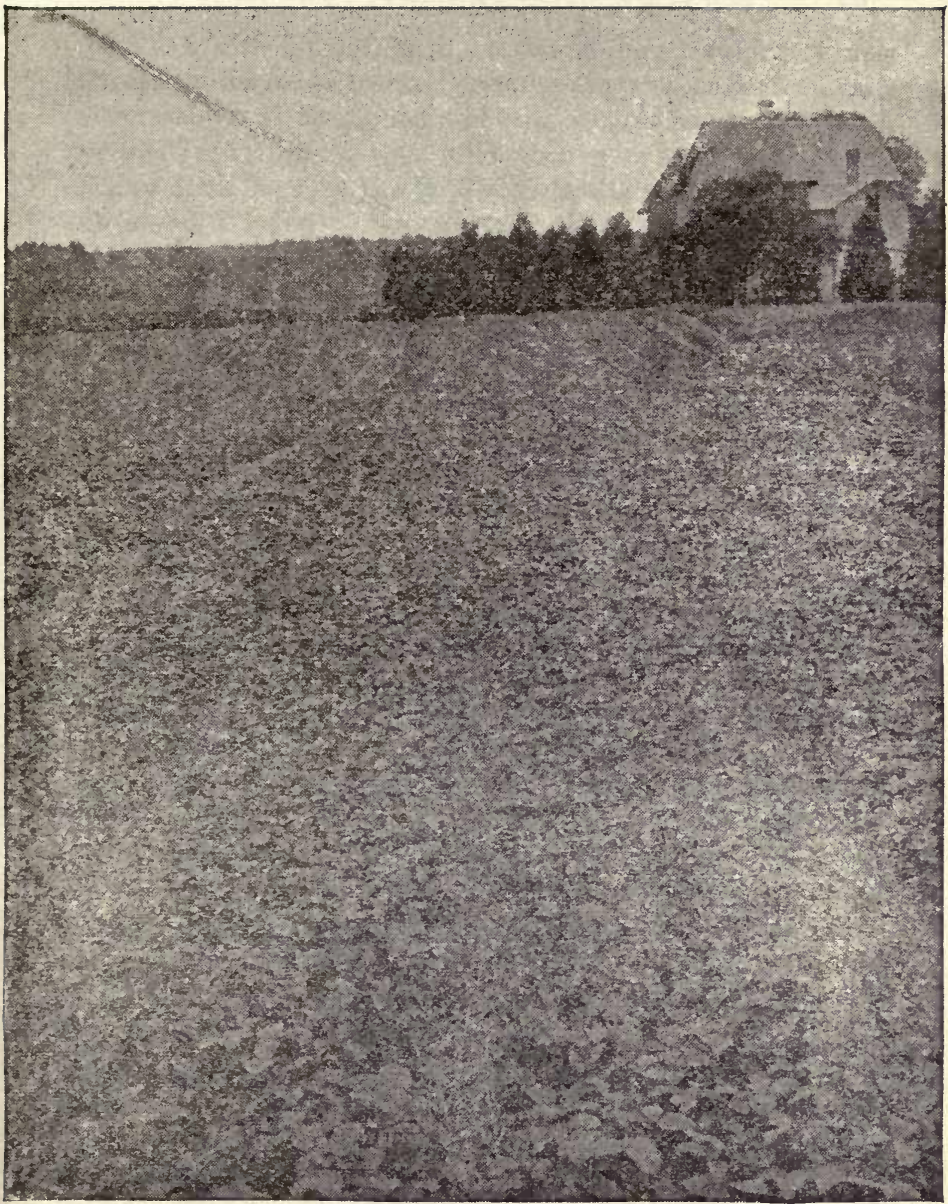

STRAWBERRY - PLANTATION SET OUT IN THE SPRING, AND PHOTOGRAPHED THE JULY FOLL,OWING. 
risk it to put the cut straw on a little thicker this fall. Mr. Crawford says he never had any berries mulched too heavily. And right here I think comes in a point that is at least of as much importance as getting early and late varieties; namely, mulching heavily to keep the berries (a few of them so as to prolong the season) from starting at the usual time in the spring. It had better be done with a perfect-flowering kind, as, if an imperfect one were kept back ten days, there might be a scarcity of pollen to do the fertilizing. I know of no better berry to try this with than the Gandy. The extra mulch should be put on when the ground is frozen solid in mid-winter, or toward spring, and not at the usual time of mulching. It might smother the plants to give them a double dose in November; but you will, I think, run no risk after the ground is frozen deep. The effect then will be to keep it frozen, or cold, and the vines from starting as soon as they otherwise would. I find that they will partly catch up afterward, however. It seems to be their nature to try to be on time; but still, I have made probably a week's difference in the time of ripening of the same variety, side by side. But, of course, this kind of work must be done with great care. The extra mulch must be removed (I would make it of long straw) just in time-when the ground has got warm enough so the plants will grow any way. This work should be done (the extra mulch removed and the other partly) just before a rain, or on a cloudy day.

Mulching, like every other good thing, has its drawbacks. The soil is colder, and there will be quite a frost on our mulched berries when there isn't any on the rest of the field. I have been out nights and watched, and the berry leaves surrounded by straw were the first vegetation on the place to freeze. But still we can not get along without the mulch, take it all around, although once in a while it may be a damage. Our berries are probably a week later, on an average, from being mulched, so the mulching may sometimes keep them back so they just es- 
cape a frost. It is about as broad as it is long; but still, if a late frost does come, the mulching will do harm.

There is a way out of this difficulty. A mulch of long straw or marsh hay can be taken off in the spring, and the surface kept stirred with a hoe or rake, about half an inch deep, wherever any of the gound is uncovered by vines, and then cut straw or cut hay cou'd be put back just before the fruit begins to ripen. But it can not be done as perfectly as when put on in the fall, and the plants grow up througb it. Some of our best growers do this way. Mr. P. M. Augur does, except that he does not cut the mulch that is returned. Mr. J. M. Smith takes off the mulch (marsh hay) and hoes the surface that is exposed, and puts no mulch back. He says the berries do not get very sandy on his soil.

There is another point in this connection that is worth thinking of. You know that a light shower would do a great deal of good in Mr. Smith's well-hoed strawberry-patch. He says himself that he has been astonished to see the effect of a light shower that would hardly lay the dust in the street for more than two hours. The change was almost marvelous; while upon similar soils not cared for, the suffering plants would scarcely be affected at all. On a patch where a straw mulch is left on all the season, will the light showers do as much good as on a field where the earth mulch is used and the soil is all mellow, and exposed directly to the precious drops from the clouds? Who can tell us? I have time and again noticed the same thing in the potato field. Where a man has done his best, and the surface is all fine and mellow, a light shower will do so much good that one can not fail to notice it with the eye, while it will have no noticeable influence where the soil is hard and neglected. Between bare surface, mellow, and the same hard and unbroken, in the strawberry-field, there can be no question as to which is the better; but between bare surface, mellow (the earth mulch), and the same surface covered with a straw mulch, I should not dare to decide positively. 
Either is very good. I incline to think the latter way the most practical for me. Certainly the straw once taken off cain not be put back among the plants as evenly as my straw now lies. Last spring (1889) we covered most of our strawberries two or three times to prevent their freezing. We used the straw that was between the rows partly, and brought in considerably more. By careful watching we found that blossoms not so covered were mostly frozen, while those covered escaped injury from the frost as far as we could see. But at fruiting time we were not as well pleased with the result of this plan. Many berries did not amount to much. They were small, or had hard spots, or parts that failed to grow. We thought this might be owing to injury to the blossom while putting that straw on or taking it off. The short-stem varieties were the least injured, which would be natural if the straw or handling of it did the injury. But I have not yet light enough on this subject to advise one way or the other, except to exercise caution in covering. Better try it on a few.

A very successful grower wrote me last fall that I could not make any better use of perhaps 20 loads of manure (strawy horse manure, which is the kind we have) than to put it on my half-acre of strawberries as a mulch, spreading it very evenly, and letting the berries grow up through. The same idea may come to some readers of this book, therefore I had better ex. plain. I am a farmer, and not a gardener or fruit grower reg. ularly. We grow clover, potatoes, and wheat, in rotation in our fields, and the strawberrits take the place of potatoes on the half-acre we have. After the berries are pickel, the land where they are will be plowed; and then after the potatoes are dug, this fall, the entire lot will be sown to wheat. Now, that land is rich enough to yield at least 40 bushels of wheat per acre now, which is all that the straw will stand up under, and probably more. More manure would ruin my chances for wheat, although it would probably pay on the berries Again, I am a farmer, and need what manure we make for the fields, 
and can not rob them to enrich a pet half-acre for fruit. Take it all around, I had better put in a little more ground to berries than to fertilize any higher, as I am situated. My friend Smith is a market-gardener, and some truck crop will follow his berries (never any grain), and he can not get his land too rich. But many friends can to advantage profit by the advice sent me, and mulch with manure. There is little land rich enough to grow wheat as large as can possibly stand up.

Along with this question of mulching comes another onethat of irrigation. I have talked with several large growers, some of whom have tried it, about watering strawberries in a dry time, and they all said they did not think it practicable. But in Popular Gardening for June, 1888, that well-known authority, P. T. Quinn, says it is practicable, and gives his experience with watering in 1887 . As he reports, he made 10 acres yield 85 bushels per acre, in spite of an unusually severe drouth. He says there is no doubt in his mind but that those who desire to realize the largest results from strawberry growing will have to resort to irrigation. Now, how much water did he put on ? As I figure it, 64 tons to the acre, twice each week, or 128 tons per week. Or, as a ton would be a fair load for soft ground, say 128 loads of water per acre each week. Do you realize how much iabor that means, even where the water is right handy by, and at the surface of the ground? It was put on with a sprinkling-cart, which saved all labor in unloading; but there is a good deal of work connected with loading 128 tons of water, under ordinary circumstances. To the great mass of growers this way is simply impossible, because they could not get the water. I have well-water within 16 feet of the surface. With a windmill and large tank I might irrigate a quarter of an acre; but I do not think Mr. Quinn would advise me to go to this expense for this purpose alone. If we had a large windmill to raise water for stock, or for use in case of fire, we might use the surplus for irrigation to advantage.

But now let us look and see how our friend Smith got a 
crop in that same dry year of 1887 , and how large a crop he got, and compare it with Mr. $Q$ 's that was saved by irrigation. The years 1886 and 1887 were each very dry seasons in Wisconsin-so dry that ordinary growers met with almost entire failure. Mr. S. raised, the first year, over 250 bushels of strawberries fer acre, and the next year 223. This was without any watering-I might almost say without any rain. Now, how did he do it? He says that drainage was at the foundation, and plenty of manure and tillage did the rest. (There was one other important point, however, which I will try to speak of again; viz., naturally moist soil-plenty of water not far down.) I have told you how he mulches and takes off the straw or hay in the spring, and keeps the surface, where exposed, slightly mellowed with hoes, or, rather, mellowed to a slight depth. In a dry year he goes over the patch three times with hoes, the last time just before beginning to pick the berries. Thus he forms a mulch on the surface, which greatly checks evaporation. Mr. Smith says he thinks this mulch of stirred soil protected the ground much more perfectly than any straw mulch could have done. Now, practically, for large fields, tillage makes the cheapest and best mulch, perhaps, as far as tillage can be used; but I should like to have had two or three rows of Mr. Smith's berries covered among the plants all through, as well as between the rows, with straw, the same as mine are, and know the result.

That noted veteran, J. J. Thomas, says that stirred soil is the best possible mulch for newly set trees. N. Ohmer tells of selling $\$ 3000$ worth of raspberries from four acres, when his neighbors' berries all dried up on the bushes. A slight mulch, made with a cultivator kept constantly moving, did it. But would not straw have done it just as well? Alas! we do not just exactly know. Another well-known authority in the Northwest, Mr. C. H. Hamilton, told me that, in that terribly dry year of 1886 , berry-growers in his vicinity reaped rewards just in proportion as they $\mathrm{k}$ ept the cultivator and hoe moving, 
shallow, to make a mulch of earth. Those who did their best had little to complain of ; those who said, "It is of no use ; they will all dry up any way," got just what they expectednothing. Those who half way tended to them got a half-way crop.

Now, I hope all these experiences may throw a little light on the irrigation question. I came back from visiting $\mathrm{Mr}$. Smith, with the idea in my head that either mulching or tillage is vastly more practicable to accomplish the desired end than irrigation. That idea still remains there.

\section{CHAPTER XIII.}

MANURING, AND THE USE OF FERTILIZERS.

For the market-gardener who does not grow small grain crops after his strawberries, one of the secrets of great success will undoubtedly be very heavy manuring. The strawberryvines do not exhaust the land particularly, but they do a good deal of business in a short time, in the second spring and early summer; and to do all they can, they must have an abundance of available fertility right at hand. From all I have picked up on the subject, I would not advise any one attempting to grow 200 to 300 bushels per acre to put all this manure on the land before setting out the plants. It has been found sometimes to make an overgrowth of vines, which do not produce fruit as expected. I would rather put part of the manure on the previous year, say enough to make the land rich enough to bring 40 bushels of wheat or 250 of potatoes per acre, and then use the rest of the manure as a top-dressing, or mulch, putting it on as soon as the ground freezes hard in the fall or early winter. In this way you will get a strong healthy growth of plants, 
but not an overgrowth; and the last applied manure will be used largely for making fruit. I know some think that there is stored up in the crowns, in the fall, the substance from which the fruit is made, largely; but nevertheless I think you will find that manure applied in the fall will help greatly to increase the crop.

I think it was at Black River Falls, in Wisconsin, that I stopped with a Mr. Lake, who beat any thing I ever saw or heard of in the way of heavy manuring. His strawberries brought him $\$ 500$ an acre the year before. The soil (?) was about as clear, sharp sand as we are able to get here for mortar. Between three and four acres of his berries were covered with manure in such quantities as I never saw put on land before. It did not seem possible that it could be spread so as not to smother the plants. It had been drawn on snow and dumped in piles. It was pretty much all one pile. The snow had just melted, and they were getting ready to spread it when I was there. The snow is all the winter protection needed in that latitude. There were over 500 "pinery loads" on the three or four acres. Unless you have been up in the pine woods of the Northwest, and seen their huge sleds, you will not have much idea of a "pinery load." The growth of vines where this manure was to be spread was about such as can be found on my patch in the winter. But if that immense quantity of manure does not smother any vines, the yield ought to be enormous. Mr. L. expected a good deal more than $\$ 500$ an acre. Now, one reads often of such manuring as this without getting all the circumstances connected with it. There were two important ones in this case. The manure did not cost any thing, except the hauling, and the land was so poor it would not grow a thing without heavy manuring.

Mr. J. M. Smith's success is partly due to heavy manuring. He uses about 40 large loads per acre on his land each year. His land is worth too much, being near Green Bay, quite a city, to 
practice rotation with clover. It is cheaper to get more manure from the city, and keep it in garden crops all the time.

Hon. H. C. Adams uses about 60 loads per acre of manure, drawn from the city, for the most part, although when I was at Madison he was keeping a fine lot of Jersey cows to make manure. His sales of strawberries and cream to one restaurant in the city he told me had been $\$ 1000$ in a season. Thirty or forty cords of good stable manure per acre are probably necessary to raise such crops as these men do on land of moderate fertility. Of course, much of this manure will remain in the soil for following crops. On land as good as mine, with clover worked in every three years, I doubt whether more than fifteen to twenty cords of manure could be used on an acre to advantage, and perhaps not that. But still, I may be wrong.

Mr. Putney, in his admirable little book on strawberries, says : "All heavy crops are grown on rich soils. Measure the profit by the amount of manure."

Friend Crawford evidently speaks from experience when he says: "It is a mistake to grow strawberries, or any other crop that requires hand labor, on poor land. The same labor that will produce 50 bushels on poor soil will produce 150 on rich. (This extra hundred bushels will pay for all the manure needed to make it rich, and a very large profit besides. See ?) He who cultivates poor land works for small wages. It is too much like running a ten-horse-power engine with a three horsepower boiler; or like driving a poor horse that can draw but an empty wagon."

But now the question will come up with some who haven't stable manure in abundance, and can not buy it, whether commercial fertilizers can be made to take its place. On my own soil they can not. I have tested this matter most thoroughly during the last two years. Bone meal was tried, and also Mapes' special vine manure, made on purpose for strawberries. We put on large quantities, in the most approred style; but they did us no good whatever. It is strange, but we have had 
the same experience in the use of commercial fertilizers for potatoes, also, on our soil. The remark of Prof. Green, of our Experiment Station, to the effect that, where a good heavy clover sod was turned under, one need not expect any returns from commercial fertilizers, throws some light on this point. On certain soils, other growers have had no better returns from fertilizers than I; and, again, on some soils they pay well, more particularly on poor land or heavy soil.

I have taken single plants and worked the fertilizer into the soil for a foot around, all through the season, with a liberal hand, but failed to make them show a particle of gain over their neighbors, either in foliage, growth, or fruit. The same thing has been done, also, with whole rows. So I think that, before investing largely in fertilizers, one had better carefully test them on his own grounds, and know whether they pay or not. As a rule, berry growers on quite heavy soils have had the best results with fertilizers so far as I have been able to learn. Mr. Crawford says bone meal and ashes or potash are the best fertilizers for strawberries. His soil is much heavier than mine, and I presume it does not get a heavy clover sod turned under once in three years. I will not attempt to say (because I do not know) why fertilizers do not show good results wherever more stable manure would on my farm; but.I know, from years of experience, that they do not.

To show more clearly the different results on different soils, and to encourage all to test this matter thoroughly for themselves, I quote some from a report published in the Rural NereYorker:

"I have been experimenting with fertilizers on strawberries, but have not been, to any great extent, successful either in increasing the size or improving the quality of the fruit. A plot on which no fertilizer was used produced as much and as good fruit as any of the fertilized plots near it. This has been the result of my experiments for five years. A few years ago Mr. Hale recommended a heavy application of bone dust, two . 
parts; ground fish, two parts; muriate of potash, one part. He said in substance: 'If you want a good crop, use $1200 \mathrm{lbs}$. to the acre; if you want a better crop, use one ton to the acre ; and if you want a big crop, put on all you can afford. Then shut your eyes and put on as much more, and it will pay every time' Early in the spring of 1882 I prepared a tenth of an acre, carefully measured and staked off, and applied 400 pounds of the above mixture, at the rate of two tons per acre. It was thoroughly harrowed in after plowing, and the plants were set three or four weeks later. There were six rows. Three rows were kept in hills, and three were allowed to form matted rows. The plot was part of an acre set at the same time, and all were treated alike as to cultivation, etc. Variety, Wilson (same as Mr. Smith manures so heavily). Great was my disappointment when I found, in the picking season of 1883 , that the rows not fertilized produced as many and as good berries as the fertilized ones. $\mathrm{T}: \mathrm{e}$ growth of plants was a little stronger on the fertilized plot than on the rest of the ground. In 1884, however, there was quite an appreciable increase in the size of the fruit, but not enough to render the fertilizing profitable."

Now, Mr. Hale was right, of course, for his farm, and so was the other man for his, and still they arrive at entirely opposite conclusions. It is the old story-circumstances alter cases. We must know our own soil and be our own experimenters. We can get hints and ideas from others; but on some points like this we must learn by experience, and be careful that we do not lose too much while learning. 


\section{CHAPTER XIV.}

PICKING AND MARKETING-A FARMER WHO DIDN'T HAVE THE PRICE FIXED FOR HIM-GROW FEWER BERRIES AND BETTER ONES.

In the small way that we grow strawberries, we have not yet had occasion to hire any pickers by the quart. We have had regular help enough to do all the picking ourselves, so we do not need to have the berries measured as picked. We use common peck baskets (grape-baskets) to pick in; and when the picker gets four or five quarts they are brought to the cellar and emptied into half-bushel drawers (those that are used in the common two-bushel stand). The berry-patch is right close to the house, so it is little trouble to take the berries to the cellar. Sometimes when it is cool, however, we fill the drawers under a tree. Our dealers here prefer to have the berries in bulk, in these drawers, rather than put up in quart baskets. They say people like to see the berries measured, and see what they are buying; and then I suppose a well-filled halfbushel drawer will measure out 18 or 20 quarts, sometimes. The drawers are certainly less trouble to us than quart boxes. They cost 40 cents per stand of two bushels (four drawers), if bought new of a manufacturer. Second-hand ones can be had of any dealer who buys Southern berries. Mr. Farnsworth writes me that he buys second-hand stands in Toledo, nearly as good as new, for 25 cents each. Dealers here ask 40 cents, as the Cleveland firms allow them that for them if sent back. But I guess they have the freight to pay, and could afford to sell for about 30 cents.

We do not measure the berries into the drawers, but simply fill them as full as we can. Mr. Crawford says a bushel of strawberries should weigh between 38 and 39 pounds, but he always gives 40 . We can not get enough in our drawers so they will weigh over 40 pounds. When we sell less than half a 
bushel (to some neighbor who calls here, as we do not retail in town) we weigh them instead of measuring, giving $1 \frac{1}{4}$ pounds for a quart. This saves all extra handling, which, of course, is injurious to the berries. When picking, our folks put either a quart or two-quart tin can in one end of the basket, and into this they put all small berries, and any that for any reason are not strictly first class. We have used these for canning, or sold them at a reduced price to others for that purpose. Parties have told us that they found them far superior to common, shipped in market berries, as there was no waste to them. I do not thiuk they are quite as nice for canning, unless you mash them up and make strawberry jam of them. However, the difference is mostly in the looks. I hardly think one could often tell the difference by the taste alone, if his eyes were closed and the berries mashed up: But my wife thinks the looks fully as important as the taste; and I am sure that, if she could see them, small canned berries would not taste as good to her as large ones.

These small berries (not very small, by any means) do not cost any thing except the trouble of picking separately, as the large choice ones will bring in our market as much as or more than the entire crop would unsorted. We live near a town of half a dozen or so stores and groceries. The first year we grew berries, not a word was said in advance to any dealer about our having any. They knew nothing about it. Many readers of this little book will know that the writer has always preached that there is plenty of room for excellence in any line, and he determined to test this matter in the berry line in our little town. There is never any scarcity of berries here, as we are close to Cleveland, and there are several small local growers also. Now, into this market, where it would seem that a new man stood no clauce, we determined to go, entirely unannounced, and sell what we had, on the merits of the article. Nothing but large, fine, choice berries, just ripe enough to be at their best for eating, were taken. With these we usually 
went in twice a day, so as to have them in perfect condition, and we sold to dealers only, unless some one else wanted half a bushel and we had too many for the grocer.

The first berries we took in were carried to the store of $\mathrm{Mr}$. R. P. Williams, an old merchant with whom we had dealt for 25 years. He looked at them with considerable surprise. "Why," he said, "I didn't know you grew any beiries."

"We shall have a few bushels to sell this year like these." "What do you want for them?"

"They ought to retail for 15 cents."

"Why, we have been selling for $121 / 2$ cents for some time." "Never mind that ; I think these will sell for 15. ."

Just then Mr. Williams' head clerk, Mr. Blackman, came up and said : "Yes, sir ; those berries will sell for 15 cents."

"Well," Mr. Williams said, "if they do I will pay you $\$ 4$ a bushe1.'"

A clerk reported to me afterward, that the first half-bushel went in twenty minutes after they were put in sight. Folks had then got a taste of berries such as few ever get in market, and there was no more trouble about prices. You see berries from a distance have to be picked before fully ripe to stand shipping, and in quality they can not compare with those fully ripened on the vines. Again, in how many small towns can one buy large choice Downings and others of our sweetest and finestflavored berries?

Having too many berries for Mr. Williams, I one day called on another grocer, Mr. G. V. Miller, and asked him if he wanted any. He said he had been selling about a bushel a day, and then had a bushel and a half on hand, and they were getting stale, they went so slowly. He was retailing them at 10 cents a quart. He wanted to know what I asked for mine, although he could not use any more. I told him $\$ 4$ a bushel. Well, he looked just sorry for my simpleness, and took out and handed me a bill from a Cleveland house which showed that his berries, received that morning, cost him only $\$ 1.75$ a bushel. In an- 


\section{A B C OF STRAWBERRY CULTURE.}

swer I said: "Now, my friend, come out and see what I have, any way ; no matter about buying them." "Oh, yes! I should like to see what you raise," he said, coming out to the wagon ; and didn't I enjoy the sudden change from utter indifference that came over his countenance when I laid off the cover? Now I will give you exactly all that was said.

"Are these berries the same all through as on top?" (Wasn't I glad just then that they were?)

"Yes."

"Then bring them in."

It took perhaps ten seconds to make the sale after the berries were uncovered. I left as soon as possible, but not too soon to see him measuring them out to customers as fast at 15 cents a quart as he could. Trade had suddenly stiffened! After that, Mr. Miller had our berries fresh twice a day through the season. At the end of the season, Mr. Williams said to me when settling up :

"We never managed our strawberry business so satisfactorily all around as we have this year. Everybody was pleased and satisfied, and there was no waste or loss. We have made a little something, and helped you to get a paying price."

Now, this is an exact statement of how we came out in our first attempt to get into the upper-story of strawberry-selling. But not the half has been told, by any means. Those berries were the talk of the town for some days, and ever so many people spoke to us about them-how choice they were, etc., and were anxious to know how long they would hold out. I couldn't help but think of the old cry that the farmer has the price of every thing he sells as well as what he buys fixed by the dealer. This farmer fixed his own price once, that is certain.

Please do not think I am telling all this to brag of what we did. We have had our fill of glory and praise from our friends here in town; but I do want to show that it pays to practice excellence. And many others have done far better than we. A friend in Indiana told, in the Country Gentleman last year, 
about how he grew Sharpless berries on heavy soil, in hills, and they were so large and fine that "they never brought less than 20 cents a quart in his market, while Crescents and others were selling as low as 5 cents, and bushels of them spoiling, and not finding sale even at that price."

I could fill pages with just such experiences. We have a great many people in this country now who do not think of price if the quality is high enough. I was talking with a friend last winter who makes fancy butter for private customers, and they are not wealthy city people either. He gets 50 cents a pound. "There is no money that would tempt me," he said, " in butter at market price, say 25 cents a pound. But if I can get 25 cents a pound for a little extra care and skill in making and marketing, then there is big money in it."

Now, it is a fact that most of this man's customers have an income of less than $\$ 1200$ a year, and still they are ready to pay two prices for a gilt-edged article, that is strictly tiptop every time, delivered with the fresh aroma in it, in the finest shape known to the art. It is a good deal the same with the strawberry-grower who has a quarter or half an acre, such as I am writing for particularly. He will not make much selling berries at 5 or 6 cents a quart. It is a grand thing, however, that many large growers, like Mr. Farnsworth, can grow common berries cheaply for the masses, who couldn't afford to pay for the best, and must have cheap ones or go without.

As hinted at above, I would have the berries, in whatever package they are sold, just the same all through. A reputation can soon be built up in this way. Hon. H. C. Adams told me he thought it puid him to "place" all the berries on the top of his quart boxes which he sells in - that is, turn them all stems down. This, of course, is honest, where the berries are the same all through the basket, as it is simply turning the berries so they will look attractive. But it is not honest, under any circumstances, to "top out" a box or drawer of berries. Ask a paying price for a choice article, and then give good measure 
and straight goods every time, and you will make money, and it will be clean money.

I should like to have you read the following lines, selected out of an article from Prof. L. H. Bailey, of Michigan Agricultural College, which I think first appeared in Popular Gardening. They express my ideas in better words than I could put them in :

"The tendency of fruit-growing is to specialize, to grow one or two products on a large scale, and solely for the money there is in them. Fruits which endure rough handling and long shipments are taking the places of the better fruits. The person who depends solely upon the city markets can not know or appreciate good fruit. Quality must al ways suffer when dessert fruits are grown and handled by the wholesale. The flavor and relish of the individual varieties, the appreciation of delicacy of taste, the appetizing influence of the best and freshest products of the thrifty garden do not appear. The commercial tendency of the times is toward the money rather than the product.

"Still, there is an abundance of people who are willing to pay for the best. Every town contains such people. They make it possible for the gardener who is ambitious, to exercise his skill in the production of the very best product. I rarely advise my students to pursue horticulture on a large scale. I urge them to grow less and grow better. Superior fruits command remunerative prices at nearly all times."

These are excellent words for any one growing strawberries on a small scale, to ponder over. Grow larger ones. Grow choicer ones. Get them to the consumer in more perfect condition. You can not hope to compete with large growers in the ordinary market, nor can they hurt your trade much in the direction pointed out so forcibly by Prof. Bailey. 


\section{CHAPTER XV.}

SHALL WE LET OUR BEDS BEAR MORE THAN ONE YEAR ?MR. SMITH'S GREAT YIELDS, AND TWO OF THE SECRETSSOME FIGURES ON THE COST OF MROWING BERRIES.

You will learn, from the first part of this book, that the writer thinks it best to plow strawberry-vines under after they have borne one crop. One gets the finest fruit and the largest crop the first year. It seems to be but little more work, if any, to set nut a new bed than to clear up and care for an old one. Keeping a bed more than one year in bearing gives all injurious insects a better chance to multiply. Some must be set out every year, any way, in order to have proper plants for setting. Do not be so unwise as to set plants from an old bed. On this point Mr. Smith says : "If we allow a strawberry-plant to bear fruit, and then plant the weakly, dwarfed runners that it produces, we can not hope for a healthy, vigorous continuation of the variety."

Mr. S. has grown the Wilson since 1861 , and has found no berry yet that can go ahead of it for market. He plants but once on the same ground, using only healthy, vigorous runners (or new plants) from plants that have not borne fruit, and considers this one great secret of his success. So if you let a bed stand more than one season, at least set out a few plants each year so as to keep vigorous and proper plants for setting.

There are quite a number of our best growers who agree with me in regard to keeping a bed in bearing only one year; but there are also some who do not. You shall have both sides. Mr. W. W. Farnsworth has kept his bed in bearing two years. I asked him if the second crop was not mostly smaller and inferior fruit. He said they got some choice fruit at the first pickings, and the berries ripened somewhat earlier than on the newly set plantations. Further, his pickers always wanted a 
good many berries, and he let them have the last pickings on the old patches at a reduced price. But still the last time I heard friend F. talk at an institute on this subject, be seemed almost converted to the plan of leaving his berries to bear but one season. At any rate, he spoke of that as "probably the best way." I think he would be more positive where one grows, say, only part of an acre a year, and that is the class of growers I am writing to.

Mr. Adams, of Wisconsin, when I was there, left his beds to bear two years. He says they will not produce as well the second year, but that the second crop costs him but little more than the picking. His land must be quite free from weeds and grass. My friend Sisson, of Pennsylvania, says he lets his berries bear two years. The first jear they are kept in hills, or quite narrow rows. After the fruit has been picked he plows the soil away from the rows on each side, leaving a strip only about eight inches wide. This plowing buries the mulch and vines so that they soon decay. Meanwhile he cleans the little eight-inch strip that was left, with hoes. After two or three weeks, the soil plowed up in the middle between the rows is worked back by the use of the cultivator, and then the runners are allowed to spread and form a matted row. Mr. S. is an excellent cultivator, and when berries are left to bear two seasons perhaps his plan is as good as any. The weak point is, that the parent plants that send runners out to make his matted rows are old, exhausted plants, which Mr. Smith would think not capable of producing the most vigorous of runners. Of course, heavy manuring, and his most excellent tillage, would somewhat balance this. He will get a large crop, any way. But couldn't he get a larger one?

I have had much to say about friend Smith, of Green Bay. Let me now tell you just what he did the year before I was there, which was a very dry year too. I saw $31 / 2$ acres in his 40 -acre garden, that yielded $\$ 2215.24$ from strawberries. I looked over his sales and tcok the figures right from his books, 
at his request. S'xty thousand plants were taken from the same land in the spring, worth $\$ 300$, and then between $\$ 700$ and $\$ 800$ worth of celery and cabbages were grown on the same $31 / 2$ acres after the berries were plowed under. I could not get the exact figures on the vegetables, as they were not all sold. These figures fairly take ont's Jreath away. Mr. S.'s largest yield for a single season was 446 bushels per acre. Certainly we may all give careful attention to all friend Smith says on any point connected with strawberry-growing. But I believe I have not given you what seemed to me one of the great secrets of his wonderful success. Heavy manuring, and the most thorough tillage that man knows how to give, and the choicest plants that can be grown, with such a man as Mr. Smith at the helm, are important factors; but there was one more point, as it seemed to me: Mr. S.'s land is very sandy, and but a few feet above the water of the bay. There is abundant moisture at all times. Capillary attraction brings it up readily, through the mellow sand, and with Mr. Smith's tillage his crops suffer little or none for water, whether it rains or not. $\mathrm{He}$ has tiledrained and surface-drained, in beds, his land, to take the surface water, after a shower, off quickly, sandy as it is; but there is a never-failing supply but a little way down. His land is notably such as I spoke of in a previous chapter as best for strawberries-well drained, but moist. Much of your success, my friends, may depend on your selecting land of this character.

Now, some realers, perhaps, would like to know about what the profits are in strawberry-growing on a large scale. It has been difficult to get figures on this point from growers. In fact, the only man who has followed the business for years, and would tell just what he made, was Mr. Adams, of whom I have spoken before. The following are his figures as to the cost of growing an acre, on the average, for a term of years: 


\section{A B C OF STRAWBERRY CULTURE. 101}

Plowing............................................... \$ 125

Harrowing ........................................... 100

60 loads of manure..................................... 3000

7000 plants............................................ 2800

Planting................................................... 500

Hoeing 7 times...................................... 2100

Mulching.......................................... 800

Work second spring................................ 500

Picking................................................ 5000

Boxes ................................................ 2500

Total..............................................\$174 25

His average crop for a term of years has been 5000 quarts per acre. The cost of production, then, not including land and marketing, is about $31 / 2$ cents per quart. The actual price he has received on the average has been 8 cents a quart, or $\$ 400$ an acre. This leaves him a net profit, certainly of $\$ 200$ per acre-a fine showing. Knowing the gentleman well, I have no doubt it is a fair statement of what he has done. His manure cost him but 50 cents a load, delivered, from the city. It is - very seldom one can get it at that price. Some of Mr. Adams' figures would seem very low to a beginner. For example, I could not set 7000 plants for twice $\$ 500$; but I am told that an expert would set that many well in 3 days. I can hoe an acre for $\$ 3$, however, so I am up to Mr. Adams in that respect. My man will hoe our half-acre in a day, nicely. By the way, I have just noticed that our friend forgot to put in the cultivating; but that would not add a great deal to the cost.

Now, friends, take just this thought with you in parting: Do not be satisfied with any thing short of the very best. 


\section{CHAPTER XVI.}

YIELD OF OUR HALF ACRE THIS YEAR (1890)-QUALITY RIDES OVER A GLUTTED MARKET-NUMEROUS NOTES ON THE SEASON'S EXPERIENCE.

Since writing the previous chapters the berry season has come and gone, and a few words in regard to this year's experience may be of interest. The cash sales from our patch were $\$ 237.00$. We were painting house and barn, and building an addition to our covered barnyard, during the berry season; and as we had to board the carpenters, tinners, painters, etc., as well as four men of our own, besides our own folks, we had a very large " home market" for berries. We certainly ate, canned, "jammed," and gave away $\$ 50$ worth, probably more, as some days I know by actual measurement that we ate three pecks. We may safely say that the total value of the crop at wholesale prices was $\$ 287$. No attempt was made to get the last dollar out of them, or the receipts might have been pushed up to $\$ 300$. We all got pretty tired of picking; and when the yield got so light that there was not much profit in it we let them go and told the neighbors to help themselves. One lady picked more than a bushel. As we had taken up plants from one end of the patch, taking all clean as we went, the above yield was obtained from several rods less than half an acre. I haven't figured up the exact yield in bushels; but it was over 100 , or considerably over 200 bushels per acre. With the exception of three bushels the berries were all sold at the door, or in our little town of Hudson. That we were able to do this was a surprise to us. There are plenty of other growers here, and the streets were full of peddlers all through the season. They took the berries from door to door. We sold to dealers only, or to families who wanted a half-bushel drawer. I fixed the price of our best selected berries at $\$ 3.20$ a bushel, and the 
small ones for canning at $\$ 2$, and held it there without any regard to how low others were selling. I believed our town people would appreciate a good thing, and be willing to pay for it, and they were; and after the first day they took all we had, so that we did not have a single quart of berries spoil after they were picked; and the demand was so great that we could not get a chance to can any for ourselves until the very last, when we shut down and positively refused to sell any more. Nothing in the world but extra quality gave us this good market in this season when berries were so plentiful. The markets were all glutted with common berries; but such as ours were not crowded in the least, and never will be. I went through the market in Cleveland during the best of the season, and through the most fancy groceries on Euclid Avenue; and in all that great city there was not half a bushel of berries that would match what I was furnishing to our grocers. Now, talk is cheap; but photographs tell the truth. It occurred to me, when I was going to town one day, that a picture of the berries in the drawers, just as sold to customers, would be more convincing as to the soundness of my method of culture than pages of mere writing, and so I drove to the gallery and had some pictures taken. The berries are exactly the same size all through the drawers (not "topped" at all), and these drawers were no better than many others which our dealers had. One picture shows the Sterling and Haverland. When the Gandies first came, some eight days after the others, they were so magnificently large and fine that I got a picture of two drawers of them also. They sold readily at $\$ 4$ a bushel. These two drawers that you see a picture of brought me $\$ 4$, and retailed just as fast as they could be handed out, almost, at 15 cents a quart, when, I was told, people were peddling berries at 8 or 10 cents, and when you could buy common berries in Cleveland for $\$ 2$ a stand of two bushels. By the way, I give you a picture of a drawer of these common berries, so you can better judge the size of the others. My wife says these are better than the aver- 


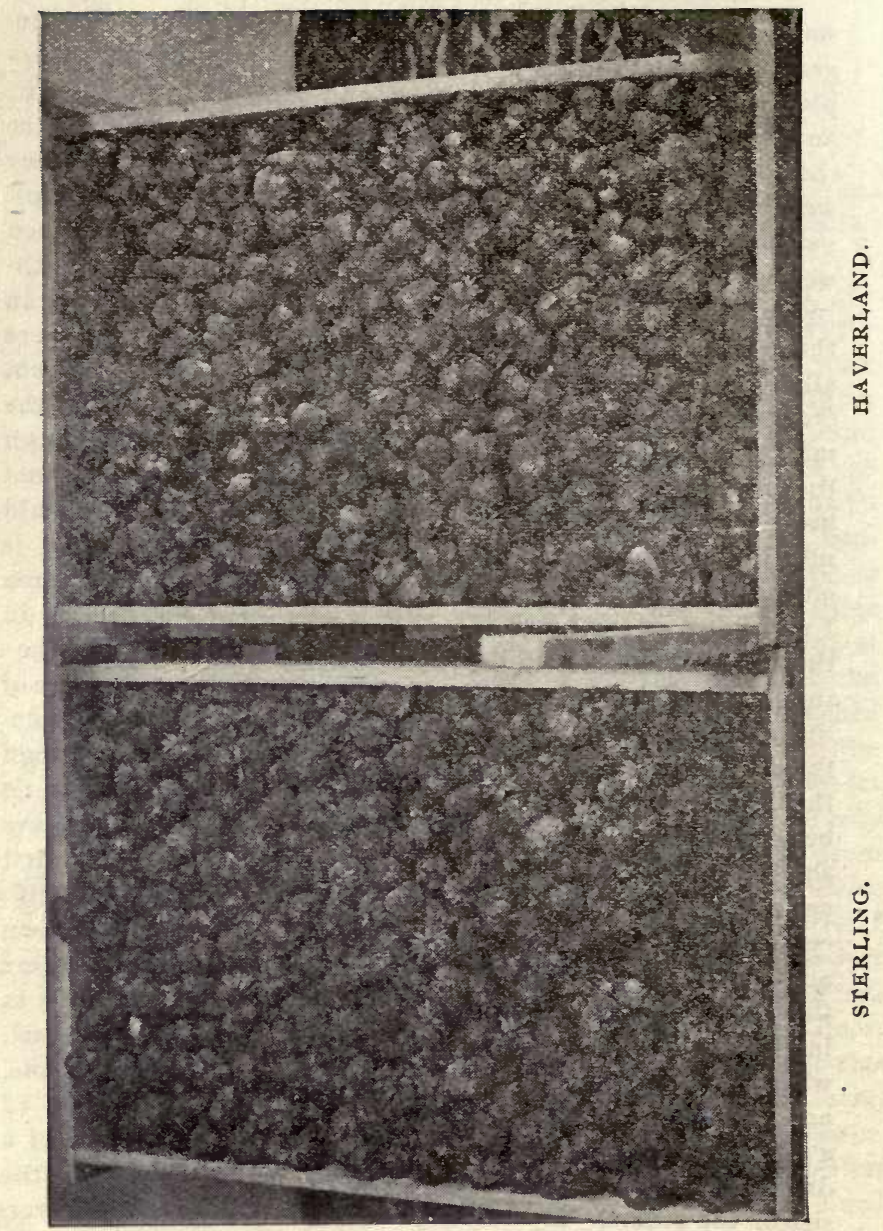




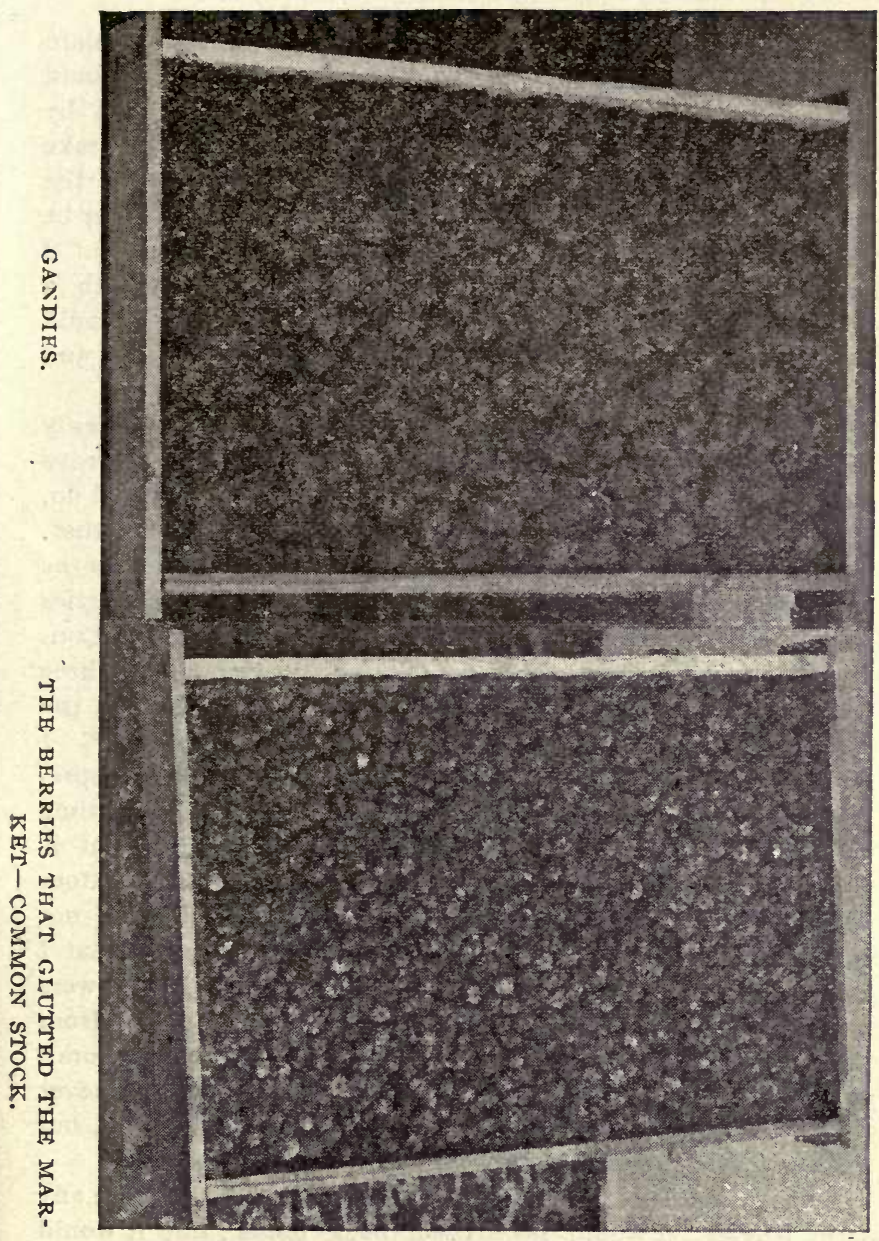


age of what we used to get from Cleveland. Farmers complain much about there being no money in 80 cent wheat. I should think there must be a great deal more than in berries sold by the dealers at $\$ 1$ a bushel. The dollar-a-bushel man has to take just what he can get, and has the world to compete with; the \$4-a-bushel man can set his price, and his market will never be glutted. I do hope my experience may teach this lesson. I was anxious to go to a fancy store on Euclid Avenue with a bushel of those magnificent berries, just to see what I could get for them; but our people wanted them all, and more, and we let them have them.

But the first day we picked almost too many to suddenly put on our little market, and early the next morning I drove to Akron (12 miles) with three bushels, to see what I could do, not dreaming that Hudson would take all we had after that. Before I got there I met men returning who said I might as well turn around, as Akron never knew such a glut of berries before, and no more could be sold at any price. But I went on. In fact, my spirits began to rise. I cared little about the three bushels I had; but I thought to myself, "Here is just the chance I want to prove-whether or not excellence pays." I drove up before a grocery, the owner of which I knew appreciated a good article. I found him at his desk, and for a time could not induce him to look at the berries at all. "What is the use?" he says. "I know they are nice, from the potatoes we have bought of you; but we are overloaded, and can not sell what we have, and there are so many new growers that I can not see any prospect for any thing better. The growers can not sell any more to dealers, and now they are going from house to house, selling at very low prices, and utterly demoralizing our trade. We are just 'stuck.' In twenty years I never saw such a glut. I should gladly help you out if I could, but we can see no possible outlet."

I told him that, of course, I did not ask him to take any more berries. I would take them back home; but it would 


\section{A B C OF STRAWBERRY CULTURE.}

give me pleasure to show him what I could do in the berry line. It was with much difficulty that I at last induced him to come out; he was utterly sick and disgusted with berries. But he finally came. I uncovered them. He bought them. I went home. Before night of that same day he wrote me to bring him four bushels more of these berries, offering an advance of $25 \mathrm{cts}$. a bushel, and $\$ 1$ if his market should recover any so that he possibly could. But our home trade wanted them all, and I did not go to Akron again. I dislike to blow my own horn, friends; but I see no other way to make this important point so plain to you. The plain truth is, such berries will make a market for themselves. People who wouldn't have looked at ordinary fruit couldn't pass such berries without taking home some; and after they had one taste we were sure of them for the season. Even our canning berries were made to advertise themselves. If one box went into a neighborhood, every family near would want some. For example, I sold to a Mrs. C. a drawer at 4 P. M., and called there in the evening to get the drawer back, and took orders from four neighbors, who were waiting there to see me, for $2 x / 2$ bushels. Good fresh berries that there would be no waste to, and good measure did the business. We put about 18 quarts in every drawer, 41 pounds on the scales; and if that didn't seem to fill the drawer very full, we put on a few more.

Now, while there are plenty of people able and willing to pay for our best selected berries what such an article deserves, it was with a great deal of pleasure that we sold many bushels of good berries, but not the very largest, at prices that any one could afford. Many families who could not afford 15-cent berries bought half a bushel of 6 -cent ones, and ate them freely, and canned the surplus. We sold a good many berries at $\$ 2$ in this way that we might have got a little more out of, and we were real sorry that we did not have enough to go around even then. We had to refuse many of our friends.

I have now told you of the yield and the income therefrom. 
May I tell you what was done with the money? I have one son and two daughters, and we all worked hard during the berry season, I tell you, and my wife also had to keep a boardinghouse for the time being. Well, when we got through I just handed them $\$ 50$ apiece to do what they please with. Certain1y I can afford them the returns from a paltry half-acre of land. My wife and I are partners, and I do not believe in her earning money separately; but I had heard some hints of a certain new dress wanted, and thought it a pretty good time to put some bills in her private pocket book. She doesn't take enough when I leave her to help herself. The $\$ 37$ left will more than pay all money I am out for extra help; and the fun of succeed. ing, and all the berries we could eat, are pay enough for me

Let me tell you how we managed so as not to have ti:e farm work suffer. I hired two good extra men, and then my son and two men took care of the crops and farm work, while $I$, with the rest, handled the berries. Our largest picking in a day was about 13 bushels, which sold for $\$ 36.55$. It required frum four to six good pickers to keep right up. I did the marketing, and looked over every drawer, and knew they were right.

In regard to the yield of different varieties: The patch we have set out this year, which I have told you about, has just about the right kinds in the right proportion. I must change my mind a little. I told you that, when I found out the two or three kinds that did best for us, I should not grow so many varieties. I believe I was wrong for our fancy trade. People like a change. When they tire of a sweet berry, one with a little more acid will fill the bill. Then they want something beautiful to look at now and then. By a little careful changing we can hold our customers to the end, constantly giving them new surprises. The two rows in the foreground of the picture (see page 81 ) of our patch for this year are Haverlands. Doubtless they are the greatest yielders, and one of the most beautiful berries to look at that I ever saw. There is one-sixteenth of an 
acre in those two rows. We usually picked two bushels a day from them, and practically all first class $\$ 320$ berries By the wiy, I should have said that the drawer of $\mathrm{H}$ tverlands that had its picture taken was just as they grew-no sorting. Now, this I know: that that sixteenth of an acre brought us at the rate of over $\$ 1000$ per acre. The berries just lay in piles all over the ground, and visitors said they never saw such a sight. I took a sample to an old dealer in the city, and he said, "You may talk quality to people to the end of the world, and every mother's son and daughter of them will buy that which pleases their eye. That berry is beautiful, and it will sell bigh." He is about right. The Hwerland is a little weak in flavor, and rather soft with us; but it is beautiful, and enormously productive.

The Bubachs were very large-ten or twenty per cent larger than the S.erlings shown in the picture, at first; but the yield was quite moderate. The Sterling was grand, as usual, holding out to the very last, not in size, but in quantity. I think this berry has nearer the wild-strawberry flavor than any other I know of. The Jessie, on our soil, is the poorest yielder of all. The Cumberland did only moderately well, and the Downing also. In fact, all our perfect-flowering varieties were away behind in yield. The imperfect ones brought in the bulk of the dollars. Do not grow perfect berries for market, except what may be necessary for fertilizing. Wouldn't I except the Gandy, which brought me such magnificent $b \in$ rries? No, except that you might grow a few to make a change for your customers. They are small yielders. The first picking was grand; the second, fair; the third, hardly ordinary. As to lateness, it will not prolong the season at all It is eight days or so lat $r$ in ripening its first 'herries; but the last picking of Haverlands and Gandies was on the same day, and the former are the larger. It has a p.culiar flavor, something like pineapple, which I should soon tire of, but some people were delighted with it. It is also a wonderful keeper. Ripe berries will keep ferfectly 
in our cellar for two days. I should not be afraid to pick them Saturday night, for sale Monday morning early.

Now, do you want to know what berries, of all tested this year, I would grow for my own eating? (We tested several varieties not mentioned). By all means the Downing and Sterling, with perhaps a few Summits to surprise our friends with. These would fill the bill with us for family use. The Downing is just deliciousness itself, and the Sterling more tart and excellent-in fact, the best I have, to can.

I am more than ever convinced that the very heavy manuring practiced by some is all unnecessary on good soil where clover is grown in rotation and the best of tillage is given; also that fresh manure plowed under is better than rotten manure barrowed in on the surface. The latter will be more likely to grow an excess of vines, on my soil, with small fruit-yield; and the former, moderate vines and abundant fruit.

In our strawberry-harrow we used, this year, teeth sharpened flat, like a chisel, at the bottom, instead of round-pointed, putting the beveled side back. They take hold and work better. See cut, p. 66.

We found the width of our rows all right except with the Haverlands. They throw out their fruit-stems over on the straw in the paths so far that it would have been better to have the rows five feet apart, giving the additional foot to the path. The photograph of our bearing bed was taken a few days before picking time; that of our newly set bed July 3 , just as we had let the runners begin to grow. A few had taken root. Our boys had ust finished tearing up the soil with the cultivator, roughly, after a heavy rain had packed it down, and were about to hitch on to the strawberry-harrow, to stir the light-colored strip of soil you see under the leaves of the plants, as well as fine what the cultivator had left so rough. I tell you, this harrow leaves little for the hoe.

Our plan of mulching, which was something of an experiment, we consider now quite perfect, and shall do exactly the 
1.3.

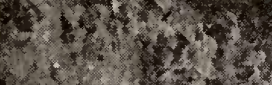

3.t.

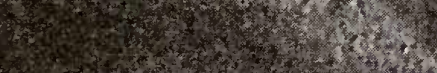

36

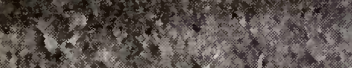

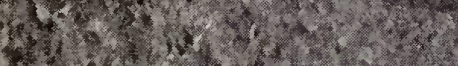

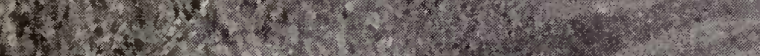

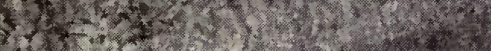

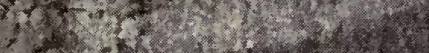

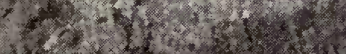

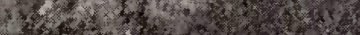

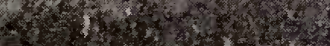

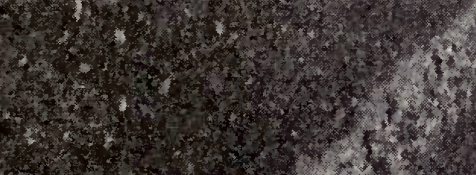

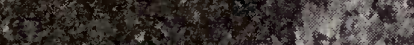

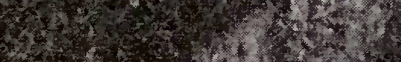

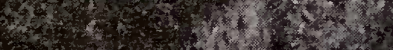

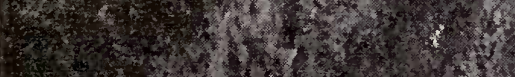

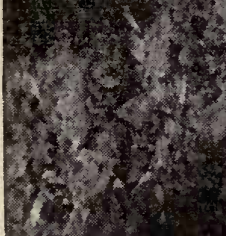

a

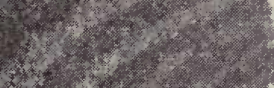

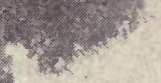


same another year. Our berries were perfectly clean. The lorg straw which you can see in the paths (see p. 81) made a nice carpet for the pickers to knetl on, and protected the fruit on the outside, the cut straw doing the same in the beds. Many customers said to us, in substance: "We never used strawberries before without washing them; but it is labor thrown away on yours."

Since I wrote the above, the Ohio Farmer for July 5 has come. In it Dr. Chamberlain, now president of the Iowa Agricultural College, says, in speaking of our berries :

"I did not see his (Terry's) farm this year in hurriedly passing through Hudson, but I saw some of the fruits of it. Passing a grocery I saw finer stands of strawberries than I ever saw in New York, Chicago, Philadelphia, or Washington markets. It was nearly nine o'clock at night, and they had just been brought in for next morning's sales. Having a curiosity to test them I said to the grocer, 'Put me up a quart, and count them as you put them in.' He heaped the measure to its utmost capacity, and there were just twenty.eight strawberries."

Some quarts, the grocer told the writer, counted out but twenty-two berries, earlier in the season. It was a little late when Dr. C. saw them. He continues :

"I took them in the next door, ordered a dish of ice-cream and a large extra saucer, hulled the twenty-eight strawberries, stirred the ic them, and for one of the first times in my life I realized what perfection in strawberries means. The whole country smiled last year when Mr. Terry told of eating a quart of strawberries at a meal for each member of the family. Shall I confess, with shame and confusion of face, that I performed the same am: $z$ ing feat, and felt the better for it?"

I put this kind notice in along with the photos and my report, hoping that all these things together may make it plain to you that strawberries can be grown finer and larger than 
many city people ever saw. I have told you how ready they are to pay for such, and just how to grow them.

In one corner of the picture of our new strawberry-bed you can catch a glimpse of our small-fruit garden, containing 100 rods of land. I wish you could see how the bushes are loaded. We are hardly through with the strawberries yet, and still there are black raspberries, and red ones, almost as large as strawberries, waiting to be picked, bushels and bushels of them; and such a show of blackberries I never saw. As a visitor to-day remarked : "They fairly touch each other all over, a hedge of berries." (The rows were cut back last spring, much like a hedge.) These bushes, grapevines, etc., have been growing only two seasons, and we had probably ten bushels of berries last year.

After you have mastered the strawberry business, push ahead until you get all the other choice small fruits. Severa farmers have been here (two to-day) to see about getting plants. Our little success has roused them up, and quite a revival in strawberry-growing will take place around here. Would that the same may be true in every locality that this little book reaches, that the people in the towns may be able to buy choice fresh berries in abundance, and particularly that the farmers may have such, as free as water, for three weeks every season ! I have been around to-day gathering up my strawberry-drawers (this chapter is being written piecemeal, as I can get a few minutes to spare), and I just wish those who talk about there being no market for berries could have been with me. At every place it was, "Mr. Terry, can't you bring me a bushel of nice large black raspberries to can?" or, "Half a bushel of those beautiful Cuthberts (red);" or, "Don't you forget, now, I wan a bushel of those splendid blackberries." Why, friends, it just makes me want to keep out of sight, I so dislike to say to these good people that we can not begin to supply them.

This afternoon a well-known clergyman from Pittsburg called here. I should say he was 60 years old. He went all 
through my fruit-garden, and satisfied himself with the great beautiful berries. I showed him the photographs of strawberries that you will see in this book. At last he said to me: "Friend Terry, I am quite disgusted with myself."

"What do you mean?" I answered.

"Why, I have half wasted my life so far."

I couldn't think what he was driving at, and asked for further information.

"Why," he said, "I have land enough, and have only myself to blame because I have not lived like a prince, as you are living, all these many years. To be sure, we have bought some market berries. But this feasting of the eyes and body on such luscious fruit, month after month, is something we know no more about than that horse of yours does." (The horse was drawing the harrow through the strawberries.) I thin $\mathrm{k}$ my friend will not neglect any longer these healthful and beautiful luxuries that God gives in such abundance and magnificence to those who will work for them. Reader, have you any cause to be "disgusted" with yourself for the same reason? I hope not; but if you have, there is just one noble way out of the difficulty- "Bring forth fruits meet for repentance." 


\section{STRAWBERRY CULTURE.}

BY THE PUBLISHER.

Of course, I have been for many years interested in the cultivation of the strawberry, or I should not have been so anxious to have friend Terry write this little book for me. Before, however, I undertake to tell you any thing about my experience and my ideas in regard to strawberries, I wish to tell you of a visit I paid to friend Terry while his berries were right in the height of the season. As the following sketch was taken mainly from Gleanings in Bee Culture, our readers will please bear in mind that it was written with the supposition that the reader was conversant with former numbers of Gleanings:

When the first chapters of the strawberry-book came we were so full of business I did not pay very much attention to them. I knew that, when the printers got ready to take hold of them, I should have to read them any way. In fact, I have become so tired of reading letters and following out the different lines of business through the letters, that I do not know but I have lost energy somewhat. Before I got through with the strawberry-book, however, it all came back. Why, in the concluding chapters I could hardly sit still. I looked at my plants out in the plant-garden, and I looked at the ground on the hill by the windmill where I am preparing to plant berries, and I could hardly contain myself. Before I got many pages further, I got into a fever to visit friend Terry. But there were the letters piled up, many of them grievous complaints because the writers had not got their goods. I could not be spared one whole day, that is, in the month of June, and I did not feel as if it would be right for me to desert my post so long. I did, however, write to friend Terry that I wanted the privilege of dropping in upon them some night between nine and ten o'clock; and I wished them, also, to let me go back about sev- 
en or eight o'clock in the morning. I bade him tell his good wife that all the preparation she need make for my entertainment was plenty of bread and butter for breakfast. With the berries I could help myself to, I should be quite satisfied and happy. Then I counted the hours until a reply should come. A reply did come-not in answer to my letter, however, for it was written before my note had been received. Here is a part of friend Terry's letter :

Friend Root:-Our patch is a grand success, bringing us about $\$ 15.00$ a day. We get our price, without a bit of trouble, in spite of great competition. Pleuty of room $u p$ above.

Hudson, O., June 18, 1890.

I received it just before noon. Friend Terry lives about 25 miles from us; and a little before four o'clock one of our Clydesdale horses was standing before the office, waiting for me to get the letters looked after so I could be spared until the next day at noon. My wife admonished me that the barometer was falling, at a pretty good jog. But the strawberry fever was too strong to be allayed by a summer shower, so off we started. My teamster has always been rather skeptical in regard to Mr. Terry's farming; and I am sorry to say that a great many farmers and teamsters throughout our land are somewhat the same way, and yet I do not believe that they could give any good reason for it if they were to try. I rather enjoyed his proposal to go along with me to take care of the horse. Mrs. Root said, before I went away, something like this: "Now, husband, remember that Mr. Terry's folks are in the midst of farming, besides taking care of their berry crop, and very likely Mrs. Terry is burdened. Stop somewhere and get your suppers, and feed the horse, so that you may make them as little trouble as possible."

We came into the pretty town of West Richfield just about six o'clock. Did I ever tell you that I have a special liking for hotel-keepers? Well, I have. I like every thing about a hotel -especially the country hotel. I like the landlord and the 


\section{A B C OF STRAWBERRY CULTURE.}

landlady; I like the girls who wait on the table (as you may rem:mber); I like the boy who tends to the horses in the stable; yes, and I like pretty well the folks who lounge around the door and bar.* I should like them better, however, if they were busy in something good-in the line of our text, $\uparrow$ for instance. These country hotels are homes for homeless people ; and I always enjoy seeing how well they carry out this idea.

"My good friend, we want some supper just as soon as our horse can eat his feed. We have quite a piece to drive yet, and we wish to get there before the people have gone to bed."

I was pleased to see how quickly he moved to the kitchen to tell the women-folks to start it going. Then he directed in regard to the care of the horse, and stepped briskly to the meat-shop; and almost before the kitchen door was shut we heard them pounding steak. Before I had time to become impatient or nervous, we were called to partake of the nice steak and potatoes, with a couple of fried eggs, nice sweet butter, good bread, and a good saucer of strawberries. If you want to see me have a good appetite, just let me ride twenty miles across the country. For serving us thus handsomely, the whole charge was only 25 cents apiece. The horse counted the same as a man. Now, when I get promptly served, and yet on such short notice, and at so small a price, do you wonder that I thank God for hotels, and that I feel kindly toward hotelkeepers ?

Just a little before nine o'clock I had the pleasure of telling my companion, Mr. W., that this was friend Terry's home. I watched him as he looked at the bright pretty barn and tool-

* When I use the term "bar" I do not mean a place where drinks are sold, as used to be the custom forty years ago. A good many of our country hotels here in Ohio do not sell any thing at the bar-not even cigars or tobacco. Perhaps the term "bar" had better be changed for "office." I wonder how it is with you, friends. Do the hotels in your small towns nowadays sell drinks of any kind?

†The text alluded to is, "Lay up for yourself treasures in heaven, where neither moth nor rust doth corrupt, and where thieves do not break through nor steal." 
house in the dim moonlight. Friend Terry was off to Hudson, with berries; but his son and a hired man welcomed us.

"You said you would be here between uine and ten; but you are a little ahead of time, are you not?" said the young man.

I always like to be ahead of time. It is a grand idea, in business, boys, to make your promises, even in traveling, so that you are on hand a little sooner than you agreed to be. You try it awhile, and see if you don't find I am right. We were warmly welcomed by all the family, even if we did come three or four days before we were expected. Friend T. soon returned, then got a lantern, and we went to see those wonderful strawberries. The first glimpse I ever had of the Grand Rapids lettuce was by the light of a lantern. I shall never forget it. By the way, there is something wonderfully fascinating to me in going about among the plants after dark. How cool and beautiful the ground looked in friend Terry's new plantation of strawberries! (See cut on p. 81.) The beautiful, thrifty little plants, each one as much like its neighbor as two peas can be alike, at exact distances (rows four feet apart, plants two feet apart in the rows), with all the intervening ground in process of being raked until nothing could live except the strawberries -why, I fairly ached to get hold of a fine-tooth steel rake, just to stir the beautiful, fine, soft rich loam. If there were any weeds, they had not come to the surface of the soil. In fact, weeds never get so as to be visible on the Terry plantation. Then we went with the lantern over to that half-acre in full bearing. (See p. 81.) But no photograph can begin to do justice to the sight we beheld. The varieties of strawberries are selected so as to have no rusty leaves. . Every leaf is thrifty, perfect, and has that bright new look that indicates a rank luxuriant growth. The whole ground between the plants is carpeted with cut straw, so not a berry can find any thing gritty or that will soil it in the least. Strawberries growing and rip. ening on the "straw"! and, oh what clusters of them! It 
seemed as if there were hardly room enough for them to ripen without lying piled up on each other. Paths were provided for the pickers, a foot wide; but these paths were also filled with straw. The Sterling, Cumberland, Gandy, Downing, and Bubach, kept their berries out of the path; but the wonderfully productive Haverland could not be satisfied with piling the berries up in the row, but it just kept pushing its great long stalks full of fruit clear out into the path; and it was very difficult indeed to walk in the paths without stepping on these great beautiful handsome berries. Did anybody ever see such a plant as the Haverland? One reason for wanting to visit friend Terry was, that I wished to see whether his Haverlands were really lying in heaps around the plants, as ours were. They were doing that very thing. Friend $T$. is not excitable. I never saw him get very much excited about any thing. $\mathrm{He}$ is cool and quiet in almost all emergencies. He does not sail his hat nor get as enthusiastic as I do ; but for all that he enjoys nature's gifts fully as much as the rest of us, if I am correct. Now, the catalogs have been severely censured for being extravagant in regard to many of these new things; but since I have been home I have searched all the catalogs in vain to find any thing that does half justice to the Haverland. It is true, the berries are rather tart, and have not very much flavor compared with some of the others; neither are they as large as some. But the berries are of good size; and with a little sugar they are almost as good as any of them. And, oh my! what an abundance! I have not any figures just now about the amount per square rod; but you will find them in the book. It seems to me that this plant is destined to bring about a new era in strawberry culture. We have had them for two years. The first year we kept our griginal plants so busy furnishing runners, that we did not get very much fruit. During the last spring I let the old plants go, and they were pretty well covered with grass and weeds; but when they began to set their fruit I was almost alarmed. I could not believe it possible that 
any plant could ripen the quantity of green berries that lay around them on all sides. But they did do it; and as fast as they turned red they increased in size to such an extent that it seemed almost like popping corn.

The lantern was put away, and we went to bed. I obtained permission to get up at daybreak, and I proposed not to disturb anybody else. The barometer's prediction troubled me a little, and so I was not surprised to hear the patter of the raindrops a little before daylight. The rain let up, however, a little after daylight, and, oh what a beautiful sight met my view! One of friend Terry's hobbies is keeping things painted. The barn and tool-house and covered barnyard had just been treated to a coat of bright new paint. By the way, this covered barnyard has just been enlarged to about twice its former capacity. But I tell you, it is handy, especially where one has as many tools as friend Terry and $I$ have. Friend $T$. has a knack of combining colors, with a small amount of architectural curves about the covered yard, that makes it wonderfully pleasing to the eye. The fence before the house was also neatly painted, and in good repair; gates all working nicely. The graveled walk, the shrubbery, and vines by t'.e porch, tell their own story; and a row of evergreens on the right and on the left called forth exclamations of surprise from me on account of their regular appearance and beautiful shape. The house, it should be remembered, is on the north side of a street running east and west. These rows of evergreens, therefore, run north and south; and there is another row, seen in the strawberry picture, just across the back end of the dooryard, thus making an inclosure.

When I asked him what he did to the evergreens to make them so even and regular, and of such bright luxuriant growth, he replied that he did nothing at all. They are the ordinary arbor-vitæ. For a while I was a good deal puzzled to know why they did not look as our evergreens do, and a good many others'-one small, indifferent tree, and then another large one, 
and so on. The secret of it is, the ground was underdrained, enriched by thorough tilth and clover before the trees were put out. In fact, all the ground around friend Terry's home has been worked up to a degree of fertility and evenness of texture that makes all the plants and trees just alike. If the arbor-vitæ grows of its own accord of the beautiful shape of those about friend Terry's home, I should never think of bringing them into artificial steape with shears and trimmers.

Having now viewed the front, the reader will please go with me up the gravel walk. We will turn off to the right, near the corner of the inclosure. Right here is the out-building that friend Terry has several times described in our agricultural papers. It is such a beautiful, secluded spot, overshadowed by the evergreens and other trees, that a picture is given in one of our rural papers as a hint to farmers in the way of comfort and convenience to their wives and grown-up daughters, to say nothing of the younger ones. As we step through the evergreens we come into the half-acre of strawberries. (See picture on p. 81.) This picture was taken from a hill, or gentle elevation, north of the house. Many of the strawberries were in blossom at the time it was taken. If you put on your specs you can get a glimpse of the blossoms here and there.

There are fourteen rows of berries, as you will see by the picture. Perhaps an expert could tell the varieties by the foliage. Next to the potato-field, on the left, there are three rows of some variety, the name of which I can not now remember; then come three rows that I am pretty sure, by their looks in the picture, are Sterlings. As the Sterling is imperfect, a row of Downings comes next as a fertilizer. Then we have Cumberland, Gandy, Bubach, Haverland, Jessie, and perhaps some others. The two rows in the foreground, that come right up to the foot of the reader, as it were, are the wonderful Haverlands we have spoken of. They are alternate, so as to have one row of perfect after every two, or, at the furthest, three, rows of imperfect. The straw mulching is plainly visible in the paths; 
but the cut straw between the plants can not be seen except by moving the foliage aside; but in the whole patch there is no ground visible-nothing that can soil the berries. During picking time the straw is tramped down in the paths much flatter than it appears in the picture; and one of the worst troubles, if it was a trouble, was the long stems of the Haverlands thrusting themselves right square in the paths in order to get sunshine to ripen. I believe Mr. Terry proposes to make the paths, especially through the Haverlands, a little more than a foot wide hereafter. Over in the field beyond the fence we saw the wonderful crops of wheat -35 or 40 bushels to the acre, right straight through the field. There are notrees on Terry's premises, except around the house. He does not tolerate a tree in his grain-fields at all.

A gravel walk led around to the front door, and a gravel driveway on the other side of the lawn led around to the rear of the house. Friend $T$. has a gravel bed, or bank, on his own. farm, and therefore it is not a very expensive matter to have neat gravel walks all about his home. The painters had also been at work about the house; and when I suggested that most of us would think that it did not really need painting, he remarked that it was cheaper to paint before buildings really needed it, in the common acceptation of the term; and there we have the same story over and over again all over friend Terry's premises. Every thing is done before it begins to suffer from lack of attention. The weeds in the strawberrybeds are killed before they get to the top of the ground. His fourteen-acre potato-field is tilled in the same way, even during this remarkably wet season. The potatoes stood so regular through the field that one might think they were spaced by machinery, which, in fact, they were, by the machinery of the potato-planter. Instead of there being hills of potatoes, however, there was a single stalk standing up like a little tree, each one just like its neighbor, as in the strawberries. This comes from the "single-eye" idea. If we let a great lot of sprouts 
grow in one hill, it is like having eight or ten stalks of corn in a hill-you have only nubbins instead of fine large ears. This single potato-stalk produces only a few potatoes; but as these are not crowded at all, they are large, fine-shaped ones; and his potatoes, like his strawberries, command an extra price. Some time last fall I sent friend Terry an order for 25 bushels of potatoes, to be kept for seed. I was too late. They were sold out, and I was astonished to learn during this visit that 280 different people sent money for potatoes, after the potatoes were gone. That is worse than any thing we have done-or better, whichever you choose to call it. The receipts for strawberries during the day I was there were something over $\$ 23.00$.

When I mention about friend Terry's farming, many people reply at once, " Oh, yes! friend Terry has got money, and can afford to hire all the help he needs."

Now, this is a sad mistake. One great feature of Terry's farming is to manage with the very smallest' amount of help. If I am correct, he has only one hired man, aside from himself and boy, and the assistance his wife and daughters give in berry-picking. Many people ask, with wonder expressed in their eyes, "Why, do Mr. Terry's daughters work outdoors in the strawberry-beds?" Yes, my friend, they do. After they had finished their education, they, like most young ladies, wanted something to do. They might teach school, clerk in the store, or perhaps find a situation in an office in some of our large cities. They preferred to stay at home, however, and work with their father, rather than be "bossed" by some one who is not their father. Do you blame them? Their father suggested that they raise strawberries, instead of teaching school; and I think they are getting more money than most schoolteachers. I did not see them picking strawberries when I was there, because it rained. As they were living at home, and working for their father, they could work when they chose. I looked several times longingly at the beautiful large piano that has recently been purchased, and which stood right in sight; but so 
many important matters crowded I hardly dared ask them to treat us to some music. Now, I suppose women-folks should be free to choose an occupation, just as men are; but if it were myself, or if it were my daughters under consideration, I should say, "Give me strawberry culture a hundred times over, rather than schoolteaching or any of the other employments open to women-folks." When I mention these rural pursuits, and the wonderful success some have met, the constant objection raised is, that the markets are frequently overstocked. Strawberries a week ago sold in our town at 5 cents a quart. Ours, however, when freshly picked, at the same time brought 8 cents readily.

When I was there, the Gandy had just begun to bear. Friend $T$. had taken a sample to Hudson, and they brought a dollar a peck, without any trouble. No wonder, for they looked like luscious peaches or plums, more than like strawberries. As we stood by the buggy, ready to bid our friends adieu, I ventured the remark, "Friend T., why don't you have 14 acres of strawberries instead of 14 acres of potatoes? They would not be very much more trouble, and then, think what a lot of money you would have."

He shook his head, and smiled. I don't remember just what he said, but it conveyed an idea to me something like this:

"Fourteen acres of strawberries would make my home a thoroughfare. Its quiet and sanctity would be invaded. My wife and daughters, instead of having this quiet pretty home all to themselves, would have seclusion and peace no longer. It is true, I might make more money; but I am not working for money. It is not the end and object I have in view. I am a farmer, and always expect to be one. I love my work because I am enabled by it to demonstrate what farmers' homes may be, compared with what many of them are at the present moment I want to see farmers' boys and girls find something to do at home on their farms. I want them to love the farmer's home, and to feel proud of it. I want them to find peace, com- 
fort, contentment, where too many of them have found only drudgery, privation, and long hours of toil. I want them to work at home on the farm, and to learn to lay up treasures in heaven, as well as treasures on earth; and I want to show them the buried treasures that lie unused only a little way below the surface of the soil-just below the surface of so many farms, where at present we see only an unsightly and dreary waste of weeds and disorder."

Now, my good friend Terry did not say any thing of the sort. He is not as talkative a man as I am, and he did not say very much about it, only that he did not want 14 acres of strawberries, with their attendant care and bustle. In going all over the premises, all over his home, and talking with his wife and children, one was impressed at every step that he is not bent on making money. It seems, however, that the kind Father has provided the money. That little text that has been for so many years a hobby of mine, explains it all: "Seek ye first the kingdom of God, and his righteousness, and all these things shall be added unto you." So long as friend Terry is working with all his might and main to emancipate the farmer from the drudgery of ordinary farming, God will see to it that he has the wherewith to do his work. Moody once said that he believed that God would furnish his ministering servants with the wherewith to carry on their work. I said, as soon as I heard it, "I, too, believe it is true."

Before I left I told my good friend, that, although there were to be more chapters to the strawberry-book, he could have his pay for what he had done, just as well now as at any other time; and I added something like this:

"Friend T., I have been having many heavy cares and burdens to bear i uring the past few months; but I am glad to be able to say that lack of funds has not been one of the burdens."

He replied :

"Thank you, Mr. Root; but I do not need it. A lack of 
funds has not cramped me and troubled me in my work either; " and a pleasant look on his face impressed me with the thought that a spirit of thankfulness to the great Giver above was in his heart as well as mine, and gave an added enjoyment to his work.

We bade adieu to that pleasant home. The surrounding homes for quite a little distance seemed to have caught friend Terry's spirit, for they were well-to-do, progressive farmers; but the potato-fields right over the fence from friend Terry's were as different from his as any thing you could well imagine. Notwithstanding this, they were rather better than any thing we had seen in our drive of 25 miles across the country. I looked in vain on this side of the road and that, but no such farming greeted us anywhere as we saw there.*

We took a different route home. You never see me going the same road twice, if I can avoid it. At Cuyahoga Falls we called on the veteran strawberry-man, Mr. Matthew Crawford. Friend C.'s whole business is strawberries-not raising them for the market, but testing the different varieties, and raising plants for sale. I saw something there which I had never seen anywhere else, and perhaps I shall never see it again-little beds of two or three rows, of all the kinds of strawberries known. In some places great luscious berries were rotting on the ground. When I remonstrated, he said so many were coming daily to discuss the different varieties that he left a few so as to be able, during the season, to furnish specimens of deadripe fruit. I mentioned ever so many kinds I had heard of, but I was promptly led to the very variety in question, where I saw it doing its best. Friend Crawford is a devoted, faithful Christian. In fact, it shines forth in his face, looks, and ac-

* Later. - Since our visit I have received the following on a postal, fiom frit nd Terry :

Well, it dried off Saturday, so we sold 10 bushels of berries, $\$ 26.00$; and Monday 13 bushels, $\$ 36.55$. Not quite so thick to-day, but we got a bushel of Gandy's Prize, that sold for $\$ 4,00$. I had a photo taken. The Gandy will not hold out long.

Hudson, 0 ., June 24 . 
tions. As my paper is getting long, I shall be obliged to pass over this visit briefly. As an illustration of our talk I will give the following :

"Friend C., will you please show me the largest berry known?"

"With great pleasure, Mr. Root. But do you really think you want to invest in the largest berry known?"

"Why, surely. If it is a good one, why should I not?"

"Yes, it is a good one-that is, fairly good. Come and see."

He parted the leaves, and there, to my great astonishment, was an immense fruit that I should hardly have called a strawberry had it not been for the surroundings. Instead of being like other strawberries, it was much the shape of a very badly scalloped tomato; and I declare, the berries were pretty close in size to some tomatoes. I picked a great big one and took a bite. The quality was very much like that of the Bubach; but there was not a single specimen that was not knotty and gnar$1 \mathrm{y}$, with protuberances growing out of one side or out of another. At first I declared I would make a planting of it; and then it occurred to me that everybody would object, and prefer something a little smaller, of good shape, and firm enough to ship-something like the Gandy for instance. If one wanted, however, a great lot of berries, and something that could be picked very quickly, I rather think this would be the berry. My companion told me that he had found ten of them that would make a quart, and he thought it very likely that he could do it then and there. As 1 ts shape suggested tomatoes I asked:

"Friend C., why is it not probable that some time we shall have a single strawberry combining so many of the desirable qualities of others that only one variety will be needed-like the tomato, for instance?"

"I have thought of it a good deal, Bro Root; and, by the way, I am very much rejoiced to know that we have finally one tomato summing up all the good qualities to such an extent that 
no other is needed. I am myself, at present, planting only one kind of tomato, and it seems now that I may never care to plant another kind."

I almost held my breath as I asked, "Why, friend Crawford, you astonish me. Will you please tell me the name of that one tomato that you put in place of all the long string of tomatoes known to seedsmen and catalog-makers?"

What do you think he said? He smiled just a little as he replied, "The Ignotum."

I did not at the time know whether he was aware that I first gave it to the public, but he said he had heard it so stated.

"Now, Bro. Root, I have something to tell you that will greatly please and interest you. I do wish you could meet friend Little (of Granton, Ont.), who gave us the great big strawberry you hold in your hand, and he has given us almost numberless other valuable strawberries. You will notice that I have nur:bered them in different places over my ground-No. 4 , No. 8 , No. 75 , etc. Well, friend $L$. is a Canadian. Some years ago he was very low with consumption, and his case was pronounced by nearly all the physicians incurable. There was nothing before him but to get ready to die. As he was a good man, and a most devoted Christian, his friends could not bear the thought of losing him, and his children could hardly give him up. A son of his was interested in strawberries, and he begged his father to stay outdoors and get interested in berrygrowing, suggesting that, if he should get as full of enthusiasm as some of them did, it might make him well." I began at once to think of our good friend Mrs. Axtell.* "The father very quietly assented, and placed himself as pupil under the son. In a little time he became deeply interested in the matter of perfecting new varieties. At present he has done more work of this kind than perhaps any other man in the world; and this season," so our friend Crawford went on to say, "he has a whole half-acre covered thickly with plants, and each plant is 
a different seedling from its neighbor. These are to be tested, with the hope that they may furnish the world something better than we have already." Those who have made experiments in this line can conceive how much of an undertaking is such a project; and the outcome of it has been that he has regained his health; and although he is quite an old man now, he will probably live some years yet. So you see it is not only worldly gifts which shall be given to those who seek first the kingdom of God and his righteousness, but the promise seems to include health; for friend L. has found a new lease of life in propagating new and better varieties of strawberries for his fellowmen. I do not know whether he is rich or not. It may be that, like Terry, he does not care to be rich, but holds fast to the text of our talk to-day.

Lay up for yourselves treasures in heaven, where neither moth nor rust doth corrupt, and where thieves do not break through nor steal.MATT. $6: 20$.

PUTTING OUT STRAWBERRIES IN THE SUMMER AND FAII, MONTHS.

Friend Terry has told you all about spring planting; and he has alluded to setting out plants in the summer, and especially in August. I am very well aware that, as ordinarily managed, there is much disappointment and failure in planting in August. 'But as I have had several years' experience in the matter, I think I can give you a plan that will be successful with any one, and under almost any conditions, providing you raise your own plants or get them near by, so that they are out of the ground not much more than 24 hours. I do not mean to say by this that you can not order plants long distances in August and still be successful, for very many do this ; but it requires the skill and judgment of an expert. Potted plants are pretty sure to work all right, but they cost quite a little more ; and as they are bulky, the express charges are considerable if you purchase any number. I will first explain to you the idea of potted plants, as it paves the way, as it were, to my invention. 
It may seem a little strange, but I shall have to confess that I had eaten strawberries and raised them a good many years, before I was even aware of the way in which the plant is propagated. Let us suppose that you have a single strawberryplant, say in the month of April. You plant it out in good soil, keep the weeds down, keep the ground mellow around them till it begins to put forth leaves and enlarge. Pretty soon you will notice a crown, or a larger bud, starting up from the center. This puts forth a fruit-stalk with blossoms. Not long after this, most varieties will send out an occasional runner. The runner looks exactly like the stem of a leaf, only that it is much longer and ends in a bud, as it were. There are also embryo leaflets at certain distances, making joints, so to speak. These runners grow from a few inches to a few feet in length. They start along the ground, as if their plan and purpose were to get as far away from the parent plant as possible. Finally the bud on the end of the runner sends up little leaves like the parent plant; and from the under side, little white roots go down into the soil. If the ground is hard and the weather dry, these little white roots sometimes have much trouble in getting a foothold. Where plants are wanted, you can assist them greatly by keeping the soil mellow, and still more by laying a lump of dirt across the runner, just back of the plant. A iump of good old stable manure is much better than a lump of dirt; for when a warm rain comes, the strength of the manure will go right down by the new little roots. When every thing is favorable it is absolutely wonderful to see these little roots push down into the soil and get hold so as to be independent of the mother-plant. Now, if this little plant is made to root inside of a small-sized pot, such as is used by florists, we have a "potted" plant. The pot should be filled with rich soil or compost. Set it in the ground right under the plant; lay a little stone, lump of dirt, or a chunk of manure, as comes handy, on top of the runner; and in ten days, or even less, the roots will so fill the pot as to be just a solid ball or mass of roots. See cut. 
A B C OF STRAWBERRY CULTURE. 131

Now, there is something wonderfully fascinating to me about this matter of plant growth. If you want to see how fast your plants are rooting, you can lift the pot out of the soil at any time, even while attached to the parent plant by the runner. Put your fiugers across the plant, one on each side;

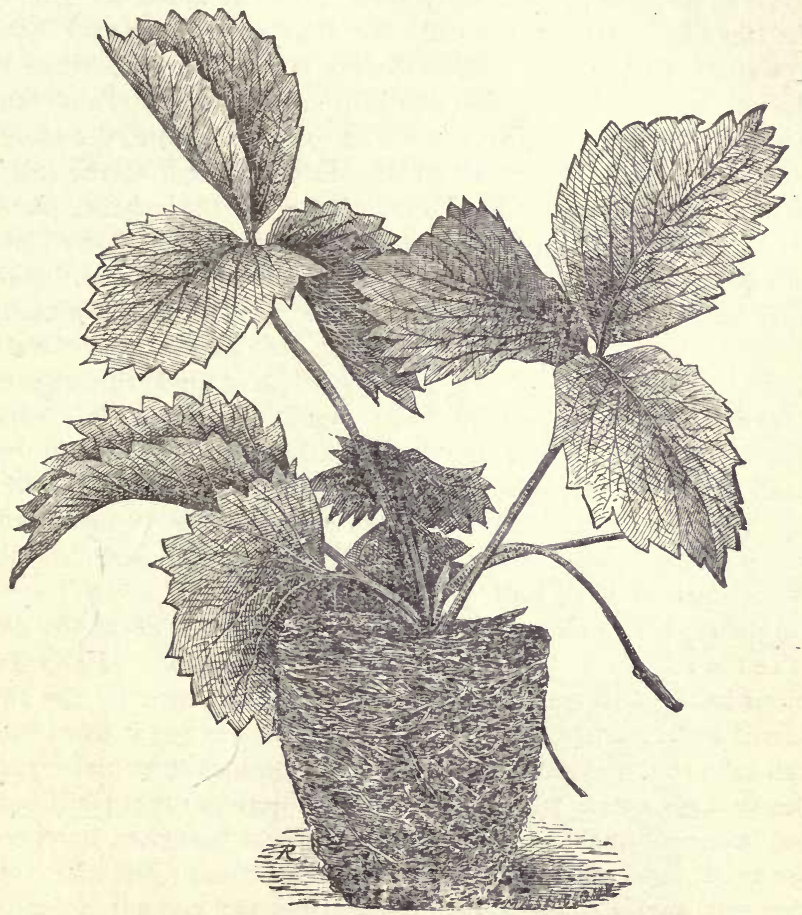

A POTTED STRAWBERRY PLANT AS IT LOOKS WHEN TURNED OUT OF THE POT. 
carefully turn the pot over, and knock with your trowel on the edge, and out will come plant, roots, dirt, and all, just as it looks in the cut. You can look at your plant every day if you wish, and see when the first white roots reach the outside of the pot. Then you can watch them night and morning, and see how fast the little roots grow. This frequent bandling will do them no harm, providing you do not let so much air get to the roots as to dry out the soil. In that case you would have to water it frequently. When the pot is filled with roots, as in the cut, or even before, you can clip off the runner, and your plant is independent. If you are in too much haste, the infant plant may not be able to stand the scorching heat of the sunthat is, after severing the connection with the mother-plant. On this account, pots are frequently moved to some shady place and watered until they get thoroughly " weaned," as gardeners term it. They can then be put out in the field. How many such plants can you grow from one old one, do you ask? Well, there is hardly a limit. The variety of plant, and the expertness of the operator, would have much to do with it. I frequently have had one dozen fine potted plants growing around a single old one all at once. We spread out the runners like the spokes of a wheel. This same runner, after it has made one plant, will start right out to make another, and so on. Sometimes we have balf a dozen plants strung along from a single runner; and when you take up a potted plant you can take the runner with the attached plant beyond it. If the first plant has a good mass of roots, like the one shown in the cut, it will sustain and keep alive three or four beyond it until they can take root and sustain themselves. Besides this main runner that goes straight ahead, a strong vigorous runner will send out branches at the different joints. These branches, however, are small, and not as strong as the main runner; but with very rich soil, such as I am going to describe, you can get splendid strong stocky plants, even from these secondary runners, if it is a choice variety that you are anxious to propagate. 


\section{A B C OF STRAWBERRY CULTURE. 133}

HOW TO GET LOTS OF STRONG, VIGOROUS YOUNG PLANTS.

We will suppose you have some rows of strawberries from which you wish to get plants. If they are planted 4 feet apart, and 2 feet from plant to plant, as friend Terry directs, you are fortunate. If they are nearer by, it is not so well; but you can get along, even then. If the runners have already commenced to take root, loosen the plants with a trowel, and swing them around so as to give you a chance to run the cultivator between the rows. Now keep your horse going back and forth until the soil is as fine as the dust in the road, or pretty nearly that. Now get some old fine manure or compost-the best you can get hold of, and work it into the soil. If you can afford it, put in a wheelbarrow load to every two rods; then cultivate some more until it is all mixed up. Rake the surface down flat and level, then cover it with ashes an inch deep, if you have the ashes. If not, put in hen manure pounded up fine; manure from pig pens; peat from the swamps, or any thing else that is good to make things grow. Now bring your runners back and put them down in this rich soil, fixing each one in its place as I have described. If you want to grow potted plants, put a pot under each runner. Keep out the weeds and spread the runners, spacing them judiciously as fast as they shoot out and you will have plants to your heart's content. Fix as many rows in this way as you wish plants. If you have only a small bed you can do it in the garden with a rake, hoe, and spading fork.

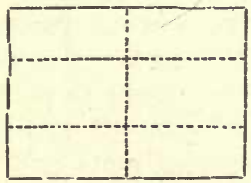

HOW TO CUT THE TIN.

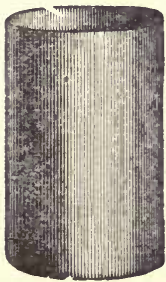

TIN TUBE FOR TRANSPLANTING. 
When your plants are well rooted in the ground, instead of in the pots, you are ready for my invention.

Provide yourself with several sheets of extra heavy IX tin, size $14 \times 20$ inches. Get a tinsmith to cut each sheet into six pieces, exactly alike, as indicated in the cut.

Each of these pieces will be about 10 inches long by $4 \frac{1}{2}$ wide. Have the tinsmith roll them, locking the joints so as to make a tin tube or cup, without top or bottom, as shown.

If you wish to try them first, you can make only a dozen, but for practical work you ought to have a hundred or more. Set these transplanting-tubes in a tray, something like the one shown below.

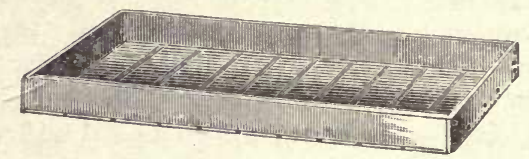

SHALLOW BOX FOR HOLDING TRANSPLANTING-TUBES.

Put about two boxes of tubes on a wheelbarrow, and go to the patch of plants we have been talking about. Remember, you can do your transplanting right in the midst of the most severe drouth. You do not need to wait for rain at all. If the ground should be very hard, however, it will be convenient to have water near by, to moisten it, so the tubes may be pushed down easier. If, however, the ground where the plants are growing has been thoroughly cultivated, this will not be necessary. To use them, gather up the leaves of the plant; and if a runner extends beyond it that has not rooted itself securely in the ground, gather this up also with the leaves. Push the tube over the leaves, and then force it into the ground so as to cut off all attached runners, and down into the soil perhaps half its depth. By tipping and turning it you will easily see when it is deep enough to take up the plants, roots and all. You should push down about half its depth; and if the plant is a good strong one, you will see the roots protrude through 
the soil below as you pick it up. Our boys use a short stick to lay across the top of the tube, so as not to hurt their fingers. As fast as the tubes are filled with plants, set them back in the tray. When you get a wheelbarrow load, take them to the field, or where you wish your new plantation. Before going further, however, I wish to tell you how I fix the ground for putting out these plants.

PREPARING THE GROURD FOR SETTING OUT STRAWBERRIES, IN SUMMER OR FALI.

My favorite ground for this purpose is the piece where we took out our early potatoes. These come off by about the middle of July. A month later we can have the piece of ground where sweet corn has been gathered. But any good ground will answer where some crop has been taken off. We first work up the soil fine and mellow, with a cultivator, or, better still, a cut-away harrow. Then we draw on stable manure at the rate of forty or fifty loads per acre. In fact, we put on just about as much as we can plow under. After plowing we harrow again, and roll until all lumps are mashed, and the ground is fine and mellow. Then if we can we cover the surface with fine old well-rotted manure, put on with a manure-spreader, and this is also worked in with a cut-away or Acme harrow. If we can get hold of a dozen loads of ashes we spread them on with a manure-spreader. Last of all, I harrow the ashes in likewise. Now roll it, picking out all stones larger than a hen's egg, in the act of rolling. In fact, we continually pick up stones in this way until no more are to be found larger than a hen's egg, or even smaller than that. The ground is now ready to mark out for strawberries. I would mark it as friend Terry does, with rows four feet apart. We use what is called Darnell's patent furrower and marker, for this purpose. As you may not be familiar with it we submit a cut of the machine here.

You will observe the machine is kept steady by a pair of iron runners, something like sled-runners. The metal disks 
must not be set so deep as to carry too much of the weight of the machine, or it will make it dodge about. With practice, a light mark, or even a deep furrow, can be made absolutely straight, and exacily the same distance apart. The disks being

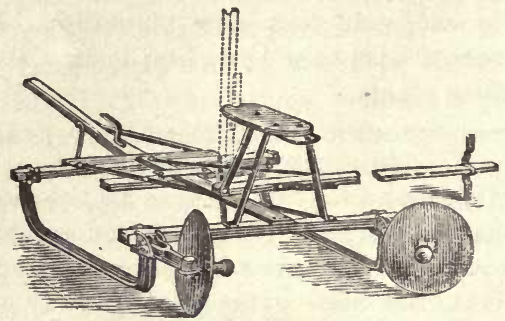

DARNELL'S FURROWER AND MARKER.

For prices, etc., address H. W. Doughten, Moorestown, New Jersey.

adjustable both up and down, and at any angle, you can make the furrow of any depth you wish. The machine can also be used as a coverer for covering potatoes or similar crops. We are now ready for our wheelbarrowful of plants. Put the tin tubes in the furrow so as to bring the plaut just as deep as it stood originally. If you are going to set toward an acre or more, the same machine shown here can be arranged so as to throw the dirt up around the tubes very nicely. Now comes the problem of getting the tubes off quickly and without disturbing the plant. It cost me more thought than any other part of the invention. We now accomplish it as follows :

A boy follows with a watering-pot, and fills the unoccupied part of the tube with water, say a teacupful at each plant. After he has watered perhaps two dozen, another boy follows him, and, by taking hold of the tin tube, and shaking it a little, plant, dirt, and all, slip right through. If you wait long enough, the contents become soft, almost like mud. Now draw a little mellow soil over the wet ball of earth, and there will be no baking, even if the sun shines directly on it. Your young plant has also had water enongh to keep it moist for several 


\section{A B C OF STRAWBERRY CULTURE.}

days, if covered with the fine rich soil, and if carefully dove there need be no losses whatever. I asked my wife to see whether she could find a missing one in a plantation of about 3000 plants. She finally thought she had found one that was dead. But I opened the dead leaves, and showed her a green leaf just started out. Where there is a runner attached to the plant, carry it off to one side, but in a line with the row of plants. Lay a lump of dirt on it and it will very soon be a good plant itself. We frequently have two such young plants, one carried to the right and one to the left; and they are just about as sure to grow as the mother-plant that was in the tube. In fact, plants taken up in this manner will send out runners within three or four weeks, and behave themselves very much like spring-set plants; and you have had the use of the ground for a crop of corn or potatoes. Another advantage these tubes give is, that enough rich soil or compost is carried from your plant-bed or nursery to give the new plant quite a start. It answers every purpose of potted plants, and yet you do it all at one operation-that is, you get your plants and set them out and have it all done in one day. We have never found any shading needful, even during the hottest summer day. Various other plants can be worked in much the same way. In every other respect I most thoroughly indorse friend Terry's instructions and methods. As he is a farmer it is more convenient for him to enrich his ground by turning under clover, and planting in the spring, while we as market gardeners prefer enriching our ground with large quantities of stable manure, and putting our plants out after our first early crops are off the ground.

\section{INSECT ENEMIES TO THE STRAWBERRY.}

We have never yet found any thing on our grounds, in the line of insects, injurious to the strawberry ; and for this reason nothing has been said in the book in regard to insect enemies. I am told that the white grub that preys on the roots of gra: $s$ is sometimes very destructive when strawberries are put on freshly turned sod. We have had no experience with it here. 
The only objection that has ever been made to the transplanting-tubes is that they would carry insect enemies or disease along with the plant to a new plantation; whereas if the roots were washed thoroughly from all adhering soil, as friend Terry directs, we should overcome this danger. Where the plants are taken from poor hard ground, I have sometimes found the ball of earth an objection; but this could be broken up with the fingers, after the plants have got well started. By far the better way, however, is to have your ground very rich where the plants are grown on purpose for taking them to the field.

\section{DISEASES OF THE STRAWBERRY.}

I do not know of any disease, unless what is termed "rust" may be said to be a disease. This belongs to certain kinds of strawberries, and not to others; and sometimes a variety will rust in one soil or location where rust is unknown in another. I hardly need tell our readers that rust is the reddish spots that appear on the leaves. They appear like iron rust, and sometimes they injure the thriftiness of the plant very materially. The varieties recommended in our book are almost rust-proof; that is, they are almost if not quite absolutely free from rust in most localities. Sometimes during a severe drouth the leaves curl up, something like the curled leaf on the peach; but with plenty of rain the new leaves that come out, and the new leaves from young plants, are as bright and straight as any. Lack of water is generally at the bottom of most difficulties with the strawberry; and plenty of water, accompanied with plenty of manure, will usually overcome any trouble that may show itself.

Perhaps I should add something to what has been already said in regard to irrigation for strawberries. While I agree with friend Terry in regard to what he said about irrigation,I feel quite sure that irrigation will many times pay in getting plants to set out in the field. A windmill and a tank answer excellently for this purpose. A few days ago a neighbor sold me some very nice blackberries. He said he was going home 
to draw water in barrels placed on a wagon, to water his halfacre of blackberries. I asked him if he felt satisfied that it would pay. He said he had practiced it a good many years, and it had paid big, and that he would, without doubt, lose $\$ 50$ on blackberries if he did not water them to prevent them from drying up. While visiting friend Terry's I remembered that he had his blackberries and raspberries, as well as his strawberries, mulched with straw so as to cover all the ground between the rows perhaps a foot thick. It at once occurred to me that straw mulching would be cheaper, probably, for a man who raises wheat, than to draw water in barrels. I wrote him, making inquiry, and here is his reply:

Friend Root:-The straw mulching on raspberries and blackberries worked to our perfect satisfaction. Every raspberry ripened up plump and good, although it was so dry that wild ones amounted to but littlesoon dried up. We had them in abundance some days over three weeks. The same is holding true of blackberries. We have been picking nearly three weeks. Most of them are good size. There are many on the vines yet. We have picked nearly a bushel to-day; and I think never a day since we began, less than 20 quarts. I never had such a feast of berries before. There are no weeds or grass growing through the straw. The berries are evidently not feeling the drouth to amount to any thing. From about 35 or 40 rods of land we shall get raspberries and blackberries that could have been sold for $\$ 120$. We have had to sell a part, as we could not use them all.

T. B. TERRY.

Hudson, O., Aug. 11, 1890.

\section{A BOX OF GANDY STRAWBERRIES.}

On pages $57^{\circ}$ and $58 \mathrm{I}$ have, in a footnote, alluded to a pint box of Gandy strawberries. After showing this sample box to Mrs. Root, I took them over to the factory, and they were so much admired that I decided to have them photographed. Before I got it done, however, my box was tumbled down, and the berries spilled out, in consequence of assisting a young lady to handle a horse that had become frightened. I picked them up as best I could, but tried in vain to replace them in the box with the freshness and beauty they exhibited when I first laid them there, as picked from the vines. I de- 
cided, however, to have the photograph, as it was toward the close of the season, and there was no chance of getting any better before the book was put out.

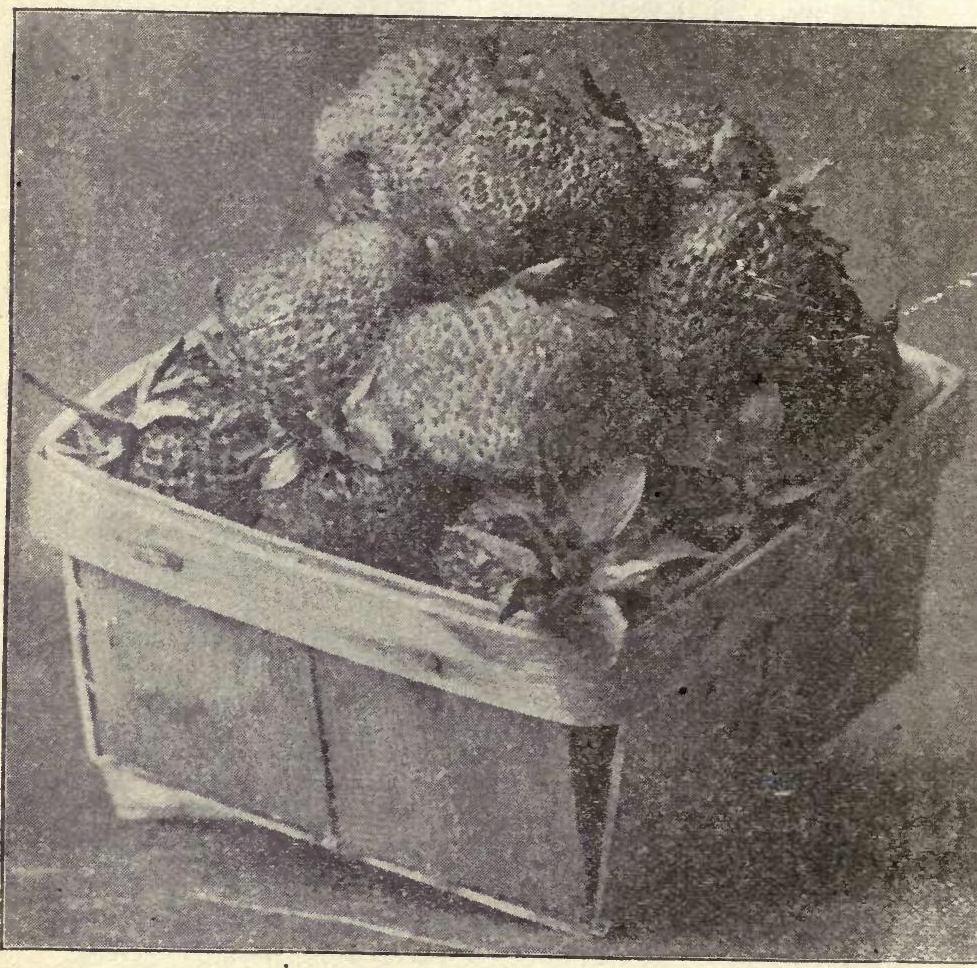

A PIN'T BCX OF GANDY STRAWBERRIES. 
A characteristic of the Gandy strawberry is the large bright-green sepals around the fruit-stem. This green contrasts so finely with the shining scarlet of the berry that it looks like a beautifully colored picture. These sepals also, on account of being unusually large, keep the betries apart in the basket so as to give them air, and prevent bruising. The berry at the corner of the basket in the cut shows particularly this feature. See also cut of Gandy on page 53.

THE VALUE OF STRAWBERRY PLANTS TURNED UNDER.

On the 15 th of July we plowed under a bed of Sharpless strawberries that had borne an $\epsilon$ xcellent crop of fruit, and had made a prodigious growth of foliage, runners, etc. Before turning them under, however, the ground was covered with a heavy coat of stable manure. With the manure and vines together, the plowman had considerable trouble in getting them all turned under nicely. In fact, a man had to follow (with a hoe or similar tool) to push the tangled vines from under the plow-beam. When it was all turned under, however, it was harrowed and rolled until fine and compact. Then a heavy coat of ashes from our steam-boiler was put on. These ashes ке e mostly coal. Considerable basswood and pine, however, goes in with the coal. In order to get out the coarser portions we run it through a sieve, or riddle, such as is used for sifting sand or gravel. These ashes were put over the surface, from one to two inches deep, and harrowed lightly into the mellow surface soil. In this we sowed, the same day, radishes, lettuce, and turnips. Well, on the 15th day of Augus', just thirty days from the day the seeds were put in, beautiful radishes were ready for the market-in fact, the finest I ever saw. A nice shower fell soon after the seeds were sown, and the ashes bad sufficient strength to destroy all insect enemies. Not everi a flea beetle punctured the first leaves of the young radicles. They grew with a rich dark green, and a rapidity I never saw them grow with before. Neither have I ever had good-sized radishes fit for market in just thirty days, 
before. The varieties were Early Frame, Chartier, and Chinese Rose. The roots were beautiful, glossy, scarlet, straight, and true. In fact, we could easily have made a bunch of Chartiers equal to the colored plates sent out by the originator. The Early Frame may have been a little ahead of the Chartier; but three days later, the Chartiers were much larger and finer. In three days more (thirty-three in all) we had Early Bloomdale turnips fit for the table. They, too, were wonderfully handsome, both radishes and turnips being crisp and sweet, far beyond the ordinary. The Grand Rapids lettuce was also fit to put on the market-wagon in thirty days. Of course, it did not make large heads in that time, but the leaves were as large as one's hand, and the plants made very fine basket lettuce. How much of this is due to the strawberry-plants and how much to the manure and how much to the ashes, we can not tell; but I think just about the combination was needed for the results noted. Mr. E. C. Green, of the Ohio Experiment Station, looked them over yesterday, and he said he had never seen any thing to excel it in the way of a crop, in only thirty days. It should be remembered, that the ground was our best creek-bottom ground that had been enriched and worked over for the past four or five years.

Adjoining the above patch are some of our rows of strawberries which were also put out with the transplanting-tubes on the 15 th of July. We did not think best, however, to put strawberries where strawberries had been the season before. These strawberry-plants, in thirty days have sent out runners and made little plants so that some of them are well enough rooted to bear removing from the parent plants ; that is, by the aid of the tubes. Now, these few results give one a glimpse of what is possible in market-gardening, as well as in strawberryraising. In forty days the radishes can easily be cleaned off, and another crop of something else can be turned off before winter. I am planning to transplant some of the Grand Rapids lettuce where the radishes are taken off, and thus get large 
heads before winter. With this high-pressure treatment, manuring, and tilth, there are quite a few crops that can be taken off the ground in forty or fifty days. The energetic, go-ahead gardener should have them off promptly the very day the crops have arrived at their best, and more seeds or plants should take their place within one hour. I know from experience that it is a very hard matter to push things like this; but I tell you, friends, it pays.

On another piece of ground, when I saw the crop had almost reached maturity I allowed the weeds and purslain to grow for a while. It did not take the weeds more than a week or ten days to cover the ground with a wonderful growth while the crop was ripening; and just as soon as the crop was removed, weeds, tops, and all refuse matter were plowed under. In doing this, you want to be careful that no seeds of purslain or of any thing else have become matured enough to grow; for if you do you will seed the ground with weeds. Keep your eye carefully on the weeds, and a good many times you can have a heavy growth to turn under, almost as well as not. Be careful, also, that this heavy growth does not take away any thing from the maturing crop. A great many times it is better to wait a little until the crop is mature enough to be gathered, rather than to undertake to clean out the patch from weeds, etc, just before maturity. In fact, the nicest way in the world to make sure with purslain is to turn it under out of sight. Keep the cultivator going, however, so that no chance sprig stuck up through the dirt shall get on top of the ground and grow again. At this season of the year (Aug. 21), if any piece of ground, enriched as we have ours, is left idle for a week or ten days, he weeds will make their appearance. I would rather have the cultivator go over the ground, say once in five or six days, if we can manage to have it. And this reminds me t'. at we are in the habit of using the Acme cultivator in the same way that friend Terry uses his harrow arrangement shown on page 66 . We go through with the Planet Jr., just as he does. Then in 


\section{A B C OF STRAWBERRY CULTURE.}

two or three days, or sometimes right away after, we go over the ground with the Acme. This can be run close up to the leaves of the strawberry-plants without doing them injury. It simply pushes aside every leaf without cutting them off, and it leaves the ground very fine and level.

SELLING PLANTS; DIRECTIONS FOR SHIPPING THEM EITHER BY MAIL OR EXPRESS.

As I have before hinted, we do quite a business in sending strawberry-plants by mail and express. We often send them. out in March, and continue until June, or until the plants are bearing fruit. When the season is favorable we commence again in the middle of July and send them out until the ground is frozen-say November and sometimes into December. The plants are taken up with a trowel, and all the dirt shaken off. The roots are then washed and tied up in bundles. To keep them from wilting, we use sphagnum moss. This moss is found in the huckleberry-swamps of Obio and many other States. It has the peculiar property of never heating, even when quite wet. In fact, its native place is a damp swamp, sometimes covered with water for quite a period. Your moss, however, must not be too wet when put around the roots of the plants. The best rule I can give for getting it just right is to take a double handful of it, dip it in water if not already wet enough, then squeeze out every drop of water you can get out with your hands. Now put it around the roots, and tie them as tight as you have a mind to, leaving the tops exposed. Before tying them up, pull off all dead leaves and runners; and if the top is very large and the root rather small, pull off the largest outside leaves. Girls or women will do this very rapidly and nice1y. Now, in case there should be a severe drouth at the time, and the plants are going to be out some days, the whole should be wrapped in oiled paper or enamel cloth to prevent evaporation. Outside put some manilla paper on which the address is written; but let the leaves be partly exposed. In taking up your plants at a dry time, unless your soil is very loose and 
highly enriched, as I have directed, the ground should be watered until it is soft enough so that all the roots can be preserved. Do not send anybody plants with mutilated roots, caused by pulling them hastily out of the hard soil. The purchaser is entitled to every root that belongs to the plant.* On page 21 is a picture of a good plant. This, however, has been trimmed. In sending them out we do not trim them. We leave our customer to suit himself in regard to trimming.

STRAWBERRY CULTURE AS AN OUTDOOR INDUSTRY FOR THOSE IN POOR HEALTH.

On page 128 I have told of one who was restored to health when the doctors could give him no help. I do not know of any other plant that grows that one can work with, propagate, and see grow almost every month, when the ground is not frozen, like the strawberry. As cold weather comes on, confine your operations to a piece of ground protected by hills or buildings, or both; and if you still wish to have them make runners and start plants, cover your bed, or a portion of it, $w$ ith $_{\text {is }}$ sash, when the frost is severe. Whenever the weather moderates so as to enable you to move the sash safely, do so; and whenever it rains, the sash are better off than on. By taking pains you can see them thrive almost all the year round, and you will have your reward in getting fruit a month earlier than those not protected. Of course, by the aid of artificial heat you can make them bear fruit in the winter time; but this is a more difficult operation.

Mr. Terry has also several times alluded to the benefits to be derived from outdoor work in successfully growing strawberries.' We take the following from Vick's Magazine, in regard to gardening for those in poor be 11 th :

* See the following from one of our customers :

The 200 Jessie and 50 Bubach plants are at hand, and set out. They could not come in a better shape. You certainly deserve every order sent you, if treated as mine was All are living, and I am satisfied with your exertions to do as you would be done by. Thasks for the few extra ones.

Forest City, Mo., Aug. 20.

GEO. W. BALDWIN. 
"One will seldom or never be disappointed who turns to the garden for recreation, or who seeks there the building-up of over-wrought nerves, or who would follow out to discovery some of the innumerable secrets of the vegetable world, that are to be found by the earnest and patient observer. It is the place for at least an hour or two every day for women, as a change from household duties, or professional men, editors, merchants, clerks, and all who may be engaged in indoor, and especially sedentary employments ; more or less garden work should be engaged in every day, and by every member of the family, whenever it is possible."

GETTING A CROP OF STRAWBERRIES IN THE FALI, EVERBEARING STRAWBERRIES.

When we have abundant rains in August and September, especially after a severe drouth in July and the fore part of August, many varieties of strawberries will put forth blossoms, and sometimes ripen a limited quantity of fruit during the last of September and October. The Jessie strawberry seems to be especially given to this, and in almost every plantation of the Jessie you will find more or less berries and green fruit during the month of September. The Jessie is also particularly adapted for greenhouse culture or for getting berries in the winter time, on account of this peculiarity. A new berry just being introduced, called Michel's Early, also known in some localities by the name of Osceola, is also recommended for fruiting in winter. Our Ohio Experiment Station pronounces it the best extra-early berry we have. Now, my impression is that almost any strawberry may be made to give a small crop of fruit in the fall by timely irrigation. On Thanksgiving day, 1888, I was entertained by my good friend George B. Woudberry, of Verdugo, Cal., on strawberries and cream. The variety was the Manchester. He had half an acre in full bearing, and he managed it by the timely application of water on purpose to have his berries on the market Thanksgiving time. 
He made a nice thing of his crop, for he got $25 \mathrm{cts}$. per $1 \mathrm{~b}$., which is rather better than 25 cts. a quart. Within a few years the Everbearing strawberry has been introduced from Oregon, called the Oregon Everbearing. It is now on our grounds, and has been giving us some berries right along, but not as many as we get from the Jessie. While I write, Sept. 2, 1890, we have a small bed of Jessies full of blossoms, green fruit, and some ripe berries. They are set out in very rich plant-bed ground, and they have been watered whenever they lacked rain, so as to keep the plants in full vigorous growth. Some of the berries are of quite good size; and if I had a quarter of an acre of them bearing as well, I could put quite a quantity of berries on the market. During this season of scarce fruit $I$ think I could, without doubt, get from 20 to $25 \mathrm{cts}$. per quart, at the present time; and at this price it would have been a splendid investment. Where one has the time, and will take the pains, I have no doubt that strawberries can be very profitably raised for marketing at county and State fairs. Some years ago in the city of Indianapolis I saw very fine large strawberries offered for sale at $40 \mathrm{cts}$. a quart, in the month of October. I presume they were made to bear in this way. I have never had any experience with the Monthly Alpine strawberry; but from what I have heard I believe I should prefer to use the Jessie and Michel's Early for getting a fall crop.

\section{RAISING STRAWBERRIES UNDER GI,ASS.}

This is carried on mostly in our very large cities, where berries can be sold for about 50 cts. to $\$ 1.00$ a quart during Christmas time, and all along through the severe winter months. Any of you can do it if you are willing to take the necessary pains ; but it will not pay financially unless you can get something like the prices named above. The plan is, to get, by rich soil and excellent culture, very strong heavy crowns ready to put out fruit-buds. Let them remain outdoors until they are well ripened and ready for fruit. They should, however, be in 
pots, so as to admit of being brought readily into the greenhouse. At the proper time, put them under glass and give them an artificial spring; and finally, when the fruit is ready to ripen, increase the heat so as to give them an artificial summer. Large-sized berries will bring, if grown under glass, from 10 to $25 \mathrm{cts}$. each, according to the market.

\section{GETTING RUNNERS AND PLANTS, OUT OF SEASON.}

With new and rare varieties of strawbirries it is oftentimes quite desirable to get runners not only in warm weather, but to keep the plant propagating runners right along through the winter time. As I have never succeeded very well in getting plants to send out runners in the greenhouse, I wrote to the horticulturist of our Ohio Experiment Station in regard to the matter. Here is his reply:

Mr. Root:-In reply to your query as to whether we had been able to get strawberry-plants to throw out runners in the greenhouse, I will say that we have, but not freely. The fact is, however, that, if the plants are started in pots in the greenhouse, and then put out of doors when the season is sufficiently advanced, they will commence very early to send out runners. In the case of new sorts that you wish to propagate freely, you can cut the tips as soon as they form, and strike them in pots or in frames. This is better for the original plants than to allow the runners to take root; besides, you get more plants.

W. J. GREEN.

Columbus, O., March 22, 1890.

In conclusion, friend Green speaks of taking the little plants from the ends of the runners before they have struck root. We have several times done this, where it is desirable to get plants as fast as possible, cutting the runners off so as to get an inch, perhaps, on one side of the little plant. Then take off the largest leaves, leaving only two, or three at the most. Put the:e into very rich ground containing a good deal of sand, which is kept constantly wet, much as you would for cuttings Shade it from the sun with a frame covered with cotton cloth. This will also keep the air moist. If the temperature is right, and your soil is right, the largest part of these cuttings, or embryo plants, will take root in about week. If 
you once get them started there is no trouble. Sometimes we get a bed full of beautiful plants; but at other times the leaves decay and turn dark around the edges. We are, however, daily practicing this method of getting plants. At the present time we are short on the Haverland; therefore each day, when we take up plants for shipping, we preserve all the sets beyond the plant that have not yet made roots, and these are put out in just this way. In fact, we have been setting out more or less every day for the last month; and the greater part of them produce very fine plants in three or four weeks. Where there is not even a root started, by sufficient care we get a plant; but when there are little roots, say $1 / 2$ or 1 inch in length, the work is very much easier.

A LIST OF SOME STRAWBERRIES, BOTH OLD AND NEW, THAT ARE PROMINENTLY BEFORE THE WORLD.

Just as our book was ready for press we received the "Strawberry" number of the Orange Judd Farmer. In it we find cuts of 30 different strawberries favorably known; and through the courtesy of the editors we make a selection as seen on the adjoining pages. These cuts do not by any means give the true size of the berries, but only the form and general appearance. The cuts given by Terry in the fore part of this book are taken from nature, and are exactly the size of the berries he grew on his own grounds.

The Bubach and Sharpless have been described already.

Warfield has not been fruited on our grounds, but it is very highly spoken of. It is thought to be a seedling of the Crescent, and if, as claimed, it is ahead of it, it surely has a great future.

The Crescent, perhaps, is more widely known and raised than any other berry in the world, unless it is the Wilson. In fact, a new impetus was given to strawberries with the advent of the Crescent and Wilson. The Crescent has been called the "poor man's berry," because it will grow anywhere without 
care or expense ; and somebody has likened it to the Canada thistle as regards hardihood. It also produces an enormous quantity of fruit; but unless the plants are thinned out, and the ground is well enriched, the berries are quite likely to be small. I have seen berries of the Crescent grown in single hills, with runners kept off, that came pretty nearly up to some of our large berries in size.

There seems to be a wide difference of opinion in regard to the Belmont. In some localities it does wonders, and in others it does not bear much fruit. In still other places it rusts badly. When we first tried it I was at once struck with the beautiful light-green foliage, and its rank, luxuriant growth, without a trace of rust, on our grounds. When it came to bear it created much merriment by its queer shape-long, and pointed at both

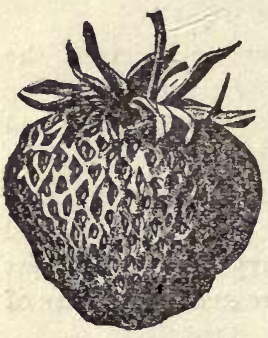

CHAS. DOWNING.

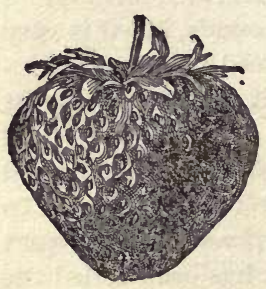

CUMB TRIUMPH.

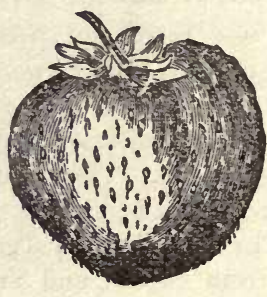

WII.SON.

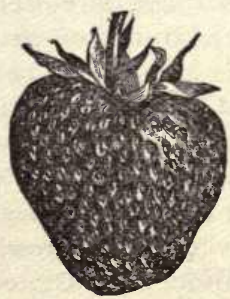

MAY KING.

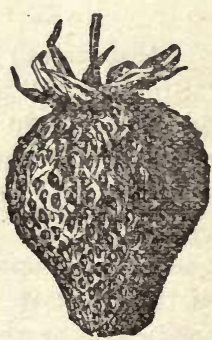

BIDWEI, .

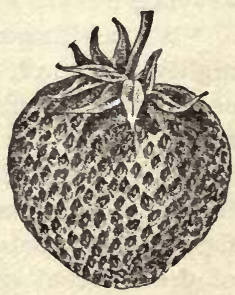

CAPT. JACK. 
ends-something like a "gimlet-handle." When the ground is very rich, many berries are quite irregular. In fact, they look like "chunks of pudding;" and when you put them into your mouth you find them equal to any pudding ever produced by the culinary art.

The Jersey Queen was for several years our standard late berry. The shape is beautiful, and the flavor of the berry is equal to almost any; but with us it has been a rather feeble grower, and not very productive.

The Cloud Seedling is a very pretty berry, and produces runners and young plants to such an extent that it will soon be

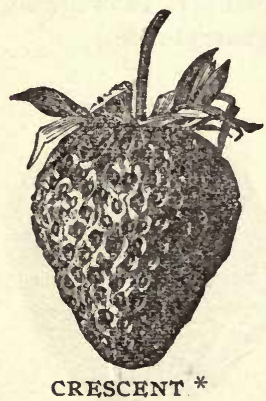

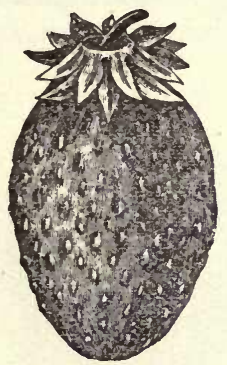

BELMONT

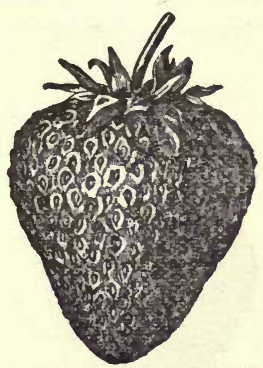

HAVEKLAND. *

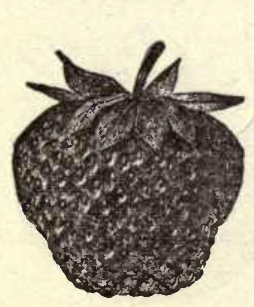

SHAR PLESS.

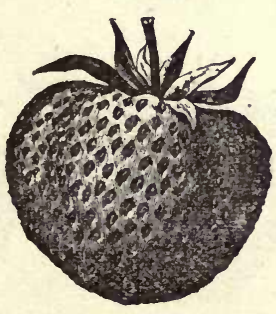

MAMMOTH.

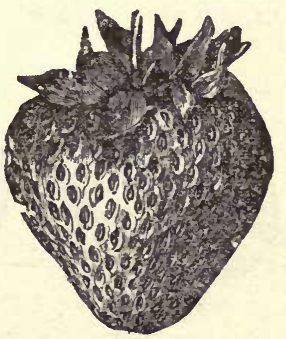

GANDY. 
a swamp unless looked after. It has, however, been voted a failure, at least through the Northern States.

The Eureka is a rank, strong-growing vine, free from rust. The berries are large and finely shaped, and in some localities it has been wonderfully productive.

The Charles Downing has been described already. It is equal to any in quality, and in a good many localities is very productive. It will always have its firm adherents.

I hardly need mention the.Wilson. Everybody has it ; and a good many large berry-growers, including J. M. Smith, of Green Bay, Wis., declare that it will give the grower more money than any other berry known. The Wilson is the berry that gave strawberry-growing its great prominence. It is a great bearer, rather tart, and not very large, as a general rule.

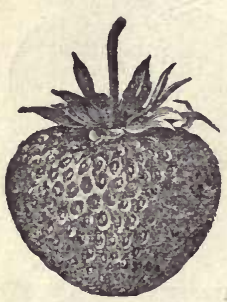

CLOUD SEEDLING.*

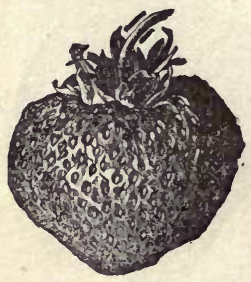

BUBACA NO. 5.*

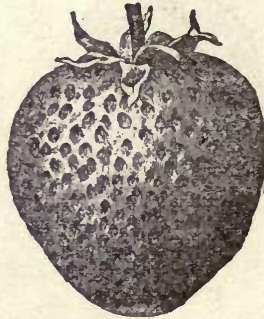

EUREKA.*

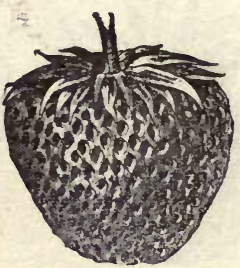

DAISY.

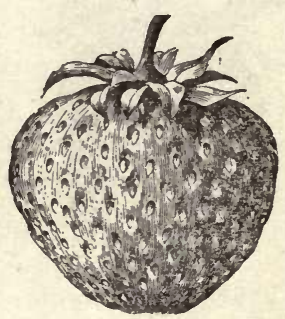

JESSIE.

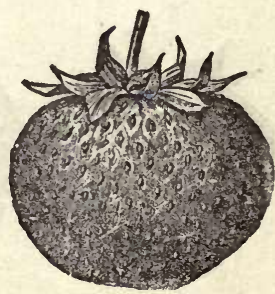

JERSEY QUEZN. * 
The cut of the Gandy shows its beautiful shape, and the large sepals.

The Crawford was originated by Mr. Matthew Crawford two or three years ago, and I believe it is, at the present time, recommended by him as being at least equal to any strawberry in the world.

The Cumberland Triumph, or simply "Cumberland," as it is usually called, is perhaps the handsomest berry, when shown by the drawerful, of any berry known, unless it is the Gandy. Its shape is so perfect that one might think the berries were all turned in a lathe; and with good care the size is more even and regular, just as they are picked from the vines, than any others I know of. The picture named "Cloud Seedling," it seems to

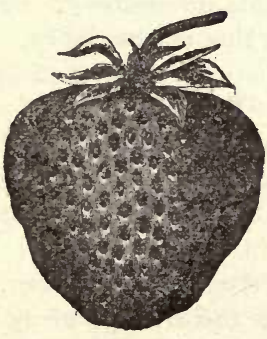

CRAWFORD.

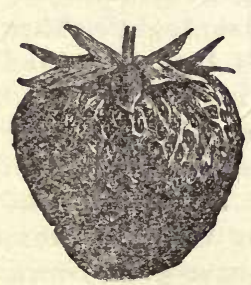

LIDA.*

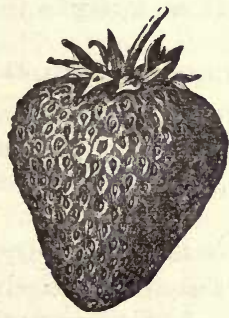

SUMMIT.*

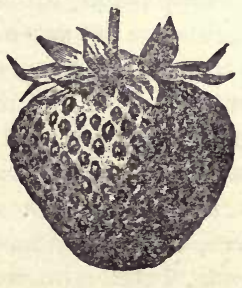

ONTARIO.

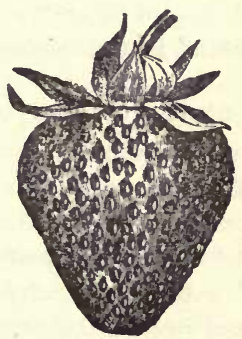

WARFIELD NO. 2 .*

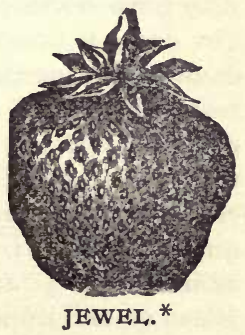


me, represents the Cumberland very much better than the one marked "Cumberland."

The Lida is another new berry that has been attracting considerable attention. The plant is not very large, and the leaves are down close to the ground. But it is a wonderfully vigorous grower, and the fruit is very handsome.

We have tested the Ontario, but they are so much like the Sharpless that it seems to me it is hardly worth while to have both of them under different names. Those of which I have made no mention, I am not sufficiently acquainted with to describe. Those having a star after the name are imperfect, or " pistillate;" the rest are perfect, or " staminate."

There, just as I got my strawberry book all ended, a point not touched on occurred to me ; and I should not be surprised if it should prove to be one of the most valuable thoughts to be found in the book. It follows along in the line of the query,

SHALL, WE LET OUR VINES BEAR MORE THAN ONE YEAR?

This matter has already been discussed on page 98 , and Terry strongly advises plowing them under after they have borne one crop; but this, mind you, refers to strawberry-plants set out in the spring.

Now, where plants are set out in July, August, September, and even October, as we frequently do with the transplantingtubes, it seems a pretty hard matter to turn them under after they have borne only one crop; and, in fact, I would not advise doing it where the plants are set later than August. Then comes the question, How shall we keep old beds clean, and free from weeds, without costing more than the berries will come to? If we keep off all plants and runners, and grow them in hills, they can be cultivated and hoed as well as other crops (but removing the runners as fast as they start, is also quite a task). If, however, we wish to have a thin matted row, as friend Terry recommends, I tell you we have got business ahead of us. If mulching has been used this must be removed, 
and the harrow kept going through the whole season. The beds had better be worked rather narrow; then the weeds must be kept out by hoeing and hand weeding-mostly by hand. The only hope in either case is to keep the weeds from getting a start. If they once get the advantage, and get away above the plants, you might as well plow it all up. I will give you a hint, however, in the line of "prevention is better than cure."

\section{A PLAN TO LESSEN THE LABOR OF WEEDING.}

Some years ago during August I visited quite a strawberrygrower. He showed me with pride a beautiful plot of perbaps half an acre growing vigorously, and remarkably clean. Said I,

"Mr. S, how many times have you weeded that patch during the past summer?"

"Only twice."

"Only twice!" repeated I, in great astonishment. He smiled while he nodded bis head. I saw at once that there was some trick about it. Finally a thought came into my head.

" Mr. S., will you please tell me what crop you had on that ground last year?"

He smiled again as he replied, "No crop at all."

"Well, what did you do with the ground last season?"

"Oh! I just plowed and harrowed it, and kept doing so all the summer long. After I had made every weed grow that could be induced to start, and killed it with a harrow, I set out my plants on it this spring, and there did not many weeds grow to bother me, as you see."

Mr. S. was a farmer, and could spare an acre of ground for one season much easier than he could hire hands to pull the weeds from between the plants. I stated the matter to friend Terry, and asked him if he could not grow a crop of something, and still kill the weeds as effectually as Mr. S. did. He said at once that he could, and grow a crop of potatoes. And this once more suggests the reason why friend Terry has little labor in the way of weeding to do, compared with what the 
average farmer or gardener has when he tries to raise strawberries. So the moral of this concluding thought is this: Be sure that you do not choose ground for your strawberry-patch that is already abundantly seeded with weeds. In fact, if you are going to be a successful grower, and if it can be so managed, neither should any weeds be allowed to go to seed in a neighbor's land adjoining.

Now, I think we can not have a better ending to our strawberry book than to give a couple of letters showing what may be done on a small amount of ground devoted to strawberries, and also showing what enthusiasm and excellent care will do. The first comes from a friend whom I ran across by accident. While visiting bee-keepers in Wisconsin it became convenient to be carried by a livery across from one town to another. I had no destination in Boscobel, so I told the driver to set me down at some place where there were plenty of bee-hives. When I saw a very pretty dooryard comprising about half an acre, with not only bee-hives, honey-house, etc., neaţly arranged, but containing, also, a bed of nice thrifty strawberry-plants, I told him he might let me drop right there. The following letter refers to this visit. This letter also shows what irrigation may do during severe dry weather.

STARTING STRAWBERRY-BEDS FROM NEW PLANTS IN JULY.

In friend Root's special department in Gleanings he once said, "You can set out strawberries (providing you have the plants ready) in the months of July, August, September, and October. But the earlier you can get them out, the greater will be the crop the coming season." I called my wife's attention to it, and told her that I was going to try a bed of strawberries set out in July; and on the spur of the moment, when it was fresh in my mind, I went to a bed of Jessie strawberries that I had set out last fall and this spring, and had not allowed them to mature their fruit, on account of wanting plants from them early. Well, between the 10 th and $15 \mathrm{th}$ of July, this season, I took therefrom 270 fine plants, and set them out in a bed that I had prepared for them. The bed consisted of 3 rows, each 4 rods long, and about 30 inches in distance between the rows. I did not have any of friend Root's transplanting-tubes. But I lost only two or three plants out of the 270 . I took extra care of them, and kept them wa- 
tered and shaded when the sun was at the noon-mark. Then when these got nicely to growing I looked over Root's special kinds of strawberries. Besides the Jessies, which he had spoken very highly of, I found that he also had put the Bubachs near the head of the list, so I sent immediately to friend Kellogg, of Janesville, Wis., for 100 Bubach strawberry-plants, and within four days I had them nicely set out among my 270 Jessies; and when friend Root made his Wisconsin visit some time ago he called on me because he saw a garden and some hives of bees in the yard. He said they were as nice as any he had seen. I wish he could see them now as they cover the ground from one side to the other nicely. I spend many happy moments of time with my fruit, and especially with my three beds of strawberries. There is hardly a day when I am at home but that I look at and do some fixing with them.

We have been having extremely dry weather here, and some strawberry-beds are almost burned up. But mine are rank and green, as if in a wet season. Whenever I have a few moments of time I go to the strawberry-bed and straighten out the runners and bury the roots of the plants formed on them, and keep doing so as long as it is so dry that they can't take root; then when the sun gets so low down as to shade the bed I wet them all with water that has been pumped out of the well 12 or 15 hours. I actually take delight in working in my garden, and I devote hours of time therein when I can't work among the bees.

BENJ. E. RICE.

Boscobel, Wis., Sept. 7, 1889.

To show the result of this care, watering, etc., we now give a letter received just after the berry-picking season of 1890 :

EIGHTY QUARTS FROM A PIECE OF GROUND $5 \times 82 \frac{1}{2}$ FEET.

Friend Root:-The strawberry-bed you saw in my yard in Boscobel, the day you arrived there, is $82 \frac{1}{2}$ feet long by 5 feet wide. We picked 80 quarts of as fine berries as any one ever saw, from said bed. They are the Jessie and Bubach varieties. The little boy measured one that was $5 \frac{1}{2}$ inches around. This bed was only eleven months old when it produced the 80 quarts of berries. You saw this bed a few days after it was set out, it being a very dry time.

BENJ. E. RICE.

Boscobel, Wis., July 2, 1890.

And now, dear friends, we give one more letter, which seems to be a fitting one for the end of the book, especially as it emphasizes the little text that has long been one of my especially favorite ones from God's holy word. The text is this: "Seek ye first the kingdom of God and his righteousness, and all these things shall be added unto you." Lest the 
readers of this little book who are not acquainted with me through our journal, Gleanings in Bee Culture, may think it a little unusual that an entire stranger should write in a way that may seem extravagant, I may say, by way of apology, that such letters have, during the jears of my labors with the bees, stra:vberries, and other growing crops, been worth more to me, a hundred times more, than the money I have received from my work as a journalist, as a bee-keeper, and as a market-gardener.

BEES, STRAWBERRIES, AND-ETERNAL LIFE.

Friend Root:-Youl have been a friend indeed to me for ten years. (through Gleanings), and great has been the pleasure and considerable the profit from this friendship, which I hope may increase until we may meet together on this earth if possible; if not, in another and brighter one above. I have followed you faithfully through your different channels of "what to do and how to be happy doing it ;" and although I am employed at good pay, ten hours a day in a factory at my trade (die-sinker and mold-maker), I utilize my spare moments in caring for my bees and helping things to grow.

The Honey Statistics for Aug. 15 doesn't seem to do our State justice. If you will send me your cards I should be pleased to report at any time. I am situated in the exact center of the State, as the town signifies (Middletown). From 13 colonies I have taken about one thousand pounds surplus, $400 \mathrm{lbs}$. of which is comb-an average of $77 \mathrm{lbs}$. per colony, and increased to 19. Our honey is all from white clover, and all gathered in June. The hive on the scales showed a gain of $10 \mathrm{lbs}$. per day for three days, and $91 / 2$ one day.

I have also been in the strawberry business, and you can't send me the strawberry book by Terry any too soon. I have read all his books, and am anxious for more, with the enthusiasm that goes with them.

My strawberry-bed is composed of seven square rods, from which I picked nearly eight bushels ( 250 quarts); market price, $\$ 37.50$. I not only supplied my neighbors with nice fresh strawberries at paying prices, but have given a great many the strawberry fever, and now am supplying them with plants and advice (I charge only for plants). I have also raised 40 bushels of potatoes, getting $\$ 1.00$ per bushel for 20 bushels of early ones; and, dear brother, this is not all I have received from your teachings and example. I have received the pleasure and blessings that come to one who strives to serve the Master, and do his will. I am an Active member of the Young People's Society of Christian Endeavor connected with the Congregational church, of which I am a member. I thank 


\section{A B C OF STRAWBERRY CULTURE.}

God for the Y. P. S. C. E., and the good it has done and will do in the future. I also thank him for A. I. Root, and pray for more like him ; for the greatest compliment I receive is, "That is just like Root ;" or, "That is just what he would do;" for in being like him, or doing as he does, I am following one who is following the Master and striving to please him and not himself.

I have not told you of what I have accomplished this summer, dear brother, to brag, but to show you the good you have done me and mine. and encourage you in the good work you a re doing. CHAS. H. LEwis.

Middletown, Conn., Sept. 1, 1890.

May God in his great mercy bless you, my dear friend, and help me to deserve a little better your very kind words. Oh may grace and strength be given to me to deserve even faintly the very high compliment you pay me! and may I be able to remember the friends $w$ ho are looking at me, and who perhaps are influenced by my example.

And now, in conclusion may I ask that God's blessing rest on every reader of our strawberry-book; and may others find the pure and innocent happiness and enjoyment that I and these other friends have found in working with and enjoying. all of these, God's gracious gifts.

END OF THE FIRST EDITION AS PUBLISHED (OR PRETTY NEARLY AS PUBLISHED) IN 1890. 


\section{PART II.}

THIS PART CONSIDERS STRAWBERRY GROWING THROUGH A PERIOD OF TWELVE YEARS, FROM 1890 TO 1902.

A large portion of Part II. consists of extracts from Gleanings in Bee Culture during the past twelve years; and we commence it with a. letter from T. B. Terry, furnished one year after the strawberry book had been before the people.

TERRY'S STRAWBERRIES IN JUNE, 1891; THE MAY FROSTS : IN HIS LOCALITY, ETC.

Friend Root:-You may remember that, when you were here about a year ago, asking me why I did not put out five or ten acres of strawberries, and get rich, I did not make much reply; but in your report in Gleanings you told what you thought passed through my mind about spoiling the privacy of my home, etc., all of which was almost word for word what I did think. I was surprised that you could read my thoughts so perfectly. But there was one thought that you did not get hold of at all, that flashed through my head. It was this : This is not a safe locality for growing strawberries largely. One could make a great deal of money from five acres, perfectly tended to, of fine large berries, put into Cleveland when just right for eating, and only two or three hours from the vines, if the late spring frosts did not interfere. Last year they did not, and our success was all we could ask for. This year our halfacre went into winter in perfect shape. No pains were spared to give every plant the best chance possible. We mulched them heavily to keep them back; but alas! the freeze of May 16th killed all the blossoms and many of the buds, and most of the leaves, and many of the plants themselves. The earth froze here from one to two inches deep. I actually dug up pieces of frozen soil in the morning, two inches thick. The Bubachs and Haverlands are just about ruined; all suffered severely, but, as usual, the Sterling stood the frost best. They are altogether the safest berrv for our farm. I suppose in that one night we lost $\$ 200$ worth of herries. The frosts early in May hurt us little, as our berries were mulched so heavily they had not started much. This loss does not trouble us, because we expected it sooner or later. We are liable to killing frosts 
until June, and even then feel a little unsafe until a week has passed. We were growing that half-acre of strawberries large. ly for the pleasure of doing our best on a little land, and not as a source of income. Now, do you not see that, if we had made a business of it, and had five or ten acres, we should have been hurt badly? I know these conditions to exist here, and have no right to put out a crop that it would cripple me to lose, and then blame Providence for bad luck. All these points have been studied most carefully. Our crops of potatoes, wheat, and clover, are almost perfectly safe. They have never failed to pay us. I could make more money from strawberries, if they were as safe; but they are not, here. There are places where they are. Within a mile is a hill of rich, mellow, moist soil on which I would not hesitate to put out strawberries large1y. As it is, one does not like to work hard for nothing half the time, and we shall set out only plenty of strawberries for our own use in the future. We decided on this before the frost, knowing well the chances, and set out this year only what should bring us, say, 20 bushels in a good year. We will do our best to succeed in what we undertake; and then, if failure comes, it will be no fault of ours. Special farming is not very popular, but we will grow what nature has best fitted our farm for. We want safety and almost certainty with as little of luck and lottery as possible.

Now, this is the jdea that went through my mind, friend Root, when you asked me why I did not put in many acres of strawberries. I wish I had brought it out more fully in our little strawberry-book. Being rather set up by success then, I hardly made as plain as I should this point of going against nature. But still that book was intended mostly for farmers, who raise berries only for their own use, and this I would do in any locality, however unfavorable. By setting out the varieties that stand frost best, and by heavy mulching, and, best of all, by setting out a great plenty, berries may be almost a certainty; and if not particularly profitable some years, it will not matter on a small patch.

T. B. TERRY.

Hudson, O., June 4, 1891. 
STRA WBERRY TIME; GETTING RID OF THE CROP WHEN THERE IS A GLUT IN THE MARKET.

From Gleanings in Bee Culture, July $1,1892$.

The latter part of June is generally the height of the strawberry season in our locality. Mrs. Root has several times worried about strawberry time, for she said it would make us so much business that I would overwork again. It is not only the pickers that have to be looked after, but the folks who do the selling; and as we have a larger area of strawberries than ever before, it looked quite likely that there would be difficulty in selling the whole product. Of course, we might ship them off; but my experience has been so unsatisfactory in shipping strawberries that I have decided to sell what we can at home, and let the rest go. To-day, June 22,1892 , we are right in the midst of the battle. The town is full of berries, and loads are coming in from every direction; and the report comes, that, even though they offer them at 5 cts. by the bushel, they do not sell. I knew by past experience just what was needed-more energy and care all around. Of course, we have been having excessive rains, and many kinds of berries are soft. The pickers, too, where they pick by the quart, get eager to fill the boxes, and quite a few that are soft on one side, and sometimes rotten, get in. I went down among them myself, and told them that we could not sell our berries unless they were more careful. Sometimes, through false economy, they picked berries too small to be of any account; and every little while some new hand would be getting them before they were fully ripe. A little kind exhortation made quite a difference in the looks of the products. Then the market was watched, just as we watched the barometer. By ten or eleven o'clock, if sales were dropping, pickers were stopped, each one being directed to make a mark in his row just where he left off, so he could find it when he commenced again. As they began work at five in the morning, and sometimes eariier, they did not much mind resting from ten till two or three. If the folks on the wagon sold out sooner, of course we started to pick earlier; and when sales were so close on the heels of the pickers that they had to wait for berries, there is quite an advantage in being able to tell purchasers, "There, these berries have not been off the vines an hour." If any stock began to get poor or old, the directions were to let it slide for any decent offer. They were also directed to keep the berries out of the sun. For several days I have 
been stationed in front of our factory, where the berries are stored on the north side of our fruit-house, right out upon the walk. To save myself steps, half a dozen small boys are across the street in the plant-gardens, weeding, picking peas, cleaning the walks, or doing something to keep themselves busy until I need them. If a message comes from t'?e wagon, half a dozen of them can pick peas, go to the berry-patch and help the berry-pickers, or bring in berries on the Daisy wheelbarrows. Monday we picked $10 \mathrm{r} / 2$ bushels; yesterday (Tuesday) we picked $93 / 2$. A heavy rain broke in upon us in the afternoon. This morning the wagon started out with an unusually heavy load; but by nine o'clock they had sold out. In the mean'ime I had done a lively business on the sidewalk, selling by the bushel where I had a chance. The price had been running from 5 to 7 cts., till one of the boys brought in a basket of Park $\mathrm{r}$ Earles. These went off so quickly at $8 \mathrm{cts}$., that, when anoth. er boy came in with some very cho:ce Edgar Queens, I put the price at $10 \mathrm{cts}$, , and they sold without a bit of trouble. Both of the two above varieties are wonderful acquisitions. The Beder Wood, spoken of in our last issue, have ripened up better than I supposed they could ripen; but the vines were so overloaded that the largest part of them are necessarily small. While speaking of varieties, I wish to say a good word for Warfield No. 2. It is not a large berry, but it is of the deepest red of any berry that comes in market; and with this bright attractive color comes the most fascinating and dainty tart flavor. and that makes them my favorite berry. It is also quite firm; and when the weather is so wet that the others are in danger $\mathrm{cf}$ mashing down in a heap, the Warfield is firm and solid. Tr * Haverlands, on very rich soil, and with a superabundance if rain, are rather too soft to be handled. In fact, the Haveriand and Bubach both, many of them, taste watery, and they sometimes begin to spoil before they are fully ripe. The matter may be remedied somewhat by planting them in single hills instead of matted rows; and this gives still larger berries; but it is quite expensive to mulch where plants are, say, a foot apart. In the matted row, very little mulching keeps all the berrics out of the dirt. We have lost bushels and bushels of beautiful berries this season because the excessive wetness and lack of mulching made them too muddy to bring even half price. I should not forget to add, that, when all other resources failed to get rid of a great quantity of berries, the cook in our lunchroom has disposed of many bushels by making them into strawberry jam. 
THE BUBACH PLANTED IN THE FALL, UNDER FAVORABLE CIRCUMSTANCES.

The following extract is taken from Gleanings in Bee Culture for June 15,1893 . It touches three important points in strawberry culture : First, strawberries put out in the fall may, with proper management, give a profitable crop the next season. Second, it emphasizes the value of the Bubach strawberry when properly handled. Third, it shows what persistent heavy manuring will do in the way of getting your money back.

Michel's Early did not yield enough to supply the demand, and there was a "corner" in strawberries. It was Monday aft. ernoon. They were all sold out in the lunch-room, and one of the clerks asked if I could not get a few more, even if they were not real ripe. The pickers had been all over the grounds in the forenoon, and had picked every thing they thought would do to sell. I said I would go and get some that were ripe on one side, and perhaps our customers would rather have these than none at all. As I rode along the path on my wheel I got glimpses of some bright-red berries through the darkgreen foliage of some young plants that stood almost kneehigh. Friend Terry once spoke about having strawberry-leaves large enough so a single one would cover the top of a teacup. Well, we could show some leaves this spring a good deal larger than that. I sprang from the wheel and found a berry on the very first plant in the row, that looked more like a peach than it did a strawberry. The plants were put out last fall, two feet apart, and they made but few runners; but each plant had in consequence got to be something immense. At the next plant I found another like a small peach. Pretty soon my hands were full. I called to a boy to bring me some boxes; and while I filled them I began to speculate as to what those plants were. Said I to myself, "Why, this must be the Edgar Queen; and if this is the way it behaves I will just go and plant acres of it." Then I felt pretty certain that we did not put any of the Edgar Queen on that part of the grounds. What could that wonderful plant be? It was not Parker Earle, because the latter is a late berry, and this particular one was not more than three or four days later than Michel's Early; it must be a wonderful acquisition. Twenty rods ahead was a stake with a label, 
but I could not read it so far off. I decided I would pick berries until I reached the stake; and as I filled box after bex with the great beauties, my enthusiasm ran up to fever heat. Said I again. "Why, I never heard of any early strawbersy that gives such wonderful great fruit as this, before. The Haverland, Jessie, and other early varieties have hardly commenced to ripen. What can it be?" When I reached the stake I said, "Why, you old stupid, you might have known that the rich dark-green color of those great broad leaves belongs to no other plant in the world than to the Bubach. Three cheers for the Bubach in its perfection!" How does it come that we have had Bubach all these years, and have not found out before what it can do? Well, I will tell you. Almost ever since we have had the Bubach the weather has been overwet. They rotted before they got ripe, or were too soft and watery in taste. Just now we are having a little bit of drouth, and the Bubach has for the first time come to the front. Another thing, these plants were growing on a strip of creek-bottom ground that has been dosed and dosed with manure until everybody said I could never get my money back. Let me tell you something. Strawberries were selling up town for $12 \mathrm{cts}$. a quart. Our own brought 15 , because they were picked only as fast as customers wanted them. I put these great big Bubachs in pint boxes, and marked them $10 \mathrm{cts}$. a box, and they were all gone in no time. Folks bought them as curiosities to show to their friends; and after they had taken a bite or two out of one of those great big berries they found the quality so delicious under the influence of this clear hot sun from 4 in the morning till 7 in the afternoon (am I putting in too much sunshine?) that they just came back and wanted more of that new kind of strawberry "as big as peaches;" and while I am writing this, we are picking and selling more like them at $10 \mathrm{cts}$. a pint. We are now going in with more enthusiasm than ever before to raise some Bubach plants that will astonish some of our friends who get them, as the berries astonished the Medina folks.

Moral.-Old friends are sometimes equal to or better than new ones, if you wait long enough and give them a fair chance.

The above, as you will notice, was written eight years ago last June. I have tried several times to do the same thing since then, but I have not succeeded in getting the Bubach as early as it was that season, nor have I had as fine berries. So many different elements come in to make a success like the above that it 
is really a difficult matter to secure such results every time. I have had-something nearly as good by putting the plants two feet apart from center to center each way, and keeping all the runners off; but I think I may say the finest berries I ever grew were from plants set in the fall. Of course, we do not get as many berries to the acre as with a matted row; but where they bring almost double, as in the case above, it may pay just as well after all.

A WHEELRIDE TO T. B. TERRY'S AND SOME OF HIS NEIGHBORS IN JULY, 1894 ; ALSO SOMETHING ABOUT MARKET-

ING THE CROP JUST THE VERY MINUTE IT IS AT ITS BEST, AND WILL BRING THE MOST MONEY.

The following account of my wheelride has something to siy about potatoes and other things as well as strawberries that I think our readers will be interested in notwithstanding. It is taken from Gleanings in Bee Culture for July 15, 1894.

All through the month of May I was impatient to get over inlo Summit Co ; but business, muddy roads, and one thing after another. prevented until Friday, June 8 , when I got things fixed around so I thought I could go; but so many things needed attention that it was after dinner before I could get off; then something more had to be seen to until I was startled to find that it lacked only 20 minutes of 3 , and I must either give it up or make 30 miles before dark; and a goodly part of the 30 miles was up and down the tremendous hills bordering on the Cuyahoga River. I laughingly told my youngest sister that I would stand in T. B. Terry's yard before the sun went down, and off I started. The new light wheel made point after point, much quicker than the heavier one.

Down we went those great long twisty hilly roads, flying under the covered bridge, over the canal and along the edge of the river, until I found the proper road, winding along another mountain stream, up toward Terry's home. I was so animated with the idea of getting there before sunset that I did not venure to even look around. I found friend Terry in that same eautiful dooryard-handsomer, yes, ever so much handsomer, 
that it ever looked before, and I asked him a little anxiously which way I should look to catch a glimpse of the sun before it vanished. Yes, there it was through the trees, a glowing golden orb; and I had made my 30 miles in just about an even four hours, notwithstanding the hills and the amount of visiting I did while getting my supper. I felt quite anxious to know whether Terry's wheat would really show that it was a paying operation to work the soil over so many times before it was sown, last fall. And I was glad to notice the finest piece of wheat, perhaps, I ever looked upon. His locality, however, is a very frosty one, and they had been having frosts night after night, even though it was in the month of June, and he feared his wheat had suffered somewhat in consequence. It had also fallen down so as to injure it somewhat. Notice the difference in just 30 miles. We had been picking strawberries for a week or ten days, and yet none of his were ripe. Heavy mulcbing, and a location north of an evergreen hedge, had likely something to do with it.

Friend Terry and his son Robert are enlarging their farm. ing operations somewhat this year. Robert is getting to be somewhere near 21 years old, and his father is naturally quite anxious he should choose for his associates those who neither drink, smoke, nor swear. Well, somebody told me, or else I dreamed it, that the boy has concluded he would be on the safe side by choosing a nice-looking girl for an associate-at least, when he goes out riding in that nice new buggy. You see, a girl would be quite sure to be free from any of these bad habits, and I am not a bit surprised if the boy finds her quite as agreeable, as a companion, as any of the young men. And now please do not understand me as casting reflections on the young men in the vicinity of Hudson, Ohio.

Well, the boy has a farm adjoining his father's-or at least they two, father and son, are working at it together. The old fences have been removed, and new ones-that is, where any fence was needed-have taken their place. Old trees, big stones and stumps, and all useless rubbish, have been cleared away, and the potatoes are already coming up on this neglected waste. Now, wouldn't it be funny if those potatoes this very first year should conclude to behave themselves exactly as they do over on the father's farm, and bear great crops from the word go? I went through the fruit-garden where the raspberries, blackberries, and currants have not seen a hoe nor cultivator for the past six years. Mulching with straw does it all. 
Friend Terry thinks it would not require over two tons of straw per acre where this amount is put on every year. And this is all there is to it. The berry-patch always looks neat and tidy, always bears a prodigious crop, no matter how dry it is, and all the owner has to do is to pick the berries, each in its season.

Next I whirled into the beautiful town of Kent, Portage Co., O. A niece of mine has recently got married. Somebody said she was a little bit inclined to be homesick since living in Kent, and I must call on her. I found her husband in one of the drygoods stores. He marched me into the best room of one of the pretty little cottages in Kent, and in a minute more I heard something like this : you."

"Millie, there is a man in the other room who wants to see

"Why, who is he, and what does he want?"

"I don't know. You will have to go in and talk with him." "Oh bother!"

You see, the new wife was deep in the mysteries of breadmaking-that is, her fingers were; but when she caught sight of the said "man," who insisted on seeing the lady of the house, she just threw up her hands and ejaculated, "O Uncle Amos! have you really got over here?"

I do not know whether any of the flour from her fingers got on my coat-collar or not; but there was danger of it. Perhaps I did look rather fresh and bright for an uncle toward 60 years old ; for, about half a mile out of Kent, I found a pretty watering-trough, with a sort of annex at one end where the water poured over into a stone basin, where the dogs could drink with comfort. I first had a good drink of the soft water, then I washed my hands in the dog trough, and some way or other my head got down under that cooling stream. If you have never ridden a wheel you can not imagine the delicious sensation. So you see my niece found me with my face washed and hair combed. After a little we took our wheels (this young couple are both provided with wheels) and ran around the town. You see they did not have to hitch up nor even pay a cab-driver. I do not know how it happened, but my wheel turned up almost of itself in front of an ice-cream stand. Some beautiful strawberries out on the walk, right in front, must have had something to do with it. Millie ordered some strawberries while I was asking for ice-cream; and-did you ever try great luscious Bubach strawberries mashed up in ice-cream, when you were hot and thirsty? I began wondering who put such 
beautiful strawberries on the market so early in the season; and within an hour I was having an enthusiastic talk with the very man, my friend L. B. Pierce, of Tallmadge, $O$. No one who reads the agricultural papers of the United States needs an in. troduction to friend Pierce. About a year ago (see page 534, July 1,1893 ) I told you about his strawberry-plantation out in the sandy woods, or on ground that had been woods but a short time before. New ground just reclaimed from the forest must have some special fitness for strawberries. It was Saturday, and friend Pierce was about as much astoniched as any of us to find that there were just bushels and bushels of berries ready to pick. He had picked the afternoon before, and decided they would do nicely until Monday; but the beautiful warm weather, after such a protracted cold rainy spell, had done the business. We sampled all the new varieties, and tasted and tested, until we could not tell a good berry if we saw it. I insisted that friend Pierce should hunt up his pickers, and get those berries into market before night. But he got his work laid out otherwise, and could not break up his plans. Perhaps he got as much money for his berries the Monday following, but I felt pretty sure he would not. Besides, some of them would be overripe. I said so much about it, that friend Pierce would have been almost excusable in saying he knew how to manage his own business. He did not know, however, and neither did I, that my own berry-patch at home was pretty much in the same predicament. Wait a little.

Then I visited my cousin, Wilbur Fenn. He has just got a new potato planter, and I found him out in the fields, his group of bright pretty children all around him as usual. We had ever so much to talk about. The planter that he had just purchased does not miss hills. It leaves the soil fine and mellow underneath, and all around the potato, and it was just as accurate as planting by hand, or even more so. In fact, it is hand-planting. We went out into the field where the potatoes were coming up, and looked into the matter. A bright little girl ten years old was so much interested and animated in regard to the whole matter that I very soon discovered she did some of the dropping. She sat behind her papa, on the machine, and placed the pieces of potato in a series of little cups arranged in a circle. There were, perhaps, two dozen of them; and the dropper has only to keep a piece of potato in each of these two dozen cups as they revolve in a circle. It seems to me that the machine is a magnificent success. But something else impressed me during that visit, and it was this: There is 
no success with machinery, or any thing else in the line of progress and civilization, to be compared with the success that attends the man who has his own children so much interested in all his work on the farm that they find more delight in his companionship than any where else. You see, it was vacation time, so the children could be with their father from morning till night. The good mother told me, while we were eating dinner, that the little girl kept wishing and hoping that something would hinder the hired man from coming the day they were going to plant, so she could just ride on that machine all day and put the pieces of potato one by one into those magic cups. I began making some inquiry in regard to the family, as I looked from one bright little face to another. Cousin Fenn replied, "There are just five, and the oldest (the little girl who dropped the potatoes) sits there feeding the youngest some bread and milk." You see, she knew how to help her mamma by feeding the baby, just as well as she knew how to help make that complicated machine a success in planting potatoes. I told them I should miss my train unless I were in Akron by 3 o'clock; but I had to see the potatoes down cellar again. And, by the way, that big crop of Monroe Seedlings was planted the last week in June, instead of the first, as I have had it in some of my writings. When I did get started I just made the Victor Flyer "fly," for sure ; but I reached the station ten minutes too late. I did not care much, however, for I can pretty nearly keep up with a good many of our branch-railway trains. There was another train two hours later; and I decided it would be much more to my liking to spend the time at Fairlawn, Summit Co. I found my friend, C. W. Frank, enjoying himself among his crops, at high-pressure gardening. We got around to the strawberry-patch in a little while, and then I ate ever so many more. Just as I was getting ready to go over to the depot, his sister announced that supper was ready, and that I must have some "strawberries and cream." I told them that I should "get left" again, and it was Saturday night, and our boys doubtless needed me sadly to help them wind up their strawberry-picking of the day; but friend Frank said he had just been over to the station, and the agent said the train could not possibly come along sooner than 45 minutes; but just as we were half through our merriment with strawberries and cream, the whistle blew. I sprang for my wheel; but the boys had been riding, and the handle-bar was twisted. I was left again, an $d$ I want to tell you why I got left this time. The station 
agent has a clock worth about 50 cts., and, as a matter of course, he had to keep sun time. Every time a passenger wants to know when the train leaves, he ciphers the difference out between sun time and standard time, and he generally makes a mistake, just as he did in my case. Never mind. I went back and finished my strawberries and visit. Then I rode 16 miles up and down some pretty hard sand-hills a part of the way, in just 96 minutes. I found the boys had picked the berries except those up by the windmill (see picture in Appendix to our book "What to Do and How to be Happy while Doing It,") which needed picking more than all the rest. They picked $11 \mathrm{r} / 2$ bushels, and sold them, so they did pretty well; and as they did not see any thing of the boss at the time he agreed to come, they went home tired, and concluded that those great big berries on the clover sod, a la Terry, would have to stand it tili Monday. So much for having a clock run by sun time.

Later.-June 23, while trying to ride uphill in the sand, I passed a buggy, and thought the faces looked familiar. It was friend Pierce and his wife. After a little talk I said :

"How much did you get for those strawberries that you left on the vines until the next Monday?"

"Oh! I got 10 cts. for those I got into the market Monday forenoon; but some of them that the boys took in Monday night brought only 6 . I suppose they were pretty soft in consequence of being overripe."

There you see it, friends. Had the strawberries been picked Saturday afternoon, and rushed into the market Saturday evening, they would have brought almost twice as much money as they did Monday afternoon, when they were overripe and everybody else was pushing them into the market. A little later, on the same morning, I saw a large crop of peas, just right to pick, between the rows of celery, at friend Atwood's celery farm, near Copley. He said he could not get around to it to market them that day, because it was Saturday, and he guessed they would have to wait till Monday, even if some of them were a little past their prime.

Moral.-When you strive with all your might, and leave no stone unturned to get a fine crop of any thing in advance of the market, do not let your enthusiasm ooze out at the last moment, when the most critical time of all comes to turn your product into cash. 
SPACING STRAWBERRIES IN ORDER TO GET THE BEST POSSIBLE RESULTS WITH THE I,EAST AMOUNT OF LABOR.

\section{From Gleanings in Bee Culture, Jnly 15, 1895.}

I have once or twice mentioned the difficulty of getting strawberries for field culture evenly spaced over the ground without having it cost more for labor than we could afford to pay. Let us go over the matter briefly.

Our strawberry-book directs that the rows be 4 feet apart, and the plants 2 feet apart in the row. This is the plan Terry has decided on, and he gets his fine even stands by letting the runners go out and set pretty much their own way; then in the fall he goes over the plot and takes out the superfluous small plants so none are left nearer than about 6 inches apart. I believe he assists in getting a complete matted row by spacing the runners while they are beginning to root-that is, he assists nature by placing the runners so as to cover the ground evenly. When it comes time to put on the mulch, the matted row is from 18 inches to 2 feet wide; and none of the plants, as I have before mentioned, are nearer than 6 inches apart. Well, a great part of our planting is done, as you know, in the early fall, after some crop is taken from the ground; and while our fall-set plants put out runners to a considerable extent, they do not, of course, produce so full a stand as where they are planted in the spring; therefore it becomes exceedingly desirable to have the new plants evenly spaced. In fact, we get finer and larger berries, because our plants have more room. But it is exceedingly desirable, as I have said, to have what plants there are, pretty thoroughly distributed over the ground-that is, over this strip of ground, say 18 inches wide and the length of the field. Now, I have for years been trying to find a man or boy who would do this spacing, and do it well. I hope none of our friends will feel hurt when I say that I have been again and again disappointed. I have said to myself, "Now, I am sure this man or boy will understand, with sufficient explanation, just what is wanted, and that he will fall in love with the job, just as I love it." In fact, I do not know of any prettier work in the world than to take a nice piece of ground, with strong thrifty plants putting out runners rapidly, and train them so as to have a nice even beautiful strawberry-bed. You think the matter is very simple, do you? Well, let me explain some of the points that the workman must keep constantly in mind :

First, he must swing the runners around to the right or left, so that the new plants shall not all be on one side of the old 
plant, at the same time keeping in mind that each new plant shall be at least 6 inches from its neighbor.

Secondly, as we keep the cultivator constantly running between the rows, the first thing to do is to make a narrow rowthat is, avoid stretching a runner out at right angles so it will run out where the cultivator will be sure to dig it up. Of course, the man who runs the cultivator can swing around a plant thus stuck straight out, or he can jump his cultivator over it ; but I emphatically object to putting him to this trouble. His business is to stir over every inch of ground possible, with the cultivator; and the man who sets the plants must bear this in mind and keep his row narrow-that is. he must gradually widen the bed out to 18 inches or 2 feet. Of course, some very thrifty plants will make the row a little wider at some points than it is at others; but it can be gradually widened as the growth of any part of the bed demands.

Thirdly, the one who spaces the runners should keep constantly in mind that he is to fill up vacancies. If one of the original plants should die, by stretching runners straight out toward the spot it occupied, from each side, the vacancy can very soon be filled up; and during a favorable time, say just after a rain, some of the oldest and best-rooted plants can be taken up with a trowel, and moved to a part of the row where more plants are greatly needed. Now, this is not a difficult matter, neither does it require a great amount of labor, to have a nice stand of plants at no place being greatly crowded, and at no place having very many vacancies. I said I had tried a great many men and boys. I have not tried a smart woman yet ; but if I don't have better success, I believe I shall try one. The trouble is this : Almost everybody I set at it gets along too fast. He says the strawberries are all done. I go out and look at a row; but before $I$ have gone a rod I will find plants taking root not two inches from each other. I will find altogether too many plants at one side of the old plant, and too few, or none at all, on the other side. Then there will be runners sending out their white roots that have not been put in the ground at all ; a good many plants right out in the path of the cultivator, when there was plenty of room to place them either at the right or the left-at least, very much more out of the way than where I find them. I suspect the trouble is this: The one who does the work is not particularly interested in the strawberry business, and his mind is on something else. Dear friends, it is next to impossible to do any sort of work well and thoroughly 
unless the work in question occupies all your thoughts, all your time, and all your attention. After the above prelude I have something to tell you.

Last week I had a splendid wheelride right in the month of January (1895). I was attending a farmers' institute at Ada, Hardin Co., Ohio. While there I got acquainted with Henry Young, the originator of the Enhance strawberry. It is now one of the prominent strawberries before the people. It is a perfect berry, very prolific, beautiful in color, a strong grower, free from rust, and, in short, would be a model berry were it not for its awkward shape, and that some object to its tartness. This latter quality, however, makes it especially desirable for canning. The shape, however, has with many rather thrown it into the background, although the berries are about as large as any of the newer sorts. Well, I was greatly pleased to see friend Young's plantation, even in the month of January. This Enhance strawberry is his pet-his child. He loves it; and, as a consequence, it does wonderful things under the training of his loving hands. He too has met the same problem I have figured above, and he has solved it-at least, he has invented a way by which even a stupid man, or one with his mind a part

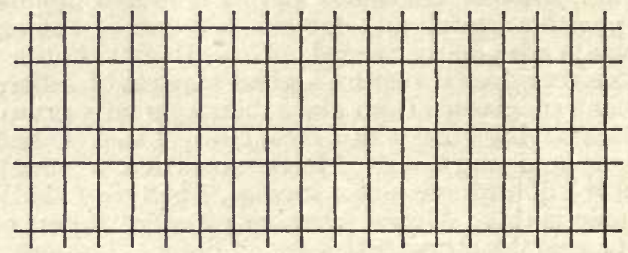

FIG. 1.-MARKING OUT THE GROUND.

of the time or something else, might set out a bed so as to give a perfect stard. He does it this way : He sets out his plants in double rows, and this is done by setting the plants 18 inches a part each way. Now, this double row is 3 feet from the next double row. Fig. 1 will show how he marks out his ground.

After the ground is marked as above, with any sort of marker, jou are ready to put out your plants. The path for picking the berries or for running the cultivator is just a yard wide. The plants, after the plantation is put out, are 18 incles apart each way. Let me show you some stars standing just as 


\section{A B C OF STRAWBERRY CULTURE.}

the plants stand when they are growing nicely, before putting out any runners :

\begin{tabular}{|c|c|c|c|c|c|c|c|c|c|c|}
\hline * & * & * & * & * & * & * & $*$ & * & * & * \\
\hline * & * & * & * & * & $*$ & $*$ & * & * & * & * \\
\hline & * & * & * & $*$ & * & * & * & * & * & $*$ \\
\hline
\end{tabular}

FIG. 2.-PLANTS AFTER THEY ARE SET OUT.

Now a word about cultivating. The broad spaces, or the paths a yard wide, of course can be cultivated without any trouble; and if you set your plants with a spade, on the plan given by Dan White, you can run the cultivator within an inch of the plants on each side, without injuring them. As the rows between the plants are only 18 inches wide, you will probably do them easiest with a wheel-hoe. Friend Young uses a wheel scuffle-hoe. With a horse trained to the business, and a cultivator that will shut up narrow, I have sometimes done quite a good job of cultivating where plants were 18 inches apart. Please notice, before the plants have put out any runners, you can, with the horse-cultivator and the hand-cultivator, go through them both ways, so as to cultivate close up to each plant on four sides. By this means an acre of plants can be kept almost perfectly clean with modern cultivators and noth ing else. Not only this, we can break the crust after every rain so quickly and so easily that we can afford to keep the ground loose and mellow, banishimg all weeds at the same time that we do the stirring; and there has never been any thing invented, and in my opinion there never will be, to get great crops of any sort of fruit like this mellow, soft loose soil. So far so good; but when the runners put out and begin to take root, what then? Here is what I learned of friend Young's invention: No plants are allowed to take root in the broad path 3 feet wide-that is, not the first season, any way; but when the runners are just right, and begin to take root, your man or boy is taken into the patch with a trowel, and told to '... a g od plant about half way between all the old plants and one in the center of the square. After he has doue this he is to zut off all the others. Let us have another diagram to make this plain. We have placed the stars a little further apart, s') you can see better what you are doing. 
The large stars represent the original plants, and the small ones the new plants at the end of the runners. This, you will notice, makes a matted row, with the bearing plants just 9 inches apart each way. This is a little further apart than what Terry directs; but with the strong thrifty Enhance, the space
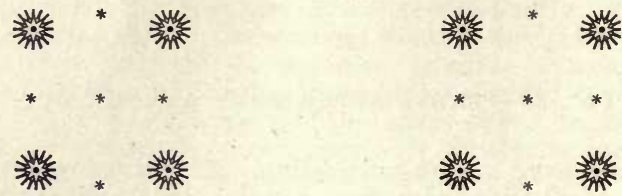

FIG. 3. - HOW TO PLACE THE RUNNERS.

is not any too great. Each square contains nine bearing plants; and each bearing plant should give a great cluster of immense berries. If your plantation is made either in the spring or fall, your first crop will be like cut Fig. 2; and it will be an easy matter, with the horse-cultivator in the three-foot path, to keep this matted row clean, for the plants stand like hills of corn, except that the hills are only 9 inches apart, and you can work them with a narrow hand cultivator, or you can use a hoe. Then comes the question, How many crops shall we get from this beautiful plantation before plowing it up? Mr. Young thinks it pays to get two crops; and he sometimes gets three. If you work for a third crop, after the first crop is picked, clean out your bed thoroughly, then let the runners set where they choose. Just let the whole plantation grow up to a thick mat of vines, leaving a 2 or a $2 \frac{1}{2}$ foot path for the pickers. Through this path, of course, you keep the cultivator going. After you have secured the crop from this solid matted row, then turn strawberries, weeds, and every thing, all under, the very day you do the last picking. That is, you ought to do it the very day, if you are going to work up to the highest notch of high-pressure gardening.* Now, friend Young goes to work and plants strawberries again, because his whole ground is used

* Please notice, in fall planting the routine would be something like this: Use potted plants; in fact, this is the way friend Young always does, for he is a greenhouse man, and handles pots every day of his life. Use potted plants, and the next summer you will get part of a crop of immensesized berries. After fruiting place the runners as in Fig. 3, and the second summer you will get a full crop-all large fine berries. Gather your fruit; 
constantly for strawberries exclusively, or almost so. Meantime, however, he is pretty well convinced that some other crop should be put on before planting again for strawberries; and, by the way, you can get a good crop of cabbage, wax beans, early sweet corn, and ever so many other things, after turning under your strawberries. You may remember that, last season, I got a splendid crop of Freeman potatoes after the strawberries were all picked.

\section{DAN WHITE'S MODEL, PATCH OF GANDY STRAWBERRIES.}

From Gleanings in Bee Culture, Oct. 15, 1895.

I reached New London after 9 o'clock at night ; but as the rain had spoiled the wheeling I got up at five o'clock next morning and found the way over to our friend Dan White's just as the hired man was getting out of the back door. As soon as Mr. White was informed that A. I. Root was on the premises he hustled on his clothing quickly, making some apologies for getting up so late on a rainy morning. After we had shaken hands and talked over matters a little he commenced :

"O Mr. Root! You are just in time to see the neatest thing in the way of a strawberry-patch there is out. Just come this way."

Mr. White marks out his ground in the spring of the year so as to put the rows 4 fcet apart; then the plants are carefully set 18 inches apart in the row. As soon as they send out runners, one new plant is made to grow half way between the original plants. That leaves them 9 inches from center to center.

DAN WHITE'S SYSTEM OF GROWING STRAWBERRIES.

get out the weeds, then let the whole plantation have pretty much its own way. Run the cultivator, of course, and do as much hand-weeding as you can afford to do, more or less; then the third summer you will have an immense crop of berries as before; but a great many of them will probably be small, because the beds are too much crowded. Pick as long as it pays to bother with them, then get them under the sod, and have your field clean and lovely once more. 
Now the next step is to put a plant 9 inches off on each side of every plant in the row. The diagram shown will make it plain. The large stars are the original plants, and the small ones where the runners are put down.

You will notice that the above arrangement makes the plants 9 inches apart from center to center; each old plant is to furnish five young ones. The row of plants is 18 inches wide, the path $21 / 2$ feet wide. Well, after you yet these three rows, plants 9 inches apart, then you are to pull off every runner. Go over the ground so often that not a weed gets a start, and not another plant gets a start except the three rows as given above. The effect is to make each plant, by the time frost comes, a strong bunchy cluster. It is several years since we first practiced taking off all the runners so as to get strong bushy plants; but I am firmly convinced that in no other way can we get such large fine berries.

The next question is, What variety shall we use? Dan White's model strawberry-patch is Gandys-nothing else. You know there has been a complaint that the Gandy does not bear very much. Some large strong plants, for instance, will not bear a single berry-at least, not the first season. Well, friend W. says it is because the plant has not grown to a sufficient size. He says if you take the first Gandy runners that set in June or July, give them good cultivation, and stop off all the other runners, you will get a plant by fall big enough to give a good crop of fruit next year, and I believe he is right. Our Gandys always did better the second season from planting.

This patch of strawberries on friend White's premises is, I believe, the handsomest, and the most of a model patch, of any thing I ever saw anywhere, unless it is those of Henry Young, Ada, O., that I looked at last winter. There are absolutely no weeds in it. There was a plant wherever there should be one, and no extra ones. And I tell you, friends, it is a grand thing to have a full stand in raising any crop. This reminds me that I forgot to say that T. B. Terry's potato-fields were absolutely a full stand. There were no missing hills-at least, I did not see any. But his planting was all done by hand. Since digging his Freemans he tells me that, on his best ground, they ran as high as 195 bushels per acre. Now, for the season we have had. especially the severe drouth in his locality, and for a potato of such fine quality as the Freeman, this is certainly doing pretty well, especially where a whole farm, as it were, is planted to potatoes. But, to come back to friend White's. 
It is a big lot of work to set each runner in place by hand, and to pinch off all superfluous rumners. But, there is no excellence without great labor. Friend W. had a large crop of strawberries during the past season, and sold them all at extra prices. Three or four cents more per quart for your berries will easily pay for the extra labor; and when you get right down to it, a good many times it is about as cheap to do any thing right as to let it go, or to get out the weeds by fits and starts after they have dore a big lot of damage. He placed his berries right in the market, side by side with other berries that were selling at 5 and 6 cents. When the dealers protested about his asking 10 and 12 for his he replied :

"You need not buy them at all, my friend, unless you have a mind to. Set them right out here on the walk, put a tag on them, stating the price, and I will allow you a commission for selling."

It the above conversation took place on the sidewalk, where it usually does, about this time somebody going by wanted some of the berries. Then somebody else wanted some more; and pretty soon the dealer says, "Here, Mr. White, I will take them at your price." Now, this is the same thing Terry describes in his strawberry-book. It can be done every time when you have something away ahead of the general run in the market. Terry accomplished the matter of getting his plants so as to give each one plenty of room, by cutting out the surplus plants in the fall. Friend White's plan is more work, but I think it is a little ahead, because the surplus plants are out before they get started. And then, what a pleasure to show to your friends-I do not mean the berries-I mean the plants and the strawberry-garden! I should judge friend $\mathrm{W}$. has something like a quarter of an acre close by his dwelling, managed on this high-pressure principle.

The summer after the above was written we received the following from friend White, on a postal card:

The Gandies are giving 72 quarts each morning, with prospects of keeping it up the week out.

DAN WHITE.

New London, O., June 161896. 
" THE BEST STRAWBERRY IN THE WORLD."

From Gleanings in Bee Culture, July $x, 1896$.

In our issue for June 15 we were inclined to give the Jessie the palm for being the best strawberry if we could have only one of all that are before the world now. Later on we were inclined to change our decision and give our preference to the Parker Earle. Well, just after our last issue had gone to press, I think it was June 12, I happened to remark to the wife of a neighbor that our nice strawterries were all gone. I was just on my way over to the house to take my before dinner nap. After waking up and rubbing my eyes, the first thing that met my gaze was a heaping quart box of strawberries-the largest berries-that is, a whole quart of them-that I perhaps ever saw before in my life. Mrs. Root informed me that they were sent over by Mr. Horn. She said the boy called them "Great something," she could not exactly remember what it was.

"Great American?" said I, as I picked up one of the great awkward chunks of delicious fruit and sampled it.

"Oh, yes ! that is it-Great American."

It was not long before I was over to my neighbor's, on my wheel. Now, his strawberry-patch is not over a hundred rods from my own down on the creek bottom; and yet he has beaten me all to pieces - at least on late strawberries. Why, if somebody had exhibited that box of berries, and had offered me a hundred plants of the same for a five-dollar bill, I should have handed over the bill "quicker'n a wink." Best of all, these berries were grown on soil precisely like my own : and this yield of enormous berries was after even the Parker Earle was almost done fruiting. The bed had been neglected, and the foliage was so thick you could not see a berry until the leaves were parted. The great leaf-stems were toward a foot high or more, and the fruit was tangled in the foliage. There was such a treniendous growth of plants covering the whole surface of the ground that the heaviest storm could rot soil the berries a particle. Very likely this great mass of foliage was one reason for the season being beld back, as the sun could not get at them.

Now, I have heard of the Great American before. In fact, some years ago I gave it a partial test; but my plants may not have been true to name. Neighbor Horn sells his berries at the groceries. He said the first pickings brought $61 / 4 \mathrm{cts}$; then 8 
and then 9. But the last which he sold for 9, he said the grocer retailed out at $12 \mathrm{cts}$. for every quart of them before the boy left the store. The fruit is shaped very much like the Sharpless. You rembember when I first commenced raising the Sharpless I said the berries looked like "chunks of pudding." Well, that describes the Great American exactly. In point of flavor they are exactly like the Sharpless, as nearly as I can remember.

I had been thinking I could not eat strawberries, especially for supper. When Mrs Root placed the heaping saucer of Great Americans close to my plate at suppertime I felt almost sure, both from looks and taste, that they would not hurt me, and they didn't. I suppose they are a very large per cent water; but when fully ripened they have a delicious pineapple flavor that is most fascinating. Our Mr. Turner, you know, has been for years at the Ohio Experiment Station, Columbus, where they test every thing in this line. Said I :

"Mr. Turner, you people, of course, tested the Great American with other strawberries? Now, will you please tell me why it has not made more of a stir in the world?"

He replied in just two words :

"Too soft;" and that tells the story exactly. If fully ripened they certainly would not stand shipping; but for home use, or for selling in the way we do, picking the berries between 4 and 6 o'clock, and selling to consumers before noon, I believe I should call them the "best berry in the world "-at least, the best late berry. Very likely the berry does not ordinarily produce as many quarts per acre as the Haverland, Parker Earle, Bubach, and some others; but managed in the way I found these, the yield was certainly very satisfactory; and it does not take any time at all to pick the fruit.

By the way, why can't this berry be profitably grown and let it cover the ground entirely, having no paths, no weeds, no management at all? Make the ground exceedingly rich; keep out every weed until the plants get complete possession, as in the new celery culture, and then just let the whole thing take care of itself. Grown in this way they do not need any mulching, and I do not believe the plant would ever be thrown out by frost; neither would a late frost injure the blossoms, for two reasons-the bloom is very late,* and the immense foliage would protect it. But I tell you, you would neea to have some

* The blossoms are prrfect, so no other variety is needed near them. 
careful pickers. The average boy would be sure to set his foot right square on one of these immense bunches of huge berries.

Now, mind you, the Great American will never be popular as an all-purpose berry, because it is "too soft ;" and during very wet seasons they might, like the Bubach, rot before ripening. But for home use, or for selling right around among your neighbors, I believe I should call it one of the best.

Before the sun went down that night I had some of our best creek-bottom ground prepared; and before another day had past, some Great Americans were taken up with a lot of soil adhering to the roots, and transferred to our rich ground. Of course, we had to take old plants, because they have not commenced to send out runners yet; but we are going to make plants this fall, and get out a plantation that will bear fruit next year-you see if we don't.

The above berry, described as the Great American, we decided later on was the Sharplers. The old plants I took up while they were in full bearing, had the fruit all picked off, and in a little time they sent out runners. These runners were taken care of, and gave a crop of immense berries the very next season, not quite as large, however, as those in the bed of my neighbor; and although I have tried almost every year since to get such a crop as they had, with the best of care and with. out any care at all, I have not succeeded. Perhaps the season has not been just right for that method of treatment, and may be his ground is peculiarly fitted for it. The bed was not a very large one, but the paths were all grown up full of plants, so there were no paths at all. The leaves were immense in size, and the berries were borne on long stems. I presume the plants stood from six to ten inches apart in this bed. There had been a big crop of fruit on it the year before, and then it was allowed to stand, thinking it might give part of a crop another year. I think we paid him 10 cts. a quart for the remainder of the crop after I found the bed. We sold them without trouble for 14 to $15 \mathrm{cts}$. On account of the size of the fruit; and that was when common berries were selling from 5 to $10 \mathrm{cts}$. When every thing is favorable I still consider the Sharpless one of the 
best if not the best strawberry in the world, especially for my own eating.

FIRMING THE GROUND WHERE YOU WANT TO GROW CHOICE VARIETIES OF STRAWBERRIES, AND WHERE YOU WAN'T TO GET BERRIES OF IMMENSE SIZE.

From Gleanings in Bee Culture, Sept. 15, 1896.

Somehow or other it seems almost impossible for me to take a wheelride twenty miles from home without getting lost. During this last trip I took a back road because it happened to be better; but it took me through a new part of the country. There were no guide boards, and pretty soon I was at a loss to know which way to turn to strike T. B. Terry's. I took the wrong road, as it transpired, and by and by I was astonished to find myself close to the home of Matthew Crawford. Just as soon as he saw me and my wheel he expressed his pleasure by saying he had something special he wanted me to see. Friend C. has little beds for starting strawberries, and for his potted plants, much like my own, except that they are only 4 feet wide. He started this way, and has therefore got all his beds made this width. Instead of having them in a compact group he has them here and there in different points all around his house. For potted plants waiting for orders he plunges them into beds up to the brim, and then shades them with frames covered with cotton cloth until they get "weaned" after being detached from the mother-plant. Then choice varieties are planted out in these same beds, making two rows lengthwise of the bed. These rows are about 2 feet apart, and the plants stand 6 inches apart in the row. By keeping the runners pinched off he'gets enormous berries in these rich specially prepared beds.

We soon came to a bed containing about thirty plants. These plants had a little more room, perhaps a foot apart. As soon as I saw them I raised my hands in surprise, for they were the finest-looking, rankest-growing strawberry-plants I ever saw in my life. The runners that were just taking root here and there were almost the size of leadpencils; and the colors of these great runners were almost as brilliant as the colors of a ripening peach.

"Well, I do declare! Friend C., is this a new variety that gives this enormous growth, or is it some special treatment?" 
"Mr. Root, the wonderful growth you see is due both to the variety and treatment. The plants are the 'Nick Ohmer,' and you have four of them already. The special treatment is this : There is quite a quantity of rich old compost spaded under the surface of the soil; but it is not the compost alone. After preparing the bed I stamped it down as hard as I could tramp the mellow ground; then I afterward pounded it as I would pound the ground around a post, and this is the result."

"Now, old friend, you have missed quite a little speculation. Had you showed me these plants, and told me they were a new variety just out, and were worth $\$ 100$ a piece, I would have taken half a dozen, without a moment's hesitation. As it is, I want to say to you that the sight of this bed has been worth my whole hard ride of 25 miles over the hills this morning."

You see, this is nothing particularly new after all. T. B. Terry and others fine up their wheat ground on the surface until every lump is pulverized - until the ground is like the dust in the road, in fact. After having done this the soil is packed down hard with a heavy land-roller. This is the nay they get such enormous crops of wheat. Now, mind you, this can be done only when the soil is very $d r y$; and it is especially needed on light sandy soils like friend Crawford's, or any soil where a great amount of stable manure has been applied. As soon as it was explained to me I understood exactly why strawberries do not do well at this time of year in my plant-beds where the soil is almost half stable manure.

After the above I went home and tested this firming matter most thoroughly on a great variety of plants, especially our choice ones. It has always given wonderful results, both in variety and fruit; but we use it in our plant.beds only where there was an excess of old manure. I do not know how it would work in field culture. If it answers as well as it does in our rich beds, the ground can probably be firmed with a very heavy roller loaded down, drawn by horses. A strawterrygrower of much experience once told me that my old plants, close by a path where the ground had been tramped down hard and solid by many feet, would stand over winter, without the plants heaving out, better than in soft ground, and that has proved to be the case. 
THE STRAWBERRY INDUSTRY AT BARNESVILLE, OHIO.

From Gleanings in Bee Culture, June 15, 1897.

For several years I have been thinking I should like to visit Barnesville, and see how they manage where they grow strawberries by the carload and trainload, and also see what varieties, where they plant whole farms to stra wberries. Well, last Saturday evening I received the card below :

Dear Friend Root:-The strawberries are ripening now, rather late I think the first of next week would be a good time to visit the patches. I shall be pleased to show thee around.

$\therefore$ Barnesville, O., June 4.

WM. L. AshtoN.

I looked up the state of things on the new wheel-book sent out by the L. A. W., and found that our Medina railway strikes a station in Belmont Co. called Bannock, where a limestone pike goes down to the old national pike; and by making a wheelride of toward 20 miles over these stone pikes I found I could reach Barnesville without any wailing. I will not stop to tell you about my wheelride, but only say that I met with about the usual number of adventures. In fact, I am bearing the scars of some of them while I write.

I was warmly welcomed by our Quaker friend and his boys, for he proved to be the superintendent of the Quaker school, a mile out from Barnesville. Near by was one of the strawberry-fields; and my first introduction to the strawberry-grower brought back a host of memories belonging to forty years ago or more. Shall I tell you why? Well, it was because the introduction was something like this :

"Brother Smith, this is Aunos Root. Brother Root, I make thee acquainted with Solomon Smith."

"Amos Root!" Away back in my boyhood, when I was so bashful that I wanted to slip around out of sight rather than meet strangers, they used to call me "Amos Root ;" and somehow or other it did my heart good to be called by that old familiar name. It seemed to say to me, "You are at home, and among friends - yes, friends indeed;" and it seemed to strip off business and business cares. Just the very words made me feel that I was a boy again - a quiet, backward, awkward boy ; and it made me feel, for just a little time, loose from all business entanglements and complications. I do not know but I drew a long breath of relief. "A. I. Root" does not sound boyish ; neither does "The A. I. Root Co." And, oh I do so love to be a boy once more when I get away off with my wheel! 
My first glimpse was of a patch of berries on a southern slope; and, by the way, there are slopes and nothing but "slopes" around Barnesville - every thing slopes-gardenpatches, whole farms ; but, notwithstanding, I believe Belmont Co. is the most thrifty and the finest-looking agricultural county I ever saw anywhere in all my travels. Every bit of ground is covered with something green at this time of the year. No matter how steep the hillsides, nor how high their summits, something is growing. The forests have been mostly cleared away, and cultivated fields-that is, fields over the hilltops and down in the valleys-take their places.

The strawberries are grown in matted rows, just about according to Terry's directions. The ground was well mulched with straw in the fall, and there has been no cultivation since, except to pull the weeds; and just now they do not even do that very much, because the weed brings up a lot of dirt, and that is pretty sure to make the berries gritty.

The first row I struck was our old friend Warfield, that I have just been talking about; but the Warfield berries were larger than we have ever grown them here in Medina Co. This is owing to having the plants not too thick in the rows, to the rich gravelly loam on the hills, and to the great amount of stable manure or other fertilizer used. Almost every grower I visited, however, threatens to stop putting stable manure on strawberries, on account of the weed seeds. Some are using phosphates; but the greater number, I think, are using bone dust and ashes, or some other preparatiou of potash, in place of stable manure.

I felt anxious to know how many of the varieties we have been advising and recommending were flourishing there; and my good friend Ashton smiled when Bro. Smith told us that one of their best berries was the Warfield. Now, they have around Barnesville the very berries we have settled down on, and but only a few other kinds. The Jessie has been partially dropped, although a few growers still stick to it; and the same with the Parker Earle. Michel's Early they grow for extra early, but for no other reason. Bubach takes the lead for a large strawberry. Where Bubachs are grown with the plants far enough apart, so as to have plenty of room, they select choice specimens for fancy city trade. Such berries bring from 25 to 40 cts. a quart. Where you can get, say, ten berries that will fill a quart basket, it is not much trouble to find a purchaser for them, among traveling people on the railways, at from 30 to 40 cts. 
Brandywine is just beginning to attract considerable attention. It does not bear as many berries as the Bubach, perhaps, but they are so firm they can be handled and shipped almost like potatoes, even when they are well colored all over. This is certainly a wonderful thing in its favor. The Marshall has been grown to some extent, but I believe it does not produce berries enough for field culture, as a general thing.

One of the largest berry-farms in the neighborhood of Barnesville is managed by the Cowan brothers, one of them having over 100 acres devoted to small fruits, and, if I am correct, something like 40 acres entirely in strawberries. We were a little surprised to find the proprietor a colored man; and it was a surprise indeed to see how he was making berries grow on every foot of the land, hilltop and valley. Even in the ra. vine back of his house, where it was about as steep as the roof of a house, great rank luxuriant strawberries were growing and bearing there. Mr. Cowan says the side of the hill is much better for strawberries than the extreme top. He thinks this is much owing to the cold winds that strike the summit, while the berries part way down, especially where the hill slopes to the southeast, are protected from the cold northwest winds. It was indeed amusing to see the great clusters hanging over and spread out on the straw mulching on the down-hill side of each row. The Haverland, you know, is remarkable for its long stems, and these were literally piled up in heaps. The day before our visit, they had picked and shipped 50 bushels.

Mr. Cowan objects, like the rest, to stable manure for a mulch, especially that which comes from the livery-stables in town. I do not know just why manure from livery-stables should contain so many weed seeds, but perhaps it is because they have to purchase large quantities of hay from all sorts of farmers. A man who has a horse and cow of his own, or who grows the feed for his stock, would not be so likely to risk taking weeds on to his premises. Several men told me they had got their ground filled with kinds of weeds they had never seen on their premises until they brought them in by purchasing stable manure for their berries. Now, this is indeed a serious matter. Another source of weed seeds is the straw mulching put under the berries to keep them clean. The small quantity of grain left in the straw makes trouble, but the trouble is not as bad as with pernicious weeds. The prickiy lettuce is one of the worst, because it will mature seed, and send it flying about even while the berries are fruiting.

Permit me to mention here that Mr. Cowan was using very 
successfully over a part of one of his fields the refuse from a cane-mill near by. It answer? the purpose perfectly, contains no weed seeds whatever, and he said the only objection in his case was the distance they were obliged to go for it. In their work they use two tons of straw per acre, or its equivalent in something else. This, of course, is for mulching, to protect the plants from heaving out in the winter, and to keep the berries out of the dirt in fruiting-time.

The berries grown on this piece of 40 acres are mostly those I have mentioned. Warfield, Haverland, and Bubach are sure to be found; then Parker Earle, Jessie, and Michel's Early are grown more or less.

I asked Mr. Cowan how often he shipped berries that sold so low as to pay for only the packages, express charges, and cost of picking. He said he had never come out quite as badly as that, even on a single bushel, although he had heard of oth. ers who had to advance money, besides the value of the berries, to pay the expense of shipping and marketing. I was somewhat surprised at this ; but when I became better acquainted with the man I found that he was unusually bright and wideawake. He is a hard worker himself, and he keeps right along with his help, which, if I am correct, is mostly colored people.

There is a factory at Barnesville for making crates and boxes for berry-growers; and they have certainly got the prices down very low. The cheap gift crates to hold one bushel, or 32 one-quart boxes, are furnished at Barnesville, nailed up, for only $12 \mathrm{r} / 2$ cts.; and as the nailed up quart boxes are sold for $\$ 350$ per 1000 , the whole expense of a paskage for a bushel of berries is only about 23 cts.

As we prepared to take our leave he informed me that, when he started in the berry business some years ago, he had only about $\$ 200$ or $\$ 300$ to make a payment on the farm. The place was already pretty heavily mortgaged. It was only a short time ago that the last dollar of the mortgage was paid; and now he can breathe a little easier while he plans to make every yard of ground produce fruit of some kind. Besides the strawberries he has considerable ground devoted to currants and gooseberries, and these have always paid him well. Instead of paying large sums of money to nurserymen for plants, he grows his own, makes cuttings from the currants and gooseberries, and has a very pretty little nursery where they are cultivated and cared for until they are ready to go out into the field. 
When I got out on the national pike I called on two more strawberry-growers. One of them told me how he had been growing berries a great many years, but had just made a discovery-in fact, had just got his eyes open so as to know how to grow berries profitably. He took me down a side hill to show me his new invention-another patch of Bubachs fertilized with our old friend Sharpless; and, oh such berries! not only in size, but in luscious sweetness; and I actually believe I would rather have the Sharpless berry for my own eating than any other berry grown. But, let us get to the new invention.

The plants were all put out last fall ; and neither the Sharpless nor the Bubach had produced a very thick matted row. In fact, in some places there were not enough plants; but they had had good care, and each plant had an abundance of room so that it was growing great whoppers, even if there were not so many of them. This man sells the greater part of his crop by sorting out the largest ones and selling them at fancy prices. It is almost like growing berries in hills. The runners are kept off, or mostly off, as soon as a sufficient stand is secured for large berries. He does not get as many bushels per acre, but he gets better prices for what he does grow. A neighbor near him was managing a plantation a good deal the same way, but he was using the Brandywine. Here again we had great berries that could be tumbled about like potatoes, while the Bubachs in the same patch would be, many of them, too soft to handle before they were fully ripe.

\section{A NEW TRANSPIANTING-MACHINE.}

Something like two years ago a transplanting-machine was sent to Matthew Crawford, but for some reason or other he forwarded it on to me, asking me to test and report. On account of many cares, and other things to be looked after and tested, the little machine was laid under my desk until well along into the season before I took the trouble to take it out and try it. Another thing, I have tested so many machines that did not seem to be as convenient as some we already had in use, I was a little skeptical about it ; but when I did get hold of it I was agreeably surprised to find that I could in a twinkling move any small plant to another location so quickly and so safely that it seemed almost as if it must be some sleight-of-hand performance. 
The drawing will make the machine plain, almost without any particular explanation. You hold it in both hands, and with an auger-like motion back and forth you set the steel tube, No. 1, over the plant. It is pressed down till it will bring up the plant, roots and all, in a lump of dirt like No. 2. It is not advisable to push it any further down than is necessary to get all the roots. In fact, if the tap-root is broken off, with most plants they will do just as well.

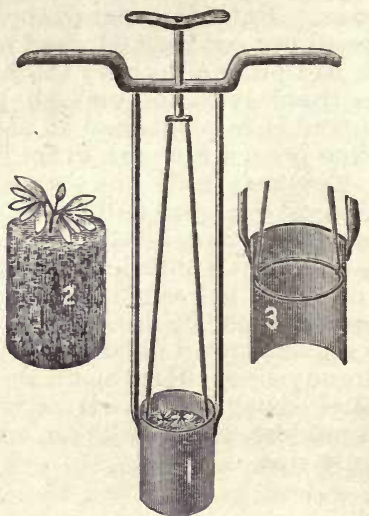

MACHINE FOR TRANSPLANTING SMALL PLANTS.

After the plant is out of the ground in its ball of earth, you place your two thumbs on the lever at the top of the machine, and push down, releasing the ball of earth. With strawberries you can load these balls into a wheelbarrow, or with appropriate trays you can load them into a wagon. Fit your ground nicely, as described in our book on strawberry culture ; mark it out according to your notion, then with the transplantingmachine make holes to drop your "potted plants "into, for they are potted plants, to all intents and purposes.

Some time in the fore part of April we put out with this machine several thousand strawberry-plants, including all the different varieties; and if there is one failure in the whole lot, I have not seen it. Aimost any boy, with a little instruction, will operate it nicely; and with any soil that I have yet used it 
on, the dirt, if wet enough, will hold around the plant so it can be handled. The nicest way, in my opinion, is to grow your plants in a plant-bed made up of exceedingly rich compost; then you carry enough of this compost out to the field to give your plants a big start, even if the ground is comparatively poor. We have not yet tried shipping plants by express, taken up in this way; but by breaking off a part of the ball of earth, so as to decrease the weight as much as possible, and yet have enough left to keep the roots perfectly, then packing these balls of earth with sphagnum moss, I think valuable plants could be sent this way with profit. The weight of the adhering soil would, of course, be a serious objection to sending any plants in this way unless it were a small number of something exceedingly valuable. Sometimes it seems desirable to swap places with certain valuable plants. With the above machine this can be done in a twinkling; and even the plants that have been transplanted do not seem to know they have been swapped. The machine has a cylinder 3 inches in diameter and 5 inches in length. The whole thing amounts to the same thing as our transplanting tubes; but you have no tin tubes at all to pick up and put away. The machine itself does the whole business.

Perhaps I should explain that cylinder No. 1 is made of the very best crucible steel; and while in use it is as bright as a polished saw-blade.

It has now been tested by many competent men, and there is but one verdict in regard to it-it is away ahead of any other transplanting-arrangement of the kind that has ever been brought before the public.

The little plant you see in the picture is a basswood-seedling. One day when one of our small boys was out of a job I told him to mark out one of our plant-beds with one of our markers, then pick up the basswood-seedlings all over the garden, wherever he could find them, and put them in the bed. No. 2 shows one of the basswood-seedlings just as we picked them up. In a little while he had a bed of 300 nice ones. And this reminds me that we have pretty much failed in getting basswoods to grow where we planted seeds; but wherever we are making up beds near the basswood-trees, these little seedlings come up plentifully. Under one small basswocd-tree we picked out over forty plants.

I may add that, since 1897 , we have manufactured and sold a large number of these machines, and they have now come to 
be a standard tool with many strawberry-growers; in fact, they may be used with melons, squashes, etc., and very many oth er kinds of vegetable-plants where there happen to be hills missing. Take a plant or two from a hill that has it to spare, and fill out the vacancies. With strawberries it is very useful for removing plants where there are too many, and taking them toa part of the row where there are vacant spaces.

\section{GROWING STRAWBERRY-PLANTS.}

From Gleanings in Bee?Culture, Aug. $1,1897$.

I have before explained many times why it is that a wellrooted young plant in July is worth ever so much more than one later. It is a good deal like the old adage-

\footnotetext{
A swarm of bees in May

Is worth a load of hay ;

A swarm of bees in June

Is worth a silver spoon ;

A swarm in July

Is not worth a fly.
}

But the way honey has been coming this summer, and that, too, during the last part of July, makes me inclined to think that a swarm of bees in July might this season be worth considerable after all. Well, a strawberry-plant put out in July may make two good plants in August ; four in September ; eight by October, and sixteen by November. If you have the plants in beds, and put on sashes, you may make thirty-two by Christmas. Again, if you keep off all runners, and just make the plant grow big and stocky, you may get a whole quart of berries from a plant that has not been located even one year. For the reasons just given, we push plant-rearing during this month. In fact, we have been shipping plants at a lively rate every day for several days back. Now, how shall we manage to get good stocky plants with the least expense and trouble? There is no better way to start them than the way laid down in the strawberry-book. Set out your plants in the spring in good rich ground well fined up, in rows four feet apart, the plants being two feet apart in a row. By July, if you have done your part with the cultivator and weeder and hoes, the plants will be setting considerably. Some say, keep the runners off till the 
plant gets strong; but this would deprive you of your early plants.

If, then, we are going to make the most of these early plants, how shall we manage to keep on cultivating, stirring the soil, and keeping out weeds? A problem besets us right here that I have discussed many times in these pages. The trouble is to find a man or boy who will put the runners in place so as to have them crowd each other as little as possible, and at the same time not get out into the row in the way of the cultivator.

Well, now, I have hit upon a little device that has enabled me to give my plants space in very good shape, and at comparatively small expense. When they began to put down runners on the Brandywine and Wm. Belt rows, I called two of my good boys, Carl and George. We first stretched a string just as near the row of plants as we could have it and still give room inside the string to set all the runners. Then the boys were given two trowels to break up the crust between the plants where the cultivator could not go, and make it all mellow. Then they put the runners down, placing a little dirt with the trowel over and around the bud, making each plant go inside the string. They thought I might give them a little more room by putting the string further away; but I told them we would put it further off next time. They got them all in nicely, leaving a space of five or six inches between every two plants. Then they took a hand-hoe and cultivated the ground up soft and fine clear up to the string. The string was then moved to the other side of the row, or, rather, two strings were used, one on each row of berries, leaving a path from 15 to 18 inches wide between the two strings. Here the boys stood (or sat down) while putting the plants in place.

After the row was finished, of course so much walking on the path would make it hard from the stamping. The boys therefore always went through with their wheel-hoe, and fined it up again. After the boys had finished their work, a nice shower of rain came up, and every plant they had put down was soon rooted, right where they put it. It was indeed a pleasant sight to behold, especially as the edge of the bed where the string was stretched was as straight as a line. A man could go in with a horse (and, in fact, did go in with a horse), and keep the space between the rows beautifully fined up and keep down all weeds.

You may say it is lots of trouble to put every runner down by hand where you want a plant to grow; but $I$ believe it is 
less trouble than to have your rows in certain places so wide that scarcely a path is left. A man who has any taste and skill at all will go into a nice strawberry-patch made as I have directed, and run his fine-toothed cultivator clear up to the point where the string was stretched, and will do you a handsome job. If you are selling plants, you get ever so much better roots to have the ground evenly occupied. Now try it, and see if my invention in strawberry-growing is not worth something. even if said invention is not (when you come right down to it) any thing more than a ball of string that costs only a nickel.

HIGH.PRESSURE STRAWBERRY GROWING AND SUB IRRIGATION.

From Gleanings in Bee Culture, Sept. $1,1897$.

If you haven't ground enough for a garden, and have only a few rods where you can get sunshine, you can grow wonderful strawberries even there; and if there be such who read Gleanings in Bee Culture. who have not even a few rods, if they have even a few yards of ground where the sun may shine a part of the day, and where the plants may get the benefit of the summer showers, they may have much enjoyment and much delicious fruit, even with a few yards. Almost the only condition is plenty of daylight. During mid-summer, very fine strawberries may be grown entirely in the shade; but during the rest of the year it is much better to have the sunlight.

Few people are aware of what wonderful things can be done with strawberries where they are provided unstintedly with water and plenty of fertility. You need not urge that it will not pay; for if you get interested in the matter, I think the enjoyment will almost pay you, to say nothing of the luscious fruit; and then the pleasure of being able to astonish your friends by showing them strawberries as large as smallsized hen's-eggs, and almost as perfect in shape, which you may do with some of our finest new varieties!

To commence with, we must have sub irrigation ; and when you succeed in managing sub-irrigation for strawberry-plauts you have the matter fully in hand so you are ready to apply it to almost any other crop. You may commence on a very small scale at first-in fact, I rather prefer you should do so. When 
you make a success of this small scale you can easily enlarge it as much as you choose. Perhaps the present month of September is as good a time to start as any, for we can now lay the foundation for great bushy plants to furnish us quantities of immense berries next spring. For sub-irrigation you must have some sort of bed or box that will hold water; and you can start the business very well with a large-sized common washtub, if you do not like to go to the expense of making a watertight box. A tub would be rather deeper than is necessary, but it will illustrate the plan. Provide some good finely sifted garden soil-enough to fill the tub a third full. Then get some old well-rotted manure, old enough so you can work it through a coarse sieve. Such a one as is used for screening. coal ashes will answer very well. Have equal parts of garden soil and sifted manure. A little clean sand and some swamp muck will help make a nice compost if you have materials handy. Set a common drain-tile on end at one side of the tub, and fill it with the compost. Now you want a strawberry-plant. The plant should be a young one; but if you can not find a young one, almost any strawberry-plant will do. But I would start with a potted plant (see cut, p. 131) of one of the very best of the new varieties, because it is just as easy to propagate high-priced plants as low-priced ones. Set the plant in the middle of the tub. Let your tub stand where it can get both rain and sun; but should there be a very heavy rain so as to endanger filling the tub with water so it rises above the soil, the tub must be covered-that is, when the soil is wet enough. If it does not rain, pour water into the tile until it rises and stands say two or three inches below the surface of the soil. This water underneath will always keep your soil damp enough. But do not water your bed every day. Air through the soil at intervals is as important as water at intervals.

If the weather should happen to be dry and warm, evaporation will take away the water until it sinks in the tile almost to the bottom of the tub. When it gets down say within an inch of the bottom, then fill it up to within an inch or two of the top; then let it gradually sink down again. If you have rain every two or three days you will not need to water your little bed at all. But keep watch of it, and do not let the plants get drowned by too much water, nor dried out by lack of water. When the plant gets to growing vigorously it will put out runners. Spread these out like the spokes of a wheel, and let them take root. But a better way is to plunge a li.tle pot, say two inches in diameter, down to the surface of the soil, 
and make the plant take root in the center of the pot. This enables you to move your young plants without having them stop growing. On page 131 is a cut of a potted plant when the roots have filled the pot so that it needs to be taken out and given more room.

What is meant by "pot-bound" is letting the plant remain until the roots have so filled the pot that they become cramped and stunted. If you start plants in pots you must be sure to take them out before they become pot-bound. The plant, with all the soil adhering to the roots, is easily removed from the pot by turning it over and striking the edge of the pot a smart blow on some solid body-the edge of the tub, for instance. When your plants are ready to come out they should be put out in a similar tub, and placed at least three or four inches apart. If you want them to bear fruit they should not stand nearer than six inches. If you are going to keep the runners off, and grow them in hills, they ought to be planted as much as two feet apart. The largest and finest berries are grown by the hill system. This has been fully described.

Now, in the above you have the whole thing in a nut-shell. Sub-irrigation is certainly the way to grow strawberries. The objection to it is the expense of having water-tight beds. You can probably make a wooden box much cheaper than a tub; and if you are going to make a box it ought to be large enough to take for a cover a common-sized hot-bed sash, the regular run of these being 6 feet long by $31 / 3$ feet wide. This box can easily be made sufficiently water-tight of lumber well nailed together; but it is generally considered cheaper to take less pains with the lumber and the carpenter work, and make the joints tight with water-lime cement.

There are many opinions in regard to the depth of soil needed to grow plants; but I believe four or five inches is deep enough. Perhaps you had better have six inches of soil and manure. With the glass sashes I have spoken of you can protect the plants from frost, and have strawberries one or two months earlier than you can get them in the open air. The sash can also be used to keep off surplus rain when observation shows you there is enough in the bed. For a bed 3 by 6 feet you will want at least two tiles-one in opposite corners; and if you expect to neglect your bed, and let it get full of water during some heavy rain, you will need a hole bored down close to the bottom, with a cork to stop it up. But I do not like this arrangement. Whenever you let water off because you have so much as to drown the plants, you are leaching away the fertili- 
ty of your soil. That is the way we do in all outdoor farming and gardening, but it is a bad way nevertheless. A small quantity of manure will do a tremendous lot of fertilizing in growing plants if we never permit the fertility to be leached away and washed away by excessive rains.

Well, after you get your sub-irrigating strawberry-bed,"3 by 6 feet, to working nic-ly, you are ready to try a larger one. Your bed may be 6 by 6 feet, so as to take 2 sashes, or it may be 6 by 12 so as to take four sashes; or you may have it 6 by 50 feet so as to take 14 sashes. That is the size of bed we use in our high-pressure gardening. I would not have it more than 50 feet long, because you have to carry the sash so far when you pile them up at each end of the bed. You will find cuts of these beds in our tomato-book.

"But can we not," somebody is always inquiring, "practice sub-irrigation outdoors?" We can ; but a heavy rain is sure to fill up our beds and necessitate drawing off the water. It works all right in a greenhouse where you have control of the water supply; but I do not know how sub-irrigation can be made a success in the open air unless you arrange valves to be opened to let the water off when there is too much of it; and the water that comes out of these valves will show by its color that it is carrying away the fertility of your manure. And is not this an objection to all kinds of underdraining? Yes, my friend, it is an objection; but it is much better than to have the plants drowned by a surplus of moisture. These watertight beds are expensive, I know ; but for high-pressure gardenwork they are alm sst a necessity. When you have them nicely arranged you can push strawberry-growing or any thing else right through the most severe drouth; and with the sashes put over your plauts, you have nothing to fear in the way of frosts. I suppose, however, such arrangements will be particularly used for supplying yourself with extra-strong vigorous plants to put in the field, say during August and September; and if the plants are of some new variety that commands a high price, you can push your propagation without regard to what the weather may be.

These plant-beds should stand exactly level. If they do not, the water you introduce through the tiles will settle to the lowest point, and you want it disseminated equally all through the bed. With beds say 50 feet long or less, two lines of tiles should run the whole length of the bed. These are laid in cement, and the joints closed half way up the diameter of the 
tile. With this arrangement the water may be introduced, say, at each end; and you will in time moisten the soil equally the whole length of the bed. Now, while the bottom of the bed is on a dead level to facilitate even watering, the sashes should have an incline when placed on top of the bed, so as to carry off the rain water; therefore the north side of the bed should be an inch or two higher than the south side.

HOW TO GROW EXTRA-FINE STRAWBERRIES.

From Gleanings in Bee Culture, Sept. 15, 1897.

The beds I have described will probably be used for growing plants to set out in the fields rather than for producing fruit, although by far the finest fruit can be secured by this same plan of sub-irrigation When your beds are all full of plants, as they will all very quickly be providing you follow up the work without any neglect, you will probably ueed to set them out in the open ground. This plot of ground, be it large or small, should be thoroughly underdrained. The objection to sub-irrigation in the open air, I have already given. When you have potted plants to spare, put them out in ground well work. ed up and fertilized, in rows 4 feet apart. I would put the plants about a foot apart in the row. Run through them with your hand cultivators or horse cultivators, keeping the ground constantly soft and mellow, and free from weeds.

In order to facilitate cultivating, every time you go to work potting plants, stretch a string on each side of the row. Now, have this string as near the mother-plants that are putting out runners as you can, and have just the young plants potted inside of the string, and yet arrange to have no two nearer than five inches from its neighbor. We do this in order that we may keep running the cultivator clear up to the line made by the string. The space between the plants must be kept mellow, and free from weeds, by some of the various hand weeders. Below is a cut of an excellent one for this purpose.

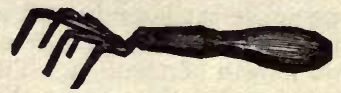

A HAND WEEDER FOR WORKING AMONG STRAWBERRIES. 
Now, the above arrangement is all right for growing fruit on the plan called the matted-row system, only we avoid letting the plants stand near together, on the plan that Terry recommends.

If you want to grow extra large nice fruit, there is a still better way ; but there are several objections to this "better way." First, it is lots of work to do all the cultivating by hand. Second, it is lots of work to keep the runners off. Third, while you are growing fruit you can not grow plants for sale ; and where the plants are rare and valuable, this is quite an objection. But, dear friends, you must remember that in strawberry-growing you can not grow the finest fruit and grow plants for sale at the same time. In bee culture you can not get great crops of honey and a great amount of increase of colonies in the same season. You will have to decide whether it shall be more valuable plants, or simply grow big berries and more of them. By the way, perhaps I should say that, while you are growing plants, all fruit.stems should be clipped off. You can not get the finest plants if you let the mother-plants that are sending out the runners bear fruit.

We will suppose, then, that you have in your sub-irrigating beds, and even in your very rich beds in the garden, kept off all blossom-buds. You have got to the point where you have hundreds or thousands of nice strong plants with great bundles of roots. They ought to be potted transplanted plants. What shall we do with them? Well, in the first place we want a piece of ground-the nearer square the better, although this is not particularly important. It should be at least an eighth of an acre; but if you have not that much we will try to get along with less. Have it well underdrained, then work it up fine and soft down 12 or 15 inches, or even 18 inches deep, if you can afford the expense. If the patch is small, get some expert gardener to spade it two "spits" deep, working in all the manure meanwhile you can get hold of. If you do it with horses, spread as much manure on the ground as can possibly be plowed under. Have a man follow the plow to pull the manure into the furrow ; and then after the ground is plowed and harrowed, get some fine manure that will not clog the cultivators, and work in a lot more in the surface. Harrow it or cultivate it until it is fine and loose; then roll it until it is level; and I would take considerable pains to level it with a rake and shovel before rolling it.

In order to have surface drainage as well as underdrainage I would have a good deep ditch all around the piece, and have 
the ground slope gently from the center toward these outside ditches. Never let the water stand in puddles anywhere on your strawberry-patch.

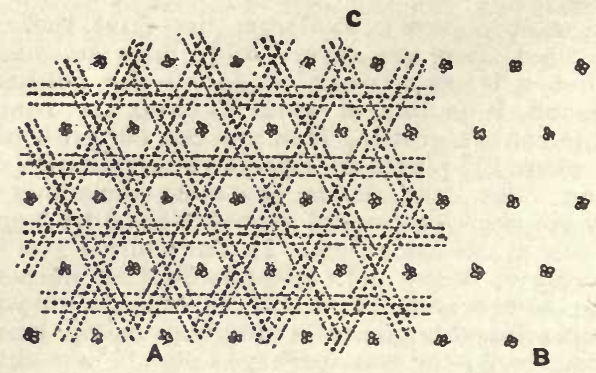

HOW TO PLANT STRAWBERRIES FOR HILI, CULTURE,

Now with the marker described on page 136, mark the plot, say from east to west, with marks as near 21 inches apart as you can make it. Any sort of mark that you can see plainly will answer. We now want to set the plants 2 feet apart in these marks; but you do not want them to come in squares. Each row of plants should "break joints" with the preceding row ; then any three plants in the plot will stand in the form of a triangle; and this triangle will be 2 feet on each of its three sides. The diagram above will help us to get the idea.

You will see by the diagram that each plant is the center of a circle of six plants. The plants are equally distant from the center one and from each other, like the cells of a honeycomb, if you choose.

There are two reasons for planting in this way. When the plants are large and bushy, they entirely cover the ground much better than if they were planted in squares, and each plant has all the room it possibly can have. Second, you can cultivate them from right to left and diagonally two other ways -see marks made bv the cultivator on the left hand side of the cut above. With this arrangement every runner is to be clipped off just as soon as it can be seen. The plants are to be pushed into fruit-bearing. They are to make fruit and noth$\mathrm{ng}$ else and if you have never tried the experiment you will be astonished to see the size and beauty of the fruit grown in 
this way. All the great strawberry-growers all over the world are practicing this or a similar plan, where they want extra-fine fruit. If you mark the ground and put it out as above, your plants will be just about two feet apart from center to center.

Perhaps you may ask how to get these plants exactly on this equilateral-triangle arrangement. In the cut you will see three letters, A, B, C. These letters form an equilateral triangle. Make it as large as your plot of ground will admit. Take three strings of equal length; stretch one of them on the first row from right to left: then stretch the other two so they will meet at the point C. Now cut two sticks just 21 inches long, or the distance between the marks made by your marker. Use a stick at each end of the row to measure from the first string, and stretch the string every time you put in a row of plants. These rows are to be parallel, either with the line B C or A C. Set a potted plant wherever the string crosses a furrow mark. The cultivating is all to be done with the hand cultivator or garden-plow pictured below.

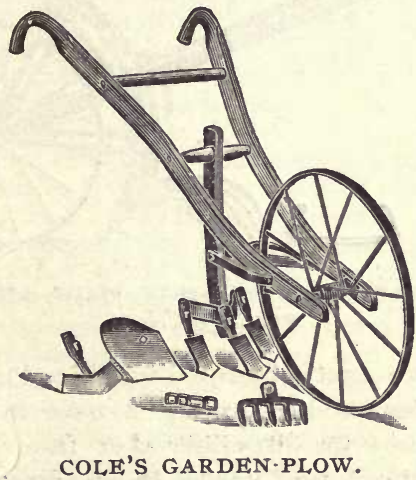

Price $\$ 4.50$, with all the above attachments ; made by G. W. Cole, Canton, 111.

This plow has three teeth, as you will observe, and makes three furrows. The dotted lines between the plants in the cut are to represent these furrows. Run this cultivator through the plants in three different directions, as I have indicated, say as often as once a week; and be sure you run it once after every shower when the ground in the beds is in the best state to pul. 
verize. Any boy will do it after you show him how, and he will think it is fun-that is, if the field is not too large and the boy is not too small. If you have a spell of dry weather, such as we are having now, keep your garden-plow going, and it will almost take the place of watering. In fact, that is what our garden-plow is doing just across the way while I write these lines. Some kinds of plants are better suited for this hill-culture system than others; but almost any variety will do ever so much better when it has room and good cultivation, and does not have to make runners.

While on the subject of hand cultivators for strawberries, I might say we have used the cultivator figured below, purchased of Montgomery Ward \& Co., of Chicago.

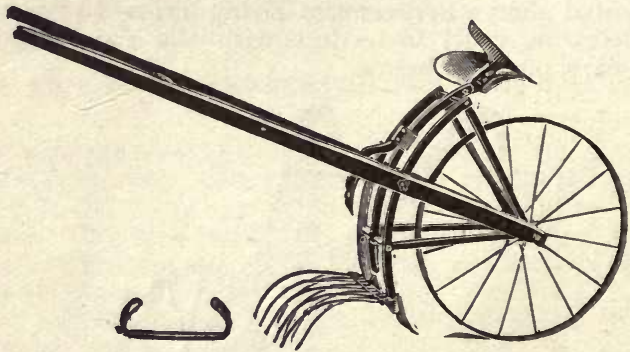

HAND CULTIVATOR, SCUFFLE-HOE, PLOW, AND WEEDER. PRICE \$3.75.

The above is a most substantial tool because it is all metal except the handles; and by turning it over there is a sharp plow that will throw the dirt either to or from the plants, and that, too, without any time wasted in changing the tools-just work it upside down. The only ojection that I have found to this machine is that it is rather heavier than the Cole gardenplow; and this might be no objection at all to a good stout man. It will stand more wear and tear than the lighter implement; but the Cole plow might be found easier for a boy or an old man (say of 62 , like myself) who has not the strength to work 
the heavier tool continuously. Both of these plows are splendid tools for working a strawberry-patch by hand.

\section{PREPARING GROUND FOR STRAWBERRIES.}

\section{From Gleanings in Bee Culture, May 15, 1898.}

Right near our quarter-acre of plant-beds is a piece of poor clay ground that persistently refused to give decent crops of any thing. It was not only poor soil, but it was in a low spot where water had stood. I underdrained it, but it was soggy and sour, even then. Then I made surface-drains all around it. I plowed it up, worked down the lumps, and put on manure. I suppose a good many old farmers would have said I had better let it alone and make garden somewhere else. But the ground was near the railroad, and had cost at about the rate of $\$ 2000$ an acre. We bought it more to prevent somebody else from locating there than for almost any thing else. Well, I kept on working the ground, plowing manure under, and working old well-rotted manure into the surface, but still it did not seem to amount to much. Then I put on some cotton seed that came to us with sweet potatoes packed in them; put on poultry manure; then I gave it a good dressing with lime, and finally it began to respond and " smile." We put out Marshall strawberries and other kinds that were in demand, and began to sell plants. The results of my patient working and manuring began to be apparent. We had great beautiful berries, wonderfully large and beautiful green leaves, and then great runners almost as large as slate-pencils in size. And then what beautiful plants we secured to send out to customers!

We kept working the ground with wheel-hoes between the rows; and every little while, when the plants got to getting out into the paths, so it was difficult to cultivate, we would stretch a string and take up all the plants outside of the string. Then just after a rain we would run the hoes again until the ground was fine, soft, and mellow. At one time I felt a little fear that I was throwing money away by putting manure and work on that piece of ground. But it has given us beautiful plants that have paid several times over for the manure and abor, and the ground is in such tilth now that it goes right 
ahead without any manuring. In fact, it is the finest piece of ground, I do believe, on our premises. Any thing will grow there. You may say we get our money back because we are selling plants at good prices. But I think you will get your money back for fixing up a piece of ground like this, even if you do not sell a plant. In the first place, you get fruit that " astonishes the natives," both in quantity and quality. If you do not sell plants, you probably buy them more or less. Now, have a piece of ground like this; and when new plants come out that cost a lot of money at first, purchase just one plant. If it does not become popular, you are not much out of pocket; but if it does, you can raise your own plants at a cost of less than a cent apiece, when they may be worth a dollar a dozen, or even two dollars, on the market.

There are three or four new strawberries that command very high prices in almost any market. The man who purchased only one plant last year, and raised a lot of young ones from it, is lucky. The Nick Ohmer, Margaret, and Darling are all plants of this kind. Another thing, it is fun to bave a garden where you bave a piece of ground that just makes every thing boom. On our clay soil, when we once get a piece like this into high-pressure condition the effect of the heavy manuring lasts through a long period of years. In the shade of our machine-shop there are some beds that were fixed up several years ago They have had no manure for several seasons. As they are so much shaded we use them only for celery-plants. The ground is fine, soft, dark, and rich; and it is a beautiful place to heel in stuff for a few days, where we want it in the shade. The quality of the soil seems to invite any plant to put out roots. In fact, we have been selling the dirt to the people around town for their house plants, at $25 \mathrm{cts}$. a bushel. Now, every one of you, I am sure, can afford to have a little picce of exceedingly rich ground near your homes. First have it perfectly underdrained; then either spade or plow it up very deep. Let it freeze in winter and di $y$ out in summer; then plow, pulverizing it at just the right time after every shower. Get out all the sticks and stones. If it is heavy clay, put in some sond. Give it a coating of lime occasionally ; and, above all, work in lots of good stable manure; and be sure that you do not let it spend its energies in growing great weeds after you get it up to the high-pressure notch. Such a piece of ground will grow weeds higher than the eaves of your house in an incredibly short space of time, if they once get a going. 
OUR HILF-ACRE STRAWBERRY-P ITCH WITH PLANTS TWO FEET APART EACH WAY.

Last fall I told you about this. We are just now (May 15) having fun running the wheel-hoe through it after every summer shower, cultivating it in all three directions, as shown in the diagram. The ground is getting so soft and fine that the boys do not dislike the job of cultivating it at all; and, in fact, it is but little work to keep it clean, and the ground soft and fine. The plants are growing amazingly. The original idea was, you may remember, to take off every runner as fast as it showed itself. But a difficulty presents itself right here. As this was to be a trial patch of the different varieties for hill culture, it contains some very high-priced plants ; and to pull off the runners and throw them away would be rather extravagant; therefore we have decided to let runners grow on at least a part of these valuable plants, and get them to take root in little pots of jadoo. After the roots have started you can clip off the runner and move the plants into a shaded bed. I do not believe this will roh the parent plant of very much vitality. It will be keeping off the runners, with this difference: we allow them to commence taking root before we "wean" them, or hefore we take them away from the mother-plant entirely. But I tell you it is fun to have a strawberry-patch so you can run the cultivator all around every plant, and do it fast.

MULCHING AND MANURING STRAWBERRIES AT ONE AND THE SAME TIME

From Gleanings in Bee Culture, July 1,1895 .

We have about an acre of strawberries that are growing their third crop. We ordinarily let them bear only two years ; but we kept working and manuring this patch in order to get plants, and this season we proposed to plow it under just as soon as the last berries were picked. Only part of it was mulched during the winter. We do but little mulching, because we want to work the ground in the spring so as to get nice plants for shipping. But just before picking-time we found we should have to mulch with something. Muddy and gritty strawberries are behind the times. Every strawberry-grower ought to be ashamed of offering dirty berries. On the fairground, near our 
place, there are some horse-stables where they make a great quantity of loose strawy manure. It is so much straw and so little manure that I pay only from 50 to $75 \mathrm{cts}$. a load, and this for a load that we bring on our hay-rack. Well, I thought I would use this for mulching to keep the berries off the ground. You know : ow the frost cut them off, and just about spoiled the Jessies with some others, and then the hot drouth diminished and dried up what few berries were left. Well, we had pretty much given up getting any strawberries worth mentioning ; but a pretty good rain came on the evening of the $19 \mathrm{th}$, and lasted during the forenoon of the next day; and almost as soon as the rain was over I was happily surprised to see not only the bright new foliage, but stems of berries sticking up here and there that had just about doubled in size during the rain ; that is, the were twice the size they would have been had it not been for the rain and manure. Well, now, that acre of strawberries is bearing considerable nice fruit, and making plants at a tremendous rate, under the influence of the straw mulching and the manure. One objection to stable-manure has been, you know, weed seeds; but if we are going to plow the patch under so soon, who cares for the weeds? The more they come, the better. I propose now to let the whole thing be until both weeds and plants get at their best, then we will take out the best of the plants, with a lump of dirt adhering, and make a new plantation right beside the old one. $B \dot{y}$ this time the weeds will be up so as to be worth something to plow under; and thus we shall have a splendid piece of ground for buckwheat and crimson clover, as mentioned in the last issue, or for any other late crop.

\section{A VISIT AMONG THE STRAWBERRY-GROWERS.}

Saturday afternoon, June 15, I started out to see what my neighbors were doing in the height of the berry season. About ten miles northeast of Medina I found the Lawnsdale fruitfarm, on ground high enough so they were affected by the frost but little compared with our own locality. Friend Williams, the proprietor, raises strawberries, raspberries, blackberries, gooseberries, and currants, with potatoes for filling in and to make a sort of rotation of crops. He has about 30 acres of land, and it was really a refreshing sight to behold such a berry-farm right in the midst of a locality where every thing else is devoted to regular farming and stock-raising on a heavy clay soil.

On a northern slope near the road I found about an acre of 
strawberries that was worthy of a picture; but I did not have the Kodak along that time. The berry-plants are in rows, apparently about four feet apart, like our own. They were so well mulched with straw in the fall that not a berry could find a grain of dirt or soil to rest on. Friend W. hit it exactly in being slow to remove the mulching. He kept the plants back all he could without injury, and then gradually made openings in the straw to let the plants come up through when they were ready to start. By the way, I have never found anybody yet who would remove the mulching with sufficient care to suit me. They would go and claw the straw all away and throw it in the paths. Now, the straw should not be moved a particle. Let the berries go up through it, leaving the straw where it is; then you will have a perfect mat to keep down weeds and to keep the fruit out of the dirt It also serves to keep the berries back so as to avoid a late frost. Only two kinds were on this patch - Crescent and Downing-three rows of one and then three rows of the other, and so on. Varieties that succeed splendidly here in Medina do not prove to be the best there, just ten miles away, and therefore I feel sure it behooves every strawberry-grower to test, say, one row of each of the best kinds prominently before the public; then make a selection of what suits your locality, and stick to your selection. I do not believe any grower wants very many kinds for fruit alone in his locality. It may pay him to have a few Michel's Early, and, say, a few late ones like the Gandy ; or if other extra late ones or extra early ones do better, take them instead. Friend W. does almost all the work on his 30 acres with the help of his wife and two children. It keeps them pretty busy, especially during the berry time; but, if I am right, the happy families are the busy families. I shall long remember the hour I spent in and around that pleasant little home. And, oh! by the way, I picked up

\section{A HORSE STORY}

at that home that I am sure will interest you. Friend W. is about two miles from the town of Brunswick. His girl attends school there, and comes home nights. Now, this will do very well in good weather; but how about bad weather? I will tell you. They have a sagacious, gentle horse that takes the young lady to school every morning, and comes home himself. About the time for school to be out he goes back for his young mistress. As there is not any driver he sometimes takes things easy in going the two miles, and does not reach his destination 
till after school is out. At such times the young lady comes to meet him on foot along the sidewalks that go a piece out of town. He has learned that, when he meets her, he must turn around and go back again; so he watches all the little girls of about her size as they cor:e out of the school and come down his way, turning his head and pricking up his ears while he scrutinizes each miss to see whether she is the one he "belongs to." Sometimes he seems somewhat undecided, and stops in the road to take a better look. When he is satisfied the one in question is not his "hest girl" then he goes on for the next, and so on. This brings in an interesting point just here : How far can a horse see, and see plainly enough to distinguish one person from another? I suggested that meddlesome people might tie the horse up, thinking he was astray; and they very soon found that a card would have to be hung on to the harness, to the effect, "You let me alone. I know where I am going, and I am all O. K." After this, especially as the people round about have "caught on," he made his daily trips without hindrance.

\section{THE BARBER BERRY-FARM.}

This is about two miles directly north of Brunswick. It is near what they call Stone Hill. As I pushed my wheel up the neat graveled path under the trees, a pleasant-faced woman met me with smiles, telling me her husband was just starting off, but that I could stop him if it were attended to at once. Friend Barber has been in the fruit-business from childhood up, and he has perhaps 50 acres on a gravelly stony hill, devoted entirely to fruits. This hill is a very high one. The slope toward the west must be down a hundred feet or more; and the consequence is, he has his trees and berries loaded with fruitgrapes, plums, cherries, peaches, etc. It was a real pleasure to me to find I was able to name not only his strawberries, but nearly all his raspberries, currants, and some of the blackberries. After experimenting some he has decided to plant the Victoria currant almost entirely, and nothing else. For raspberries be has the Cuthbert for red, and Gregg for black ; some Shaffer's Colossal, and some Marlboro for early. He not only uses the hill, but, like myself, he has a creek-bottom strawberry-patch which is nice to start plants; and when the frost holds off it gives quite a lot of fruit. Various springs in the hillside would probably fill a reservoir sufficient to irrigate his lower grounds, and he is just now planning to have this done. 
REDUCING THE EXPENSE OF PICKING.

Friend Williams gave a valuable suggestion right here. Both he and Mr. Barber had their berries picked at the rate of 5 cts. for a four-quart basket. Now, it costs more than this to get our berries picked; but we pick them every other day. Friend W., by using Crescents and Cumberlands, can wait three or even four days, as the berries are firm enough to stand handling, even if some of them are a little overripe. You see, the pickers can work cheaper where the berries are very plentiful. Heavy mulching, with his peculiar soil, perhaps helps to raise berries that will stand this length of time between the pickings.

Before I was half through looking at and sampling the Haverlands, Cumberlands, Jessies, etc., the sun was setting, and I was ten miles from home Saturday night. Oh what a nice thing is a wheel! We were back in the fields about half a mile from the road, and the half-mile was up a long steep hill. I suggested that I could cross the fields and strike the road in the valley, as that route would be much less hilly for me for my trip home. Now comes in the advantage of a light wheel. I could hang it over my shoulder, climb fences, or get through bushes, without much hindrance. It made me puff some until I struck the highway, and then what a delight it was to spin along a road almost level! To really enjoy wheeling to its fullest extent you should walk occasionally until you are tired of walking; then the wheel comes in and gives you that delicious rest. A boy in his teens came down from a pretty house by the way, and mounted his wheel. He did not see me; but I thought I would, just for the fun of it, run past him and show him what an 18.1b. Rambler could do. But I did not show him the Rambler at all. Do you know why? Why, he kept ahead of me in spite of any thing I could do, and in a little time he was away off in the distance, clear out of sight, even if his wheel did weigh more than twice as much as mine did. Never mind. I always feel glad when somebody gets ahead of me, even if I had planned otherwise-at least, I hope I do ; and I am certainly happy in seeing the boys and giris put distance to naught, even outdistancing myself in it. There seems to be something especially fascinating about wheeling during twilight ; and after visiting California and Florida, and experiencing almost sudden darkness as the sun goes down, I enjoy our Ohio twilights more than I ever did before. 
REPORT ON THE NEW VARIETIES OF STRAWBERRIES IN THE MIDDLE OF JUNE.

From Gleanings in Bee Culture, July $1,1897$.

The Marshall has done grandly, both under glass and in the open air. Brandywine is just begining to ripen, and grow berries that can hang on the vines for two or three days, and still be so firm and solid that they may be tumbled about like potatoes. The Wm. Belt is well loaded with fruit, but only just begining to ripen. Margaret has given us some of the largest and finest berries I ever saw; but the Nick Ohmer caps them all, not only in great size, but in producing berries as round and symmetrical as a peach, and pretty nearly the size. I kept one on the vines for three days to show to visitors, and it was very solid and firm when picked. It weighed almost an ounce and a half. This was from a plant set late last fall. The runners were not picked off, and it was allowed to mature a full crop of fruit.

\section{WHO WOULDN'T BE A GARDENER?}

Sometimes I think it strange that there is anybody in this world who does not have a garden; and then at other times, when prices are low and we can not get the cost of our stuff, and every thing goes wrong, I do not wonder that so many people say they would rather buy their stuff, what they want, than to be bothered with any sort of garden. Well, yesterday and to-day have been bright days for the gardening business. After a severe drouth we had a succession of refreshing showers. Our beds were so full of plants that I began to fear we should never have customers for all of them; but after the shower the people came in crowds for plants. I stationed myself near the garden, and called in help for the boys, and it kept me as busy as I could be in answering questions and giving directions.

While the "boom was on" for plants people began to go for the strawberries lively. They had just got down to 8 and 9 cents, and somebody in the store was complaining that there was not a quart of strawberries to be had, and customers waiting. But there were some big rows of Bubachs, Marshalls, and Brandy wines waiting to be picked; and in a twinkling we had a lively time around the strawberry-beds. We might have put up a notice, "Beautiful strawberries picked while you wait." In fact, that is what we did do. With myself on hand 
to show off the plants, and give the names of the different virieties, it was not at all surprising that customers would say, "Well, I think I will have a quart;" or, "Why, I will take two quarts of those great big ones, if you give heaping measure like that," etc.; and just when I began to fear there were more strawberries than we could easily get rid of, they were all cleaned up-in fact so much so that the boys, in their efforts to get a few more quarts for a customer, picked some that were rather green. Oh how the new varieties have brightened up and enlarged since the rain!

This year we are testing new varieties, as I have explained, by putting them in our plant-beds 18 inches apart. This is just about right; and if you do not step on the beds at all it gives plenty of room for putting down runners. It is wonderfully interesting to me to note the peculiarities and desirable traits in the different candidates for public favor. For instance, Clyde, that has been considerably talked about, is really bearing a wonderful crop-wonderful considering that the plants were put out only this spring.

Our friend Dan White, of New London, O., told me he is putting out an acre and a half this year on the plan I gave on page 117. He says there was not a ripe berry to be found among his Gandys up to June 22, and he places the Gandy as the latest berry to ripen he has ever found.

By the way, the berry that I was so pleased with last year, and that came as the Great American (see p. 180), I am obliged to think is only our old friend Sharpless under another name. The berries are now (June 22) in their prime; and the reason they were so much later than every thing else last year was on account of their being grown in such a thick solid bed. The rank foliage and the close planting kept the sun out so as to make the berries late. Well, even if it is the Sharpless the incident has opened to me a new possibility in strawberry culture. Make your ground exceedingly rich (it had better be heavy clay soil underdrained), then let the plants grow all over. Let them stand just as thick as they have a mind to. Perhaps some currant bushes or something of the sort to help shade the ground will assist in making them backward. Now, notwitbstanding its cramped circumstances, the Starpless, after all other berries are gone, will produce great monstrous fruit. Of course, the berries will not be colored up very much; or at least not to amount to very much; but the Sharpless is very nice to eat when it is partly ripe. But you will find a purchaser at good prices while other berries are too small to bother with. Besides, such 
a plantation would be little or no trouble. When once started it would choke out every weed that attempts to grow.

SUB-IRRIGATION FOR STRAWBERRIES; ALSO SOMETHING ABOUT POTATO VINES FOR MULCHING STRAWBERRIES.

At this date, June 26, right here, we are having a pretty severe drouth, and it comes almost right in the midst of our strawberry crop. It affects us worse because the ground was packed down so hard by our excessive rainfalls that it cracks open and does much damage except where the surface has been fined up by cultivation. Our choice strawberries that were planted out late last fall, and which are in narrow rows, we have cultivated and fined up the space between the rows, so as to obviate the drying and cracking, at least as much as we could without interfering with the mulch. The mulch of straw and potato-tops is not sufficient to prevent damage entirely. Our berries are drying up, the greater part of them, and look as if they had been cooked. Had the soil been worked up down deep after the heavy packing rains, the damage would be but slight. In fact, corn and potatoes planted in well-pulverized ground after the rains are not suffering perceptibly. We have just had an opportunity of testing the benefit of water in one of our sub-irrigating beds. It is planted to strawberries, but no water was turned on during the spring. I purposely left the bed until the berries began to be small and dried up somewhat. Then we turned on water until it came up from below, so as to dampen perceptibly the surface.

In 48 hours the whole aspect of the bed was changed. Every green berry began to fill up and expand wonderfully. Those that had begun to shrivel, plumped out, looked very glossy and juicy, and they were juicy too, I tell you.

There has been considerable said about selling strawberries at the low price of 4 and 5 cts. a quart. Well, that is pretty low; but if we had our beds so arranged that we could water them from below, letting the water gradually rise up until it comes just near enough the surface, I do not know but we could do a pretty gond thing by selling water at 4 or 5 cents a quart. Choice varieties like the Brandywine, Wm. Belt, Marshall, and others, bring 6 and 7 cents a quart-sometimes 8 .

By the way, the latest berry to ripen on our ground this season is the Champion of England. I think the location of the bed, however, helped to make it late. It was on the north side of a grapevine-trellis, and protected from the sun pretty well all through the day; then it was mulched with potato-vines last 
fall, so that the plants had to creep up through the vines to get out into the open air. This helped to make them late. This morning we made our first picking. A good many of the finest berries were scattered through the potato-vine mulching. The drouth had hurt them but very little, and the great clean luscious berries hidden away in the dried-up potato-vines were in beautiful shape. To get berries extra early they should be in thin rows, or, better still, in hills, and we should work the ground without any mulching until just before the fruit ripens; but for a very late berry, heavy mulching is needed-all through the spring to keep them back, and then the shade of a grapevine or of trees will also help. This, with heavy matted rows, will enable us to have fine large berries after the others are gone; and my impression is, that sub-irrigation, with the water let on at just the right time, will also help to prolong the crop.

SOME OF THE NEW STRAWBERRIES-ONE OF MY HAPPY SURPRISES.

From Gleanings in Bee Culture, June 1, 1898.

We have been picking strawberries that were started under glass, for a month or more; and Earliest and Darling, that were not under glass at all, for the past three or four days. The Earliest was only about three days ahead of the Darling. The Darling gives rather larger berries. On account of the hot weather and lack of sunshine, both are rather tart this season. Well, my happy surprise was not in regard to the Earliest nor Darling either, but it was in finding this morning some great big Nick Ohmers, not red on one side, but red all over, and only three or four days behind the Earliest in earliness-perhaps right with the Darling in that respect. But the Nick Ohmer is ever so much larger than either of them. We had such a call for plants last fall, at $25 \mathrm{cts}$. each, that we did not save very many Nick Ohmers. In fact, there is only one bed, containing about 50 plants, and these were put out very late in the fall. Of course, they have had good cultivation and plenty of manure. But this would not quite account for their being away ahead of almost every thing else in any way that I can see, unless it is in being extra early. Why, an acre of these great big berries, large, handsome, and earlier than any other 
large berry in the field, would be worth a lot of money. I would give something to be able to present to the readers of Gleanings a picture showing the Nick Ohmers as they stand in that bed this morning.

Michel's Early, that we used to call ahead of all the others, is not anywhere near ripening at the present time, May 30 ; but, to tell the truth, Michel's Early has not been "fussed with" quite as much as these newer kinds-at least, not this season. You see, I want to be honest about it.

Now, none of these varieties mentioned is likely to bear the great quantity of berries that some of the later ones dosay Haverland, Warfield, Parker Earle, and last, but not least, the Clyde. I do not believe there is another berry on our gruunds containing such great heaps of green ones at the present time as the Clyde; and I notice the reports are now greatly in favor of the Clyde as a tremendous bearer.

\section{ANOTHER SURPRISE.}

Yes, and this is a happy one too, even if it does run against the one above somewhat. On page 175 I gave you a glimpse of my plan of hill culture for strawberries. Well, in order to test all the different varieties worked in this way we have to put in one or more rows of all the kinds we could get hold of; and I am watching with very much interest the behavior of the different plants, with runners kept off, and constant cultivation in spring as well as fall. Yesterday, after speaking of the Nick Ohmer's earliness, I went up through that hill-culture patch to see how the others were behaving. All at once I was startled by seeing a great big strawberry, ripened all over, then another and another, until I noticed there were six rows of berries with quite a good many ripe ones right out in the open field. Now, there were a few other kinds that had begun to turn just a little, but nothing like the six rows. What were they? Why, as sure as you live it was our old friend Rio. Michel's Early was near by in another patch in a matted row, but there was not one berry colored in the lot. The Earliest and Darling had just begun to color, but they were planted rather later than the Rio in the same patch. I really do not know why the Rio should be ahead of every thing else in hill culture, unless such constant stirring of the ground suited the Rio better than it did any of the other kinds. That is not quite it either, for the other kinds are making most tremendous growths of foliage and runners. Yes, the greater part of them are putting out runners, even before the fruit has colored. But this constant cultivation seems 
to have hurried the Rio forward, and did not the others-not even the Earliest and Darling. The Rios are great strong thrifty plants, with stout runners already out, besides a very fair crop of fruit it is going to bear. Now, this thing illustrates a point : Under a special system of cultivation the Rio is the earliest good-sized berry we know of. And by the way, friends, there is going to be an enormous crop of berries on that little plantation put out last fall. They were all potted plants, however; or if not potted they were set out with our new strawberry-transplanter that I have described and illustrated; and this experiment demonstrates one thing to my satisfaction: With the right kind of culture you can grow an enormous crop of berries from potted plants in only nine or ten months after they occupy the ground.

RECOMMENDING NEW VARIETIES OF STRAWBERRIES, ETC.

From Gleanings in Bee Culture, April $1,1899$.

You may remember that, some little time ago, in visiting Matthew Crawford, he showed me a strawberry of such wonderful luxuriance of foliage that, had he told me it was a new variety, and very scarce and high priced, I do not know but I would have given him $\$ 5.00$ for a single plant. But friend Crawford is not that sort of man; and then he explained to me that the wonderful growth and luxuriance were not altogether on account of the plant, but in the way he prepared the soil in that one bed. It was light sandy soil, made very rich with old stable manure, and then the ground was pounded as hard as he could make it, with a stamper, something like what we use in setting fence posts. I went home and began to experiment on some of our plant-beds that had been manured so heavily so many years that they contained almost too much humus. We have a pounder worked by two men, that we use in making cement floors and similar work. I had two of the boys stamp the dirt in one of our plant-beds as hard as they could pound it. This was along in the fall, when the ground was dry, and would bear such pounding without injury.

About this time friend Thompson sent me half a dozen Darling strawberry-plants, and I think as many of the Earliest ; also some Carrie. As he called these varieties all valuable I 
put them into that stamped bed. They all did wonderfully well, especially the Darling. In watching the new plants I fear I forgot somewhat the stamped bed, and gave the credit to the new varieties At the same time I began experimenting with plants potted in jadoo fiber, and a great number of them were sent as premiums to our subscribers. The next spring these six Darling plants gave a nice lot of beautiful berries, away ahead of any thing else unless it was the Earliest; and without thinking much about it I helped to boom the Darling, which the originator held at a very high price. Now, I have been greatly disappointed because we have not had more favorable reports of the Darling. In fact, on that account I have dropped it from our list of strawberries. Margaret and Nick Ohmer were also set in a pounded bed, and they both made an immense growth, and produced wonderful berries. I have been putting all of my new varieties in pounded beds, because, when one is anxious to get as many plants as he can, as soon as possible, he must furnish the best of conditions ; and not all plants will pay him so much better in highly fertilized and compact beds than they do in the open field. After I put the Darling and Earliest in the open field and gave them the same chance as the other varieties they have been very disappointing in our locality. I learn from others, though, further south, that in some places they do well.

From this $I$ have been learning a lesson: We should be careful, each and all of us, about recommending a new plant before we have given it field culture right along with the others.

\section{SEL,IING STRAWBERRY-PLANTS.}

From Gleanings in Bee Culture, May $1,1899$.

Now, a happy surprise comes along in the line of selling strawberry-plants. You know I talked to you last year about my handsome plantation of strawberries with the plants only two feet apart from center to center. These were cultivated three different ways with the wheel-hoe; and the original idea was to keep the runners cut off. There was about half an acre of the patch. It was well manured before the plants were put out in the fall of 1897 . Then old well-composted manure, broken up fine, was scattered all throngh the patch with wheelbar- 
rows once or twice last season. In consequence of the strong manure and abundant rains last fall, the plants put out runners and covered the whole ground. It was not a matted row, exactly, but it was a matted halfacre. Well, these plants all wintered without any mulch whatever, and not a plant was lifted out by the frost. Why, the whole plantation looked more like a thrifty field of clover than a strawberry-patch. The problem this spring was to provide paths for the pickers; for the berries will probably lie almost touching each other all over the half acre. More than half the plants are Brandywine and Wm. Belt.

I advertised in the county papers that, if people would come with baskets, and take the plants that were taken out in order to make paths for the pickers, they might have them at half the regular prices; and the thing is going on just as I write, in a way that makes it another happy surprise.

Where a path was wanted we stretched two stout cords. These cords are 18 inches apart. Then a man takes a sharp spade and cuts down along each cord. After this he takes a spading-fork and spades up a block of dirt, plants and all; then with a stout box to sit on (open on one side, about 16 inches square and 6 inches high), he, sitting astride the path, separates the plants from the dirt and puts them in the customer's basket. These plants are about the strongest and thriftiest I ever grew. Where they are too near together, of course there will be some small ones; but these small ones are thrown in without charge, and our customer can use them or not as he chooses.

Now, if all the plants are sold at half the advertised prices, our half-acre of strawberries will produce quite a round sum of money. But there has been a good deal of labor bestowed on it in the way of weeding, cultivation, etc. After the berries are picked, the whole patch will probably be plowed up and planted to potatoes; and with the amount of manuring it has had, I expect a wonderful crop of potatoes.

There has been a good deal of fault found in regard to fall planting; but this plantation was all made in the fall. The plants were, however, put in with a transplanter. They were manured and cultivated and weeded during one whole seasonthat is, last year. A small crop of extra-nice berries was taken from them last June. With this method of working strawberries they occupy the ground not quite two years. We would commence planting them, if the ground were vacant, in August, and in our locality the ground would be ready to put in a crop of potatoes about the first of July; so it would lack about one 
month of having the strawberries on the ground two years. Of course, I do not know what the crop before us is going to be. *

\section{THE EARLIEST STRAWBERRY.}

\section{From Gleanings in Bee Culture, June I, 1899.}

To-day, May 30, we are making about our first picking in the open field; and the Earliest, as before, stands a good way ahead of any thing else. On our grounds we find it even ahead of Darling; but the originator thinks Darling is a little the earlier of the two. I am surprised this season to find the Earliest bearing good-sized berries, and they are growing in a thick matted row at that. It does not give as many berries as the later ones, and they are pretty strongly acid in flavor, and perhaps rather soft to handle. But they give us quite a lot of berries two or three days before any thing else. Last year the Rio crowded close on the Earliest; but this year they are more behind. Now, another thing must be taken into consideration: Rich soil and close planting makes berries later. Right alongside our row of Earliest are some Warfields. On good ground none of the Warfields are ripe; but on a little piece of yellow ground where the top soil had been removed, the ground is so poor that the plants are scattering, and small at that. Here the sun had got in, and we found quite a lot of dark garnet-like Warfields glistening through the dew-drops in the morning sunshine. You can make any berry earlier by putting it on poor ground and having the plants far apart so the sun can get in easily. I thought once we would not plant any more Earliest, as they bear so few berries; but I have just given the boys orders to put down the runners around the edge of the patch, and before we get ready to plow them up we shall have plants enough to make a row or two for next year; and the plants must be thinned out and given room if you want Earliest to be extra early.

* At this date, Jan. 23, 1902, I am happy to state that the crop referred to in the above was one of the largest yields per acre I ever had in my life. Some of the berries, and especially the Brandywine, were as nice and fine as any thing we ever picked. The Brandywine pushed its great clusters of beautiful berries clear above the foliage; and it was for all the world like a field of red clover, except that the red heads were berries instead of clover. 
THE STRAWBERRY INDUSTRY NEAR NORFOLK, VA.

From Gleanings in Bee Culture, June 15, 1899.

These truckers have a sort of rotation in garden stuff. For instance, potatoes are grown mostly between strawberries, $c r$, rather, strawberries are grown mostly between potatoes. The rows of potatoes are five feet apart in this case, and a row of strawberries is put between every two rows of potatoes; and, judging from appearance, they are set in about as soon as the potatoes come up. The small-footed mules pull their light cultivators between the rows, only 30 inches apart, without any trouble. I believe they are rather better than horses, because they rarely or never step on the plants. After the potatoes are marketed, then the strawberries have the whole of the ground. To give you some idea of the strawberry business at Norfolk, I make the following extract from a letter irom friend Stebbins :

Saturday afternoon, at the back of one of our steamboat wharves I counted 17 sail-boats unloading strawberries at once, while others were in sight coming in to unload, and still others going out unloaded. At the front was a string of teams a quarter of a mile long, waiting their turn to unload. Three teams could unload at once, and I don't think it took more than five or six minutes to the three teams. In going a mile I counted 15 more teams coming in, all loaded with berries; that was at half-past three, and that sort of thing would keep up until six or half-past. Now, that is only one of half a dozen lines in town at the same business. You could smell strawberries for half a mile.

Broad Creek, Va., May 15.

At the time I arrived, the strawberry-gathering had come to a sudden stop, not because the berries were gone, mind you, but because the price had dropped to a point where it did not pay to pick them. In Norfolk they pay two cents a quart to the pickers. Then they have to furnish crates and boxes; and at the price offered, only three cents, it did not pay for harvesting. So the owners of the fields, even while the rows were red with berries, gave out to the country all around that whoever chose. colored or white, could come and pick, without money and without price, all they wished. We found colored people scattered all over the fields, picking; others walking into town with crates of berries on their heads. They went through the town offering them at the houses for only three cents a quart. As the berries cost them nothing, they did perhaps very well at the work ; but it seemed to me to be rather discouraging business for the grower.

In some places we found the pickers scrambling out of the 
way of the horses and plows. They were turning the berries under in order to get in another crop without letting the expensive land lie idle. Friend Stebbins says he has seen berries turned under when there were enough to make the red juice follow the plow as it crushed them in the furrow. Three of his family went out the evening before, and in three hours they gathered 70 quarts in one of these deserted fields.

One gardener whom we called on (Mr. Henry Norfleet) had about half an acre of Lady Thompsons. There had been scarcely any berries picked from the field when the price went down. I do not know that I ever saw more ripe berries on a given area at one time. Some of them were really overripe-large and luscious. Nobody wanted them as a free gift. We had been eating berries all day - at least I had-but we felt so sorry to see these wasting that we ate a good many more. The Lady Thompson is certainly a very fine berry in the South. It is hard for the growers, it is true ; but yet it certainly is a great blessing to a community to have berries so cheap that all can have all they want, morning, noon, and night. I asked some of the growers if they proposed to keep right on raising strawberries. They said there was no other way to do, and that they frequently had to make the best of a glut in the market in aimost all kinds of produce; but the man who keeps right on growing good crops is pretty sure, sooner or later, to have something to sell when the price is good and everybody wants it.

I had just one chance to see strawberry-picking going on in the regular business way. Mr. Trotman had received intelligence from Boston that berries were up to 12 cents, and, in fact, I believe he had kept picking right along. You see when the fields are once abandoned they can not very well start again, because rotten or overripe berries would get among the good ones in spite of the pickers; therefore the proprietor of a strawberry-field must keep the pickers going till he decides to stop, and then he must stop for good. When I saw the pickers in the field I said to-friend Stebbins, "There must be very nearly a hundred people who are gathering berries." I have been so much in the habit of estimating the number of hives in an apiary by simply a casual glance that I thought I could guess pretty nearly at the number of people scattered through the patch. Friend Stebbins counted them, and reported 104. There were all sorts of people-big and little, old and young, black and white; but for all that, every thing seemed to go on very harmoniously and quietly. Little colored boys, who seemed hardly big enough to carry a quart of berries, would march in with 
a tray on their heads, and offer their filled quart boses and get their tickets. Some of them did not have very elaborate clothing, but they always arranged to have a pocket that would carry their tickets safely. A smart colored man received the boxes on a sort of counter, letting the picker take his tray back to the field. The proprietor's son was stationed near by with tickets of different values stowed in handy pockets; and he always had the proper ticket or tickets to hand out just as soon as the picker was ready to go back.

We happened to be there just as the dinner-bell sounded, and it was a treat to me to see that motley crowd come in. God knows I am interested in human beings as well as in strawberries ; and I was greatly pleased to see the pleasant feeling that seemed to exist between employer and employee. Friend Trotman pays two cents a quart right through for picking the berries. He said it was a little more than some others paid, but he liked to have his workmen satisfied. I asked him where he found his most expert pickers-among the men, women, or children. He said a colored widow woman and her two little bits of children (it might have been three) were about the best pickers he had in his employ. He said he had recently paid her $\$ 23$ in cash for one week's work for herself and children. Some of those little colored boys and girls were remarkably quick and handy at the business. You see it is not so much work for them to double up and stoop over as it is for older people. In the rush at noon time it was almost impossible to prevent some confusion and disorder. I was pleased to see $\mathrm{Mr}$ Trotman gently reprove a colored man for tramping on a good new berry-box. Somebody tipped them over, and in the hurry to get ready for dinner they were not picked up. The man put his foot on a nice clean box. Now, the value of these boxes is not much over a quarter of a cent each; but letting the people trample the boxes under foot, even if they represent only a small value, establishes a bad precedent.

A STRAWBERRY FESTIVAL NEAR XENIA, GREENE CO., oHIO. From Gleanings in Bee Culture July 15,1899 .

The gathering of bee-keepers and strawberry-growers was in a grove surrounding a schoolhouse. The friends of the year 
before were present, and we were also honored by the presence of Mr. Nick Ohmer himself, and his good wife; and last, but not least, his brother, J. P. Ohmer, was on hand. The latter brought a Nick Ohmer strawberry-plant growing in a tub. I thought I had seen some gigantic specimens of Nick Ohmer strawberries and fruit on our own place; but that plant in the tub "broke the record," in foliage, size of leaf, and size of fruit. Three or four great stems of fruit, almost as large as peaches, reclined on the edges of the tub, and made a very appropriate object-lesson in letting people know the possibilities of strawberry - growing. A quart of berries stood beside the plant, showing twelve berries making a heaping boxful. Some of you will no doubt recall to mind the fact that J.P. Ohmer is the man who grows strawberries successfully through the sides of a barrel. He told us that, although the barrel culture was a success, the average person would probably be unwilling to take the necessary pains to make it a success.

\section{GROWING STRAWBERRIES IN A BARREL.}

From Gleanings in Bee Culture, Aug. $I, 1899$.

As there has been considerable inquiry in regard to this matter, Mr. J. P. Obmer, of Dayton, Ohio, the originator of the plan, has sent out a little circular describing the process: Here it is :

Take any iron-bound barrel except those which have been used for pickels, sauerkraut, or vinegar; take all hoops off but four ; bore four holes in the bottom. Then space holes around the barrel so that twelve plants will go around it. Five rows high will make sixty plants to the barrel (the fifth row can be placed five inches from top of barre1). Bore two holes, one above the other, and cut out the wood between the two holes. By using a bit $1 \frac{1}{2}$ inches, you will have a hole $11 / 2$ by 3 inches. When you plant, put the plants as near the top of the holes as possible, to allow some for settling. Use clay ground, well mixed with rotten manure. Put two inches of gravel in the bottom of the barrel to keep the drain-holes from getting stopped up. Put in the dirt till about three inches above the first row of holes. Be careful to have dirt not too wet.

The first row of holes must be 8 inches from the bottom of the barrel. Get in and tramp the dirt solid, then loosen the dirt with a trowel where the plants go: then plant that row. Spread the roots out well, then put dirt about half way up to the next row of holes; the $n$ take a common drain-tile, 12 inches long by 3 or 4 inches in diameter; put it in the center of the barrel, and fill the tile with coarse saud; then fill up the barlel with dirt a little above the next row of holes; tramp again. Be careful not to move the tile. Cover up the tile, so as not to get any dirt in it. After 


\section{A B C OF STRAWBERRY CULTURE.}

planting the second row, lift the tile. See that the sand settles, then fill the tile with sand again, then put in dirt above the next row of holes; tramp again, and plant that row, and repeat the operation until the five rows are planted. But don't fail to tramp.

After you are done planting, the tile remains in the barrel; have it empty, so as to take the water. In watering, you water in the tile for the lower rows; on top of the barrel for the two top rows. It would be im. possible to water the lower plants without the tile and the core of sand. You can water the plants too much. Fill the tile once per day, and put about two quarts of water on the outside of tile. After cold weather sets in, we quit watering. They want no winter protection. Set the barrel on bricks, to keep it off the ground. If any should die in the summer, you can replat them by taking a runner and putting the young plant in the hole, and stick it fast with two little sticks.

Use the largest fruiting variety that does well in your locality, and perfect-blooming sort, if possible. Planted early in the spring, you may expect a fair crop the same season. Paint barrel any light color, for contrast.

After hearing Mr. Ohmer describe the barrel at the horticultural meeting, he added that no one had better undertake it unless he could attend carefully to all the details, for a little neglect in watering will ruin the whole thing very quickly. Such a barrel is too heavy to carry indoors. It must be wintered right in the open air. S.mebody asked him if it needed turning around so the sun could get at all sides. Mr. O. told us if we would get up early enough in the morning we might see that the sun goes clear at ound the barrel, from morning till night, and actually laps over quite a piece. No turning around is necessary. You can get the finest strawberries in the world by the barrel plan, and more bushels to the acre, that is, if you had an acre covered with the strawberry-barrels, than you could possibly get by any other plan.

\section{OUR NEWER STRAWBERRIES.}

Although I have again and again declared I did not want our list of strawberries made any larger unless for some $e x$ ceedingly good reason, I find at least some of the new ones I have seen in bearing for the first time that promise very favorably. The first is the Ridgeway; and if it will grow on my own grounds as I saw it on Wilbur Fenn's, at Tallmadge, O., I shall certainly give it a place. The plant is a remarkably strong, robust grower. The berries ripen a little late, but are remarkable for their size, beauty of shape, and for the fact that they stand away up above the foliage and out of the dirt. Every berry seems to be as perfect, almost, as if it were turned in a lathe. In this respect it resembles the old Cumberland Triumph. Now, this is the way it behaves on cousin Fenn's 
grounds. Most of us are beginning to learn that the berry that does well in one locality may not in another, even near by.

The second one I wish to call attention to is the Empress, just brought out by Matthew Crawford. I visited his place when most of the strawberries were gone, and the dry weather was fast using up the late ones. The Empress, however, had a magnificent growth of foliage, and green berries and ripe ones were both in great abundance. When I suggested it was a late berry, friend Crawford said it commenced ripening quite early, on the contrary. I know the plant is a tremendously strong and robust grower, because we have it on our own grounds. Now, if it bears everywhere else as it does at Matthew Crawford's place, it is certainly remarkable, because it holds out "head and shoulders" above any thing else.

The above ends our extracts from Gleanings in Bee Culture; but I have something to say before closing my book about several matters concerning the work of the past twelve years. First, in regard to

MULCHING AND MANURING STRAWBERRIES AT ONE AND THE SAME TIME-SEE PAGE 205.

Since that chapter was written I have reason to put in a caution here. If all the seeds in stable manure would germinate right off, so they could be plowed under and killed that season, it would be all right; but, unfortunately, the seeds of many of our worst weeds will lie in the ground for years, and keep coming; part one year, part the next, and so on. The worst manure to fill the ground with noxious weeds I have ever found is that from livery stables. If the manure you use were made on your own premises, and you know exactly what is put into the manure heap, you are all right; or if it comes from the stable or barnyard of some good thrifty farmer who does not let weeds go to seed, you are all right; but where hay, and, worse still, the bedding comes from Tom, Dick, and Harry, if you will excuse the slang, then a few loads of stable manure may seed your land to such an extent that it will make you no end of trouble for years to come. See page 155 . 
MARKING OUT THE GROUND FOR STRAWBERRIES AND OTHER GARDEN CROPS.

A great many people grow strawberries who do not keep a horse ; and there are other people who have a horse part of the time; and, in fact, wherever a man can take the place of a horse in any operation of gardening, especially in small gardens, it is oftentimes exceedingly desirable to do so. The picture below tells how this may be done where only a mark is

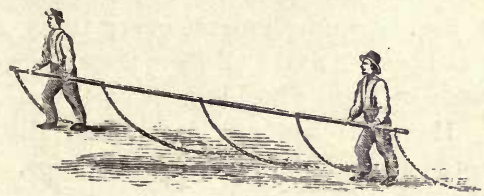

MARKING OUT THE GROUND BY MEN OR BOYS INSTEAD OF HORSES.

needed, not a furrow. The cut and description first appeared in that old standard periodical, the Country Gentleman, as long ago as 1864.

It consists of a light pole with trace chains suspended from it, at distances for each row, or 3 or $31 / 2$ feet apart, as may be desired. Two men take the pole near each end, and one of them, acting as a guide, and ranging accurately, they walk forward, dragging the chains in the soil, making a fine smooth line for each chain. The figure represents only five chains. Six or seven may be employed without inconvenience, and the field marked off with great rapidity. Two men, or a man and a boy, will mark $2 \frac{1}{2}$ acres in walking a mile.

Permit me to suggest that, especially for strawberry-work, the machine may be made very much lighter, and equally effective, by using only a few links of the chain to drag on the ground, and connecting the chairs to the pole by means of a cord or wire. The cut above was intended for marking potato ground ; in fact, it is almost the only marker used in the Traverse region in Michigan, where they plant almost entirely with the hand potato-planter described in our new book, the A B C of Potato Culture. They usually mark both ways, as the po- 
tatoes are cultivated both ways. Now, where we want to do marking like that described on pages 174 and 177 , this machine is by all means the best arrangement that can be used. It is especially the thing where there is an obstruction in the way, such as stumps or trees, as in worising new land. A bright young friend of mine-a girl of fourteen-remarked that the picture was not just right. She said that, on their farm, it should show a boy at one end of the pole and a girl at the other, and that she was that girl. This is a hint for the strawberry-grower as well as the farmer. Now, if you are going to have children use this implement, every thing should be as light about it as possible and still have it do the work. I would have a pole made of light pine, largest in the middle, tapering at both ends. Have notches cut at regular distances, so you can slip the cords as required for different crops.

For working in a small garden it may be well to have poles of different lengths. Two men with a long pole will easily make seven marks at once far enough apart for planting pota. toes. With cross-marking, as on page 174, you can slip the strings any distance apart that may be needed. This implement does not make a furrow, or not much of one. By using links from a log-chain, especially if the ground is fine and solt, quite a small furrow may be made. Where chains are not at hand, a drag-tooth or any heavy piece of iron answers nearly as well. The chain, however, would be less likely to get caught, and would more easily slip around obstacles.

JADOO FIBER, A SUBSTITUTE FOR POTTING-SOII, FOR FLORISTS.

This article for growing plants first made its appearance in America in 1896 or '97. It was manufactured and offered for sale by the Jadoo Fiber Co., Philadelphia. I believe it was used previously in European countries. Our readers will notice I have mentioned it frequently in the foregoing extracts from 
Gleanings in Bee Culture. I was much attracted by it when it first came out, and made quite a lot of experiments with it in our greenhouse for growing various plants. Later I used it for filling the pots for growing potted strawberry-plants. Now, if I am correct, florists in general have not taken very kindly to it. Some of them recommend it as an ingredient for pottingsoils. Very few adopted it as recommended by manufacturers as an entire substitute for potting-soil ; but for the strawberrygrower who grows and ships potted plants it has one great thing to recommend it. This is that the plant, soil and all, in which the root is growing, weighs only about a half or perhaps. a fourth as much as the heaviest potting-soil. In fact, beautiful growing plants can be sent by mail, and the entire contents of the pot undisturbed, for less than one cent per plant for postage. This could not be done with any kind of soil or dirt. Jadoo is exceedingly light, and it will hold water longer than almost any thing else I know of. I do not now understand why it is that florists do not recognize this fact, and send valuable plants by mail or express, rooted in jadoo fiber. I for one was very sorry when the Jadoo Co. went out of business, and I have never been able to find out why it is no longer on the market. The article is simply a very nice light muck or peat from swamps, sterilized by being boiled in certain chemicals; and those chemicals, they claim; are a fertilizing agent. A compost of swamp muck or peat and old well-rotted stable manure would, I think, answer as well; and our Ohio Experiment Station thinks it is even better than jadoo. Jadoo was sold at wholesale for from $\$ 15$ to $\$ 20$ a ton. Now, an excellent compost of old manure (perhaps cow manure would be better), and some very light peat, could easily be furnished, I think, for $\$ 10$ a ton; and it seems to me there is an almost unlimited demand for such an article-not only for potting strawberries but for the benefit of everybody who grows house-plants. I know our florists advertise potting-soil by the barrel, and it is all right, except that it is heavy, and expensive to ship, and 
none of it comes anywhere near being equal to the jadoo in this one point of light weight for sending plants already rooted, ready to grow.*

In closing this item about jadoo, permit me to copy what the originator of the Nick Ohmer strawberry-plant said in regard to some plants (potted in jadoo) I sent him by mail :

Mr. A. I. Root:-Gleanings and the Darling strawberry-plant were received. I never saw a plant shipped in as nice condition, and with such extra large roots, as the Darling. I do not know whether I can pot plants and send them in such good condition; however, I will try to send you a few plants of the numbers named. I never sold any plants or berries, but have sent many plants to friends and others. I sold my ground a year ago, where I grew berries for 26 consecutive years, and very many fine ones. I now have only the east end of a forty-foot lot, and occupy a place of, say, 35 feet by about 60 in berries; but it is astonishing to see what can be grown on a patch of that size. I am very glad to hear that you are meeting with a "happy surprise" in the Nick Ohmer. Your description of its foliage is correct, only I find some have five leaves on a stem. With me they have an abundance of fruit, and, when properly ripened, the quality is A No. 1 .

I kept the runners off all along, and it will be some time before I can send you the plants. I am nearly 72 years of age, and must soon quit, although I have great delight in raising new seedlings. I have some of the Nick Ohmer and some of the No. 34 , which are very nice. The seed was sown in pots about Christmas, and kept in the house. From one of No. 34 I have picked off four runners. I thought I could get it to bear this season; but $I$ notice it is starting new runners. If they get strong enough I will pot one for you for its beauty of plant.

Dayton, O., June 13, 1898.

Perhaps I may say to our readers that Mr. Beaver has been an enthusiast on growing strawberry-plants, especially in pro-

* As an illustration of what jadoo will do, we were at one time short of Grand Rapids lettuce-plants, and wanted some as soon as possible. We put a mixture of jadoo and sand-I think about half and half-sifted together on one of the beds in the greenhouse, perhaps a quarter of an inch thick. The lettuce seed was sown in this mixture. By keeping the moisture and temperature just right, the lettuce was up in four days, and in four davs more it was large enough to transplant. This is about the quickest wo:k I have ever known. We have tried peat and swamp muck in the same way, for starting seeds, and for filling the pots for getting potted strawberry-plants, but have never found any thing that brought the plants along so rapidly as the jadoo. 
ducing new varieties, all his life. I have also included what friend Beaver has to say about the importance of mulching during a dry time, as it is certainly of interest to all strawberrygrowers, even if it has no direct bearing on the subject of jadoo.

From a newspaper clipping forwarded me by Mr. Beaver I take the following:

\section{MULCHING DURING FRUITING, ETC.}

Mr. Beaver said one cause of failure in strawberry culture in a dry season was insufficient mulch around the plants to keep the soil cool and moist. The soil on his strawberry-beds was so wet that he had to protect his knees against the moisture while gathering the fruit, and all this without irrigation-simply plenty of good mulching. Mr. Beaver showed four plates of strawberries of such unusually large size and fine color as entirely to dispel all doubts as to the correctness of his mode of culture.

DIFFERENT VARIETIES ; PICKING THEM OUT BY LOOKING AT THE FOLIAGE, E'TC.

An expert with apple-trees will go into an orchard and pick out the different kinds by the shape of the tree, wood, leaf, etc., even before any fruit has made its appearance. In the same way, an expert strawberry-man will name many of the kinds just by looking at the plants, before they have borne fruit. It is almost impossible to explain how this is done; but most varieties of strawberries have certain peculiarities or "earmarks," we might almost say, that distinguish them at a glance. One of the most marked cases of this kind that $\mathrm{I}$ know of is in regard to the Nick Ohmer; and our friend Beaver, in the letter above, alludes to it. This plant, every little while, sends up a stem with four leaves instead of three. It is like a four-leafed clover; and, stranger still, in almost every patch of a dozen or two plants you will find here and there not only a four-leafed plant, but one of these four will have a leaf united clear around, so as to make a funnel-shaped cup; in fact, I have picked off these cup-shaped leaves and given them to the children, showing them they could get a small drink of water out of these strawberry-leaves. Now, to one who makes strawberry-plants a study, and who loves to hunt up and discover these peculiar 
freaks that every variety has, it is a most interesting and wonderful study.; and it has a practical bearing also. One young man in my employ will go through a field where the boys have been setting out plants, and will. sort out the wrong plants by their looks, where the boys have made a blunder, and in this way he prevents sending a customer some plants at some future time that are not true to name.

BEDDING THE FIRST RUNNERS WHERE YOU WANT THEM; SOMETHING FROM CORNHLL, UNIVERSITY IN REGARD TO THE MATTER.

Through the kindness of Prof. Bailey I am enabled to give a picture on next page of what I should call a model field of strawberries.

The following we take from Bulletin 198, April, 1901. The subject of the bulletin is "Oswego Strawberries."

As to methods of planting, it may be said that the old method has been discarded,-planting in rows three to three and one-half feet a part and the plants from twelve to fifteen inches apart in rows, keeping off the runners until late in July and then allowing the runners to grow and root at will, making a matted row. In this old system many plants are almost on top of others, the roots barely in the ground, and they suffer in a season of drouth. The rows are so wide that, to pick fruit in the center, it is almost necessary to crush fruits on the outside of the row. This system gives few large first-class fruits. The up to-date grower starts with the assumption that the largest and highest-colored fruits are found on plants along the outside of the rows, and therefore he plans to have as many outside rows as possible. This he accomplishes by having his rows closer together and much narrower. The rows are made from 30 to 36 inches apart and the plants from 18 to 24 or even 30 inches apart in the rows, much depending on the capability of the variety as a plant-maker. If the plants used for a new bed are strong, and start into growth vigorously, the first runners are used, as it has beeu found that, under most conditions, the plants about $t$ welve months old yield the greatest number of fine fruits. These first runners are usually "bedded in," i. e.. planted by hand, training them along the wide way of the rows, using from four to eight of the first runners and cutting off those growing later. This methor of planting allows cultivation both ways until the runners start, retaining moisture and saving labor in hoeing.

You will notice the above instruction is directly in line with the plan given us by Dan White, on page 177, and the one recommended by Henry Young, of Ada, O., on page 174. 


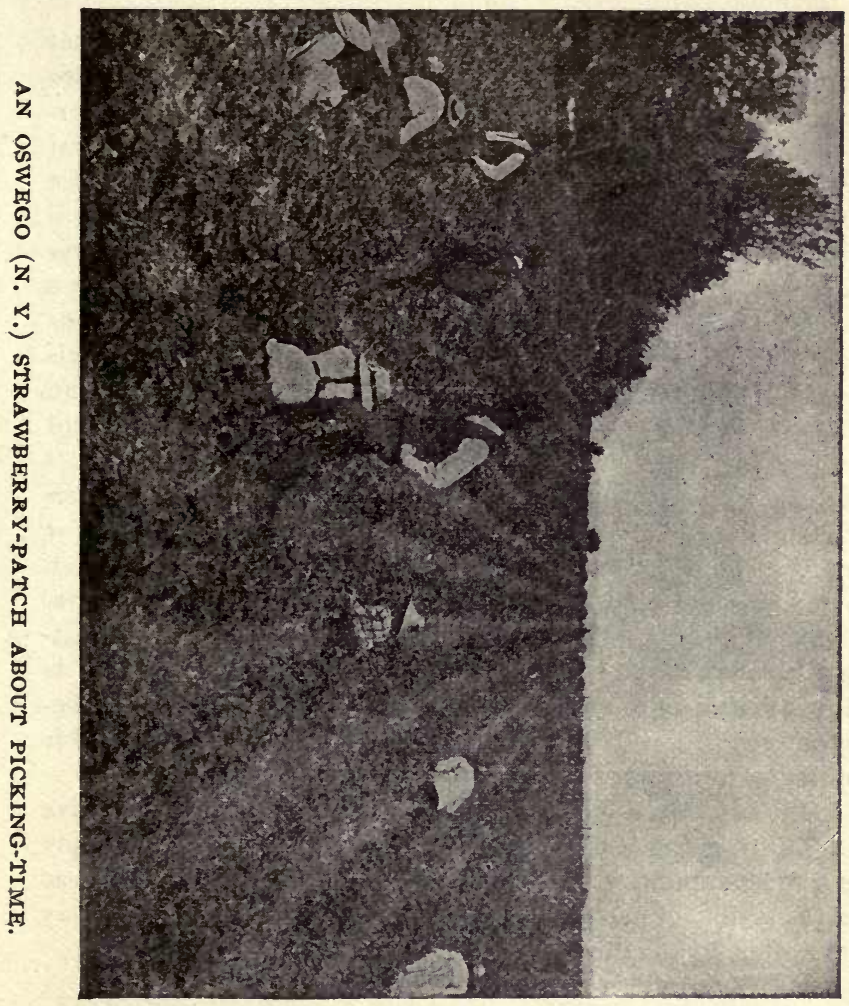


In concluding this book, perhaps I should mention that there are several allusions in the back pages to the fact that we have for many years done quite a business in selling strawberry-plants. At present we have none to sell. It is a work that I very much enjoyed, but it is now two or three years since we have done any thing in that line. As a rule I would advise you to get your plants of some reliable grower near by-the nearer the better, other things being equal; and if you wish to get a start with a certain variety that suits your location, by all means grow your own plants on some of the plans described in this book. If you are compelled to send off a distance, do not send a large order to some unknown party. Get a few samples and see how you like them. When you are pleased with a man's way of doing business and the kind of stock he sends out, then give him a large order if you choose. One of the reasons for buying at home is that you can get your ground all ready, then go and get your plants. Delays are exceedingly bad both ways. If you get your plants ahead of time, they may suffer by waiting till your ground is ready. If you wait till your ground is all ready, during the rush of the season, you may suffer by being obliged to wait till it is too late for the best results. This applies to spring setting.

Hoping that the information given in this book may give you happy hours besides much fruit, and that you may enjoy the work as much as I have enjoyed strawberry-growing, as well as trying to make this book helpful to those who may come after me, I remain

Your old friend and well-wisher,
Medina, O., Jan. 22, 1902.
A. I. Root. 


\section{CONTENTS.}

Barber Berry-farm ....................208

Beds, Starting from New Plants in July.

Bees, Strawberries, and Eternal Life

Berries, Gathering the First as soon as Ready for Market Berries, Getting Exceedingly

Berries, Gilt-edged

Berries, List of Valuable.

Berries, Number to Quart

Berries, shall Farmers Grow them to Sell?.

Berries, Small, at a I,ower Price

Berry, Largest Known

Blossoms Protected from Frost with Straw, Leaves, etc...... .

Bone Meal and Ashes...

Boys and Girls Getting Interested.

Brandywine. ...... 37

Bubach Planted in the F.......210, 2164

Bubach for Fancy Berries and Fancy Market

Bubach $.54,109,165$

Champion of England..................212

Chickens Running among Strawberries

Chickens, Why they Learn to Eat Stra wberries

Children, Importance of to the Stra wberry-grower ................ 45

Clergyman in Strawberry patch..113

Clyde. .214

Cra es and Boxes, Cost of at Factory

Crescent............................53, 207, 209

Crop. Selling when there is a Glut in the Market 162

Cultivating and Hoeing ................. 33

Cultivating Both Ways ................. 77

Cultivating Strawberries Three Ways .200 Cumberland. 57,209

Dan White's Model Patch .............177 Darling $204,213,228$
Distinguishing Varieties by Appearance .............................229 Downing..................................54, 207 Earliest......................................213

Empress .......................................224

Enhance, The................................174

Fall Planting..........................76, 217

Farmers, Shall they Grow their own Strawberries ?................5, 45 Fertilizers for Strawberries ......18, 45 Field Culture, Open v. Small Beds for Testing New Varieties......................................216 Firming the Ground for Straw. berries.......................... 183, 215

Fitting the Ground ..................... 18

Frost an Injury to Blossoms....... 26

Fruit-stems, Clipping to Get Extra-nice Plants...................199 Fungous Enemies to Strawberries

Furrower and Marker ..................136 Gandy ......53, $57,103,124,139,178,211$ Glut ting the Market....................220 Ground, Marking Out..27, $62,174,235$ Ground, Smoothing and Leveling .200

Growing the Best-Importance of............................................ 97

Half-acre of Strawberries. Plants $2 \mathrm{ft}$. apart each Way .205 Harvesting Three Crops on One Ground in One Season ........142 Hay, Marsh, for Mulching ......... 83 Haverland ..................55, 58, 103, 119 Hills and Side Hills for Strawberries and other small Plants.............................187, 208 Horse Story...............................207 How it Pays............................46, 47 Insect Enemies to Strawberries..137 Irrigation for Strawberries.....85, 212 Jadoo.....................................216, 226 Jessie............................................. 56

Lady Thompson...........................220

Location ..................................... 12

Making a Piece of very pcor Ground into the very best for Strawberries 203 
Manure, Stable, and Weed Seeds 187 Manure, Stable, Buying at Livery Stables, et .224

Manures and Fertilizers for Strawberries

Margiret. $.201,210$

Marking (;round..........................225

Marshall

" Matted " Half-acre.....................217

Matthew Crawford ......................126

Michel's Early...............................214

Mulch of Dry Earth.................... 86

Mulch, Leaving it on tili L,ate......207

Mulching. $.38,78,112$

Mulching and Manuring Strawberries at the same time........205

Mulching with Cut Straw............. 39

Mulching with Strawy Stable Manure

Mulching that does not contain Weed Seeds

Mulching, Drawbacks................... 82 40

Mulching Heavily with Straw for Blackberries and Rasp. berries

Mulching, Trouble with Grain in Straw

ick Ohmer.

$204,210,213,228$

Nick Ohmer, Ëar-marks..............24

Paths, To Make, in Matted Half-acre

Paths, Width of.

Picking and Marketing

Picking Regularly whether They are Sold or Not

Picking Strıwberries - Men, Women, or Children Which?

Picking, To Reduce Cost..............209

Plantation Bearing More than One Year.

Planting in the Fail ................76, 217

Plant, Old, shall we Cut it out of the Matted Row?. $.75,217$

Plants, Growing Nice....................195

Plants Grown from Plants that have not Borne Fruit...20, 41, 199

Plants, Growing on your own Ground ..........................72, 282

Plants, Importance of Good........ 20

Plants, Making in Jadoo..............228

Plants, Number to Acre............... 32

Planis, Pot-bound..........................196

Plants, Putting up for Shipment 144

Plants, Selling .........................216

Plants, Setting............................. 25

Plants, Setting them in the open Ground. .198
Plants, Taking them Up .......... 41

Plants. Thinuing them Out......... 74

P. tato-vines for Mulching ...........212

Potted Plants ...........................129

Potted Plants, Setting them in

the Field...............................132

Potting Soil for Honse-plants......204

Preparing Ground for Summer

and Fall Planting...................135

Product of One Square Rod.......... 50

Profits per Acre.........................101

Purslain among Strawberries...... 34

Ridgeway Berry............................223

Rio ................................................214

Rio for Extra Early.....................214

Rotation .................................... 17

Rows, Importance of Straight... 63

Rows, Matted.......................... 69

"Runners" .................................. 35

Runners and Plants, Getting out of Season .......................148

Runners, Fixing where you want Plants....................... 26

Runners, Keeping them Off......49, 73

Runners, Placing.................193, 195

Setting every third or fourth Row to a Perfect Variety...... 24,

Shade, Rooting Strawberry$28,31,32$ plants in 204

Sharpless.......................181, 182, 211 Side Hill v. Hill-top for Strawberries

Soil, Potting...............................227

Soil, Stirring during Dry Weather. Need of............................ 64

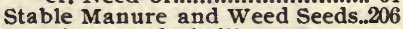
Staminate and Pistillate-Per-

fect and Imperfect............... 22

Sterling...........................54, 59, 103

Straw, Cut, as a Mulch .............. 79

Straw berries and Ice Cream 112, 168

Strawberries Beneficial to Health 11

Strawberries in Hills ................. 71

Strawberries on Sod Ground-

Danger of Grubs

Strawberries Planted between Raspberries and other Crops 14

Strawberries under Glass......147, 196

Strawberries v. Tea, Coffee, and Tobacco ........................ 43

Strawberries, 3 cts. a Quart..........219

Strawberries, 66 Meals in Succession

Strawberries, $\$ 1000$ worth on

One Acre ............................109

Strawberries, Crop in Fall...........146 
Strawberries, Different Ways

of Growing

Strawberries, Everbearing .........146

Strawberries, Gathering............... 44

Strawberries, Getting a Crop in only 9 or 10 months af-

ter the Plants are Set.

Strawberries, how many cau an Averaye Family Consume?.... 16

Strawberries Grown in a Barrel..222

Strawberries, Selling at a Big Price

Strawberries. Selling During Glut in Market

Stra wberries, Spacing for Best Results

Strawberry Culture for those in Poor Health

Strawberry, Earliest. 145

Strawberry Festival 217

Strawberry Industry at Barnesville, Ohio.

Strawberry growing for Consumptives

221

Strawberry-growing for Literary and Professional Men. 185 128 awberty-growing for Young

\section{Strawberry} wberry - growing near

Norfo $k$, Va......
Strawberry-harrow 219

Strawberry-patch Long and Narrow
Strawberry-plants for Improving the soil .........................141 Strawberry-plants, To Grow the Best ......................................192 Sub irrigation ...................... 197, 212 Sub-irrigation in Open A ir............197 Terry's Berries in June, 1891.........160 Terry's Home.............................120 Tiling the Ground for Strawberries ................................... 14 Tools for Cirltivating............65, 66, 68 Tools for Hand Work among Plants .................................... 33 Transplanting machine ................190 Transplanti:g tubes ...................... 18 Transplanting tubes, To Use......133 Ups and Downs in Gardening.....210 Varieties....................................20, 51 Varieties to Use for Fertilizers... 60 Vines, Letting them Bear more than one Year........................154

Vicit to Terry's in July, $1891 . . . . . . .166$ Visit to Terry's............................116 Water in Puddles on Strawberrv Ground.........................34, 200 Weeding. Plan to Lessen Labor of ........................................155

Weeds Getting Out, or Plowing Patch under............................. 99

William Belt ..................................210

Working Ground with a Horse instead of by Hand............... 35

Yield on Half-acre in 1890 ...............102

\section{ILLUSTRATIONS,}

Blossoms, Perfect and Imperfect 22 Bubach.......................................... 54 Chain Marker...............................225 Cumberland Triumph ................... 57 Dan White's System of Setting Plants 177

Furrower and Marker....................136

Gandy 53

Garden plow. Cole's......................201 Harrow Attachment for Cultivator. 66

Hand Cultivator, Scuffle hoe, and Weeder...............................202

Haverland .....................................55

Henry Young's Plan of Marking Ground

Henry Young's Plants after they are Set.

Hill Culture. 175

Machine for Transplanting Strawberries

\section{DIAGRAMS, ETC.}

Home Acre................................... 15 Oswego Stra wberry-patch............231 Photo of Terry's Berries Compared with Common..... 104, 105 Plants, food and Poor.................. 21 Plants, Right and Wrong way to Set........................................ 29 Potted Strawherry-plants .............131 Rows, Marking for Spacing......... 27 Runners, To Place the Second Year.........................................176

Sterling ........................................ 59

Strawherries, Box of Gandy .......140 Strawberries of Good Repute,

Old and New....................i50-153

Terry's Strawberry patch ............. 81 Terrv's Half-acre just after

Plants had taken Root...........111 Transplarting tubes. To Make...133 Tray for Holding Tubes...............131 Weeder............................................198 
fox

\title{
Gleanings in Bee

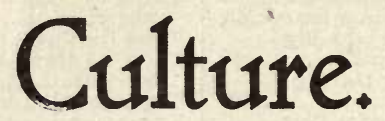 \\ SAMPLE COPY FREE.
}

\begin{abstract}
A Semi-monthly Bee-journal Devoted to Modern Apiculture, and to the General Interests of the Bee-keepers' Home, Including High-pressure Gardening.
\end{abstract}

\section{The A. I. Root Company, Medina, Ohio, U. S. A.}

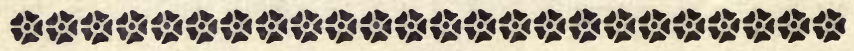




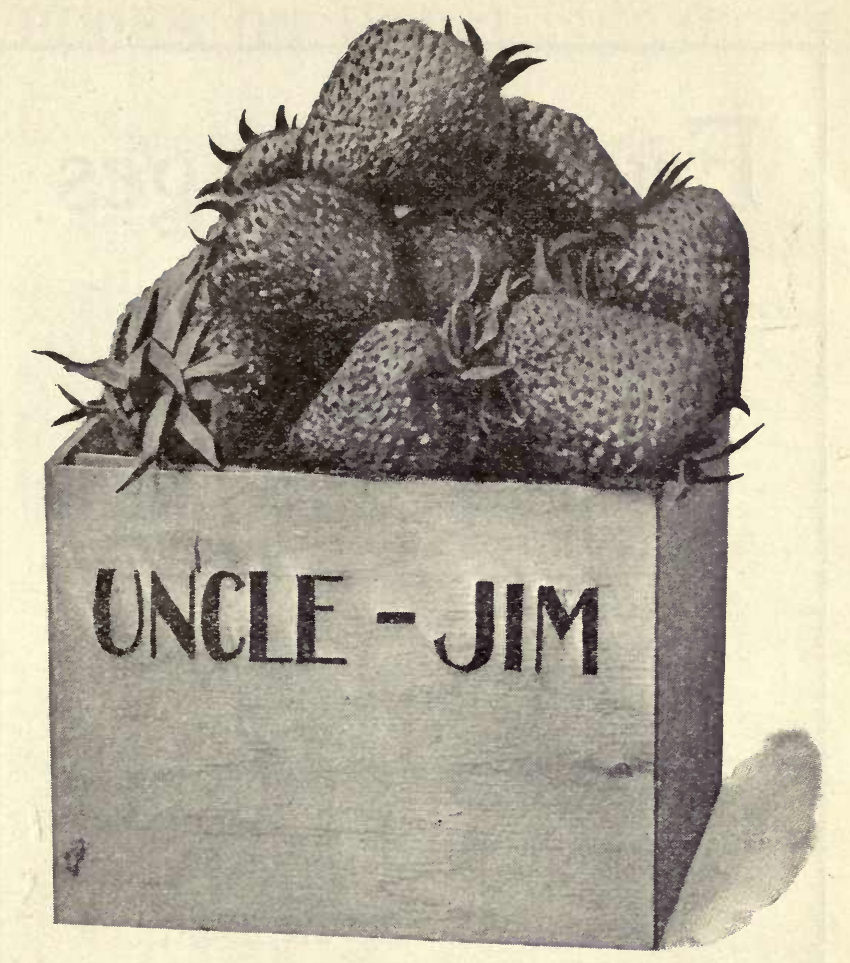

\section{Strawberry=plants and Seed Potatoes.}

Almost every season we have a large number of inquiries as to where people can get boxes for their fruit, etc. I have already recommended you to get your plants near home if possible. When you can not do this I would advise you to send to Flansburgh \& Peirson, Leslie, Mich., or to The M. Crawford Co., Cuyahoga Falls, O. We have bought plants of them for years, and have always found them to be nice men to deal with. Above we give a cut of one of Flansburgh \& Peirson's latest berries, their specialty for 1902 , called the "Uncle Jim." 


\section{Fruit Packages}

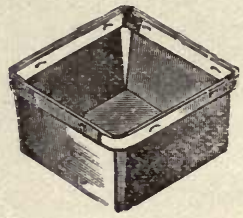

"For strawberry-boxes, crates, etc., where you can not get them near home I would advise you to send to the Berlin Fruitbox Company, Berlin Heights, Ohio.'

$$
\text { A. I. Root. }
$$

\section{Berlin Fruit Box Co.}

Berlin Heights, Ohio.

CATALOG ON APPLICATION. 


\section{B00KS ON RURAL SUBJECTS.}

Sold by The A. I. Root Co., Medina, 0.

A B C of Bee Culture.

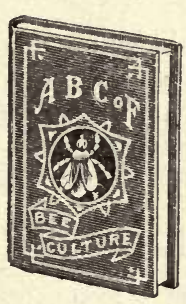

1901 edition; 500 pages ; the only encyclopædia cn bees. The last edition, 5000 cop ies, issued in October, 1899, was exhausted in the short space of ore year. Eren before the edition was out of the press. 1500 copies had been sold: a n d before thirty days had passed, 1000 more copies were taken. We $i \mathrm{~mm}$ m iat ely set to work to print a new edition. While the edition of 1899 was more thorougbly revised than anv previous ons, that for the year 1900 has now received even larger additions of new matter, so that the took from beginning to end is almost entirely new. It now contains 500 doublecolumn pages. It has been most carefully gone over by Dr. C. C. Miller, who has prepared a new set of comments, and by Prof. A. J. Cook, of Pomona College, Cal. As before, old subjects have been rewritten. Descriptions of obsolete methods have in all cases been stricken out, and the verv latest put in their place. This 1901 edition marks the 75th thousand.

While the book bas been enlarged, and hundreds of pages have been rewritten and revised. the price will be the same as before: $\$ 1.20$ postpaid, or $\$ 100$ by express or freight with other goods. or when sent with our journal Gleanings in Bee Culture, which is a constant appendix to the A B C book, a journal beautifully printed and illustrated, 36 pages, for the very low price of $\$ 1.75$ for the two. For quantity of up-to-date bee-literature there is nothing $t$ lse offered at $t h$ is low price.

\section{A B C of Strawberry Culture.}

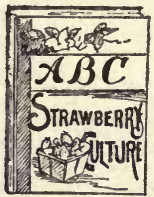

236 pages, fully illustrated Price 45c; mail, 5 c extra. This is also one of Terry's, and has rece ived some very high wcrds of praise. The 1902 edition is not only revist $d$, but the hook is vely much increased in size, me1 tioning all the new varieties and new methcds of cultivation, bringing the industry clear up to 1902 . Who that keeps hoviey - bees does not also have a jittle garden patch? If you would learn to raise in it that most luscious of all fruits, the strawlerry, with the best results, you can't be without this little book. Even if you don't grow strawberries y ou'll be the better for reading it.

\section{What to Do, and How to be Happy while Doing It.}

The above book, by A. I. Root, is a compilation of papers published in Gleanings in Bee Culture, in 1886, '7, and '8. In 1900 an appendix was added, bringing it up to date. It is intended to solve the problen of finding occupation for those scattered over our land, out of emplnyment. The suggestions are principally abcut finding employment a round your own homes. The took is mainly upon market-gardening, gardening under glass, fruit culture, poultry-raising. etc Price, in paper covers, 50 ; cloth, $75 \mathrm{c}$. If ordered by freight or express, deduct 8 and 10 c respectively. 


\section{A B C of Potato Culture.}

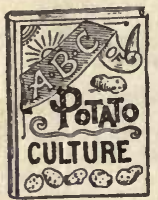

This is T. B. Terry's first and most masterly work. The book has had a large sale, and has been re-printed in foreign languages. It was revised and rewrit ten in 1893 , and the 1901 edition makes 288 pages, just the size of this, fully illustrated, and bound in leatherette cover printed in gold. Price $45 \mathrm{c}$; mail, $50 \mathrm{c}$; cloth, $68 \mathrm{c}$; mail, $75 \mathrm{c}$.

\section{A B C of Carp Culture.}

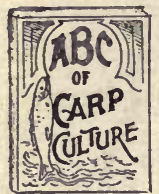

In paper covers, illustrated. This is a work of 70 pages, $7 x$ 10, written by Geo. J. Finley and A. I. Root, and the best authority on the subject of casp culture yet in print. The rearing of carp is a pleasa nt and profitable amusement. This book will tell you all about it. Price 25c ; by mail, 5c extra.

\section{Maple Sugar and Sugar=bush.}

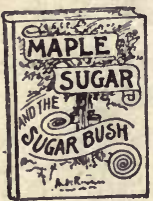

By A.J. Cook. The price is $25 \mathrm{c}$; by mail 30 c. This is by the same author as the Manual of the Apiary, and is most valuable to all who are interested in $\mathrm{th}$ h product of our sugar maples. No o n e who makes maple sugar or syrup should be without it; 44 pages, fully illustrated.

\section{Merrybanks and His Neighbor.}

By A. I. Root. This is the title of a little book of 210 pages and 68 illustrations. It narrates the alternate failure and success of a beginner who ultimately, through much tribulation, becomes a successful bee-man and a power for good in
Onionville. Appropriate original cuts, many of them humorous, are interspersed here and there, representing some of the droll experiences which a beginner with bees sometimes passes through. Besides bees, it talks of other rural pursuits, such as gardening, maplesugar making, etc. Price $35 c ; 3 c$ less when sent with other goods by freight or express.

\section{Tile Drainage.}

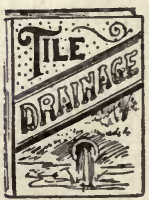

By W. I. Chamberlain. This is a very valuable companion to our other rural books. It embraces the experience of 40 vears of one of our foremost practical agriculturists, who has laid with his 0 w $n$ hands over 15 miles of tile. Price $35 \mathrm{c}$; b , mail, $40 \mathrm{c}$.

\section{Winter Care of Horses and Cattle.}

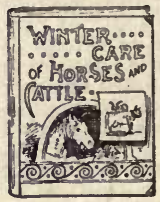

This is friend Terry's second book in regard to farm matters; but it is so intimately connected with his potato book that it reads almost like a sequel to it. If you have only a horse or a cow it will surely pay you to invest in the book. It has 44 pages and 4 cuts. Price 25c; by mail, 30 c.

\section{Tomato Culture.}

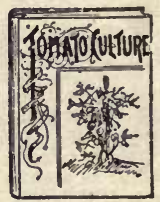

In three parts. By J. W. Day, D Cummins, and A. I. Root; a valuable treatise, embracing field culture, forcing under glass, a $n d$ raising plants for market. Valuable to any one raising garden stuff of any $k$ ind aside from tomatoes. 150 pages; illustrated. Price 35c; by mail, $40 \mathrm{c}$. 



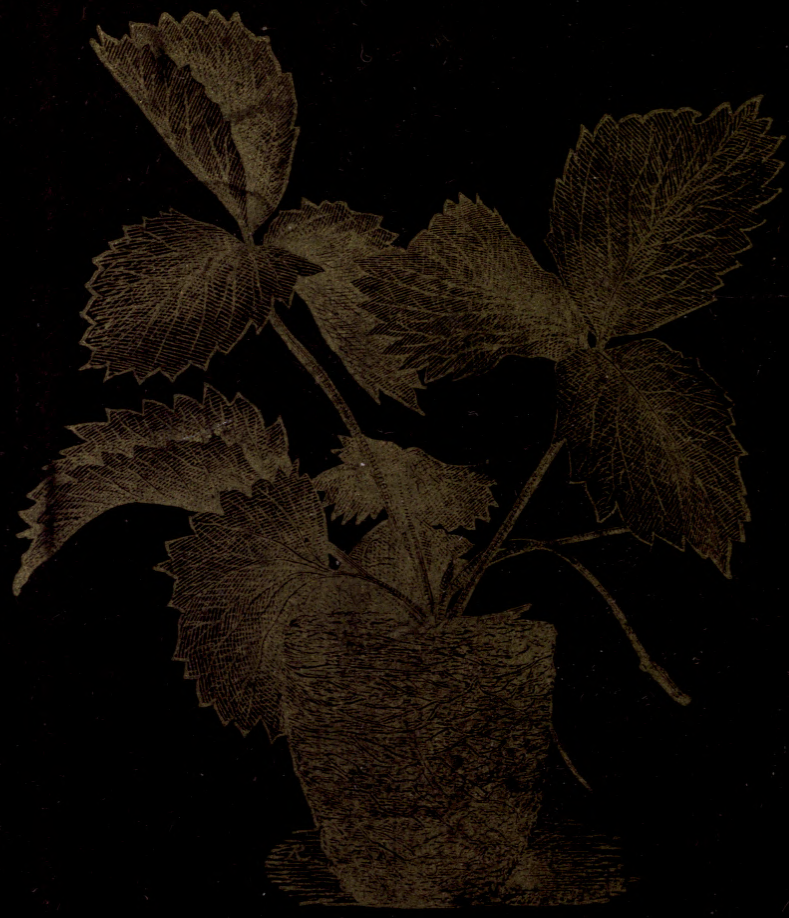




\section{DAY USE}

RETURN TO DESK FROM WHICH BORROWED

\section{LOAN DEPT.}

This book is due on the last date stamped below, or on the date to which renewed.

Renewed books are subject to immediate recall.

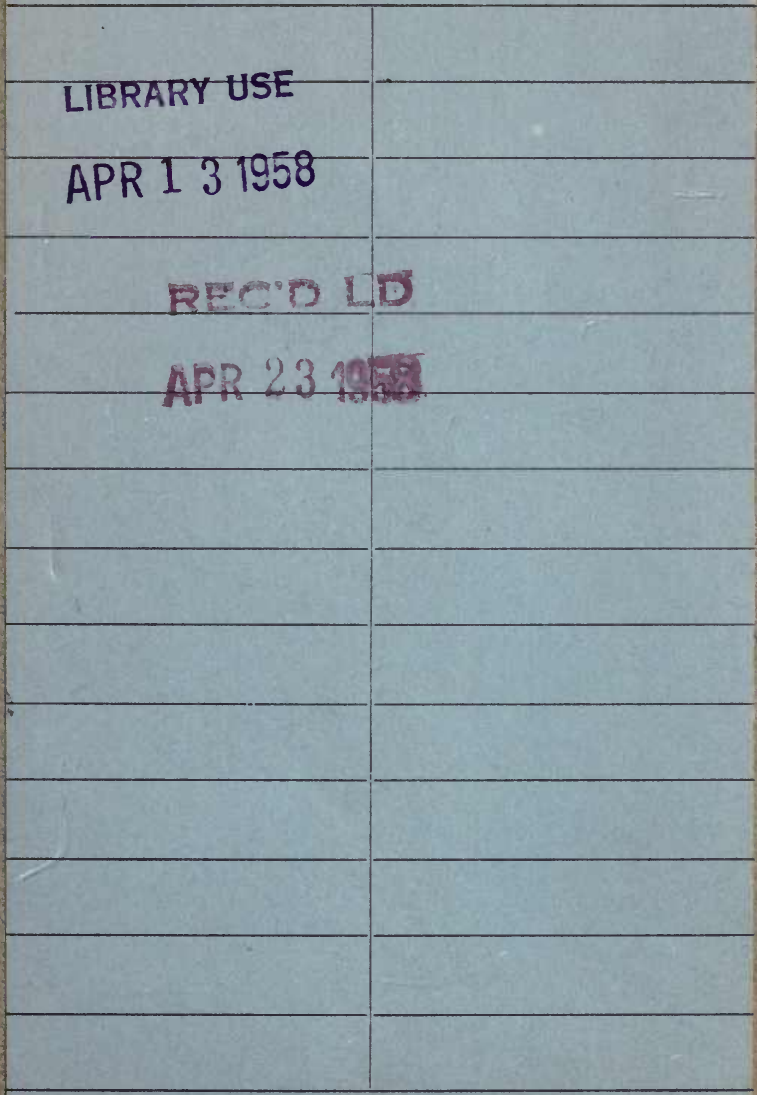



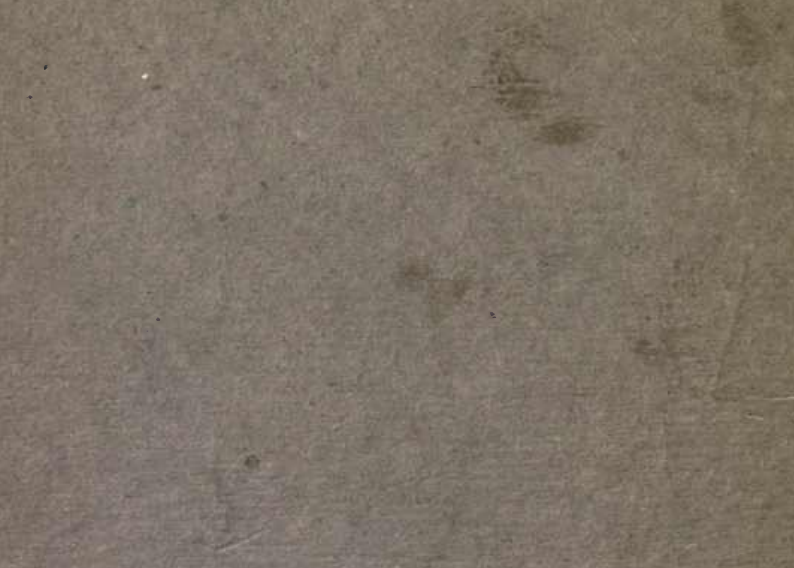

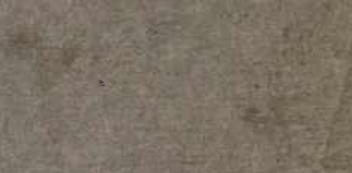

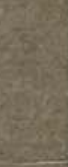

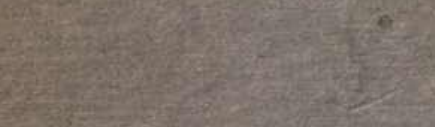

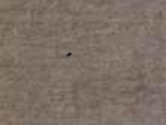

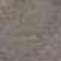

actide
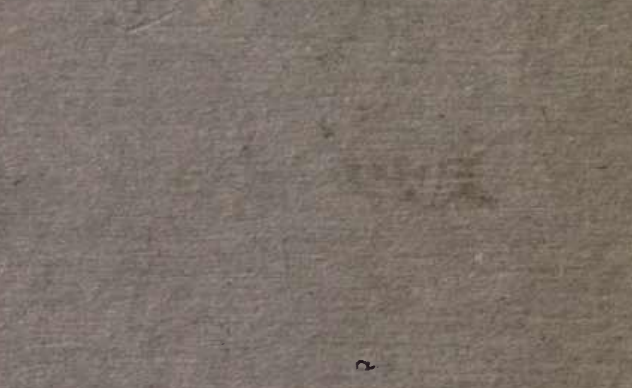

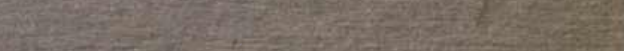

